ANDRÉ SANDOR KAJDACSY BALLA SOSNOSKI

\title{
Produção de energia por mini e micro hidrelétricas na rede de distribuição de água
}

Dissertação apresentada à Escola Politécnica da universidade de São Paulo para obtenção do título de mestre em Engenharia 


\section{ANDRÉ SANDOR KAJDACSY BALLA SOSNOSKI}

Produção de energia por mini e micro hidrelétricas na rede de distribuição de água

Dissertação apresentada à Escola Politécnica da universidade de São Paulo para obtenção do título de mestre em Engenharia

Área de concentração:

Engenharia Hidráulica e Sanitária

Orientador: Prof. Dr. Arisvaldo Vieira Mello Júnior

São Paulo

2015 


\section{Sosnoski, André Sandor Kajdacsy Balla}

Produção de energia por mini e micro hidrelétricas na rede de distribuição de água / A.S.K.B. Sosnoski. - versao corr. São Paulo, 2015.

$167 \mathrm{p}$.

Dissertação (Mestrado) - Escola Politécnica da Universidade de São Paulo. Departamento de Engenharia Hidráulica e Ambiental.

1.Geração de energia elétrica 2.Usinas hidrelétricas 3.Redes de distribuição de água I.Universidade de São Paulo. Escola Politécnica. Departamento de Engenharia Hidráulica e Ambiental II.t. 


\section{Agradecimento}

A meus pais Eudes e Christina, e minha irmã Anna pelo incondicional apoio e incentivo, que juntamente aos meus avós me levaram ao caminho do conhecimento.

Ao meu orientador, Prof. Dr. Arisvaldo Vieira Mello Júnior, pela paciência e auxílio, promovendo crescimento acadêmico juntamente com ideias de crescimento profissional. Ao Prof. Dr. Rubem La Laina Porto, pelo incentivo inicial e acolhimento como orientando.

A Fundação Centro Tecnológico de Hidráulica, por promover o crescimento e disponibilizar a possibilidade de concluir meus estudos.

Agradeço a Raissa e a CAB Piquete por disponibilizar os dados necessários para o desenvolvimento do estudo de caso.

A Universidade de São Paulo, e Escola Politécnica, juntamente a todos os professores e funcionários, pela dedicação e auxílio.

A Elisa pelo companheirismo e revisão da dissertação.

Aos amigos e colegas da FCTH, Labsid e Politécnica, parceiros e colegas de profissão, que compartilharam estes anos de estudo e trabalho, ajudando a tornar esta jornada mais alegre e produtiva. 


\section{RESUMO}

A geração de energia hidrelétrica enfrenta uma crescente restrição a sua expansão, diretamente relacionada a fatores ambientais e da limitação de terrenos com potencial economicamente aproveitável.

A partir deste fato, é relacionada uma possível fonte de energia hidrelétrica, resultante do aproveitamento dos potenciais presentes na rede de distribuição de água das cidades, ainda sem nenhum aproveitamento.

O desenvolvimento desta fonte de energia se dá com a instalação de mini e micro centrais hidrelétricas nos condutos da rede distribuidora de água.

Este trabalho tem por objetivo avaliar o potencial de aproveitamento hidrelétrico por mini e micro hidrelétricas por meio de técnicas de modelagem e de otimização, para agilizar e facilitar o procedimento de identificação dos potenciais e a instalação na rede de abastecimento.

O trabalho leva em conta as diversas peculiaridades das redes de distribuição de água e dos equipamentos eletro-hidráulicos, discorrendo sobre a possível complementariedade da geração de energia durante os picos de consumo.

Discorre também sobre a contribuição para a rede de distribuição elétrica, na logística e nos custos de implantação além de discutir a tipologia das turbinas capazes de aproveitar o potencial energético.

É avaliado, com o auxilio de modelos hidráulicos e de otimização, o posicionamento das centrais geradoras na rede e os possíveis benefícios, restrições e impedimentos ao seu uso, desenvolvendo uma metodologia para facilitar a tomada de decisão quanto ao aproveitamento para geração, ou não, em redes diversas.

A construção deste procedimento e ferramenta são desenvolvidos a partir do estudo de caso do sistema distribuidor de água do Município de Piquete no estado de São Paulo, Brasil.

Palavras-chave: mini e micro hidrelétricas, sistemas de abastecimento, otimização, redução de perdas 


\begin{abstract}
Hydropower energy production is facing limitations in their capacity to grow due directly to environmental and space limitations, questioning the actual economic benefits that hydropower have always had compared to other energy sources.

In order to face this problems and to propose a new technology, the study focus on the potential of hydropower generation in the water supply system's (WSSs) network that are yet to be studied.

Developing this new technology means the introduction of mini and micro hydropower plants in the WSS network.

This study intends to develop a methodology and evaluate mini and micro hydropower potential, adopting optimization and modeling tools to accelerate and facilitate the identification procedures of potential installation points and the possibility of implementing pressure controls in the form of turbines in the network.

The study considers all WSS peculiarities and restrictions, evaluating the introduction of electro hydraulic equipment and their interference and complementarity when considering energy consumption and production that would make the installation feasible.

There is also a discussion about how will this technique be implemented in the network without interfering in water supply, and the logistics, costs and how energy distribution issues can be treated, including turbines type and configuration and also the activation timetables.

All these features will be linked and treated with an optimization method that can provide decision making easier, locating production units and evaluating benefits and restrictions imposed by the environment.

The construction of this procedure will be applied in a case study in the Piquete municipality in São Paulo, Brazil.
\end{abstract}

Keywords: mini and micro hydropower, water supply system, optimization, water losses 


\section{LISTA DE FIGURAS}

Figura 1- Gráfico representativo do consumo distinto por fontes. Fonte: BP, Statistical Review of World Energy 2009................................................20

Figura 2 - Gráfico de barras do potencial de produção por países. Fonte:

Elaborazioni su dati IEA 2009.

Figura 3 - Esquema representativo do percentual de potencial utilizado.

Fonte: A.Sorokin 2009 e World Energy Council 2002................................22

Figura 4 - Distribuição da oferta de energia no Brasil . Fonte: Relatório de

Balanço Energético Nacional, http://www.epe.gov.br

Figura 5 - Evolução do tamanho das usinas termoelétricas em relação ao

custo médio de geração Fonte: Bayless (1994).

Figura 6- Número de pequenas hidrelétricas, sua capacidade instalada e energia gerada entre 2000 e 2020 na União Europeia retirada de ESHA

(2014a)

Figura 7 - Esquema de um sistema de abastecimento de água. Fonte:

Tsutiya (2004)....

Figura 8 - Princípio de funcionamento de uma VRP .................................44

Figura 9 - Categorias de acionamento das VRPs

Figura 10 - Variação horária do consumo de água. ................................................. 48

Figura 11 - Esquema do gráfico de comparação entre turbinas. ........................ 51

Figura 12- Esquema de uma turbina Cross-Flow. Fonte: Micro Centrais Hidrelétricas, Ministério de Minas e Energia, 2007 ............................................... 53

Figura 13 - Esquema de uma turbina Francis. Fonte: Voith (2014)................. 54

Figura 14- Esquema representativo de uma turbina Kaplan. Fonte: Voith (2014)

Figura 15 - Exemplo de gerador síncrono. Fonte: CERPCH ..............................5 58

Figura 16 - Ciclo da relação entre água e energia ................................................ 63

Figura 17 - Esquema de instalação de unidade geradora no escoamento direto de rios por gravidade associados a adutora. Fonte: Adaptado de Vilanova e Balestieri (2014).

Figura 18 - Instalação de turbinas logo a jusante dos reservatórios. Fonte:

Adaptado de Vilanova e Balestieri (2014)

Figura 19 - Instalação de turbinas a jusante dos reservatórios abastecidos por bombeamento ou reversíveis. Fonte: Adaptado de Vilanova e Balestieri (2014)

Figura 20 - Instalação de turbinas hidrocinéticas ao longo dos canais de destinação dos fluxos. Fonte: Adaptado de Vilanova e Balestieri (2014) ........ 68 Figura 21 - Instalação de turbinas nas saídas de poços de água sob pressão. Fonte: Adaptado de Vilanova e Balestieri (2014)

Figura 22 - Instalação de turbinas na rede de distribuição de água em

substituição às válvulas redutoras de pressão. Fonte: Adaptado de Vilanova e Balestieri (2014) .................................................................................................... 70

Figura 23 - Esquema de rede concebida por Afshar et al. (1990) ..................... 80

Figura 24 - Equação de otimização concebida por Afshar et al. (1990) .......... 81

Figura 25 - Equação de otimização concebida por Ramos et al. (2005) ......... 82

Figura 26 - Equação de otimização concebida por Leberatore e Sechi (2009)

Figura 27 - Redução das perdas pela redução da pressão para diferentes coeficientes de perda. 
Figura 28 - Desenho esquemático da estrutura de conexão com a rede de energia. Fonte: Adaptada de HowStuffWorks 2001 .................................93

Figura 29 - Resultado das pressões ao longo de 24 horas............................94

Figura 30 - Resultado da solicitação ao longo de 24 horas. .................................. 94

Figura 31 - Relação de perdas sobre o faturamento das principais empresas

de saneamento..................................................................................................... 96

Figura 32 - Fluxograma de dados para otimização ................................................. 98

Figura 33 - Representação simplificada de uma rede para modelagem

matemática

Figura 34 - Microrregião de Guaratinguetá e localização do Município de

Piquete. Fonte: City Brazil.

Figura 35 - Fotografia do relevo do Município de Piquete. Fonte: $C A B$

Piquete.

Figura 36- Mananciais do Município de Piquete Fonte: CAB Piquete.

Figura 37- Esquema da rede de distribuição do Município de Piquete. Fonte:

CAB Piquete.

Figura 38- Representação das pressões em um dos trechos da rede ..........114

Figura 39- Representação do detalhe das pressões no trecho de rede destacado.

Figura 40 - Rede do Município de Piquete modelada segundo escala de pressão

Figura 41 - Rede de Piquete modelada segundo escala de pressão

identificados 5 prováveis pontos de aproveitamento.

Figura 42 - Rede de Piquete modelada segundo escala de pressão com

turbina no Ponto 1

Figura 43 - Rede de Piquete modelada segundo escala de pressão com

turbina no Ponto 2.

Figura 44 - Rede de Piquete modelada segundo escala de pressão com

turbina no ponto 3

Figura 45 - Exemplo de resultado da curva de demanda ao longo de 24

horas.

Figura 46 - Curvas de rendimento de seis turbinas mantida a pressão

constante. Fonte: Harvey.

Figura 47 - Demanda nas extremidades da rede.

Figura 48 - Demanda nos troncos da rede.

Figura 49 - Relação entre pressões nos nós da simulação x Perdas

calculadas com expoente de perdas 0,5 .

Figura 50 - Relação entre pressões nos nós da simulação $\times$ Perdas

calculadas com expoente de perdas 1 .

Figura 51 - Relação entre pressões nos nós da simulação x Perdas

calculadas com expoente de perdas 2 .

Figura 52 - Curva de Potência para a localização da turbina 1

Figura 53 - Curva de Potência para a localização da turbina 2

Figura 54 - Curva de Potência para a localização da turbina 3

Figura 55- Caminho critico do aproveitamento no ponto 1

Figura 56- Caminho critico do aproveitamento no ponto 2

Figura 57- Caminho critico do aproveitamento no ponto 3

Figura 58- Limites para abertura ou não do "by-pass".

Figura 59- Configuração final dos três pontos de geração na rede do

Município de Piquete 
Figura 60 - Gráfico da evolução das pressões antes e depois da otimização 143 Figura 61-Turbinas XJ22-1.1DCTH4-Z e XJ25-1.5DCTH4-Z indicada para os

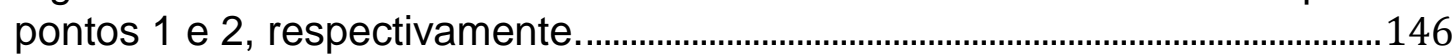
Figura 62-Turbina XJ14-0.3DCT4-Z indicada para o ponto 3...........................147 


\section{LISTA DE TABELAS}

Tabela 1 - Potencial hidrelétrico brasileiro, em MW, por Bacia Hidrgráfica dezembro de 2012. Fonte: SIPOT

Tabela 2 - Potencial hidrelétrico brasileiro em MW, dividido por categoria entre os estados - dezembro de 2012. Fonte: SIPOT ..............................28

Tabela 3- Definições de pequenos, mini e micro hidrelétricas da literatura ...33

Tabela 4 - Procedimento de cálculo dos potenciais.

Tabela 5 - Ordenamento segundo os maiores potenciais...................................121

Tabela 6 - Redução das perdas na rede.

Tabela 7 - Resultados da geração otimização da geração de energia...........145

Tabela 8 - Relação de turbinas e energia gerada ... 147

Tabela 9 - Resumo dos aproveitamentos conforme parâmetros de dimensionamento 


\section{LISTA DE SIGLAS}

ANEEL - Agência Nacional de Energia Elétrica

ESHA - European Small Hydropower Association

SNIS - Sistema Nacional de Informações sobre Saneamento

IPCC - Intergovenamental Panel on Climate Change 


\section{SUMÁRIO}

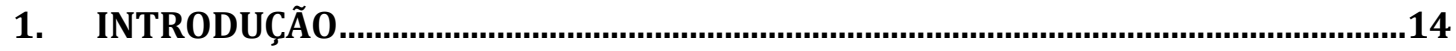

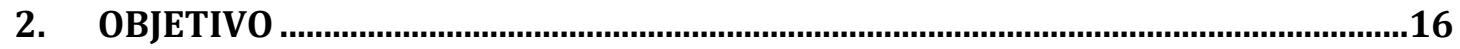

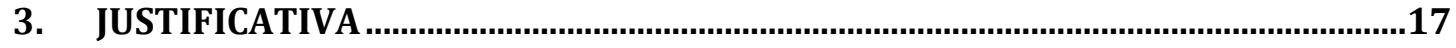

4. CONTEXTUALIZACÃO E REVISÃO BIBLIOGRÁFICA ………....................................20

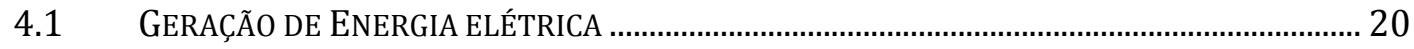

4.2 GERAÇ̃̃o DE ENERGIAS RENOVÁVEIS E DISTRIBUÍDAS .......................................................... 30

4.3 HIDRELÉTRICAS DE PEQUENA ESCALA................................................................................ 32

4.4 PRODUÇ̃̃̃O DE ENERGIA HIDRELÉTRICA ........................................................................... 35

4.5 DEFINIÇ̃̃̃O DO SISTEMA DE ABASTECIMENTO DE ÁGUA.......................................................... 39

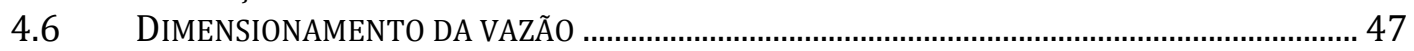

4.7 CONSUMO DE ENERGIA NA DISTRIBUIÇÃ̃ DE ÁGUA .......................................................... 49

4.8 DESCRIÇ̃̃̃O DAS TURBINAS E RENDIMENTOS ........................................................................ 50

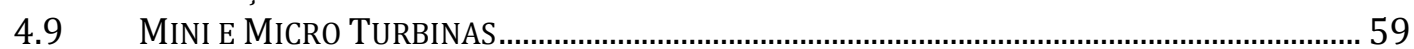

5. CONCEITOS E CONFIGURAÇÃO DA MINI E MICROGERAÇÃo DE ENERGIA..........60

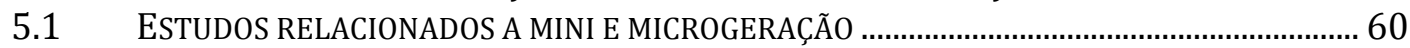

5.2 APROVEITAMENTO E BENEFí́cIOS OBTIDOS ....................................................................... 62

5.3 ESTRUTURAÇ̃̃o DE MINI E MICRO GERAÇ̃̃o NA REDE DE DISTRIBUIÇ̃̃̃O DE ÁGUA ............ 63

5.4 PROCEDIMENTOS DE INSTALAÇÃOO........................................................................................... 70

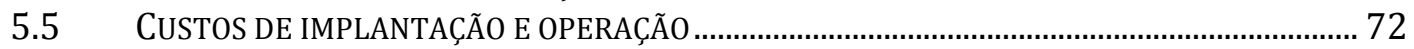

5.6 ESTRUTURA DE MODELAGEM PARA MINI E MICRO GERAÇ̃̃̃O .................................................. 73

5.7 MODELAGEM HIDRÁULICA EM REDES DE DISTRIBUIÇ̧̃̃o …….............................................. 75

6. MODELO DE OTIMIZAÇÃO............................................................................77

7. MATERIAIS E MÉTODOS.....................................................................................86

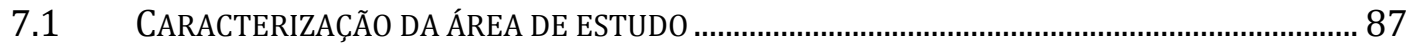

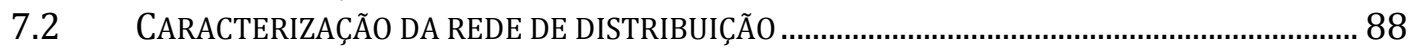

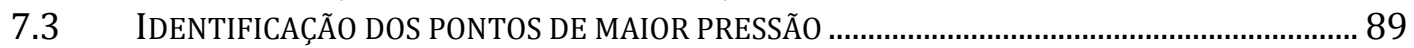

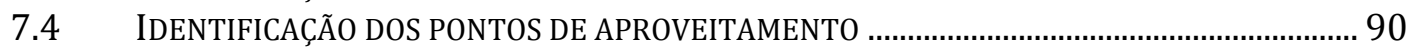

7.5 ESCOLHA DOS EQUIPAMENTOS ELETRO MECÂNICOS ................................................................. 91

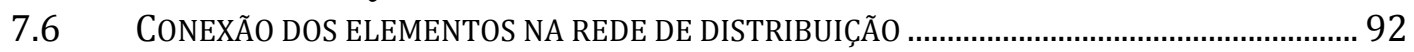

7.7 COMPARAÇ̃̃̃O E CORRELAÇÃ̃ ENTRE O CONSUMO DE ÁGUA E A PRODUÇ̃̃o DE ENERGIA 94

7.8 REDUÇ̃̃O DAS PRESSÕES E PERDAS.................................................................................. 95

7.9 DESENVOLVIMENTO DA METODOLOGIA DE AVALIAÇÃ̃O ……………....................................... 97

7.10 VIABILIDADE E RESTRIÇÕES............................................................................................105

8. ESTUDO DE CASO ................................................................................................108

8.1 CARACTERIZAÇূ̃̃o DA ÁREA DE ESTUdO Do MUNIĆ́PIO DE PIQUUETE .................................108

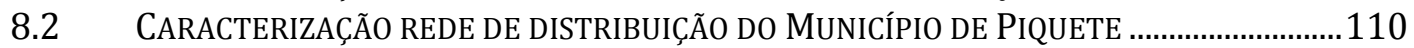

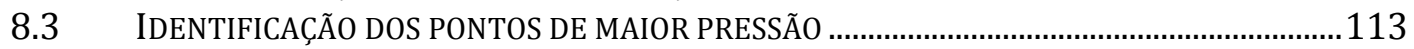

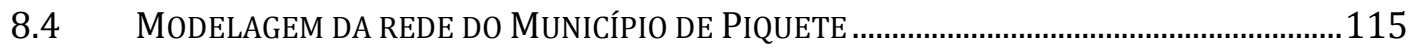

8.5 LOCALIZAÇC̃̃̃ DAS TURBINAS ..........................................................................................118

8.6 DETERMINAÇÃO DA DIMENSÃO DAS TURBINAS...................................................................125

8.7 DETERMINAÇÃO DOS HORÁRIOS DE ACIONAMENTO.................................................................127

8.8 REDUÇÃO DAS PERDAS...........................................................................................................128

8.9 MAXIMIZAÇ̃̃̃O DA GERAÇÃO DE ENERGIA..........................................................................130

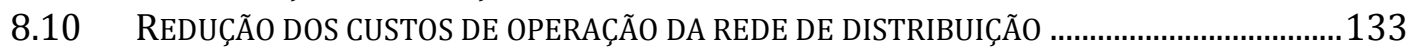

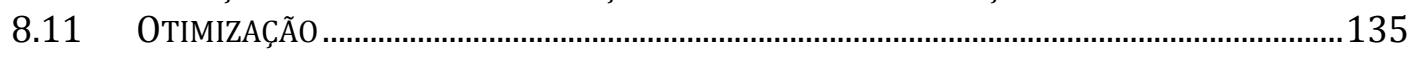

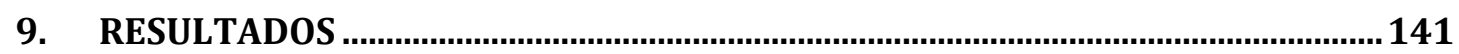

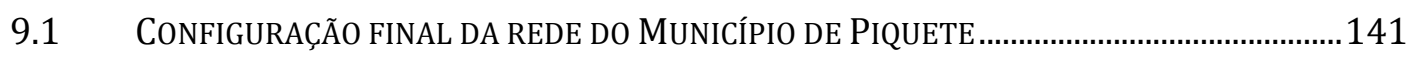

9.2 OTIMIZAÇ̃̃O DAS PRESSÕES ......................................................................................................143

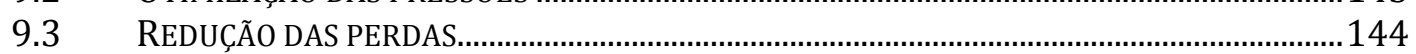




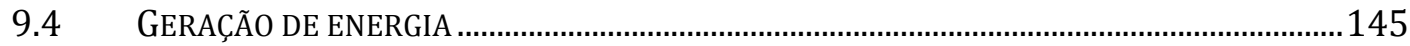

9.5 MÁQUINAS HIDRÁULICAS UTILIZADAS E CONFIGURAÇÃO ……………………...................145

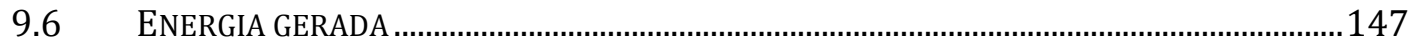

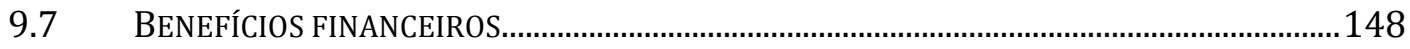

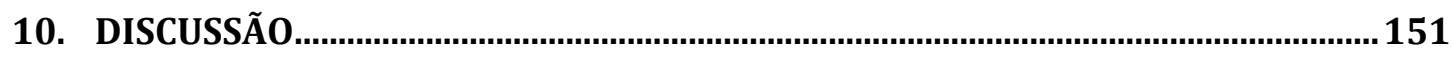

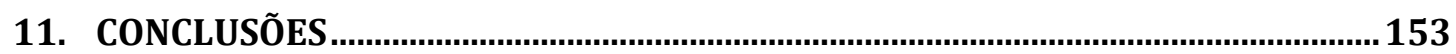

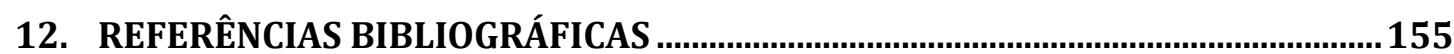




\section{INTRODUÇÃO}

O aumento da demanda por energia elétrica, e as consequentes pressões relacionadas à utilização de fontes de energia limpas e sustentáveis, e de como obtê-las, tem promovido um avanço no campo das energias sustentáveis e fontes alternativas.

As técnicas usuais de geração de energia produzem dióxido e monóxido de carbono e estão constantemente sendo relacionadas com problemas de ordem climática e na questão de espaço e preservação de áreas nativas, ocupando grandes extensões para a construção de reservatórios mais especificamente no caso da energia hidrelétrica.

Os centros urbanos muitas vezes ficam distantes dos pontos de geração de energia, causando perdas na transmissão e acarretando altos gastos na construção dos sistemas de transmissão.

A localização das unidades geradoras é, portanto, fator que deve ser considerado na produção de energia, além da busca por fontes mais próximas aos centro consumidores, uma das alternativas almejadas atualmente.

Em países europeus, as fontes naturais de energia, como a hidrelétrica, encontramse próximas ao aproveitamento limite (ESHA, 2014b).

Assim, a produção de energia hidráulica, considerada uma fonte de energia "limpa", está em um estado maduro, enquanto a produção a partir de pequenas hidrelétricas encontra-se ainda abaixo dos possíveis níveis de aproveitamento, como explica Soffia, Claps e Poggi (2008).

Deste modo, a busca por fontes de energia com enfoque em integrar a geração hidrelétrica aos grandes centros, e obtê-la de um modo sustentável e ambientalmente apropriado, fez com que a instalação de dispositivos geradores na rede de distribuição de água possua potencial de crescimento.

Aproveitando o sistema de condutos e dispositivos já instalados, os impactos de novos empreendimentos e os custos de instalação são reduzidos.

Durante os últimos anos, o aproveitamento do potencial dos sistemas de distribuição de água não avançou devido à relação beneficio custo das instalações. No entanto, os recentes avanços no desenvolvimento e instalação de mini e micro unidades geradoras e a grande variedade de pequenas turbinas, fizeram com que 0 
aproveitamento deste recurso fosse possível (Afshar et al., 1990).

Ressalta-se que não seria possível suprir as necessidades de consumo exclusivamente com esta opção, pois a energia proveniente do aproveitamento deste sistema é na sua maioria de pequenos potenciais.

A opção funcionará somente como uma medida complementar para abater os custos do abastecimento e aumentar a capilaridade da produção. No entanto, tal aproveitamento, traz grandes vantagens como não produzir poluentes e possuir impacto ambiental praticamente nulo (Miotto et.al.2008).

Como as redes de distribuição de água devem lidar constantemente com a manutenção e o aumento do consumo impulsionado pela urbanização e adensamento populacional das cidades, a expansão destas redes acarreta a necessidade de buscar recursos mais distante de onde a população se concentra.

Esta questão acaba elevando os custos de abastecimento referentes a condução dos recursos e a aplicação de motobombas para a transposição de bacias e aumento da linha piezométrica.

Desta forma, o consumo de energia relacionado com a distribuição de água também é um dos fatores importantes para o cálculo dos custos envolvidos no transporte de água.

Surge então a proposta de utilizar não somente as adutoras de abastecimento como sugerido em estudos recentes de Soffia, Claps e Poggi (2008) e Gonçalves (2012), mas também na rede de abastecimento dispersa na área dos municípios.

As redes possuem características que são favoráveis ao desenvolvimento de um sistema de geração hidrelétrica funcionando de maneira integrada às demais fontes de geração de energia. Elas seriam complementares e suficientes para reduzir os gastos com a distribuição de água, abatendo os custos com energia elétrica Silva (2012).

Sabe-se que a instalação de microturbinas na rede de distribuição aumenta a perda de carga, o que poderia comprometer as pressões e as vazões em pontos específicos. O desafio a ser enfrentado é o de determinar as condições técnicas em termos de dimensionamento, localização e condições operacionais para obter a maior eficiência na produção de energia, sem comprometer os aspectos hidráulicos da distribuição de água. Portanto, foi desenvolvida uma metodologia que engloba técnicas organizacionais e de otimização de redes que garante o melhor desempenho possível para esta fonte alternativa de energia. 


\section{OBJETIVO}

O presente trabalho de pesquisa tem como objetivo geral desenvolver uma metodologia para o estudo do potencial de geração de energia a partir da implantação de mini e/ou micro hidrelétricas na rede de abastecimento de água.

Aproveitam-se as estruturas da rede de abastecimento de água e a modelagem hidráulica como ferramentas para geração de energia, encadeando procedimentos de calculo e otimização como instrumentos de análise.

Como objetivos específicos, será identificada e otimizada a instalação das estruturas geradoras nos pontos de melhor aproveitamento do potencial, o dimensionando das máquinas hidráulicas, métodos construtivos, horários de acionamento $\mathrm{e}$ configurações mais adequadas ao aproveitamento.

Será também fruto desta análise o estudo de viabilidade dos mini e micro aproveitamentos como alternativa complementar à geração de energia tradicional.

Será avaliado o papel da redução das pressões na rede como critério para viabilizar a instalação das turbinas, devido a capacidade de controle e redução das perdas no sistema de distribuição de água.

Pretende-se também, como objetivo especifico estudar a maneira de utilizar a energia gerada como contribuição direta para a rede de distribuição elétrica, tornando-a técnica e economicamente viável. 


\section{JUSTIFICATIVA}

A energia hidrelétrica é considerada uma fonte de energia limpa e renovável, principalmente quando comparadas com as usinas termoelétricas, que se utilizam da queima de combustíveis para gerar energia.

No entanto, a energia hidrelétrica é também causadora de impactos ambientais como a produção de gases estufa proveniente da decomposição de matéria orgânica encoberta por suas represas e grandes áreas inundadas.

O uso de hidrelétricas com grandes lagos também gera conflitos com os moradores nativos e nas questões de uso múltiplo da água, privilegiando a produção de energia em detrimento de usos, como o abastecimento e manutenção da flora e da fauna aquática.

Em um cenário mundial, os impactos relacionados às grandes hidrelétricas têm sido relevados para que esta forma de produção de energia seja adotada. Este fato ocorre pois elas tem a capacidade de suprir a demanda de energia primária com custos atrativos, mantendo um papel de destaque principalmente do ponto de vista econômico na tomada de decisão.

Com o uso de fontes alternativas, é importante ressaltar que o papel das grandes hidrelétricas permanece o mesmo ao longo do tempo, sendo fonte primaria de energia, contudo 0 uso de fontes alternativas tem ganhado espaço na complementação da matriz energética.

A geração por mini e micro centrais hidrelétricas instaladas na rede de distribuição de água, pode ser utilizada como fonte alternativa de geração nos municípios onde 0 relevo e configuração permitirem. A alternativa aproveita as estruturas da rede já instaladas, sem a necessidade de grandes investimentos financeiros, permitindo 0 maior acesso a esta tecnologia.

A utilização de recursos hídricos para diversas propostas é uma estratégia empregada desde os primórdios da civilização, com foco principal no consumo e na irrigação de culturas. Não se deve deixar de lado, no entanto, os usos de recreação e alguns mais nobres como a movimentação de moinhos de transporte, ajudando no desenvolvimento e qualidade de vida das pessoas.

Usos como a movimentação do moinho são empregados até os dias atuais, no entanto em seu principio básico, que é a transformação de energia cinética da água em trabalho. No caso de usinas hidrelétricas, o trabalho realizado pela passagem da 
água pelas aletas ou pás de uma turbina transforma a energia cinética em elétrica.

Partindo do principio que esta água será utilizada em algum momento por outro usuário faz com que os usos devam ser compartilhados, uma vez que a mesma água utilizada para movimentar os moinhos e usinas hidrelétricas pode também atender outras propostas como a recreação, irrigação, consumo humano e animal, e transporte.

A Lei que regulamenta a Política Nacional de Recursos Hídricos (Lei 9.433/1997) tem em seus fundamentos 0 uso múltiplo das águas, promovendo 0 desenvolvimento de empreendimentos que utilizem de forma inteligente os recursos. Esta política reduz os possíveis conflitos gerados na disputa pelo recurso nas condições de uso necessárias para cada destinação.

Utilizando o conceito de usos múltiplos e em respeito à legislação, imagina que a água utilizada no abastecimento público possa agregar mais um uso, que é o de geração de energia elétrica, sendo coerente com o objetivo de multiplicidade e integração dos usos da água estabelecidos pela Política Nacional de Recursos Hídricos.

A instalação de pequenos aproveitamentos como a instalação de mini e micro hidrelétricas em redes existentes de irrigação, distribuição de águas e canais abertos, tem sido solução para que cidades aproveitem de forma mais inteligente os recursos hídricos disponíveis, sem interferir na função principal destas redes.

Assim, gerar energia a partir da rede de distribuição de água potável é uma solução que engloba as mais recentes tendências na geração de energia que é a descentralização das fontes geradoras e sua pulverização pelo território minimizando os impactos mais significativos da geração hidrelétrica e auxiliando no controle de pressões na rede de distribuição.

A redução das perdas é um dos fatores que por si só justifica uma intervenção na rede de distribuição. A avaliação de qual participação as turbinas tem neste quesito incrementa a qualidade dos estudos realizados.

Desta forma, o projeto aqui apresentado é justificado pelo avanço na tecnologia de geração de energia, reduzindo os impactos ao meio ambiente, contribuindo para o uso racional da água.

Segundo o Sistema Nacional de Informações sobre Saneamento (SNIS, 2010), no Brasil existem aproximadamente 660 prestadores de serviços de água, muitas vezes controlando mais que uma única rede de distribuição. Estas redes podem apresentar 
potencial para os mini e micro aproveitamentos.

Desta forma, o trabalho de formular uma metodologia de análise de viabilidade para o desenvolvimento e estudo dos aproveitamentos de pequena escala é justificado pela grande variabilidade de configurações de redes, e pela possibilidade de existir potencial com características técnicas e econômicas suficientes. 


\section{CONTEXTUALIZACÃO E REVISÃO BIBLIOGRÁFICA}

\subsection{Geração de Energia elétrica}

\section{Cenário mundial de geração de energia}

Estima-se que represando todos os corpos hídricos do mundo, seria possível obter cerca de 4,7 TW (1012 watt). No entanto, apenas 1,66 TW destes tem potencial de geração de energia segundo informações do International Journal on Hydropower, 2010 (IJHD).

$\mathrm{Na}$ atual conjuntura, a capacidade instalada é de cerca de 1000GW (10 $\left.{ }^{9} \mathrm{watt}\right)$, restando ainda $600 \mathrm{GW}$ de potencial natural desfrutável, o que pode parecer pouco, visto que a produção de energia triplicou frente aos valores produzidos há 50 anos.

Na Figura 1, a seguir, é expresso de forma gráfica o consumo de cada tipo de energia produzida ao longo do período que compreende o fim da década de 60 até 0 começo dos anos 2000.

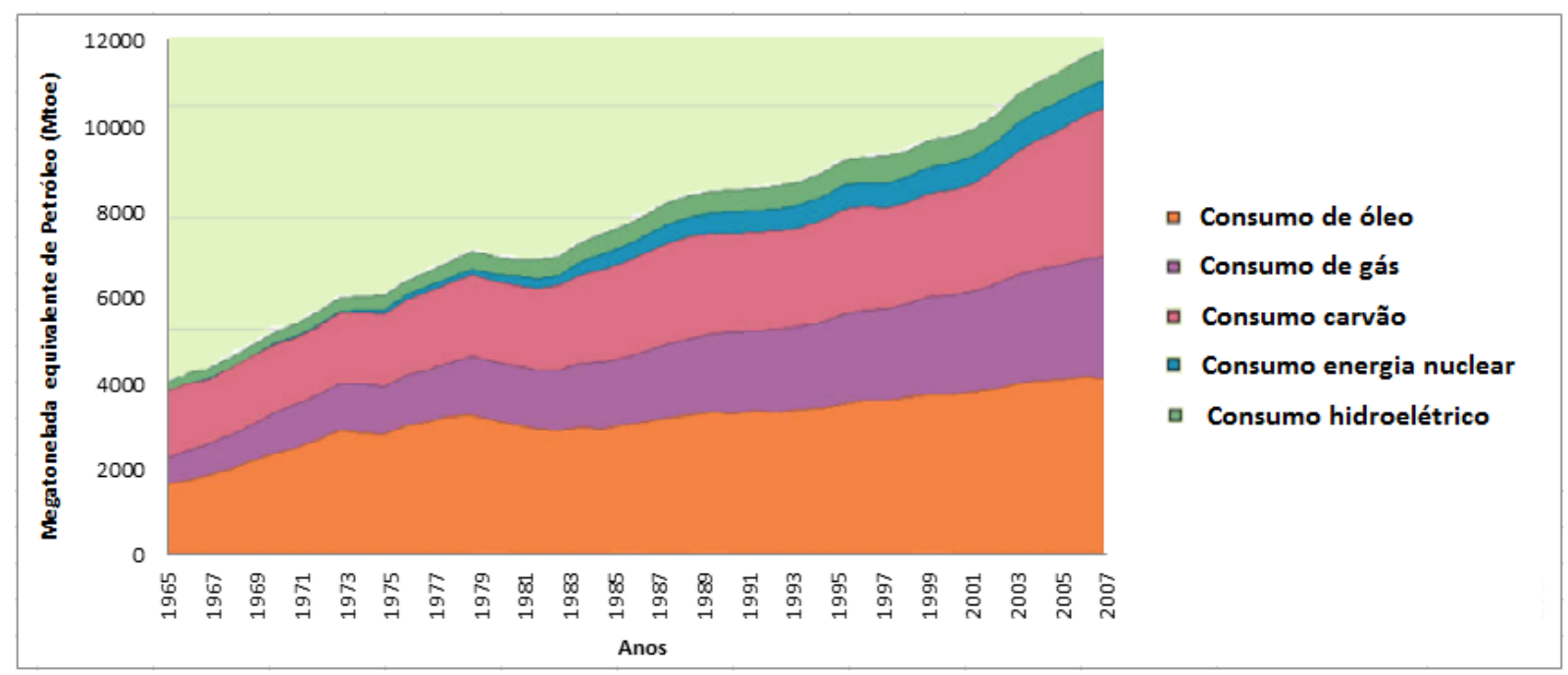

Figura 1- Gráfico representativo do consumo distinto por fontes. Fonte: BP, Statistical Review of World Energy 2009.

Pode-se prever que em algumas regiões, a capacidade de aumento de algumas destas formas de produção de energia não poderão ser facilmente desenvolvidas. Este é o caso de regiões já bastante desenvolvidas como o cenário hidrelétrico Europeu, segundo a Intergovenamental Panel on Climate Change - IPCC, 2009.

O mercado de grandes hidrelétricas europeu já se encontra próximo da saturação, 
exigindo que obras com baixo retorno sejam consideradas. Desta forma, 0 incremento da produção em alguns países não tem aumentado de forma significativa nos últimos anos, e mantém-se constante.

Aqueles que mantem 0 crescimento na produção devem este fato ao desenvolvimento de instalações de hidrelétricas a água fluente e autorreguladas, como as hidrelétricas a fio d'água, que não necessitam de reservatórios.

No cenário mundial, a produção de energia elétrica utilizável demonstra uma tendência cada vez mais marcante, que é a de amplo crescimento tanto na produção quanto no consumo.

Países desenvolvidos tem o maior consumo e consequentemente, são aqueles que têm o potencial hidrelétrico já desenvolvido quase que em sua totalidade, como pode ser visto nas Figura 2 e Figura 3.

Nelas, está demonstrado que nos países europeus, América do Norte e Oceania, a porcentagem utilizada deste recurso chega a mais da metade, enquanto países ainda em desenvolvimento como China, Índia e Brasil ainda possuem menos de um terço desta fonte comprometida.

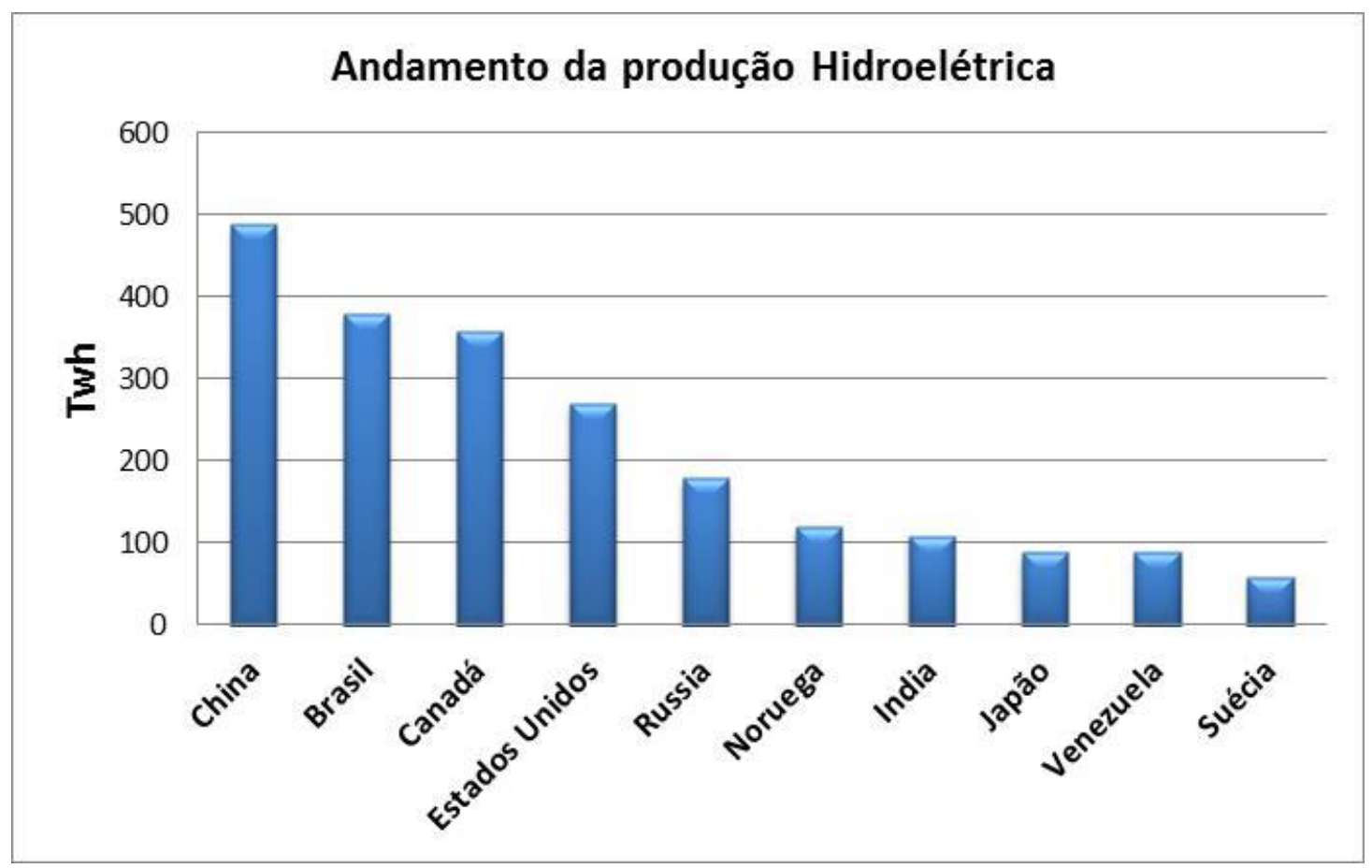

Figura 2 - Gráfico de barras do potencial de produção por países. Fonte: Elaborazioni su dati IEA 2009. 


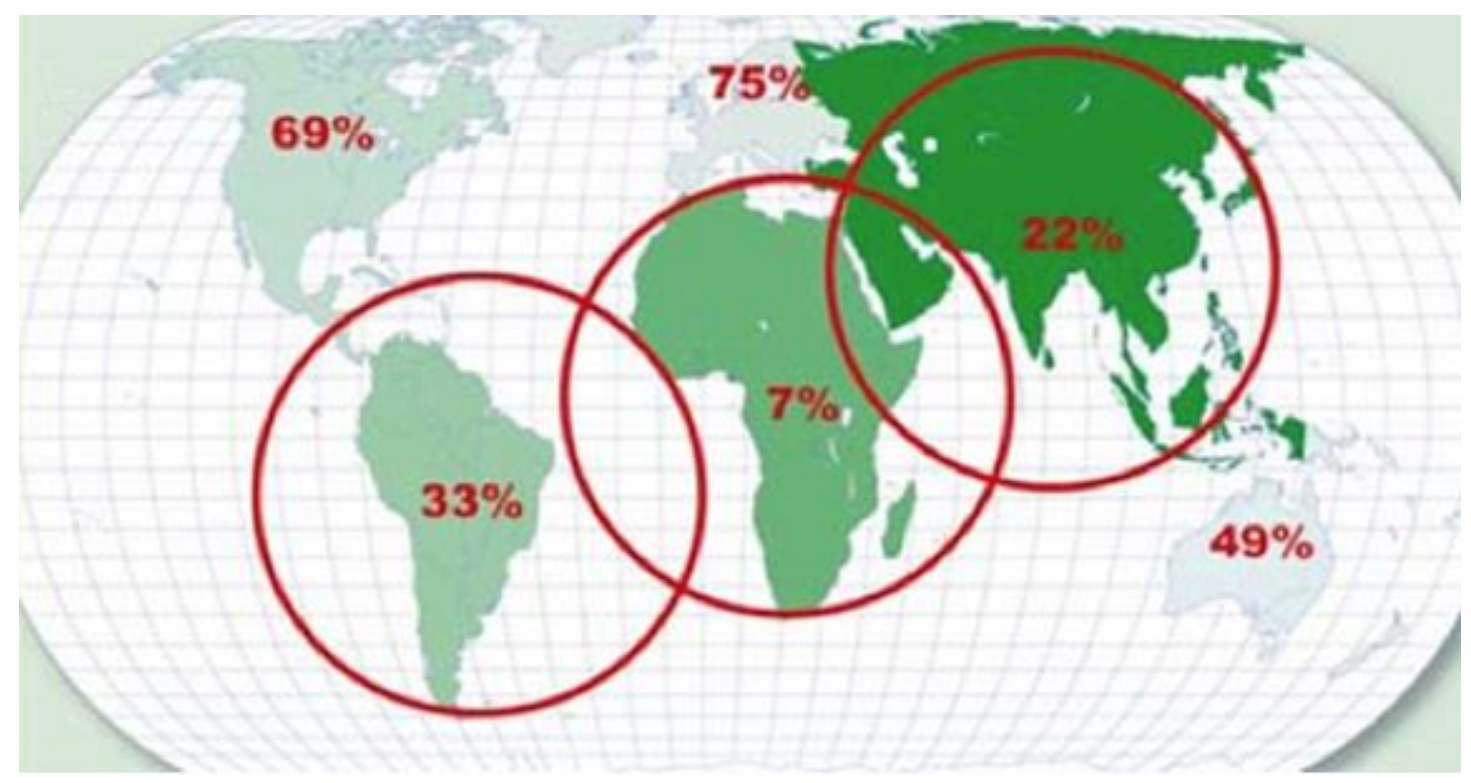

Figura 3 - Esquema representativo do percentual de potencial utilizado. Fonte: A.Sorokin 2009 e World Energy Council 2002.

Um caso extremo é o da África, que possui menos de $10 \%$ de seu potencial desenvolvido.

A partir do estudo deste cenário, é possível constatar que a produção de energia hidrelétrica em países europeus é atualmente bastante restrita devido ao seu elevado consumo e ao exaurimento das fontes hídricas naturais.

Estes países apresentam a necessidade de expandir sua produção de novas maneiras.

Já no caso dos países em desenvolvimento, os níveis de consumo devem atingir valores próximos aos daqueles desenvolvidos dentro de alguns anos, demonstrando a necessidade de desenvolver tecnologias para a geração eficiente.

O uso da geração em microescala é uma alternativa a ser considerada, pois consome os recursos de maneira consciente, aproveitando o potencial remanescente e retardando o exaurimento das fontes disponíveis.

Mesmo em países com grande potencial remanescente, grandes estruturas hidráulicas para geração de energia já não possuem aspecto convidativo, uma vez que envolve diversos participantes e demanda áreas extensas, gerando conflitos e possivelmente danos ao ecossistema e economia local.

Desta forma, o desenvolvimento da geração hidrelétrica parte para a diversificação dos grupos geradores, assim como acontece nos países onde a capacidade 
instalada já atingiu valores elevados.

A geração centralizada de energia também traz riscos envolvidos como a concentração dos problemas, prejudicando grandes regiões por torna-las dependentes de usinas hidrelétricas distantes aos centros de consumo. Neste cenário, são necessárias redes muito extensas de distribuição de energia que são suscetíveis a falhas e aumentam a vulnerabilidade da rede.

Em qualquer situação onde é necessário cessar a transmissão, grandes áreas poderiam ficar sem energia por longos períodos de tempo até que os problemas fossem sanados.

Desta forma, uma maneira mais inteligente de contornar tal problema é utilizando a produção de energia dispersa no território, sendo fornecida por pequenas, mini e micro centrais, que além de reduzir os custos de implantação, trazem vantagens relacionadas à redução dos altos custos de transmissão.

Porém, obras de grande porte não devem ser descartadas, uma vez que são de extrema importância para o desenvolvimento de uma região e do país, ressaltando que estas devem ainda ser consideradas a matriz principal, respaldadas por um sistema de abastecimento mais distribuído.

\section{Cenário da geração de energia no Brasil}

Tendo em vista as grandes dimensões do país, com área do território igual a 8.514.876,6 km2, o que representa o quinto maior país em área do mundo. Devido a este fato, decidiu-se estudar o cenário de geração hidrelétrica no país dividindo-o em macro regiões, norte, nordeste, centro oeste, sul e sudeste.

A morfologia do território brasileiro pode ser dividida também em camadas, sendo áreas com altitudes médias abaixo de 200 metros, em $40 \%$ do território, aquelas com altitudes entre 200 e 600 metros, $45 \%$ do território, e as altitudes entre 600 e 900 metros, que representam $12 \%$ do território nacional.

Com esta classificação, pode-se dizer que a maioria dos rios brasileiros se encontra em regiões de planície ou de planalto, com desníveis inferiores a 400 metros, o que pode parecer desfavorável a geração de energia.

No entanto o país possui recursos hídricos em abundância, segundo a UNESCO, o equivalente a 35.000 metros cúbicos de água por habitante, e possui $15 \%$ de toda a água doce do planeta.

Como comparação, na Alemanha, esta equivalência corresponde a 1.500 metros 
cúbicos de água por habitante.

Desta forma, existem muitos espaços aproveitáveis e volume de água considerável para a sua utilização como fonte de energia, tornando o Brasil o terceiro país com maior potencial hidrelétrico do mundo, com um valor total de $255.000 \mathrm{MW}\left(10^{6} \mathrm{watt}\right)$ de potencial desfrutável, dos quais somente $25 \%$ são utilizados (SIPOT, 2012).

Ao observar ainda a representatividade da energia hidrelétrica no Brasil, pode-se ver que é utilizada de modo extensivo, sendo que a diversidade de fontes para a produção de energia é vasta e ainda de fácil acesso.

O Brasil é um dos países que mais investem em aproveitamentos energéticos considerados como limpos e renováveis, como por exemplo, o consumo de biomassa para produção de combustíveis utilizados na frota de veículos e como fonte de alimentação de usinas termoelétricas.

Segundo estudo do Sindipeças, em 2010, 53\% dos veículos comercializados já possuem a tecnologia multi-combustível.

Somando estes fatores e comparando a oferta de energia proveniente de fontes não renováveis disponível, a energia hidrelétrica somada aos combustíveis renováveis agrupa a maior parte do balanço energético do país, sendo a energia hidrelétrica a principal fonte energética do país como apresentado na Figura 4.

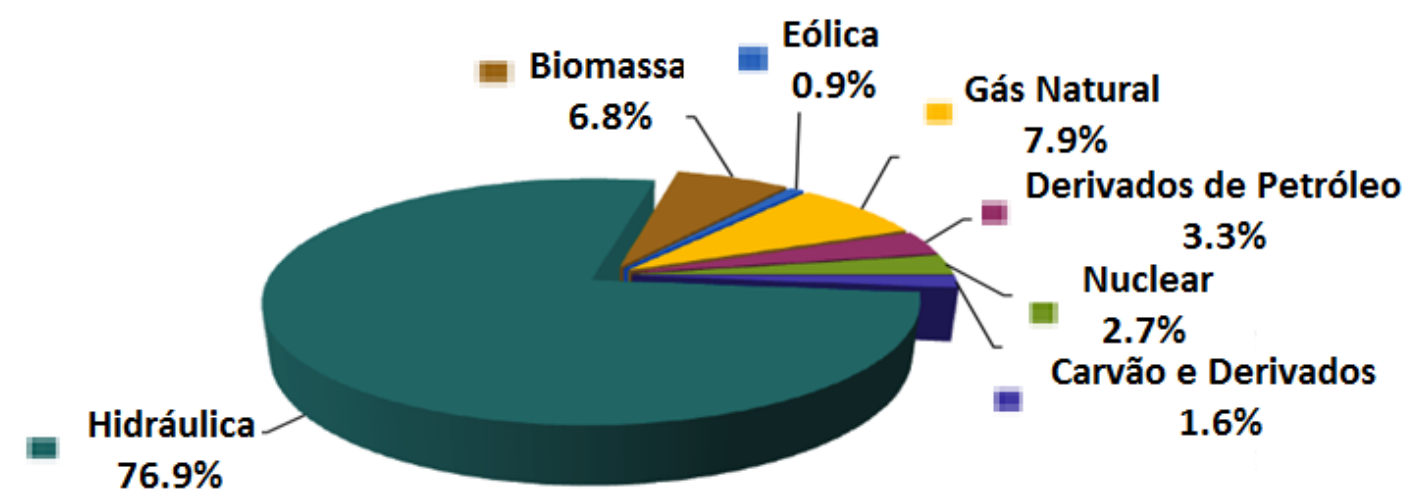

Figura 4 - Distribuição da oferta de energia no Brasil . Fonte: Relatório de Balanço Energético Nacional, http://www.epe.gov.br

Ainda segundo o Sistema de Informações do Potencial Hidrelétrico Brasileiro (SIPOT),2012, todas as localidades com potencial hidrelétrico pesquisadas tem uma classificação quanto ao seu estágio de desenvolvimento, assim sendo, podem ser 
divididas em grupos.

Os grupos são divididos em potencial estimado (remanescente e individualizado), potencial estudado (estudo de inventário, viabilidade de projeto e projeto básico) e centrais em construção e operação.

O SIPOT, com dados do ano de 2012, determina o potencial hidrelétrico total no Brasil é de $244 \mathrm{GW}$, dos quais 19,7\% correspondem a um potencial estimado, 28\% ao potencial estudado, 7,7\% em construção e 35\% em operação.

O potencial em fase de estudo e inventário, viabilidade e projeto básico tem como base, estudos precisos e metodologia definida para os cálculos do potencial, enquanto o potencial estimado é calculado a partir de dados secundários e imprecisos, ou seja, quase $20 \%$ dos dados não tem o mesmo grau de certeza, o que é um número bastante elevado.

Dentro deste valor estimado, a maior parte do potencial se encontra na zona amazônica, muito pobre em dados e informações confiáveis, além de estar localizada dentro de territórios de proteção ambiental, indígenas e de reservas biológicas.

Agregando a este fato a dificuldade logística e a necessidade de transmissão em longa distância para os centros de consumo, a sua utilização se torna complicada e com custos muito elevados, algumas vezes até impeditivos.

Portanto, tomando em conta não somente o potencial referente ao desnível entre jusante e montante e o comprimento dos corpos hídricos para calcular o potencial, deve-se também atentar a outros dados, como a viabilidade, tanto econômica quanto ambiental e técnica das usinas hidrelétricas.

A Agência Nacional de Energia Elétrica (ANEEL) fez também uma pesquisa do potencial hidrelétrico brasileiro, encontrando valores diferentes daqueles encontrados pelo SIPOT.

Esta diferença se deve tanto ao fato de a ANEEL utilizar uma metodologia diferente da aplicada pelo SIPOT, quanto ao banco de dados utilizado. A ANEEL juntamente com a Agência Nacional de Águas (ANA), emitem as autorizações para a construção de obras de usinas hidrelétricas.

Os valores são mais realistas e fazem considerações aos fatores citados anteriormente, como os problemas de viabilidade, porém não consideram as áreas onde ainda não foram realizados projetos.

Os valores encontrados pela ANEEL são a soma de 14,3 GW de potencial em 
estágio de inventário já aprovado, 2,5GW em projeto de pequenas centrais hidrelétricas e 29,2GW em estudos de viabilidade, totalizando 46GW, que somados ainda com as informações de potencial já realizadas em alguns corpos hídricos, faz com que o total salte para $79 \mathrm{GW}$.

Assim sendo, não se pode estimar seguramente se o potencial utilizado corresponde ao aproveitamento de até $50 \%$ do total disponível, mas pode-se dizer seguramente que o potencial explorado não é de apenas $25 \%$, como o divulgado pelo SIPOT.

Esta afirmação se deve a considerar todos os fatores envolvidos na produção de energia e as particularidades que podem impedir a instalação de usinas hidrelétricas em locais que possuem potencial teórico elevado.

Para analisar em detalhe como o potencial é distribuído pelo território nacional, é aqui apresentada a distribuição por tipologia de potencial. Pode-se fazer esta divisão também em confronto com a divisão de bacias, colocando em questão os potenciais em fase de estudos de viabilidade, em construção e operação ou em projeto, além do potencial remanescente em cada divisão.

A Tabela 1, referenciada aos dados do SIPOT do ano de 2012, demonstra esta divisão, identificando as principais bacias do território e dividindo o potencial pela sua tipologia. 
Tabela 1 - Potencial hidrelétrico brasileiro, em MW, por Bacia Hidrgráfica - dezembro de 2012. Fonte: SIPOT

\begin{tabular}{|c|c|c|c|c|c|c|c|c|c|}
\hline Estágio / Bacia & Atlântico Leste & $\begin{array}{c}\text { Atlântico } \\
\text { Norte / Nordeste }\end{array}$ & Atlântico Sudeste & Rio Amazonas & Rio Paraná & Rio São Francisco & Rio Tocantins & Rio Uruguai & Totais por Estágio \\
\hline Remanecente & 767,4 & 525 & 983,06 & $17.584,46$ & $3.662,33$ & 694 & $1.779,60$ & 11,7 & $26.007,55$ \\
\hline Individualizado & 655,1 & 181,7 & $1.090,00$ & $16.329,33$ & $2.659,36$ & 866,98 & 128 & 404 & $22.314,47$ \\
\hline Total Estimado & $1.422,50$ & 706,7 & $2.073,06$ & $33.913,79$ & $6.321,69$ & $1.560,98$ & $1.907,60$ & 415,7 & $48.322,02$ \\
\hline Inventário & $5.630,62$ & $1.056,15$ & $1.655,63$ & $36.571,21$ & $9.061,24$ & $3.885,11$ & $7.432,70$ & $3.928,43$ & $69.221,09$ \\
\hline Viabilidade & 919,9 & 408 & $2.218,00$ & 774,00 & $2.110,23$ & $6.140,00$ & $3.738,00$ & 427 & $16.735,13$ \\
\hline Projeto Básico & 628,36 & 49,69 & 315,68 & $1.429,43$ & $2.014,64$ & 277,88 & 40,19 & 404,92 & $5.160,79$ \\
\hline Construção & 370,2 & 252 & 88,99 & $17.659,15$ & 194,25 & 0 & 30 & 239,71 & $18.834,30$ \\
\hline Operação & $5.029,33$ & 335,25 & $3.637,48$ & $4.651,16$ & $43.141,92$ & $10.717,70$ & $13.163,27$ & $6.026,51$ & $86.702,62$ \\
\hline Total Geral & $14.000,91$ & $2.807,79$ & $9.988,84$ & $94.998,74$ & $62.843,97$ & $22.581,67$ & $26.311,76$ & $11.442,27$ & $244.975,95$ \\
\hline
\end{tabular}


Na próxima tabela, foram divididos os tipos de potencial contabilizados por estados e DF.

Tabela 2 - Potencial hidrelétrico brasileiro em MW, dividido por categoria entre os estados - dezembro de 2012. Fonte: SIPOT

\begin{tabular}{|c|c|c|c|c|c|c|c|c|}
\hline Estágio & 1 -Remanecente & 2 - Individualizado & 4 - Inventário & 5 -Viabilidade & 6-Projeto Básico & 7-Construção & 8 -Operação & Total \\
\hline UF & $\begin{array}{l}\text { Soma de Potência } \\
\text { (MW) }\end{array}$ & $\begin{array}{l}\text { Soma de Potência } \\
\text { (MW) }\end{array}$ & $\begin{array}{l}\text { Soma de Potência } \\
\text { (MW) }\end{array}$ & $\begin{array}{l}\text { Soma de Potência } \\
\text { (MW) }\end{array}$ & $\begin{array}{l}\text { Soma de Potência } \\
\text { (MW) }\end{array}$ & $\begin{array}{l}\text { Soma de Potência } \\
\text { (MW) }\end{array}$ & $\begin{array}{l}\text { Soma de Potência } \\
\text { (MW) }\end{array}$ & $\begin{array}{l}\text { Soma de Potência } \\
\text { (MW) }\end{array}$ \\
\hline$A C$ & 402,00 & 656,00 & 62,50 & 0,00 & 0,00 & 0,00 & 0,00 & $1.120,50$ \\
\hline AL & 0,00 & 17,20 & 4,50 & $1.165,00$ & 0,00 & 0,00 & $1.582,25$ & $2.768,95$ \\
\hline AM & $6.226,00$ & $6.709,00$ & $7.046,40$ & 0,00 & 7,03 & 0,00 & 250,00 & $20.238,43$ \\
\hline AP & 360,00 & 0,00 & $1.059,70$ & 285,00 & 7,50 & 439,20 & 76,95 & $2.228,35$ \\
\hline BA & 0,00 & 324,48 & $1.607,76$ & $3.037,90$ & 361,09 & 0,00 & $6.858,53$ & $12.189,76$ \\
\hline $\mathrm{CE}$ & 0,00 & 0,00 & 3,45 & 0,00 & 17,57 & 0,00 & 4,00 & 25,02 \\
\hline DF & 0,00 & 0,00 & 0,00 & 0,00 & 0,00 & 0,00 & 30,00 & 30,00 \\
\hline ES & 108,20 & 105,10 & 634,09 & 0,00 & 13,60 & 0,00 & 557,91 & $1.418,91$ \\
\hline GO & $2.564,00$ & 36,05 & $3.549,49$ & 368,00 & 94,99 & 56,25 & $5.945,47$ & $12.614,25$ \\
\hline MA & 146,00 & 146,00 & 462,35 & 755,50 & 2,50 & 0,00 & 663,18 & $2.175,53$ \\
\hline MG & 989,00 & $1.838,50$ & $7.184,15$ & 717,00 & 609,22 & 258,35 & $12.074,69$ & $23.670,91$ \\
\hline MS & 113,21 & 903,48 & 801,26 & 0,00 & 677,46 & 48,00 & $3.579,54$ & $6.122,95$ \\
\hline MT & $4.511,90$ & $1.234,00$ & $10.887,86$ & 75,00 & 761,85 & $1.322,25$ & $1.829,69$ & $20.622,55$ \\
\hline PA & $2.379,00$ & $3.713,00$ & $20.975,83$ & 930,00 & 700,00 & $12.330,30$ & $8.500,30$ & $49.528,43$ \\
\hline PB & 0,00 & 5,50 & 2,10 & 0,00 & 0,00 & 0,00 & 3,52 & 11,12 \\
\hline $\mathrm{PE}$ & 0,00 & 0,00 & 300,75 & 500,00 & 22,12 & 0,00 & 752,02 & $1.574,89$ \\
\hline $\mathrm{PI}$ & 0,00 & 0,00 & 269,50 & 91,50 & 0,00 & 0,00 & 118,65 & 479,65 \\
\hline PR & $1.212,76$ & 271,43 & $3.845,12$ & $1.953,73$ & 844,90 & 33,00 & $15.958,20$ & $24.119,14$ \\
\hline $\mathrm{RJ}$ & 422,20 & 123,00 & 699,82 & 475,00 & 82,68 & 166,85 & $1.287,07$ & $3.256,63$ \\
\hline $\mathrm{RN}$ & 0,00 & 0,00 & 2,15 & 0,00 & 0,00 & 0,00 & 0,00 & 2,15 \\
\hline RO & $1.052,46$ & $4.254,33$ & 494,37 & 0,00 & 57,10 & $3.835,40$ & $3.524,85$ & $13.218,51$ \\
\hline RR & $4.178,00$ & 84,00 & $1.301,30$ & 324,00 & 0,00 & 0,00 & 5,00 & $5.892,30$ \\
\hline RS & 491,10 & $1.296,00$ & $3.269,39$ & 146,00 & 266,92 & 61,58 & $4.418,01$ & $9.949,00$ \\
\hline SC & 254,12 & 222,40 & $1.931,41$ & 281,00 & 394,69 & 267,12 & $3.745,22$ & $7.095,96$ \\
\hline $\mathrm{SE}$ & 0,00 & 0,00 & 0,00 & $1.165,00$ & 0,00 & 0,00 & $1.581,00$ & $2.746,00$ \\
\hline SP & 441,00 & 375,00 & 879,09 & $2.161,50$ & 239,58 & 16,00 & $11.042,87$ & $15.155,04$ \\
\hline TO & 156,60 & 0,00 & $1.944,41$ & $2.304,00$ & 0,00 & 0,00 & $2.313,70$ & $6.718,71$ \\
\hline Totais & $26.007,55$ & $22.314,47$ & $69.218,75$ & $16.735,13$ & $5.160,80$ & $18.834,30$ & $86.702,62$ & $244.973,64$ \\
\hline
\end{tabular}


Nela se pode ver que no estado do Amazonas existe o maior potencial remanescente, assim como já indicado anteriormente, porém, nos estados das regiões sul e sudeste o valor total, que soma também o potencial já aproveitado, são os mais altos. Exemplos desse fato são os estados de São Paulo, Minas Gerais e Paraná.

A partir deste cenário é possível constatar que a distribuição, do potencial e da rede instalada de energia, não acompanha a ordem desejada para o crescimento da produção de energia.

Nas regiões com maior potencial remanescente, os impedimentos encontrados para a construção de novas centrais geradoras são diversos, enquanto as regiões onde a o potencial remanescente é inferior, e o potencial instalado é o mais desenvolvido, a capacidade de expansão é pequena.

Desta forma, utilizando sistemas de geração distribuídos, existe a possibilidade de expandir a produção sem exigir potencial e investimentos em novas localidades.

O aproveitamento das redes de distribuição de água é uma medida interessante, pois as cidades que necessitam de mais energia, são aquelas que possuem sistemas de abastecimento desenvolvidos e, consequentemente, maiores chances de apresentar viabilidade na instalação de mini e micro aproveitamentos. 


\subsection{Geração de energias renováveis e distribuídas}

As energias renováveis e distribuídas na rede são formas de produção que geralmente estão relacionadas. A produção de energia de forma distribuída na rede foi a principal forma de geração logo após o desenvolvimento e popularização da energia elétrica, uma vez que não existiam grandes unidades geradoras e 0 consumo era localizado e em menor escala.

Com a evolução e crescente necessidade de energia elétrica para os setores industriais, de serviço e para a população, foram desenvolvidos sistemas que concentravam a produção de energia em larga escala. Foram utilizadas grandes centrais de geração, reduzindo o interesse no desenvolvimento tecnológico das centrais distribuídas, uma vez que os custos eram mais elevados.

A partir das mais recentes crises econômicas e da fragilidade da rede geradora, nas ultimas três décadas, a geração de energia distribuída vem sendo lentamente reabilitada. Ela fornece uma forma alternativa à construção de grandes centrais de geração, que estão cada vez mais custosas e provocam inseguranças quanto a confiabilidade da rede de distribuição em caso de falha de funcionamento.

A constatação desta mudança de conceitos pode ser observada na geração de energia termoelétrica demonstrada na Figura 5, que demonstra 0 gradual crescimento do tamanho ótimo das usinas termoelétricas iniciando com 50 a 200MW na década de 30 e chegando até $1000 \mathrm{MW}$ na década de 80 , quando ocorre a inversão desta tendência, reduzindo o tamanho ótimo novamente a valores na faixa de 50 a $200 \mathrm{MW}$. 


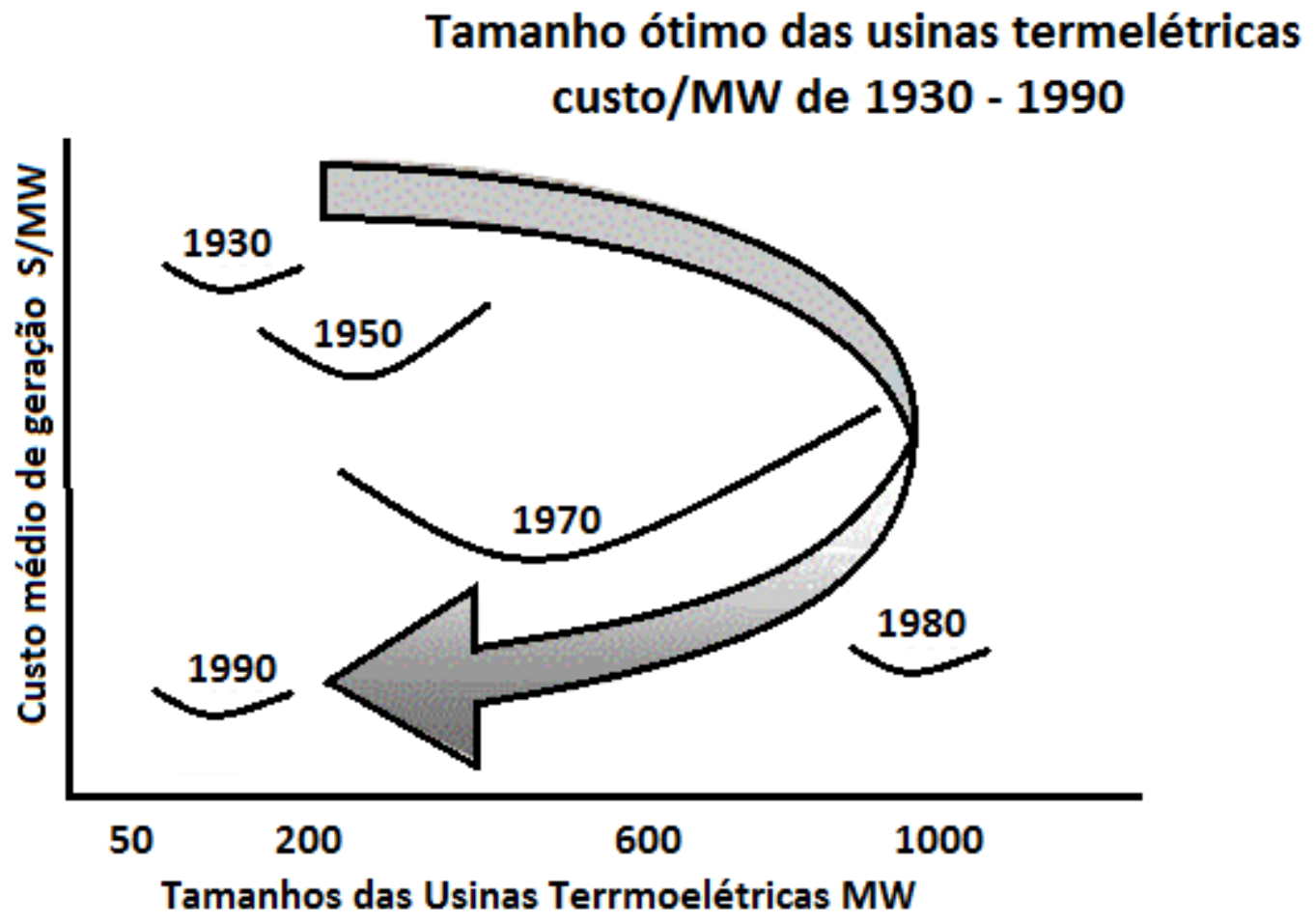

Figura 5 - Evolução do tamanho das usinas termoelétricas em relação ao custo médio de geração Fonte: Bayless (1994).

Desta forma, a produção descentralizada e distribuída na rede promove a segurança do sistema, mesmo que ainda em desenvolvimento, para amenizar os efeitos das flutuações da geração.

A flutuação na geração distribuída se dá pela utilização de fontes de energia que envolve, por exemplo, as energias, solar, eólica e de pequenas centras hidrelétricas, que são consideradas as fontes renováveis mais desenvolvidas. Estas fontes são ditas renováveis, pois utilizam da energia proveniente de fontes como o sol, dos deslocamentos de ar e do ciclo da água para produzir energia, fontes estas que não dependem de combustível não renovável como os fosseis.

As ações em prol da geração descentralizada vêm sendo tomadas tanto no meio tecnológico quanto no legal, uma vez que esta forma de geração é citada pela Lei 10.848, de 15 de Março de 2004 (Brasil, 2004), como fonte de geração distribuída.

Nela são observados os limites de contratação e de repasse das tarifas, baseados no valor de referência do mercado regulado e nas respectivas condições técnicas. Ela também inclui as usinas que produzam energia elétrica a partir de fontes eólicas, pequenas centrais hidrelétricas e biomassa, enquadradas na primeira etapa do Programa de Incentivo às Fontes Alternativas de Energia Elétrica - PROINFA. 
O Decreto 5.163/04 também respalda as empresas geradoras, fornecendo as características do comercio de energia entre as instalações bem como destes com seus consumidores no Sistema Interligado Nacional - SIN, mitigando os riscos no planejamento nacional.

\subsection{Hidrelétricas de pequena escala}

Hidrelétricas de pequena escala são sistemas hidrelétricos que transformam a energia cinética de fluxos de água, convertendo-os em energia elétrica utilizável. Este aproveitamento depende fundamentalmente da disponibilidade e principalmente da compatibilidade dos fluxos d'água com a instalação de unidades geradoras, como turbinas de ação e reação.

Elas são consideradas pelo Ministério de Minas e Energia como sendo opções tecnológicas para $\mathrm{O}$ atendimento com sistemas de geração descentralizados (Ministério de Minas e Energia, 2011).

Os aproveitamentos de pequena escala são geralmente nomeados segundo sua grandeza, e podem ser classificados em ordem decrescente de seus potenciais de produção, como sendo de pequena escala, mini aproveitamentos ou micro aproveitamentos.

Não existe um consenso internacional sobre a definição de usinas hidrelétricas de pequena escala segundo esta classificação, portanto, os valores aqui expostos seguirão a classificação brasileira. Ela determina que para valores de potência inferiores à 100 quilowatts, a classificação é de micro aproveitamento, para valores de potência gerada entre 100 e 1000 quilowatts, a classificação é de mini aproveitamentos e para valores de 1 a 30 megawatts a classificação é de pequenos aproveitamentos (Resolução n`394 de 4 de Dezembro de 1998).

Estes valores são também confirmados pela Resolução Normativa da ANEEL № 482 de 2012, que determina as seguintes definições:

- microgeração distribuída: central geradora de energia elétrica, com potência instalada menor ou igual a $100 \mathrm{~kW}$ e que utilize fontes com base em energia hidráulica, solar, eólica, biomassa ou cogeração qualificada, conforme regulamentação da ANEEL, conectada na rede de energia por meio de instalações de unidades consumidoras; 
- minigeração distribuída: central geradora de energia elétrica, com potência instalada superior a $100 \mathrm{~kW}$ e menor ou igual a $1 \mathrm{MW}$ para fontes com base em energia hidráulica, solar, eólica, biomassa ou cogeração qualificada, conforme regulamentação da ANEEL, conectada na rede de energia por meio de instalações de unidades consumidoras;

Como meio de comparar os valores adotados em literatura apresenta-se a tabela a seguir, desenvolvida por Moreire \& Poole (1993), que demonstra que o Brasil adota uma classificação semelhante a maioria dos países citados, e adota a mesma classificação dos Estados Unidos da América em relação ao limite superior para pequenas usinas.

Tabela 3- Definições de pequenos, mini e micro hidrelétricas da literatura

\begin{tabular}{|c|c|c|c|}
\hline País & $\begin{array}{c}\text { Micro } \\
\text { (quilowatts) }\end{array}$ & $\begin{array}{c}\text { Mini } \\
\text { (quilowatts) }\end{array}$ & $\begin{array}{c}\text { Pequena } \\
\text { (megawatts) }\end{array}$ \\
\hline Estados Unidos & $<100$ & $100-1000$ & $1-30$ \\
\hline Estados Unidos & $<100$ & $100-1000$ & - \\
\hline China & - & $<500$ & $0,5-25$ \\
\hline Rússia & $<100$ & - & $0,1-30$ \\
\hline França & $5-5000$ & - & - \\
\hline Índia & $<100$ & $100-1000$ & $1-15$ \\
\hline Brasil & $<100$ & $100-1000$ & $1-30$ \\
\hline Noruega & $<100$ & $100-1000$ & $1-10$ \\
\hline vários & $<100$ & $<1000$ & $<10$ \\
\hline
\end{tabular}

A geração de energia de pequena escala é mais indicada para a instalação em locais de difícil acesso e pequenas comunidades, o que não desqualifica sua utilização como sistema de geração auxiliar a rede principal de distribuição.

Produção de energia em pequena escala com o intuito de complementar a geração é, atualmente, uma das formas de obtenção de energia com mais rápido crescimento. Em projeções elaboradas pela European Small Hydropower Association (ESHA, 2014a), a energia em pequena escala apresentará um crescimento substancial até o ano de 2020, como apresentado na Figura 6 para a União Europeia, acompanhando a tendência de crescimento de 3 a 5 GW de energia instalada a cada 5 anos até 2020 . 


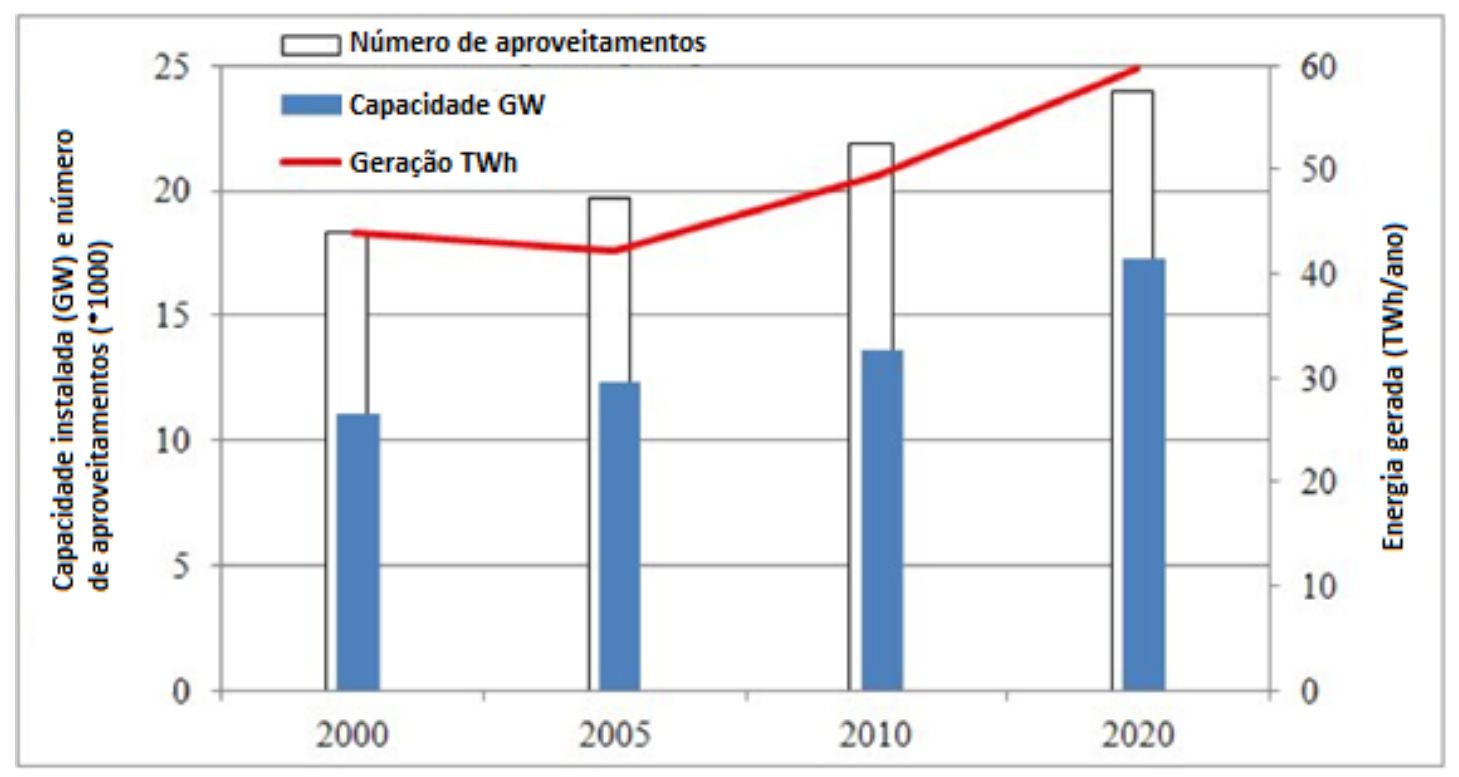

Figura 6- Número de pequenas hidrelétricas, sua capacidade instalada e energia gerada entre 2000 e 2020 na União Europeia retirada de ESHA (2014a)

Ainda segundo a ESHA, a geração de energia por hidrelétricas de pequena escala produz energia para mais de 13 milhões de casas na união europeia, o que faz com que a produção de $\mathrm{CO}_{2}$, frente a geração atual, deixa de contribuir com 29 milhões de toneladas do gás.

No Brasil, segundo a ANEEL (2008), as pequenas centrais hidrelétricas já são responsáveis por $2,29 \%$ da potência instalada, abastecendo indústrias e residências de forma dispersa na rede.

É, portanto, interessante que exista uma estrutura capacitada para receber tal crescimento, dentre elas, a conexão da energia gerada pela malha de geração distribuída de pequena escala é um dos desafios a serem enfrentados.

A Resolução Normativa № 482 de 2012 da ANEEL, estabelece as condições gerais para o acesso de microgeração e minigeração distribuída aos sistemas de distribuição de energia elétrica além do sistema de compensação de energia elétrica e de outras providências.

Esta resolução sofreu uma alteração em dezembro de 2012 resultando na Resolução Normativa № 517 de 2012 da ANEEL, que discorre sobre o sistema de compensação de energia elétrica, que segundo a resolução é o:

"sistema no qual a energia ativa injetada por unidade consumidora com microgeração distribuída ou minigeração distribuída é cedida, por meio de empréstimo gratuito, à distribuidora local e posteriormente compensada com o 
consumo de energia elétrica ativa dessa mesma unidade consumidora ou de outra unidade consumidora de mesma titularidade da unidade consumidora onde os créditos foram gerados, desde que possua o mesmo Cadastro de Pessoa Física (CPF) ou Cadastro de Pessoa Jurídica (CNPJ) junto ao Ministério da Fazenda".

Com esta determinação, é possível que os geradores de energia elétrica de pequena escala possam fazer a conexão direta na rede de distribuição instalada pela distribuidora local, recebendo também os valores equivalentes em créditos para utilização de energia.

Além disso, caso o proprietário da pequena geração produza mais energia que utiliza, este excedente passa a ser compensado com os mesmos valores vinculados à energia e repassados ao pequeno produtor num prazo de 36 meses, ou em outras instalações com os mesmos dados cadastrais do proprietário da mini ou micro geração distribuída.

\subsection{Produção de energia hidrelétrica}

A energia hidrelétrica é utilizada desde os princípios da civilização como forma de transformar a energia cinética dos corpos d'água em energia cinética para utilização em suas produções locais como no caso de rodas d'água movimentando engrenagens para a utilização em moinhos.

A partir da descoberta da energia elétrica foi então utilizada para a transformação da energia cinética em energia elétrica, para os mais diversos tipos de utilização.

A transformação de energia cinética em qualquer outro tipo de energia citado pode ser expresso em energia potencial de um corpo hídrico, como calculado a seguir. Esta forma de energia pode ser transformada tanto em energia elétrica como em trabalho para a energia cinética.

O potencial de um grupo gerador de energia hidráulica tem a potencia nominal determinada pela seguinte equação:

$$
\boldsymbol{P}_{\boldsymbol{n}}=\boldsymbol{Q} \cdot \boldsymbol{H} \cdot \boldsymbol{g} \cdot \boldsymbol{\rho}_{\text {água }}
$$

Onde:

- Pn: Potencial da planta geradora;

- g. $\rho_{\text {água }}$ : peso especifico da água, igual a $9,8 \mathrm{kN} / \mathrm{m}^{3}$; 
- Q: vazão turbinada expressa em $\mathrm{m}^{3} / \mathrm{s}$;

- H: queda expressa em metros.

No entanto, a potência que é efetivamente produzida, considera as características de perdas de carga provocadas pela turbina, que juntamente com o cálculo da altura útil da planta que representa a altura da queda efetiva ou útil de água, resultando na potência útil do sistema.

$$
\boldsymbol{P}_{u}=\boldsymbol{\eta}_{t} \cdot \mathbf{Q} \cdot \mathbf{H}_{u} \cdot \boldsymbol{\gamma}(\mathbf{2})
$$

sendo:

- Pu: Potencial útil do sistema;

- $\eta_{t}$ : rendimento total da planta geradora, adimensional;

- $\gamma$ : peso especifico da água, igual a $9,8 \mathrm{kN} / \mathrm{m}^{3}$;

- Q: vazão turbinada expressa em $\mathrm{m}^{3} / \mathrm{s}$;

- Hu: queda útil expressa em metros.

A queda útil Hu é calculada a partir da equação:

$$
H_{u}=H_{g}-\Sigma L-\Sigma \Delta Y_{c}(3)
$$

sendo:

- Hu: queda útil expressa em metros;

- Hg: queda teórica expressa em metros;

- L: Perdas de carga localizadas em metros;

- $\Delta Y_{c}$ : Perda de carga distribuída em metros;

Ou seja, a queda útil pode ser calculada pelo desnível, subtraído das perdas de carga localizada e das perdas de carga ao longo da rede, a chamada equação da energia.

As perdas concentradas são provenientes dos acessórios de rede como válvulas, entradas e saídas de condutos e também das curvas presentes no trajeto da tubulação.

O cálculo da energia resultante de um período de estudo para o sistema gerador 
deve ser representado pela integração da equação de potencia útil ao longo de um intervalo de tempo determinado, usualmente mensal ou anual, para facilitar a avaliação da produção de energia quando comparada ao consumo.

$$
E=\int_{t 1}^{t 0} \eta_{t} \cdot Q \cdot H_{u} \cdot g \cdot \rho_{\text {água }}
$$

sendo:

- E: Energia Potencial em kWh;

- Hu: queda útil expressa em metros;

- Q: vazão turbinada expressa em m3/s;

- $\eta_{t}$ : rendimento total da planta geradora, adimensional;

- g. $\rho_{\text {água }}$ : peso especifico da água, igual a $9,8 \mathrm{kN} / \mathrm{m} 3$;

A validação do potencial hídrico de geração se inicia com o estudo das capacidades de produção em quilowatts hora em um período minimamente de um ano, o que simplificadamente, também pode ser obtido com a relação de energia produzida apresentada na equação (5):

$$
E=P .8760(5)
$$

sendo:

- E: Energia Potencial em kWh/ano;

- P: Potencia em kW;

Para calcular o rendimento de uma planta de geração de energia, devem ser levados em consideração também as perdas relativas ao maquinário presente, que juntamente às perdas de carga já apontadas, demonstra o rendimento total da planta.

As perdas dentro do maquinário geralmente se devem a:

- $H_{m e c}$ : Perdas devidas ao atrito das partes mecânicas.

- $H_{\text {hidr }}$ : Perdas devido ao movimento do fluido ao longo das superfícies móveis e fixas, da qual resulta a seguinte formula: 


$$
\boldsymbol{H}_{T}=\boldsymbol{H}_{u}-\boldsymbol{H}_{\text {mec }}-\boldsymbol{H}_{\text {hidr }}-\boldsymbol{H}_{\text {vol }}(6)
$$

sendo:

- $H_{T}$ : queda total em metros;

- $H_{u}$ : queda útil em metros;

- $H_{v o l}$ : perdas devido aos condutos em metros;

Com estes valores é possível definir o rendimento global da planta de geração projetada, considerando todas as perdas e componentes do sistema. Chega-se a uma equação de rendimento igual a:

$$
\eta_{g}=\eta_{\text {mec }} \cdot \boldsymbol{\eta}_{\text {hidr }} \cdot \boldsymbol{\eta}_{\text {vol }}(7)
$$

sendo:

- $\eta_{g}$ : rendimento global, adimensional;

- $\eta_{m e c}$ : rendimento mecânico, adimensional;

- $\eta_{\text {hidr }}$ : rendimento hidráulico, adimensional;

- $\eta_{v o l}$ : rendimento hidráulico dos condutos, adimensional;

O rendimento na saída do grupo gerador no alternador $\left(\eta_{e}\right)$ será também influenciado pelo rendimento proveniente da energia elétrica.

- $\eta_{e l}$ : rendimento global do alternador que compreende o rendimento na transformação elétrica e do rendimento mecânico do alternador;

- $\eta_{t}$ : rendimento de uma eventual transmissão entre o motor e a bomba ou entre a turbina e o alternador, que permita uma velocidade de rotação diferente entre as duas máquinas;

- $\eta_{o}$ : rendimento orgânico que expressa a energia consumida para o acionamento de sistemas de controle ou de regulação, necessários ao funcionamento da maquina hidráulica; 
Relacionando os rendimentos demostrados obtém-se:

$$
\eta_{e}=\eta_{e l} \cdot \eta_{t} \cdot \eta_{o} \text { (8) }
$$

Com a grande evolução das maquinas hidráulicas, geralmente o rendimento de uma unidade moderna de geração se aproxima bastante da unidade.

Com base na relação das equações é encontrada a potência do sistema gerador, pode-se encontrar o valor de kWh produzidos no período de um ano.

$$
P=Q_{\max } \gamma \cdot \eta_{g} \cdot \eta_{e}(9)
$$

\subsection{Definição do sistema de abastecimento de água}

A água é componente fundamental a vida, e ao longo da história, a capacidade de transporte e armazenamento de água é de extrema importância econômica, social e política.

Os sistemas de distribuição de água como canais e aquedutos proporcionaram a oportunidade de construir cidades onde o acesso a este recurso não era possível, permitindo que a população usufrua de água em regiões remotas e de clima desfavorável.

Estes mesmos sistemas foram construídos com túneis e aquedutos, utilizando a topografia para o transporte a longas distâncias. Após este período ocorreu a evolução do sistema adaptando condutos em rocha, barro madeira e chumbo, que logo depois seriam substituídos por condutos de ferro fundido.

Sistemas de abastecimento de água segundo Netto (1998) são definidos como o conjunto de obras equipamentos e serviços destinados ao abastecimento de água potável a um número determinado de pessoas, para fins de consumo em diversas utilidades, como o doméstico, de serviços públicos, industrial entre outros.

A água fornecida pelo sistema deverá ser suficiente para garantir a quantidade e a atender aos padrões de qualidade do ponto de vista físico, químico e bacteriológico. Tsutiya (2004) descreve o sistema de abastecimento de água como constituído por diversos componentes, sejam eles, mananciais, captações, estações de tratamento, adutoras, sistemas elevatórios, sistemas reservatório e a rede de distribuição, conforme apresentado na Figura 7. 


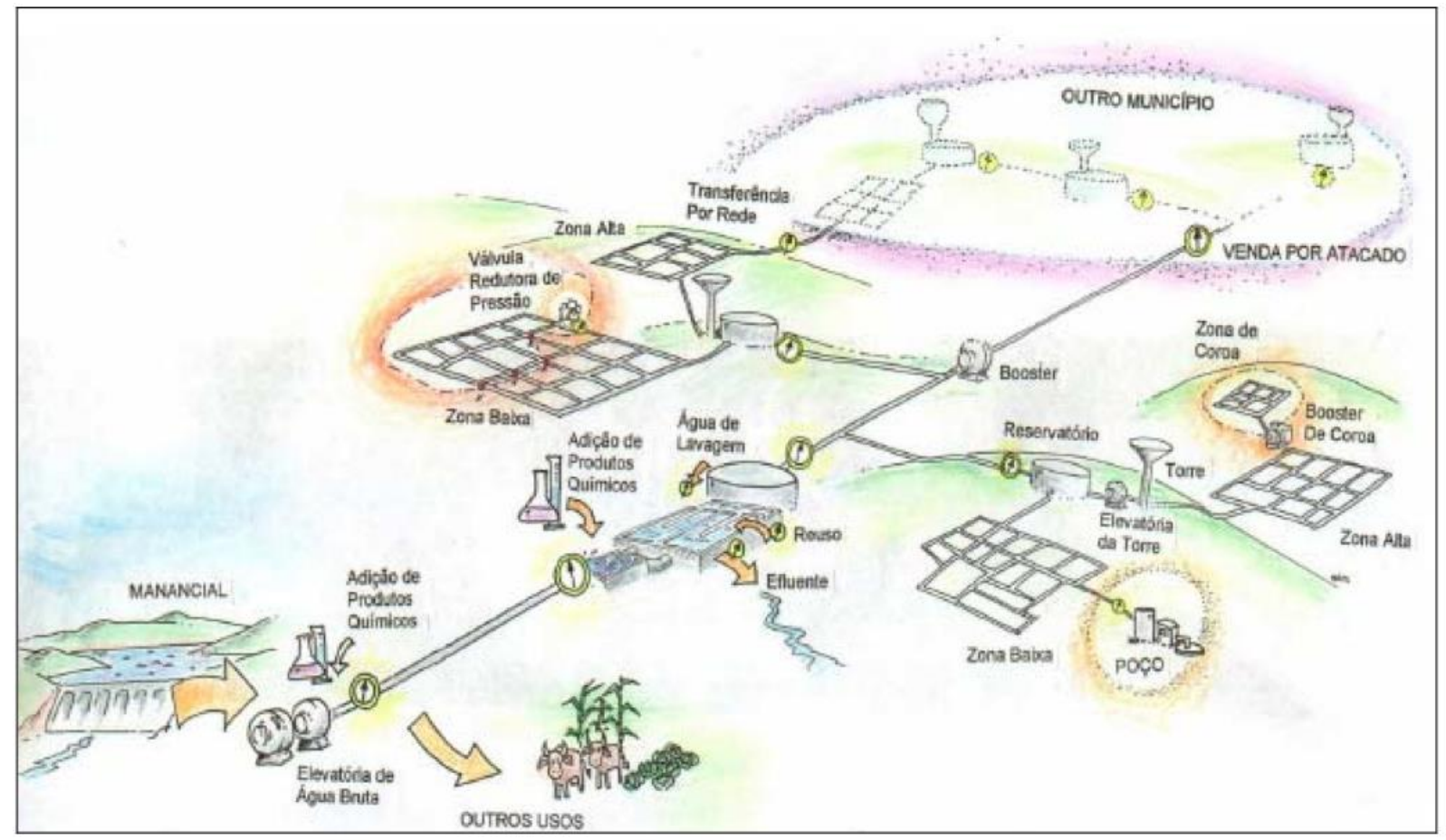

Figura 7 - Esquema de um sistema de abastecimento de água. Fonte: Tsutiya (2004)

Devem ser considerados também como componentes do sistema de abastecimento de água os componentes de menor escala, como ligações residenciais, sistemas redutores de pressão, sistemas de controle e dispositivos de segurança.

\section{Mananciais}

Segundo descreve Tsutiya (2004), os mananciais são corpos d'água superficiais ou subterrâneos que são fontes para a retirada de água para o abastecimento.

Os mananciais superficiais têm como característica serem constituídos por córregos, lagos, represas e rios que estejam na superfície. Em contrapartida, os mananciais subterrâneos são todos aqueles corpos hídricos que fornecem água a partir de água presente no subsolo, necessitando da ajuda de equipamentos ou intervenções para que possa aflorar a superfície.

Como a água proveniente destes corpos é utilizada para o abastecimento, devem possuir qualidade que atendam aos requisitos mínimos de qualidade físico química e bacteriológica determinada pelo IAP - índice de qualidade das águas para fins de abastecimento público, Cetesb (2014), ou possuírem condições tais que, após o processo de tratamento possam ser consumidas. 


\section{Captações}

As captações são o conjunto de túneis condutos e dispositivos construídos juntamente aos mananciais que propiciam a retirada de água para abastecimento. Segundo Tsutiya (2004) as obras de captação devem ser projetadas para funcionar em qualquer época do ano, permitindo a retirada de água suficiente e com a melhor qualidade possível.

\section{Adutoras}

As adutoras representam as ligações entre os reservatórios ou mananciais e as estações de tratamento e entre essas, por sua vez, com os centros de consumo, onde se conectam às redes de distribuição. Elas são consideradas como sistemas principais de abastecimento, não possuindo conexões secundárias.

Composta de condutos e tubulações de maior diâmetro, protegidas e controladas por válvulas e dispositivos acessórios, as adutoras são dimensionadas para situações futuras de consumo de água e para resistir às pressões exercidas.

Netto (1998) ressalta que as adutoras são classificadas quanto à água transportada, sendo elas brutas ou tratadas, e ainda classificadas quanto à energia utilizada para transporte da água, por gravidade nos chamados condutos livres, e por recalque nos chamados condutos forçados ou ainda mistas pela combinação das duas anteriores.

\section{Estações Elevatórias}

As estações elevatórias funcionam na elevação de água bruta, tratada ou para aumento da carga nas redes de distribuição e adutoras, funcionando como "boosters".

Elas têm a função de recalcar a água para que as etapas seguintes do abastecimento sejam desenvolvidas.

\section{Estação de tratamento de água}

É o conjunto de estruturas destinadas ao tratamento de água, fazendo com que a qualidade da água bruta atinja os padrões necessários para o abastecimento, adequando as características físico químicas e bacteriológicas.

Portanto as estações de tratamento têm finalidade sanitária, eliminando ou reduzindo as impurezas presentes na água como bactérias, compostos orgânicos, 
substâncias tóxicas e microrganismos.

Segundo Netto (1998) a água proveniente das estações é então destinada a rede de adução e à distribuição com características de dureza, cor, turbidez, odor sabor, e concentração de patogênicos e carga orgânica dentro dos padrões estabelecidos para o abastecimento.

\section{Reservatórios de Passagem e de Distribuição}

Segundo Netto (1998) os reservatórios são responsáveis por garantir que o abastecimento seja constante, e com vazões regularizadas ao longo do tempo, caso ocorra qualquer falha na rede que os abastece.

Eles absorvem as variações horárias e diárias do consumo, garantindo o fornecimento durante as horas de consumo de pico. Eles também têm a função de manter os níveis de pressão ao longo da rede de distribuição e promovem vazão de incêncio.

\section{Redes de Distribuição de Água}

Segundo Tsutiya (2004), a rede de distribuição de água é parte de um sistema formado por condutos e acessórios destinados a entregar água ao consumidor, dispondo de qualidade, quantidade e pressões adequadas.

Geralmente o sistema de distribuição de água é composto por um sistema principal e de um secundário, sendo que o principal possui condutos de maior dimensão, que normalmente transportam a água da captação até as tubulações secundárias e são chamados de adutoras.

Já os condutos secundários têm menores diâmetros e promovem 0 atendimento diretamente aos pontos consumidores. Os sistemas secundários são chamados de redes de distribuição (Netto, 1998).

As redes de distribuição de água são um conjunto de acessórios que reunidos colocam a disposição dos cidadãos a água necessária. O sistema constitui-se de condutos, reservatórios, bombas e acessórios que são distribuídos conforme as condições locais e necessidades de cada região.

A configuração geométrica da rede pode ser classificada em três grandes categorias (Tsutiya, 2004), conforme apresentado a seguir: 


\section{- Rede ramificada ou "espinha de Peixe"}

As redes de distribuição ramificadas são caracterizadas pelo fato do sentido de escoamento ser definido, e sua grandeza determinada diretamente pelo consumo de água a jusante. Apresentam uma tubulação tronco alimentada por um reservatório ou estação elevatória que transporta a água para o abastecimento direto das tubulações secundárias.

\section{- Rede malhada ou em grelha}

Nesta configuração, os condutos formam circuitos fechados o que indefine o sentido de escoamento, possibilitando a inversão do fluxo. Isso confere à rede maior flexibilidade para manutenções, minimizando a área afetada por interrupções de fornecimento de água.

\section{- Rede Mista}

A configuração da rede mista é a combinação entre as redes ramificadas e malhadas.

As redes de distribuição de água tem um importante parâmetro, a pressão a que é submetida, envolvendo o limite de resistência das tubulações e o controle de perdas. Segundo a NBR 12218, as redes devem ser projetadas para que se obtenha uma pressão estática máxima de $500 \mathrm{kPa}$ ou aproximadamente $50 \mathrm{~m}$ de coluna de água (MCA), enquanto a pressão dinâmica mínima deve ser de 100 kPA ou 10 MCA que representa o requisito necessário para o abastecimento domiciliar.

O controle da pressão na rede é feito por meio da disposição e instalação de reservatórios, "boosters" (bombas elevatórias) e dispositivos de segurança e de redução de pressão como registros e válvulas.

\section{Dispositivos de redução de pressão em redes de distribuição}

Os dispositivos de redução de pressão são estruturas de dissipação de energia utilizadas para a uniformização e controle das pressões. Dentre estes dispositivos o mais conhecido é a válvula de redução de pressão (VRP) que promove a perda de carga localizada, reduzindo as pressões para jusante. O principio de funcionamento de uma VRP baseia-se na atuação de uma válvula que é ativada sempre que a 
pressão limite da rede a jusante é atingida, aumentando a perda de carga do sistema e interrompendo seu funcionamento quando as pressões a jusante não são suficientes para atender aos requisitos do sistema.

O funcionamento deste tipo de válvula pode ser descrito como na Figura 8.

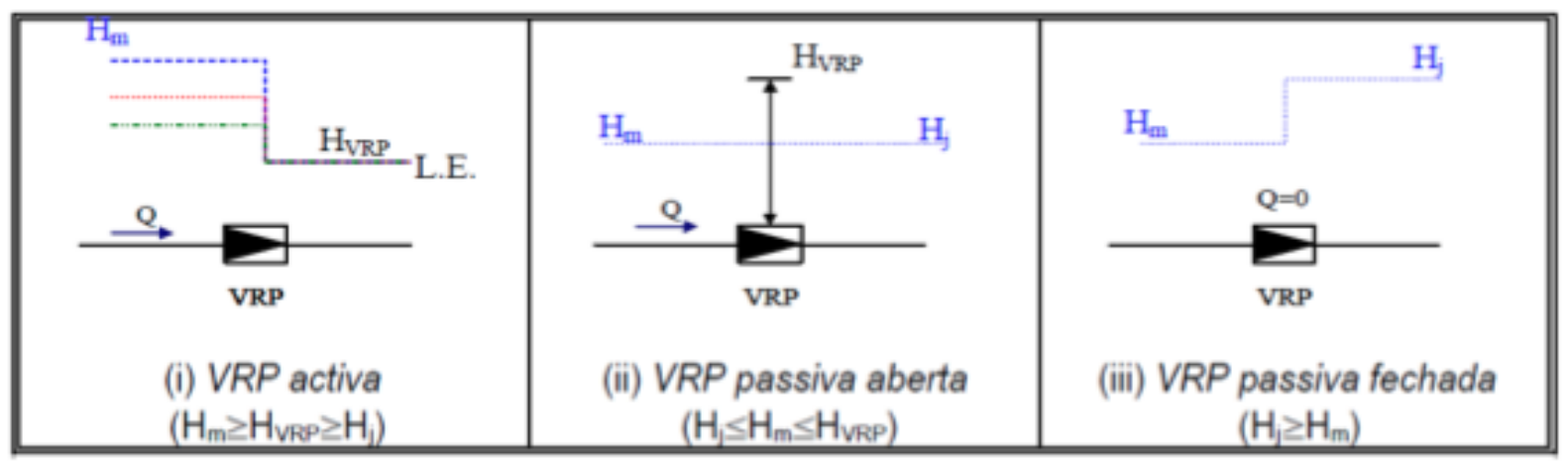

Figura 8 - Princípio de funcionamento de uma VRP

O funcionamento do dispositivo pode ser controlado de forma manual ou automatizada, com a ajuda de medidores de pressão distribuídos pela rede que monitoram as condições atuais de pressões.

As VRPs podem ser divididas em três categorias distintas pelo seu acionamento, sendo elas as VRPs controladas por molas, por pistões e por diafragmas, apresentadas na Figura 9.

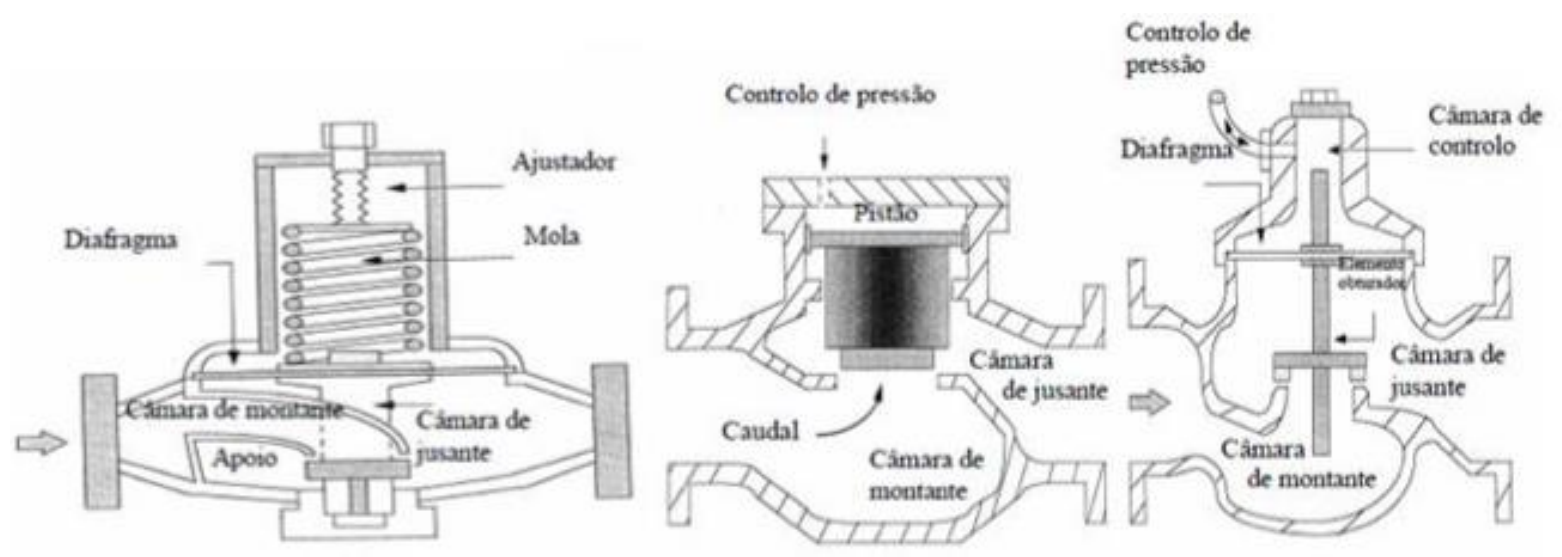

Figura 9 - Categorias de acionamento das VRPs

As principais etapas de levantamento de dados para escolha da área de instalação de uma VRP são:

- Histórico de incidência de altas pressões e rompimentos de rede e índices de 
perdas elevados

- Medição de pressão durante o período de máxima vazão

- Medição de pressão durante o período noturno de menor consumo

- Avaliação, providências e verificação do efetivo isolamento da área através do fechamento e instalação de válvulas de controle

- Escolha dos pontos de medição de vazão e pressão à montante do local da válvula

- Medição de pressão no ponto crítico, definido pelo ponto de altimetria mais elevada e/ou mais distante dentro da área selecionada.

- Medição de pressão no ponto médio

- Medição de pressão próxima a um grande consumidor

- Instalação de equipamentos de medição e coleta de dados

- Informações de demanda e sazonalidade

Para dimensionar, deve-se determinar o tamanho e as características principais da válvula para o controle desejado. Em geral, considerando os aspectos técnicos e econômicos da instalação, a VRP é dimensionada com diâmetro inferior ao da tubulação.

A razão deste dimensionamento é a utilização da seguinte fórmula:

$$
K_{v x}=Q \cdot\left(\frac{G}{\Delta P}\right)^{\frac{1}{2}}(10)
$$

onde:

$K_{v x}$ é o coeficiente de vazão, em $\mathrm{m}^{3} / \mathrm{h}$;

$Q$ é a vazão máxima horária, em $\mathrm{m}^{3} / \mathrm{h}$;

$G$ é a densidade do líquido em relação à água;

$\Delta \mathrm{P}$ é a perda de carga admissível, em bar;

Para a segurança da instalação também é utilizado um coeficiente de segurança, adotando o critério a seguir.

$$
1,25^{\star} K_{v x} \leq K_{v o}(11)
$$

onde:

$K_{v o}$ é o coeficiente de vazão da válvula selecionada. 
O $K_{v o}$ é a vazão máxima que gera uma perda de carga de 1 bar (10 m.c.a.) com a válvula totalmente aberta, seguindo as tabelas fornecidas pelos fabricante.

\section{Perdas de água nas redes de distribuição}

Segundo documento da Associação Brasileira de Engenharia Sanitária e Ambiental (ABES, 2013) relativo às perdas em sistemas de abastecimento de água, nunca haverá perda zero por mais bem implantado e operado que seja.

Portanto as redes de distribuição não estão livres de falhas e de deterioração ao longo de sua vida útil, desta forma, ao longo do tempo a eficiência em atender ao principio de estanqueidade pode ser reduzida ou ineficaz.

Segundo os estudos da ABES (2013), as perdas de água no Brasil representam em média $40 \%$ do total de água transportada nas redes de abastecimento variando de 40 a 50 \% nos países em desenvolvimento dependendo do manejo e manutenção da rede.

As perdas não só representam um problema devido ao desperdício do recurso hídrico como também acarreta custos envolvendo:

- Equipamentos e instalações

- Mão de obra

- Obras civis

- Operação

- Energia elétrica

- Compra de água

Segundo os estudos da ABES (2013), no ano de 2007, o custo das perdas somou aproximadamente 7,6 bilhões de reais naquele ano no Brasil, e aponta que com a redução das perdas em três cenários, redução de $50 \%, 38 \%$ e $25 \%$ os ganhos potenciais poderiam a chegar a 37,3 bilhões de reais.

Zyl et al. (2004) descreve os mecanismos de vazamentos e estuda em redes reais, quais as características da rede promovem maiores perdas, elencando a pressão como um fator predominante na determinação dos volumes perdidos.

Controlando a pressão e utilizando a relação descrita por Zyl et al. (2004) para a relação pressão x perdas, pode-se estimar qual seriam os custos e benefícios da 
redução de pressões.

\subsection{Dimensionamento da vazão}

O sistema de abastecimento de água deve garantir a prestação adequada dos serviços, considerando os aspectos sociais, sanitários, ambientais e legais, assim como a viabilidade técnica, econômica e financeira de sua estrutura, garantindo o acesso da população aos recursos hídricos em cenários atuais e futuros.

Para o dimensionamento das vazões, portanto, é levada em consideração a população futura para os empreendimentos, e não a população atual ao constante crescimento populacional, que é diretamente proporcional à necessidade de água.

O crescimento populacional pode ser calculado de duas formas principais:

- Progressão aritmética, no qual o cálculo da evolução populacional é decorrente da soma sucessiva de um mesmo número de habitantes em períodos iguais. Pode ser expressa pelas equações 12 :

$$
k_{a}=\frac{d P}{d T} \quad P_{f}=P_{i}+\left(t_{f}-t_{i}\right) * k_{a}(12)
$$

- Progressão geométrica, na qual a curva representativa da evolução populacional é uma parábola, que analiticamente é dada pela equação (13):

$$
P * K g=\frac{d P}{d t} \quad P_{f}=P_{i} * e^{K g *(t f-t i)}(13)
$$

onde:

Pi é a população inicial

Pf é a população final calculada

Ti e Tf são o tempo inicial e final (expresso em anos)

$\mathrm{k}_{\mathrm{a}}$ a taxa de crescimento aritmético

$\mathrm{k}_{\mathrm{g}}$ a taxa de crescimento geométrica

Para o cálculo das vazões de projeto é necessário identificar também o padrão de consumo na área em que se deseja instalar a rede. Este pode variar conforme a ocupação das áreas estudadas, podendo ser áreas industriais, residenciais e comerciais.

É necessária a verificação da oscilação entre períodos de alto e baixo consumo, 
uma vez que ocorre uma variação na demanda tanto sazonalmente quanto diariamente o que é de fundamental importância na geração de energia.

É imprescindível a discussão destas variações para que o cenário estudado envolva os instantes de maior pico de consumo, tanto ao longo do ano quando diário, para que a pior situação, que coincida a de maior solicitação diária com a sazonal, seja atendida.

No cálculo das vazões, esta necessidade é representada por duas constantes K1 e K2 que fazem referência respectivamente às variações sazonal e diária, multiplicando diretamente as vazões obtidas anteriormente.

A seguir é apresentada a variação horária do consumo, em um período de um dia.

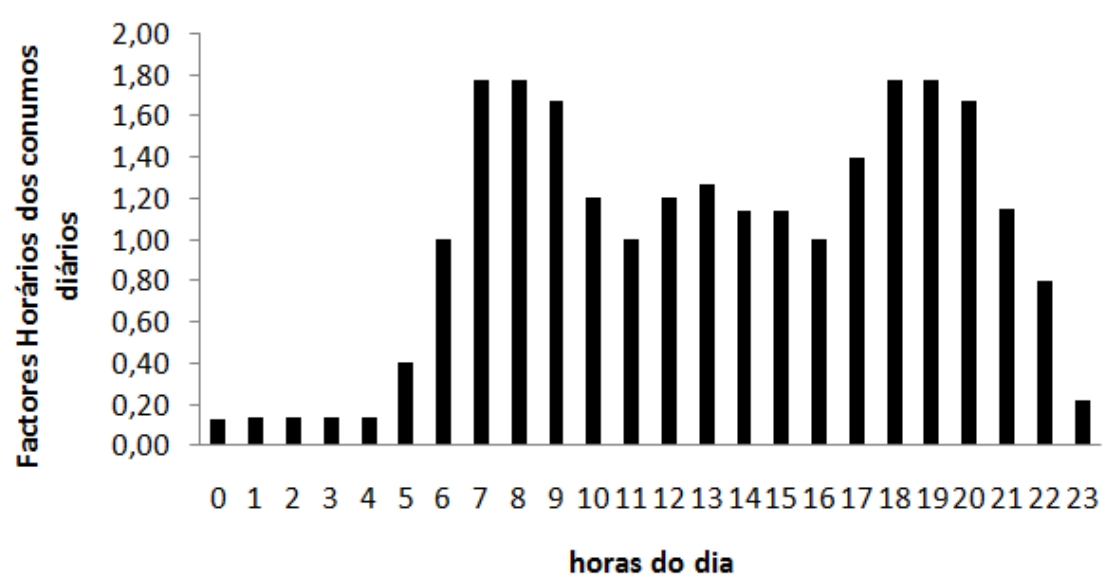

Figura 10 - Variação horária do consumo de água.

Para contornar a variação no consumo, é interessante a construção de reservatórios de regularização das vazões afluentes, possibilitando que o abastecimento seja constante.

Outra característica que envolve a instalação dos reservatórios é a redução no consumo de energia, pois em sistemas em que a recarga dos reservatórios envolve bombeamento, é possível a escolha de recarregar o reservatório nos horários em que o valor da energia é mais baixo. O dimensionamento relacionado à regularização é feito a partir da relação entre as afluências e a vazão média de solicitação do sistema.

Para a otimização do uso da energia na recarga dos reservatórios entra em questão um fator de custo, que visa ser reduzido e é influenciado pelo acionamento ou não das bombas em instantes definidos. 


\subsection{Consumo de energia na distribuição de água}

Segundo o Sistema Nacional de Informações Sobre Saneamento - SNIS (2011), o consumo de energia elétrica representa $13,4 \%$ das despesas relativas à exploração de água, o que equivale a um gasto anual de 3.14 bilhões de reais com energia para a gestão dos sistemas de saneamento no Brasil.

Deste valor, estima-se segundo dados do Centro de Pesquisas de Energia Elétrica CEPEL e do Programa de Eficiência Energética em Saneamento Ambiental- Procel Sanear expostos no Plano Nacional de Eficiência Energética (2011), que 90\% deste consumo de energia seja decorrente do uso de motobombas na adução e distribuição.

Ainda segundo as mesmas fontes, a energia consumida por sistemas de saneamento correspondem de $2 \%$ a $3 \%$ do total da energia consumida no país.

Sistemas de saneamento ainda recebem um desconto de $15 \%$ nas tarifas de energia contratadas por consumo e demanda, e mesmo assim possuem as porcentagens de energia demonstradas acima.

O horário de pico é fator muito importante para avaliar o consumo de energia no sistema de distribuição de água. Nestes horários, a energia consumida é muito maior que nos momentos fora de pico, desta forma, a energia neste intervalo de tempo é mais cara, e a produção de energia mais exigida, exatamente como os picos de consumo de água.

$\mathrm{Na}$ distribuição de água, o consumo de energia pode ser abatido tentando destinar os picos de tratamento e bombeamento para horários fora das horas de pico de consumo, utilizando assim energia mais barata.

Os picos de consumo de energia podem ser obtidos utilizando intervalos de 3 horas consecutivas em dias de trabalho, como por exemplo, 6 a 9 da tarde e 7 às 10 da noite, como descrevem Vilanova e Balestieri (2014), ou como metodologia da CPFL Energia (2014), que determina os horários de pico como sendo entre 18 e 21 horas.

Desta forma, com a introdução de sistemas geradores na rede de distribuição de água e seguindo o procedimento de compensação da energia gerada, com 0 abatimento dos valores retirados da rede de distribuição elétrica, como definido pela Resolução Normativa n482 (2012), é possível reduzir os gastos, compensando-os com a energia gerada no próprio sistema. 


\subsection{Descrição das turbinas e rendimentos}

As turbinas hidráulicas tem o papel de transformar a energia cinética do deslocamento da água em energia mecânica.

As turbinas podem ser divididas em duas categorias, sendo de ação ou de reação.

Nos dispositivos a ação, depois de incidir sobre as pás do rotor a água transforma sob pressão atmosférica, a energia cinética em mecânica.

No caso das turbinas a reação, o rotor não tem contato com a atmosfera, trabalhando sob uma coluna d'água. Desta forma, existe uma diferença de pressões entre a entrada e a saída da turbina devido à diminuição das velocidades e pressões em seu funcionamento.

A escolha da turbina adequada para o aproveitamento em redes de distribuição de água é muito similar àquele utilizado para o dimensionamento e escolha nas grandes obras. Ela baseia-se basicamente na tipologia de turbina, nas condições de desnível (pressões no caso da rede de abastecimento), vazão e rendimentos.

Portanto, a escolha e o dimensionamento devem levar em consideração o desnível de montante a jusante $(\Delta H)$, a Vazão $(Q)$, e o tipo de rotor/turbina a ser utilizado, calculando a rotação especifica do rotor (nq) que pode ser determinada utilizando a seguinte fórmula:

$$
\boldsymbol{n}_{\boldsymbol{q}}=\boldsymbol{n} * \frac{Q^{0,5}}{\boldsymbol{H}^{0,75}}(14)
$$

É necessário, após a escolha da turbina, verificar quais as dimensões a serem utilizadas, ou mesmo o número de dispositivos e forma de ligação entre eles, paralelamente ou em série para obter os resultados desejados.

O rendimento das turbinas é fator decisivo para a escolha dos dispositivos, uma vez que representa a relação entre a energia disponível e a energia gerada pela máquina e é encontrado como informação constante nas indicações dos fabricantes. Eles disponibilizam esta informação por meio de tabelas obtidas em extensos estudos hidrdinâmicos.

Estes estudos indicam também as faixas de operação ótimas, considerando condições de vazão e pressão, como apresentado na Figura 11. 

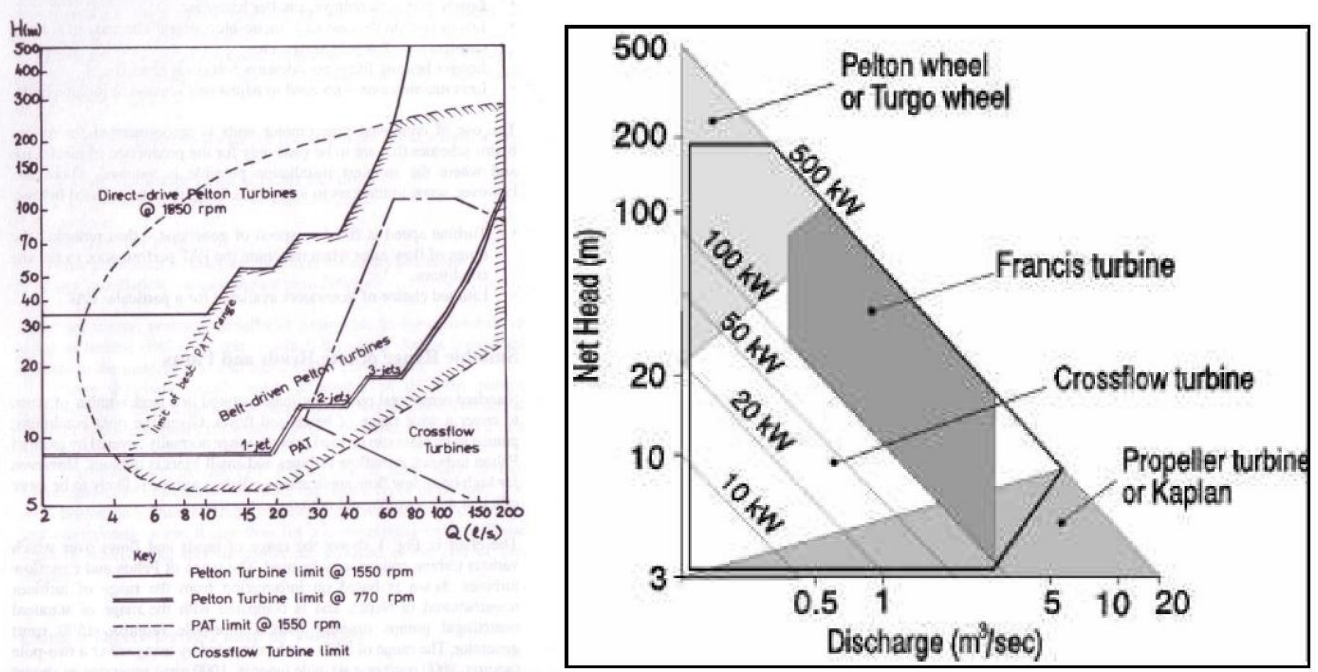

Figura 11 - Esquema do gráfico de comparação entre turbinas.

A seguir serão expostas as diferentes tipologias de turbinas divididas por turbinas de ação e reação.

\section{- Turbinas a ação}

\section{TURBINA PELTON}

Uma das turbinas a ação é a turbina Pelton, que tem como característica adaptar-se a sistemas com grandes desníveis (pressões), transformando a energia potencial em energia cinética, que depois é convertida em energia elétrica. Este processo se desenvolve quando a água proveniente de um distribuidor atinge as pás distribuídas nas extremidades da turbina.

A utilização desta turbina é pouco indicada para a geração na rede, uma vez que os desníveis encontrados são pequenos. Uma possibilidade de utilizar a turbina Pelton é a chance da rede de abastecimento possuir pressões superiores a 100 metros, situação que proporciona melhor rendimento.

Segundo a NBR-6445, é uma turbina de ação na qual o fluxo de água incide sob a forma de jato paralelamente em relação a um rotor que possui pás em forma de duas conchas.

Ela pode ser instalada tanto na forma vertical quanto na horizontal, além de poder utilizar-se de diversos distribuidores, ou seja, múltiplos jatos d’água direcionados às pás, podendo variar de 1 a 6 jatos conforme as condições. Sua construção é simples e com as partes principais confeccionadas em aço inox, o que não contamina a 
água. No entanto devido as altas velocidades do jato d'água as pás podem ser corroídas por corpos estranhos no fluxo, como areia.

O jato atinge as pás em pressão atmosférica, o que provoca uma variação de energia cinética praticamente nula no rotor, assim sendo a energia é totalmente transferida ao eixo. As pás são como conchas partidas ao meio, e tem a função de mover o rotor. A água as atinge a certo ângulo, que pode variar dependendo das necessidades e das condições de vazão e queda apresentadas no momento.

Como todo o processo descrito é realizado em pressão atmosférica, a saída deve estar localizada sobre o nível de qualquer reservatório ou canal a jusante, para que a água possa sair livremente.

Um caso especial é aquele em que a turbina Pelton se encontra sob pressão, no qual a transferência de energia não trabalha mais sob pressão atmosférica, mas sim a uma pressão levemente superior. A turbina Pelton atinge seus limites quando as alturas de queda são elevadas e as vazões são de pequena monta.

A maior queda registrada na história é na usina de Reissek na Áustria, com 1767 metros e 22,8 MW de potência instalada. A maior potencia já registrada é também da Austríaca Usina Sellrain Silz, com 1237 metros e 260 MW de potência instalada.

\section{TURBINA CROSS-FLOW OU BANKI}

A turbina Cross-Flow ou Banki tem uma atuação similar àquela das turbinas Pelton, no entanto, a água utilizada para mover o rotor tem ação tanto na entrada quanto na saída do rotor.

Como o fluxo que passa pelas pás tem um ângulo de entrada próximo ou igual ao de saída, ao final do percurso tem sua energia majorada, melhor utilizando a pressão da água nas pás.

Ela é indicada para rede com poucas elevações, da ordem de 10 a 200 metros, retornando também baixas potências, dependendo da altura da queda. Uma particularidade das turbinas Cross-Flow é a possibilidade de controlar o fluxo de entrada, podendo regular a potência gerada ou mantendo a mesma potencia com o controle das vazões. Ela é, portanto, considerada uma turbina bastante flexível em relação à janela de atuação de vazões e quedas. 


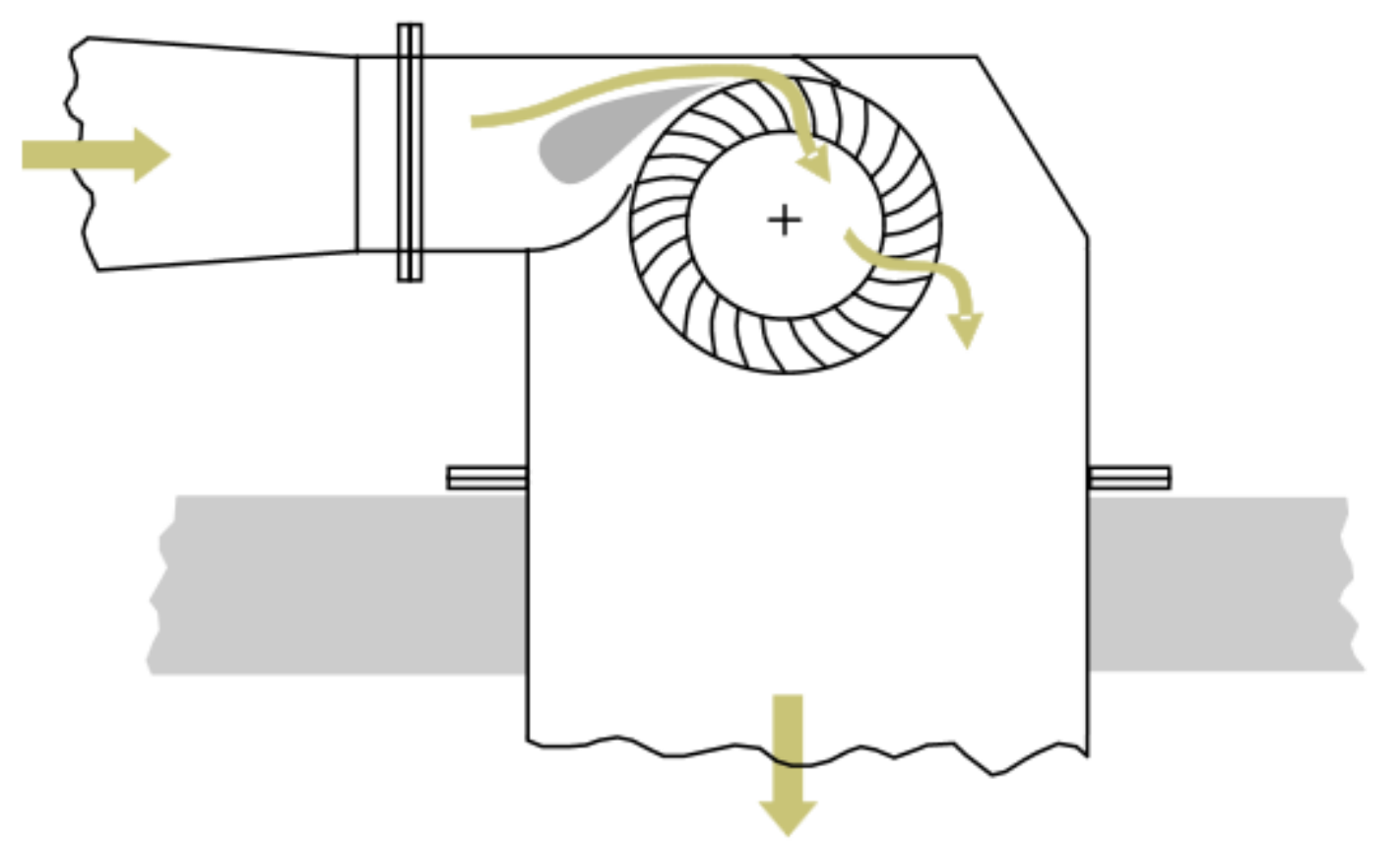

Figura 12- Esquema de uma turbina Cross-Flow. Fonte: Micro Centrais Hidrelétricas , Ministério de Minas e Energia, 2007

Assim, diferentemente de uma turbina Pelton, em presença de vazões significativas e de pressões baixas, a turbina Cross-Flow pode ser empregada, além de ter a característica de ser mais facilmente empregada que as turbinas Pelton.

Porém, a turbina Cross-Flow apresenta uma velocidade de rotação mais baixa, o que faz necessário introduzir um multiplicador de giro entre a turbina e o gerador elétrico, resultando neste caso em um rendimento inferior ao de uma Pelton.

\section{- Turbinas a reação}

\section{TURBINA FRANCIS}

A turbina Francis trabalha em pressão e por isso esta dentro da classificação de turbinas a reação. Ela trabalha com pressões diferentes em cada estagio da passagem da água dentro da estrutura de ingresso (distribuidor), até a saída do rotor, não tendo contato direto com a pressão atmosférica, trabalhando sempre sob pressão. 


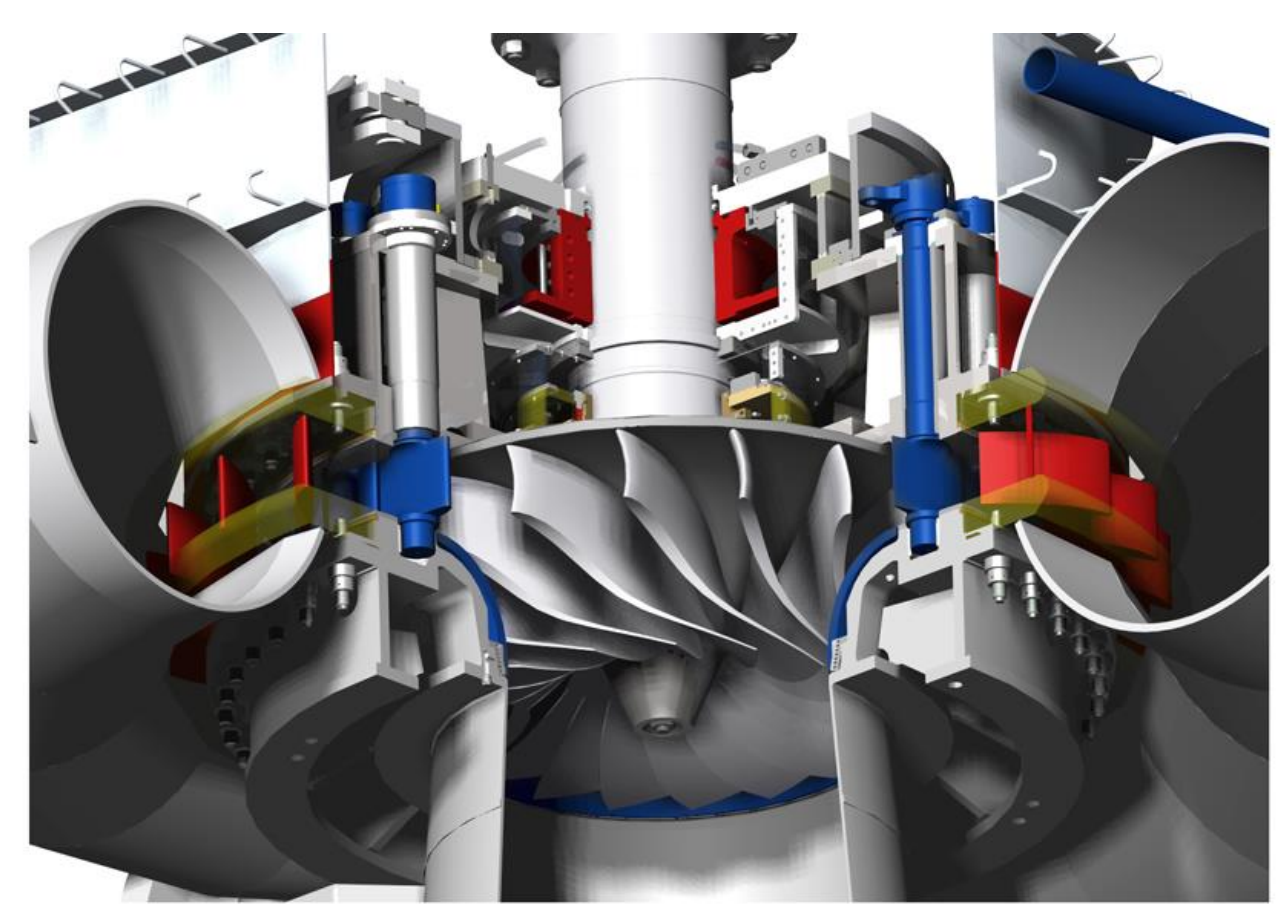

Figura 13 - Esquema de uma turbina Francis. Fonte: Voith (2014)

Segundo a NBR-6445, é uma turbina de reação na qual o fluxo de água penetra radialmente no distribuidor e no rotor no qual as pás estão fixas.

A estrutura de entrada é dotada de um distribuidor em espiral que muda tanto a velocidade, quanto a pressão da água, mudando também a direção do jato de entrada, que entra radialmente e sai praticamente de maneira axial dentro do difusor.

O difusor, também chamado de tubo de aspiração tem a função de regular a energia cinética da água, pois esta sai acelerada e com grande velocidade, fazendo com que, empregando-se um sistema conveniente, seja possível aproveitar melhor a saída do sistema, aproveitando a queda de maneira completa.

As turbinas Francis são utilizadas para quedas intermediárias, entre algumas dezenas de metros até 700 a $800 \mathrm{~m}$, dependendo do tamanho do equipamento. Como ela funciona sobre pressão, um problema comumente enfrentado é a cavitação e a interação dos componentes metálicos provocando seu desgaste.

O histórico de utilização deste tipo de turbina tem como maior altura de queda d'água já registrada de 744 m na Usina Hauesling na Áustria, onde estão instalados 180 MW, a maior potência já registrada é na Usina Grand Coulee nos Estados Unidos. 


\section{TURBINA KAPLAN E BULBO}

Nas turbinas Kaplan ou a hélice, as partes móveis são compostas por um grupo de pás distribuídas para o aproveitamento do fluxo axial e são utilizadas para o aproveitamento de cargas baixas e vazões maiores. A turbina Kaplan tem um conjunto de aletas direcionais que fazem com que a água haja de modo mais eficiente possível conforme a vazão de entrada.

Nestas turbinas a hélice, as pás não possuem este sistema direcional, portanto, tem o distribuidor de fluxo fixo, e são mais indicadas para situações onde a vazão é praticamente constante, não havendo a necessidade de reformular a entrada para a movimentação do rotor, e conforme gira, coloca em movimento o gerador.

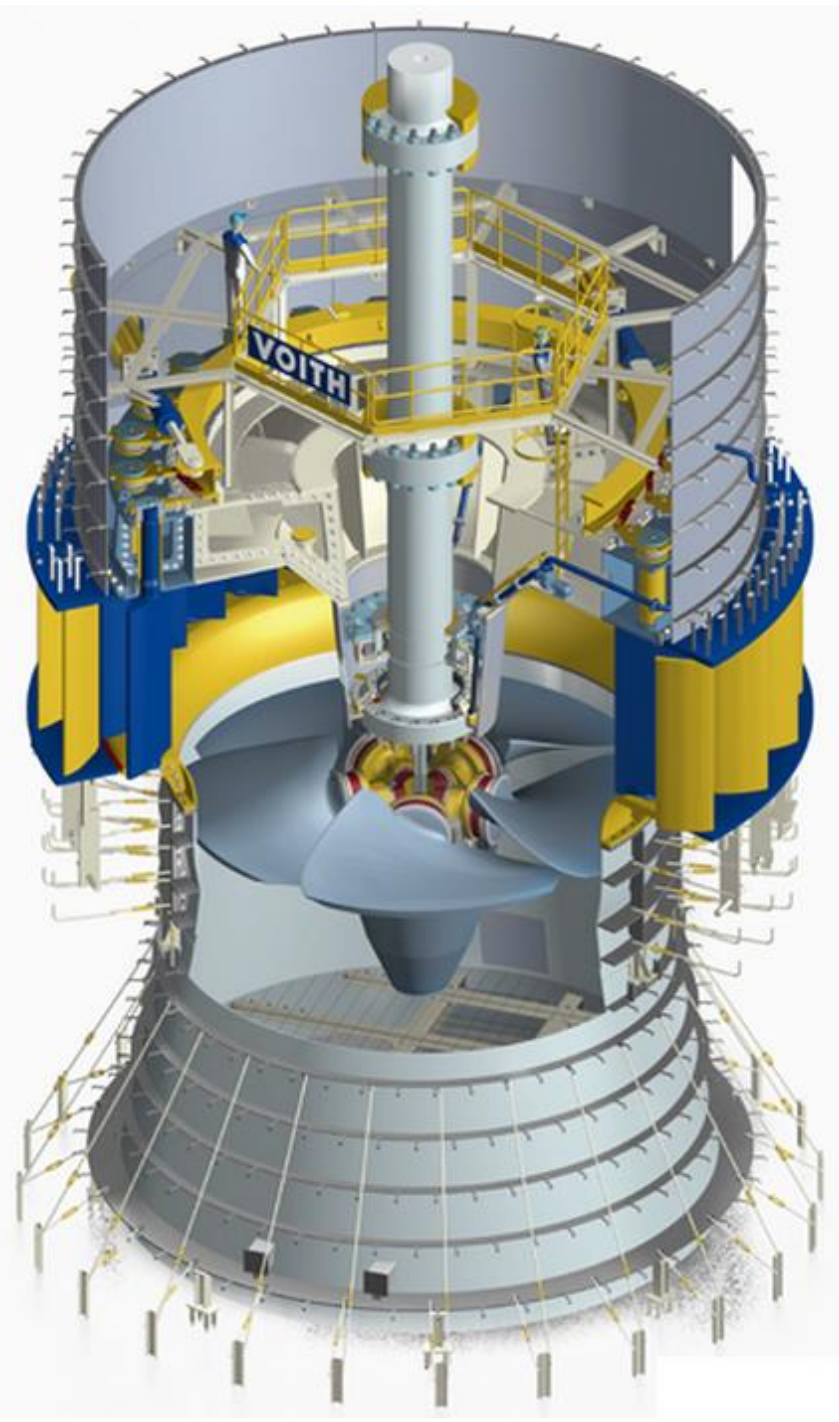

Figura 14- Esquema representativo de uma turbina Kaplan. Fonte: Voith (2014) 


\section{“PUMP AS TURBINES”, PATs (Bombas como turbinas)}

As bombas como turbinas são bombas que são utilizadas em modo inverso para que se comportem como turbinas, suportando as mesmas condições normais as quais um turbina é solicitada.

Elas são turbinas elásticas e geram potências que variam entre 1 e 500 kW.

O custo de uma bomba inversa é menor em comparação com as demais, pois combina baixos custos de implantação com os baixos custos de manutenção, uma vez que não necessita de pessoal especializado particularmente a um tipo de turbina. Os custos também se reduzem, se for levada em consideração a reposição de peças, que podem ser compartilhadas com outros equipamentos mais simples, sendo encontradas facilmente.

O rendimento de uma turbina desta categoria é variável com o fluxo, e portanto, deve ser utilizada onde as vazões se mantém a maior parte do tempo possível constante e superior a um patamar de $40 \%$ de sua carga nominal. Caso contrário, a produção de energia não é mais viável.

Como é uma bomba centrífuga, o andamento deve ser sempre monitorado, verificando as condições de pressões e de vazão que passa no rotor.

No projeto de uma bomba como turbina, devem ser previstos alguns dispositivos de segurança como válvulas de derivação, freios, e a criação de by-pass.

\section{- Componentes eletromecânicos}

\section{MULTIPLICADORES DE GIROS}

O multiplicador de giros é um elemento particular que modifica a conexão entre a turbina e o gerador, e permite que exista uma diferença de rotação nominal entre os dois elementos.

O emprego de um multiplicador de giro é indicado quando a turbina e o gerador estão ligados de maneira axial e o número de giros não é compatível.

A instalação de um multiplicador de giros provoca uma perda mecânica e aumenta 0 custo de manutenção. Em alguns casos, as mini e microturbinas instaladas na rede de abastecimento, tem seu rotor girando a menos de $400 \mathrm{rpm}$, o que para um alternador comum é muito baixo, devendo portanto atingir valores minimamente de 700 a 1500 rpm para satisfazer aos alternadores.

Esta situação ocorre normalmente em bombas inversas que geralmente é uma das 
mais econômicas, aumentando o custo desta tipologia de instalação, podendo assim torná-las menos atrativas se comparativamente ao seu valor inicial.

\section{TRANSFORMADORES}

É componente obrigatório de uma central hidrelétrica, tendo a função de variar a tensão na saída do alternador e promover a compatibilidade com a tensão da rede de transmissão.

\section{GERADORES SÍNCRONOS E ASSÍNCRONOS}

Segundo informações do Centro Nacional de Referência em Pequenas Centrais Hidrelétricas - CERPCH, os geradores tem a função de transformar a energia mecânica proveniente das turbinas em energia elétrica.

Atualmente são utilizados geradores de corrente alternada, trifásicos e em alguns casos, são utilizados ainda a produção a dínamo, que resulta em uma corrente contínua.

Estão disponíveis no mercado duas categorias de geradores:

- Geradores síncronos: que tem um regulador de tensão associado ao aparato de excitação de modo que a energia gerada esteja já na mesma tensão, frequência e ângulo de fase requerida pelo sistema. Normalmente a maior potência para esta categoria é de 5000 kVA. Devido a sua grande versatilidade e valores altos de rendimento, podendo atingir $97 \%$, eles são os mais utilizados. 


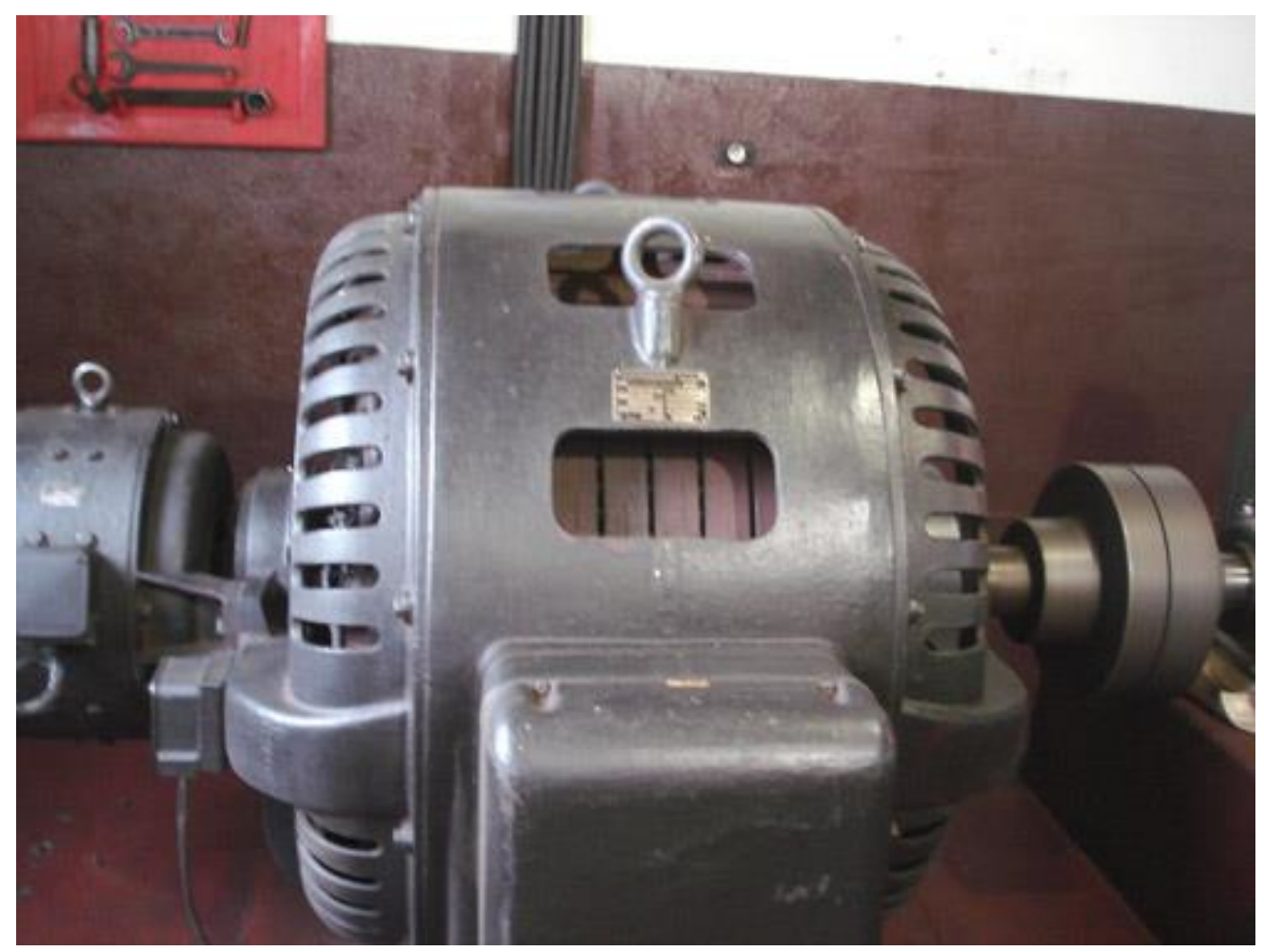

Figura 15 - Exemplo de gerador síncrono. Fonte: CERPCH

- Geradores assíncronos: Os geradores assíncronos não tem a capacidade de regular a tensão e são simples motores a indução que geram uma tensão e frequência equivalentes a sua velocidade de giro. Portanto, devem ser conectados a uma rede em conformidade com estes valores. Estes geradores não podem ser desconectados da rede, pois não tem a capacidade de prover sua própria corrente de excitação. Eles são economicamente mais atrativos que os geradores síncronos, porém apenas para potências de poucos MVA.

\section{QUADRO DE CONTROLE DE POTÊNCIA}

Com a constante necessidade de produzir energia de forma segura, uma parte importante é o controle da potência. O quadro de controle de potência monitora todos os dispositivos e seu funcionamento e, em caso de acidente, o sistema pode ser desconectado e religado em paralelo com a rede. O quadro controla de modo constante fatores como a frequência, tensão e em alguns casos o nível d'água da entrada das turbinas. 


\section{QUADRO DE AUTOMAÇÃO}

A maior parte das centrais hidrelétricas funciona sem a presença de funcionários fixos e deve, portanto ser monitorada e controlada remotamente ou por sistemas automáticos.

O equipamento deve ter a possibilidade de controle manual, mas também um sistema de automação e dispositivos que possam ser controlados por programas. Esses programas identificam situações de mau funcionamento ou a necessidade de controlar o fluxo de água que entra no sistema para assim manter a hidrelétrica e seus equipamentos hidromecânicos sempre funcionando com a segurança desejada.

Cada funcionamento defeituoso é registrado e reportado diretamente ao gestor ou técnico responsável pelo funcionamento para que esse possa assumir o controle das ações remotamente.

Assim, a manutenção destas hidrelétricas é facilitada, reduzindo custos de produção.

\subsection{Mini e Micro Turbinas}

De acordo com Ramos et al. (2010), as mini turbinas são unidades que segundo informações dos fabricantes tem potencia inferior ao limite que se situa entre 1000 kW e $5000 \mathrm{~kW}$, o que não aproxima daquela estabelecida anteriormente como a utilizada pelo Brasil, dentro da escala de100 a 1000 kW. Por outro lado, segundo Ramos et. al. (2010), as micro turbinas são unidades inferiores a $100 \mathrm{~kW}$, que corresponde exatamente àquela utilizada neste estudo.

Estas unidades necessitam de equipamentos de dimensões reduzidas, que porém não fogem aos equipamentos apresentados anteriormente neste trabalho, necessitando apenas de algumas adaptações à escala.

Ramos et. al. (2010) estuda a aplicação de bombas como turbinas como sendo uma das opções ideais de equipamento adaptado à mini ou micro geração, por serem mais flexíveis e com menores custos.

As turbinas a reação tem maior potencial para usufruir das pequenas vazões encontradas nas redes de distribuição, e dimensionadas adequadamente, podem representar as melhores soluções para as dimensões de geração.

Nestas turbinas, o alternador é montado no exterior da conduta, cujo eixo pode ser atravessado pelo fluxo de água ou até mesmo transversal, mudando a direção do 
fluxo, o que pode ser uma característica almejada no sistema de distribuição.

Os equipamentos de menor dimensão possuem instalação e manutenção mais simples, que projetados corretamente, permitem a redução dos custos relacionados às obras civis e à conexão aos componentes eletromecânicos e rede de distribuição de energia local.

\section{CONCEITOS E CONFIGURAÇÃO DA MINI E MICROGERAÇÃO DE ENERGIA}

\subsection{Estudos relacionados a mini e microgeração}

Com o desenvolvimento das tecnologias de mini e micro turbinas, e com a crescente necessidade de produzir energia, a instalação deste tipo de turbinas na rede de distribuição de água passou a ser considerada em diversos estudos de viabilidade econômica e de cunho tecnológico.

Recentemente alguns estudos tem demostrado a real possibilidade de aproveitamento, identificando os pontos positivos e negativos da instalação das turbinas.

Lima (2013) estudou duas localidades para avaliar a tecnologia proposta, o Município de Cruzeiro, cidade do Estado de São Paulo e o Município de Campo Grande, Capital do estado de Mato Grosso do Sul. Foram encontrados pontos positivos e negativos para indicar a viabilidade do empreendimento.

Foi identificado que para locais como o Município de Cruzeiro, é possível aproveitar as grandes quedas provocadas pelo relevo da cidade para gerar energia na rede de distribuição de água. No entanto, somente em trechos com vazões mais altas.

Estes trechos são as adutoras centrais do sistema de distribuição, que transportam a água até os tramos de rede secundários. Instalando turbinas também nos tramos secundários, concluiu-se que o custo dos equipamentos eletro mecânicos não seria compensado pela produção de energia, devido às baixas vazões envolvidas.

Silva (2012) utilizou um sistema de avaliação diferente daquele utilizado por Lima (2013). Ele avaliou o potencial de geração na rede do Município de Pato Branco, no Paraná, criando dois cenários de utilização da energia elétrica gerada pelos aproveitamentos na rede. $O$ primeiro cenário é descrito utilizando a energia pela própria empresa de distribuição de água, abatendo os gastos relacionados com os sistemas elevatórios de água da rede. O segundo cenário previu a venda da energia 
elétrica gerada diretamente para a rede de distribuição pelo valor integral das taxas cobradas pela energia.

Segundo Silva (2012), ambos os cenários apresentaram potencial de geração, no entanto, para a malha de pontos de aproveitamento propostos, apenas alguns mostraram-se financeiramente rentáveis. O primeiro cenário foi o que apresentou maiores benefícios, fazendo com que a energia gerada seja utilizada de forma dispersa na rede. O segundo cenário também apresentou lucros com tempos de retorno do investimento convidativos, mas que não tem impacto no caixa da empresa de saneamento tão significativo quanto o Cenário 1.

Existem, além destes estudos, análises não publicadas dos sistemas de abastecimento de Curitiba e São Paulo, que aparentemente não obtiveram resultados convidativos, mas que requerem maiores estudos de viabilidade e merecem análise sob outros pontos de vista.

No cenário mundial, o aproveitamento da rede de distribuição de água como fonte de geração de energia tem sido mais desenvolvido por países europeus como a Itália, que apresentou recentemente duas publicações relacionadas ao tema.

Na Itália, mais especificamente na Cidade de Nápoles, Nicola (2012) descreve um estudo de caso que tem como objetivo avaliar, não somente a produção de energia, mas principalmente o benefício do dimensionamento destas estruturas para redução das perdas na rede. Ele relacionou a instalação das turbinas diretamente com a redução das pressões e, consequentemente, com a redução das perdas, utilizandose de ferramentas de otimização para minimizar as pressões.

A relação mostrou-se bastante atrativa, uma vez que a geração de energia através da rede seria um complemento às medidas tradicionais de controle de pressão.

Outro ponto estudado por Nicola (2012) foi a possibilidade de dimensionar as redes de distribuição já imaginando a oportunidade de usufruir da energia potencial do sistema. A ideia surgiu pela constatação de que o trecho de rede estudado pelo autor na cidade de Nápoles é subutilizado por uma falsa estimativa de crescimento populacional, assim devendo ser novamente dimensionado para substituição dos condutos.

Estudos recentes de Carravetta et al. (2013) formularam a análise custo-beneficiário da instalação das centrais hidrelétricas na rede de distribuição de Palermo no sul da Itália, na rede chamada Oreto-Stazione, onde, apesar das pequenas quedas e grande variabilidade de vazões encontradas, constatou-se que o retorno de um 
empreendimento deste tipo na rede pode trazer interessantes benefícios aos gestores da rede de distribuição, e que devem ser utilizados possivelmente no projeto de um sistema de abastecimento ótimo.

Vilanova e Balestieri (2014), por sua vez estudaram duas unidades do sistema de abastecimento de Itajubá, instalando sistemas de recuperação de energia do sistema de tratamento de água e das estações de captação do rio Sapucaí.

Os dois sistemas eram sujeitos a cobrança pela energia em duas abordagens diferentes.

Um dos sistemas sofria a cobrança de apenas uma única taxa que variava ao longo do dia e ao longo do ano. Já o segundo sistema tinha a cobrança de duas tarifas separadas, uma para a demanda e outra para energia consumida.

Como o objetivo do estudo corrente é verificar qual o potencial de retorno da instalação dos pequenos aproveitamentos e propor uma metodologia para 0 aproveitamento, o custo da energia foi utilizado como critério para a otimização das instalações.

Como resultado, os estudos permitiram concluir que a instalação dos aproveitamentos seguindo a política de cobrança e compensações da produção de energia determinada pelas normativas brasileiras eram economicamente viáveis.

\subsection{Aproveitamento e benefícios obtidos}

Sistemas de abastecimento de água promovem a distribuição de um dos componentes essenciais para a manutenção da vida e promove o fornecimento com qualidade e quantidade suficientes para a manutenção do bem estar e saúde dos usuários.

Como o sistema é parte básica para o atendimento destas necessidades, é razoável prever que este tipo de sistema seja adotado em toda e qualquer comunidade em algum momento de seu desenvolvimento.

A distribuição de água possui, no entanto, a necessidade de ser transportada seja a curtas ou longas distâncias, sendo supridas normalmente por desníveis naturais que promovem o escoamento até o ponto de consumo, ou diferenciais de pressão que promovem o deslocamento do recurso. Para este segundo caso, existe consumo de energia na utilização de bombas. 
O fornecimento de água com qualidade suficiente para o consumo é outro fator importante na configuração de um sistema de abastecimento de água, necessitando de tratamento quando a qualidade inicial não é satisfatória.

Desta forma, conclui-se que na distribuição da água, o uso de energia elétrica é uma constante, tanto no transporte quanto no tratamento. O consumo de energia representa segundo SNIS (2011) $80 \%$ do total de custos relacionados com o abastecimento de água, tornando o processo de distribuição uma tecnologia não sustentável.

Com o intuído de melhorar o cenário de sustentabilidade e promover o uso racional dos recursos energéticos e de água, a implantação de unidades de recuperação de energia no sistema de abastecimento e, mais especificamente, na rede de distribuição viria a complementar e balancear o uso de recursos energéticos.

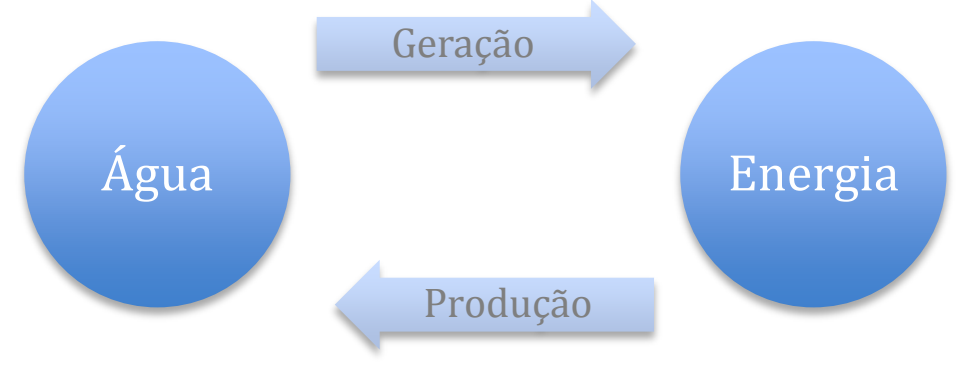

Figura 16 - Ciclo da relação entre água e energia

\subsection{Estruturação de mini e micro geração na rede de distribuição de água}

A recuperação de energia do sistema de distribuição de água pode ser realizada em diferentes pontos do sistema de distribuição de água, aproveitando-se das peculiaridades e potenciais específicos em cada ponto.

Existe a possibilidade de instalar grupos geradores no sistema adutor, entre reservatórios de abastecimento, na saída ou entrada de estações de tratamento de água bruta e na rede de distribuição de água.

Vilanova e Balestieri (2014) descrevem que a descarga nas turbinas no caso de geração de energia por um grupo gerador associado a sistemas de abastecimento, será igual a vazão que é transportada por gravidade ou com a ajuda de bombas entre vários pontos da rede. 
Existem vários esquemas de configuração de um aproveitamento e instalação de hidrelétricas que podem ser usados em um sistema de abastecimento de água e dependem, fundamentalmente, da configuração da rede, da posição desejada para o grupo gerador, do regime de operação e do espaço disponível para a instalação.

Ainda segundo Vilanova e Balestieri (2014), são seis as principais configurações de rede.

- Escoamento direto de rios por gravidade associados à adutora

- Escoamento a partir de represas por gravidade associados à adutora

- Escoamento forçado por bombeamento e sistemas reversíveis

- Sistemas hidrocinéticos de baixa carga associados a sistemas de adução

- Recuperação de energia de aquíferos

- Recuperação de energia com a substituição de válvulas redutoras de pressão

A configuração de cada uma destas alternativas estudadas por Vilanova e Balestieri (2014) é descrita a seguir detalhadamente.

- Escoamento direto de rios por gravidade associados à adutora

Nesta configuração, a captação de água ocorre nos próprios corpos d'água, sem que nenhum tipo de armazenamento ou reservatório seja introduzido artificialmente no sistema.

A localização dos aproveitamentos pode ser tanto na entrada dos sistemas de tratamento de água bruta, quanto na saída da estação de tratamento de água, no caso desta realizar o escoamento por gravidade ao final de seus processos.

As captações de água do rio devem estar localizadas em um nível superior aquele da estação de tratamento, e escoam normalmente através de um canal de regularização ou calha Parshall que faz o controle das vazões para o processo de tratamento ser realizado de modo mais eficiente.

As turbinas poderiam ser instaladas antes destes diapositivos de controle de vazão, aproveitando as quedas e tendo o sistema de tratamento como canal de descarga da hidrelétrica. 
Nesta configuração, não existe a necessidade de construções e grandes intervenções, o que reduz o custo de instalação, limitando-o aos custos relacionados ao sistema gerador.

Outro ponto que vem a melhorar o cenário é o fato da hidrelétrica estar mais próxima da estação de tratamento de água, poupando energia necessária para o abastecimento da estação, além de poder ser conectada diretamente à rede de distribuição.

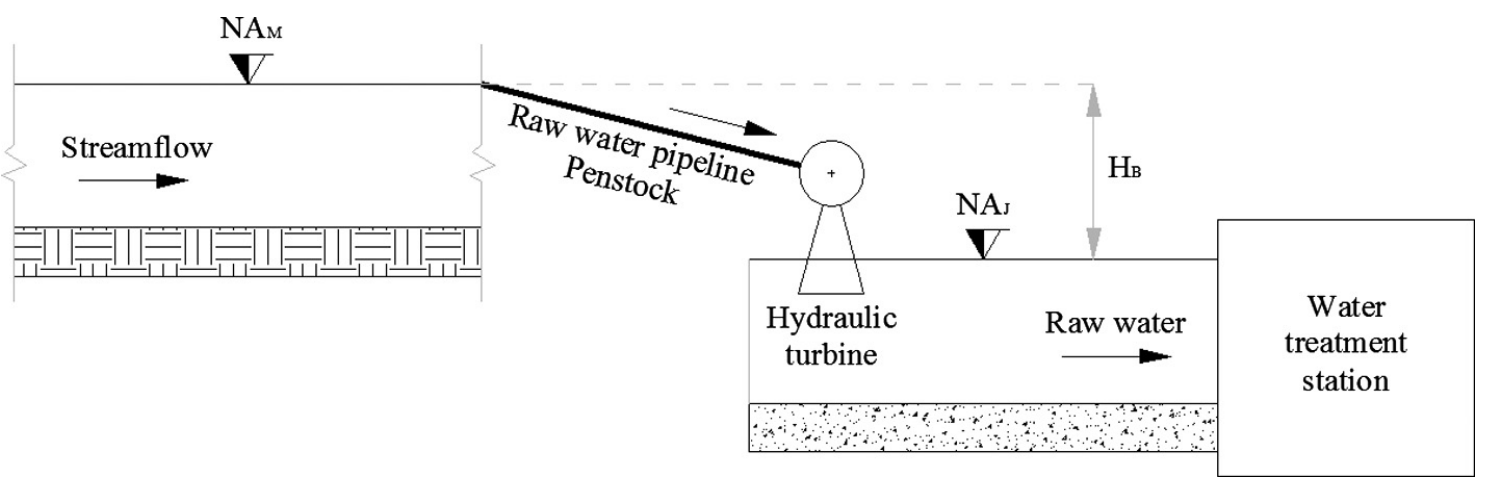

Figura 17 - Esquema de instalação de unidade geradora no escoamento direto de rios por gravidade associados a adutora. Fonte: Adaptado de Vilanova e Balestieri (2014)

Uma possível variação desta proposta é a instalação da hidrelétrica diretamente nos túneis que levam o fluxo a estação de tratamento de água, em pontos de liberação de pressão e caixas de equalização.

Os pontos negativos desta configuração são a sua distância dos centros de consumo de energia, uma vez que as estações de tratamento de água normalmente encontram-se distantes das cidades e próximas das captações, e o não aproveitamento total das cargas presentes em um sistema de abastecimento de água para gerar energia.

Desta forma, a rede de transmissão de energia, apesar de necessitar de menores distâncias quando conectadas as estações de tratamento, o que se traduz em menores investimentos, exigiriam maiores gastos quando conectadas ao sistema de transmissão de energia para os grandes centros. 
- Escoamento a partir de represas por gravidade associados à adutora

A configuração de instalação de unidades geradoras a partir das represas do sistema de abastecimento que funcionam por gravidade se assemelha a configuração sem as represas, mas apresenta algumas alterações, devido a existência dos reservatórios ou represas de regularização das vazões.

Algumas configurações de redes de abastecimento de água usam reservatórios para regularizar as vazões e garantir o fornecimento de água continuo ao longo do tempo. Assim nos períodos chuvosos, estas estruturas seriam carregadas, armazenando água suficiente para suprir as necessidades e, em períodos de seca, os reservatórios reduziriam seus níveis.

Esta modalidade de abastecimento se liga diretamente com a geração de energia, uma vez que os reservatórios são utilizados para acumular energia para o aproveitamento dos desníveis naturais.

Desta forma as represas atuariam tanto como reservas de água, eliminando variações sazonais de vazões, tanto como unidades de acúmulo de energia potencial para geração de energia.

Mais uma vez, o problema encontrado para este esquema é a distância entre as represas e os centros consumidores de energia, necessitando de investimentos com redes de transmissão de energia.

Instalando as turbinas logo a jusante do reservatório, a rede de transmissão é obrigatória e apresenta restrições para os custos do empreendimento.

Caso deseje-se instalar as turbinas mais próximo dos centros consumidores, devese incluir nos cálculos do potencial de geração as perdas de carga distribuídas ao longo do comprimento das tubulações, e a declividade entre as represas e o ponto de aproveitamento, resultando na redução da energia gerada.

As duas configurações propostas e descritas para a geração a partir de abastecimento com reservatórios são apresentadas a seguir em representações esquemáticas de Vilanova e Balestieri (2014). 

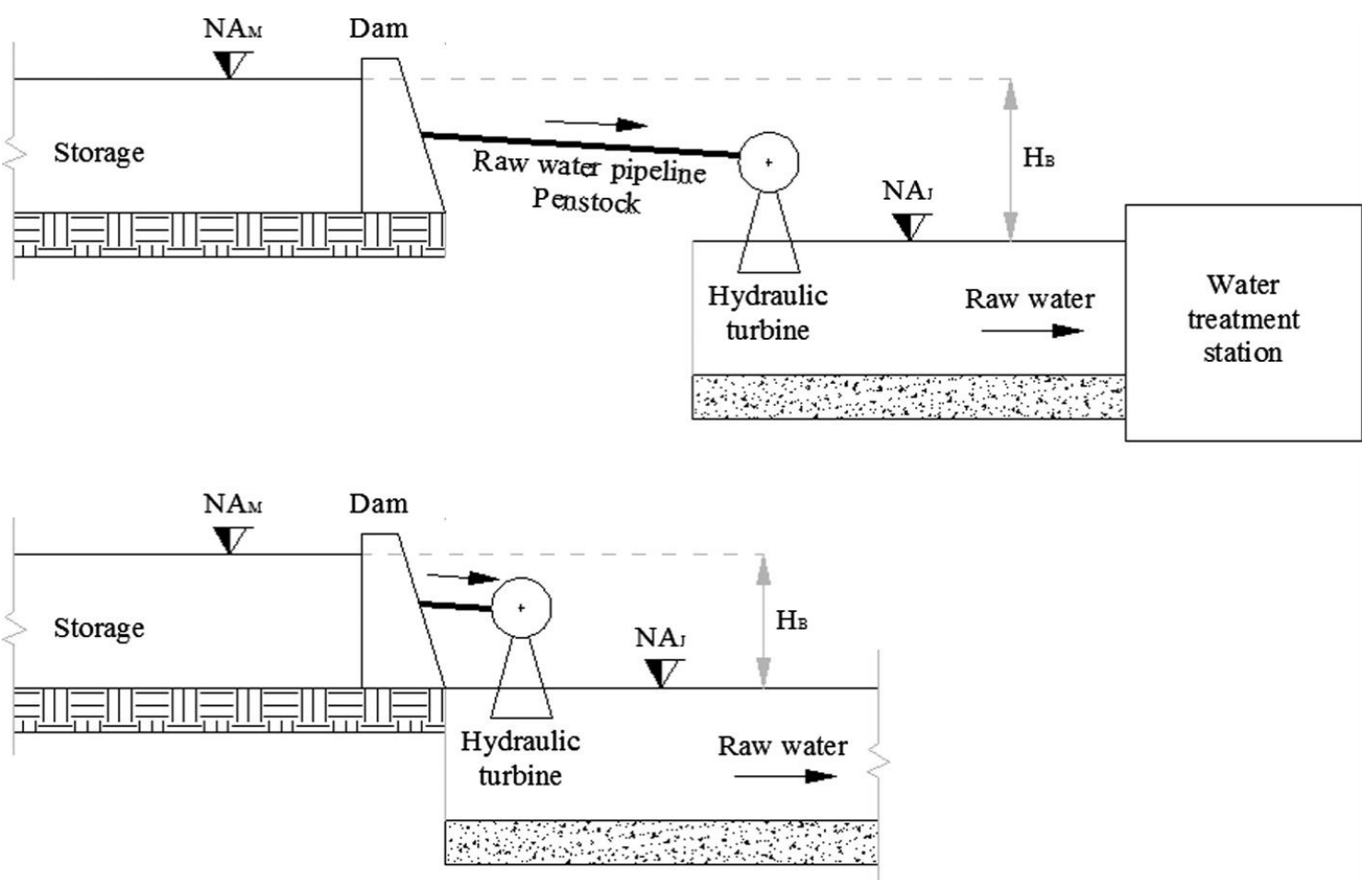

Figura 18 - Instalação de turbinas logo a jusante dos reservatórios. Fonte: Adaptado de Vilanova e Balestieri (2014)

\section{- Escoamento forçado por bombeamento e sistemas reversíveis}

Os sistemas de abastecimento com o auxilio de bombeamento fazem uso de um sistema de elevação para garantir as pressões e/ou garantir o fornecimento de água, carregando reservatórios.

O sistema de bombeamento consome energia, portanto, para abater os custos da elevação da água para os reservatórios é possível instalar um sistema reversível, que se utiliza da variação dos custos de energia ao longo do dia para reduzir os custos. Desta forma, produz energia quando o deu custo é alto, no momento dos picos de consumo, e utiliza energia com bombeamento para recarregar os reservatórios quando o seu custo é mais baixo, ou seja, fora dos períodos de pico. Segundo Ramos et al. (2005), sistemas que associam geração de energia com sistemas de abastecimento de água, promovem uma melhor gestão financeira e operacional de ambos os sistemas. 


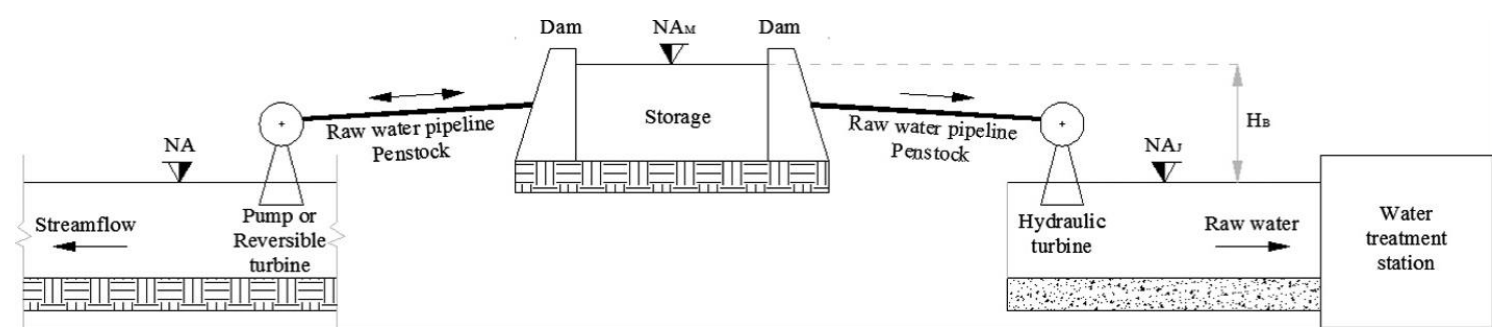

Figura 19 - Instalação de turbinas a jusante dos reservatórios abastecidos por bombeamento ou reversíveis. Fonte: Adaptado de Vilanova e Balestieri (2014)

Esta mesma configuração pode ser utilizada em reservatórios de menor porte, como caixas d'água e reservatórios de elevação de carga.

- Sistemas hidrocinéticos de baixa carga associados a sistemas de adução

Sistemas de aproveitamento hidrocinéticos são utilizados em redes com baixos desníveis e grandes vazões, diretamente nos canais onde o fluxo de água é mais constante.

O fluxo se torna mais constante em sistemas que apresentam reservatórios nos cursos d'água para regularizar as vazões e manter os níveis mínimos operacionais exigidos para o abastecimento.

Esta tipologia de aproveitamento exige o uso de turbinas que atuam em baixos desníveis, que são as turbinas na categoria de reação como a Kaplan.

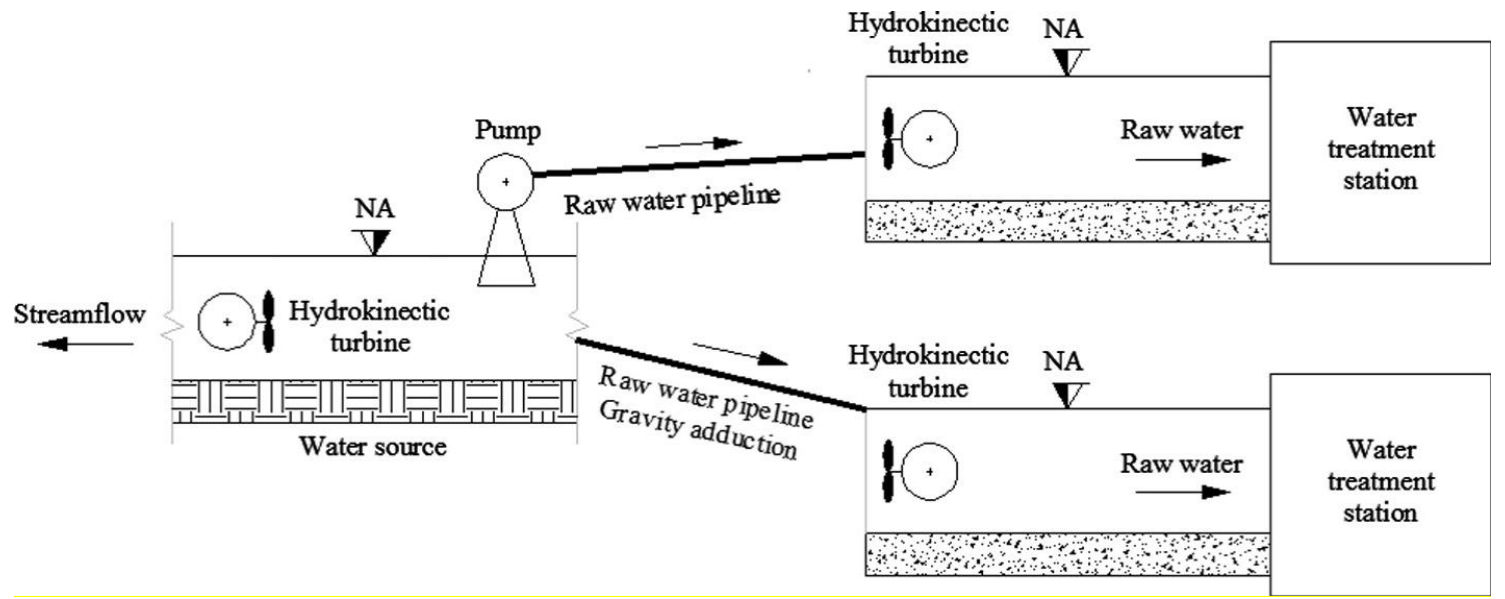

Figura 20 - Instalação de turbinas hidrocinéticas ao longo dos canais de destinação dos fluxos. Fonte: Adaptado de Vilanova e Balestieri (2014) 
A Figura 21 apresenta as possibilidades de instalação das turbinas hidrocinéticas nos diversos trechos que compõem sistemas típicos de captação e destinação das águas para o abastecimento.

É possível notar que, assim como a configuração com escoamento forçado apresentada anteriormente, a presença de bombas no sistema não impede que os aproveitamentos sejam instalados, e até mesmo que produzam energia para abater os gastos com elevatórias na rede. Este fato decorre da possibilidade técnica de equipamentos que conseguem utilizar mínimas quedas para geração de energia.

- Recuperação de energia a partir de poços

Alternativa apresentada por Vilanova e Balestieri (2014), o aproveitamento energético dos poços sob pressão se daria com a instalação de unidades de produção de energia nas saídas dos poços, uma vez que estes têm pressão e vazão suficientes para a tarefa.

Como pode-se ver na Figura 22, o aquífero confinado tem a vazão controlada pela demanda de água, fazendo com que a pressão e vazão sejam variáveis.

O dispositivo seria instalado antes do canal de fornecimento de água.

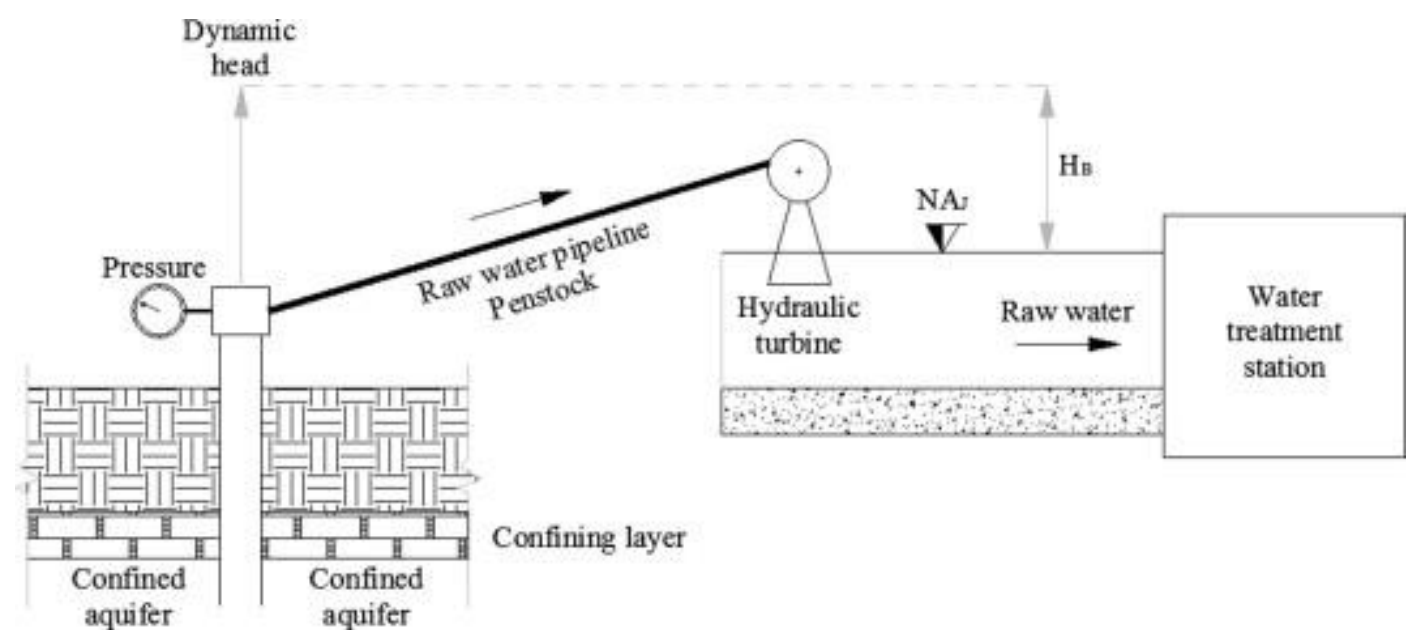

Figura 21 - Instalação de turbinas nas saídas de poços de água sob pressão. Fonte: Adaptado de Vilanova e Balestieri (2014)

- Recuperação de energia em substituição de válvulas redutoras de pressão

O próprio nome se refere a última configuração de aproveitamento proposta tem como mote substituir as válvulas redutoras de pressão para garantir a geração e controle das pressões na rede. 
Esta configuração foi a utilizada para realização dos estudos desta dissertação, por englobar uma rede relativamente simples de se controlar. As estruturas estariam previamente projetadas em redes já instaladas, pois considera que existem válvulas redutoras de pressão e em caso de projeto das redes de distribuição, poderiam ser usadas diretamente como medidas de controle da pressão.

O esquema da Figura 23 apresenta a situação onde a turbina será locada logo a montante da rede, na adutora principal.

Desta forma o aproveitamento seria o máximo, por se localizar do tramo de rede com maiores vazões.

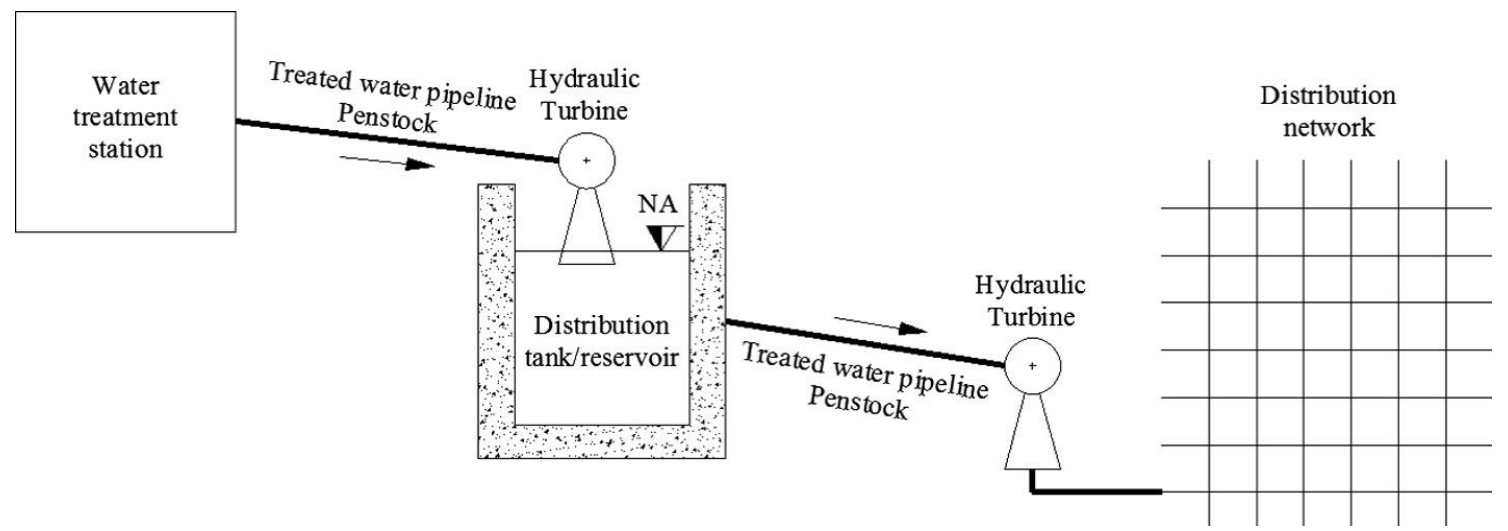

Figura 22 - Instalação de turbinas na rede de distribuição de água em substituição às válvulas redutoras de pressão. Fonte: Adaptado de Vilanova e Balestieri (2014)

\subsection{Procedimentos de instalação}

Os procedimentos para a instalação de sistemas geradores de energia usualmente se iniciam com um estudo de inventário energético de uma região ou bacia especifica, identificando os pontos de maior potencial e a configuração de quedas que melhor aproveitem o relevo. A partir deste estudo, são identificados os locais onde o aproveitamento apresenta as melhores condições para um investimento viável, passando por estudos de análise multicritérios que envolvem todos os fatores importantes à construção da unidade geradora, são eles:

- Impactos econômicos, sociais e ambientais

- Valores de produção de energia

- Viabilidade técnica

- Custos de implantação e manutenção 
Identificado o local com as melhores condições, é desenvolvido um relatório de viabilidade e paralelamente um estudo da concepção técnica da central hidrelétrica, que, posteriormente, resultará em projetos básico e executivo.

Os estudos de concepção técnica tem o intuído de analisar a melhor configuração de estrutura e equipamentos, aproveitando as características locais em beneficio do empreendimento.

No aproveitamento em redes de abastecimento, o estudo de inventário leva em conta, além da topografia do local de estudo, a configuração da rede de distribuição, que pode apresentar reservatórios elevados e sistemas de bombeamento que modificam as pressões ao longo dos condutos da rede.

Desta forma, identificar a configuração e arranjo do sistema de abastecimento representa a etapa do inventário em uma bacia hidrográfica.

Em consonância a este procedimento, a instalação e geração de energia na rede de distribuição de água a partir de mini e/ou micro centrais hidrelétricas necessita dos estudos de viabilidade, prévios aos projetos básico e executivo.

Eles desempenham papel de definir os equipamentos e localização das instalações, utilizando os detalhes da rede de distribuição e dos grupos de turbinas e geradores segundo sua eficiência e proximidade entre os pontos de maior potencial com a conexão à rede elétrica.

Serão analisados os fatores principais que são descritos a seguir, não excluindo a necessidade de estudar os demais critérios apresentados, como os impactos envolvidos.

- A identificação do potencial de geração a partir da avaliação da tipologia do sistema de abastecimento

- A escolha dos equipamentos eletromecânicos

- Definição da conexão da fonte geradora com a rede elétrica

- Custos de implantação e operação 


\subsection{Custos de implantação e operação}

Definir os custos de implantação e operação é a forma mais eficiente de determinar a viabilidade econômica de um projeto. Neste caso, a instalação das unidades geradoras tem a função de não somente apresentar custos de instalação e operação baixos para serem consideradas viáveis, mas também garantir uma taxa de retorno de investimento capaz de justificar sua instalação.

Foram levantados dados sobre os custos de implantação de mini e micro turbinas. Segundo a European Small Hydropower Association - ESHA (2014a) os valores usuais de uma mini ou micro usina de geração é de aproximadamente 2000,00 a $5000,00 \mathrm{EUR} / \mathrm{kW}^{1}$, o que equivale, atualmente, a valores de 6000 a 15000 Reais/kW.

A média de custo das instalações já operantes em território europeu é de 3986 $E U R / k W$ para instalações com baixas quedas, enquanto o custo para construção de instalações com quedas mais altas é de $3484 \mathrm{EUR} / \mathrm{kW}$, sendo que, do custo total determinado por estes valores, os valores esperados de operação representarão anualmente, de 4 a $5 \%$ do investimento total.

Dentro da temática desenvolvida, o tempo de retorno do investimento, ou simplesmente taxa de retorno, será estipulada como sendo de 10 a 25 anos. Este valor é próximo do tempo de vida útil dos equipamentos das centrais, no entanto, se bem mantidas, as turbinas e equipamentos podem ter sua vida útil estendida para valores próximos a 50 anos.

Considera-se que o custo de operação e manutenção ao longo desta vida útil seja de 4 a $6 \%$ do total de investimentos.

Carravetta et.al. (2013), apresenta em seu trabalho a análise custo-benefício da implantação de centrais na rede de distribuição de Palermo, Itália, e considera que os custos das centrais em um cenário ótimo, representado apenas por um incremento nos custos de construção, decorrentes do aumento das dimensões da rede em relação a uma condição de referência.

Desta forma, é fundamental uma análise econômica das alternativas de implantação das mini ou micro turbinas, analisando os custos de implantação e manutenção, e o possível abatimento dos custos na adução e distribuição de água.

Esta análise leva em conta a politica nacional de incentivo aos pequenos

${ }^{1}$ Cotação do Euro, Janeiro de 2010, 1 EUR = 3,01 Reais 
aproveitamentos energéticos que determina que a energia gerada por mini ou micro geração seja abatida diretamente sobre a empresa que está produzindo a energia. Assim sendo, os benefícios seriam calculados pelo fluxo de caixa de gastos de energia atual, abatimento da produção de energia e custos de instalação e manutenção.

A análise pode ser feita utilizando-se das ferramentas usuais de cálculo dos critérios econômicos de um empreendimento, como as Taxa Mínima de Atratividade (TMA) e Taxa Interna de Retorno (TIR),(Santos, 2001).

A TIR é a taxa necessária para igualar o valor atual líquido fazendo com que o caixa do empreendimento se iguale a zero, o que significa que os valores investidos e obtidos com o projeto se igualaram.

O tempo necessário para que os investimentos e os lucros sejam igualados é por sua vez chamado de Payback (Gitman, 2006).

Ele é basicamente calculado com um simples fluxo de caixa, que faz a diferença entre as entradas (ganhos com a produção) e saídas (custo de implantação e manutenção).

Segundo Gitman (2006) o fluxo de caixa pode ser utilizado para identificar se metas e projeções foram atingidas, e avaliar se existiu ineficiência no processo ao longo do tempo.

\subsection{Estrutura de modelagem para mini e micro geração}

Definida uma região de estudo, a avaliação técnica de viabilidade da instalação de mini e micro centrais hidrelétricas passa a compreender a configuração hidráulica do sistema e o atendimento às normas técnicas dos sistemas de abastecimento.

O procedimento a ser utilizado encadeia uma sequência de rodadas de simulação, utilizando o modelo matemático e avaliando os parâmetros de pressão e vazão conforme os limites estabelecidos.

A introdução das centrais na rede de distribuição de água altera seu comportamento, e para avaliar a possibilidade de instalar uma ou mais turbinas na rede é necessário criar cenários de aplicação, variando o número e posição das turbinas em cada um deles.

O resultado é a avaliação de diversas possibilidades de configuração e a escolha da que mais se adapta a rede estudada. 
Desta forma, a modelagem matemática da rede de distribuição poupa tempo e investimento, facilitando a visualização destes cenários e a produção de alternativas. O modelo da rede de distribuição deve primeiramente identificar o comportamento das demandas, e qual seria a curva de consumo aplicável.

Neste passo, é fundamental a calibração e validação do modelo, para que seja possível aplicar as centrais e avaliar fidedignamente o seu comportamento.

Após a validação, a modelagem terá o papel de identificar os pontos de maiores pressões e vazões na rede e a necessidade ou não de fazer adaptações para que seja possível a instalação das centrais.

A escolha da tipologia das turbinas também é auxiliada pela modelagem, pois determina os limites de escala das vazões e desníveis a serem aproveitados, escolhendo, conforme a faixa, quais turbinas podem ser aplicadas levando em conta o intervalo de melhor rendimento destes equipamentos.

Definidos os cenários de instalação das turbinas, o modelo deve ser utilizado para verificar as condições de atendimento dos critérios para o abastecimento, calculando novamente as pressões em todos os pontos da rede para cada cenário.

É definido também nestes cenários a quantidade de energia gerada e os horários de ativação, o que possibilita uma comparação de alternativas.

Como a simulação de diversos cenários pelo modelo é um procedimento repetitivo e que poderia se estender por muito tempo, a ajuda de um modelo de otimização é desejável.

No entanto, em casos mais simples, a resolução por tentativa e erro de forma manual pode chegar aos mesmos resultados desejados.

O modelo de otimização determina qual será o melhor cenário, variando os parâmetros utilizados e encontrando a configuração ótima, dentro das condições de contorno definidas.

O procedimento de otimização deve ser realizado para que o número de rodadas do modelo matemático seja reduzido e dê respaldo ao cálculo do número e localização ideais das estruturas na rede.

A modelagem matemática é diretamente conectada às características físicas das redes simuladas, e o procedimento aqui apresentado possibilita que sejam posteriormente avaliados, tanto a instalação, quanto a manutenção e expansão do sistema produtor de energia.

Uma forma de agregar os dados e procedimentos envolvidos na geração de energia 
por mini e/ou micro centrais, é a criação de um procedimento padronizado, que promove a conexão de todos os componentes integrantes em uma única metodologia que pode simular e otimizar cenários de instalação, além de determinar a operação do sistema.

\subsection{Modelagem hidráulica em redes de distribuição}

\section{Modelagem com EPANET}

O EPANET é um modelo de simulação matemática que possibilita a simulação de redes complexas de distribuição de água, utilizando um conjunto de ferramentas de cálculo que dão consistência à modelagem hidráulica.

O manual do usuário EPANET 2.0 (EPA, 2000) explicita, "O EPANET é um programa de computador que permite executar simulações estáticas e dinâmicas do comportamento hidráulico e de qualidade da água em redes de distribuição pressurizada. Uma rede é constituída por tubulações, bombas, válvulas, reservatórios de nível fixo e/ou reservatórios de nível variável. O EPANET permite obter os valores da vazão em cada tubulação, da pressão em cada nó, da altura de água em cada reservatório de nível variável."

Dentre as características que se destacam são citadas no User Manual (EPA, 2000):

- Dimensão ilimitada do número de componentes da rede analisada

- Cálculo da perda de carga utilizando as fórmulas de Hazen-Williams, DarcyWeisbach ou Chezy-Manning.

- Consideração das perdas de carga singulares em curvas, alargamentos, estreitamentos, etc.

- Modelagem de bombas de velocidade constante ou variável.

- Cálculo da energia de bombeamento e do respectivo custo.

- Modelagem dos principais tipos de válvulas, incluindo válvulas de seccionamento, de retenção, reguladoras de pressão e de vazão.

- Modelagem de reservatórios de armazenamento de nível variável de formas diversas, através de curvas de volume em função da altura de água.

- Múltiplas categorias de consumo nos nós, cada uma com um padrão próprio de variação no tempo. 
- Modelagem da relação entre pressão e vazão efluente de dispositivos emissores (aspersores de irrigação, ou consumos dependentes da pressão).

- Possibilidade de basear as condições de operação do sistema em controles simples, dependentes de uma só condição (p.ex., altura de água num reservatório de nível variável, tempo), ou em controles com condições múltiplas. 


\section{MODELO DE OTIMIZAÇÃO}

O modelo de otimização é utilizado para obter os melhores resultados em uma modelagem complexa, utilizando funções objetivo, condições e restrições para determinar, a zona de melhores resultados e os pontos de melhor aproveitamento. As funções objetivo relacionam todas as variáveis importantes para o problema que se deseja otimizar. $O$ trabalho de formular as equações que melhor representem 0 sistema é tarefa importante no procedimento, podendo modificar de forma substancial os resultados obtidos.

As restrições, por sua vez são limites e condições para que a rede estudada reaja dentro dos padrões pré-estabelecidos e dos conhecimentos pré-existentes de funcionamento. Eles determinarão a área na qual os resultados podem ser considerados, delimitando os espaços suscetíveis a rodadas da função objetivo, ou uma zona de atuação de algum componente estudado.

Os valores limite desta zona e os pontos de melhor aproveitamento são obtidos por meio de aproximações sucessivas, igualando, minimizando ou maximizando a função objetivo.

As ferramentas mais utilizadas na otimização são aquelas de programação linear e não linear.

\section{- Programação Linear}

A programação linear permite que problemas e sistemas de grande porte sejam solucionados de modo simples e objetivo, podendo representar problemas não lineares de forma aproximada com técnicas de linearização e decomposição.

Como exemplifica Schardong (2006), a existência de funções objetivo submetidas a restrições lineares, podendo ser elas de igualdade, desigualdade, ou composta por variáveis e valores ótimos, caracterizam um problema de programação linear, e esta pode ser concebida a partir do formato padrão a seguir.

$$
\begin{gathered}
\min C^{T} x(15) \\
\max C^{T} x
\end{gathered}
$$

Sujeito a 


$$
\begin{aligned}
& A x=b \\
& x \geq 0
\end{aligned}
$$

onde $A, x$, b e $C^{T}$, são:

- Matriz A: m x $n$ dos coeficientes das restrições;

- Vetor $x$ : vetor $n$-dimensional das variáveis de decisão

- Vetor b: vetor m-dimensional com os valores dos recursos disponíveis

- Vetor $C^{T}$ : vetor r-dimensional dos coeficientes da função objetivo

\section{- Programação não Linear}

Na programação não linear, por sua vez, os problemas a serem resolvidos não possuem características lineares e devem ter uma abordagem diferente.

Assim como descreve Bertsekas (1991) problemas não lineares podem ser considerados como:

$$
\begin{gathered}
X=R^{n}(16) \\
\min f(x) \\
\text { sujeito a } x \in R^{n}
\end{gathered}
$$

onde, X e $R^{n}$ são:

- X é uma partição de $R^{n}$ e pode ser especificado por limites determinados por curvas de igualdade e inigualdade - $R^{n}$ espaço amostral

A função $f$ pode ser assumida na maior parte das vezes como sendo continuamente diferenciável, normalmente duas vezes, sendo que a primeira e segunda derivadas da função tem grande importância na determinação das soluções ótimas.

Relacionando estas modalidades de otimização com a problemática da otimização de redes de distribuição de água, geração de energia e redução de perdas, foi possível chegar aos seguintes pontos descritos a seguir.

Segundo Lansey \& Mays (1989), o problema geral de otimização de sistemas de distribuição de água pode ser descrito em termos de pressões $(H)$ e das dimensões dos componentes do sistema (D), que são organizados normalmente com o intuito de minimizar os custos por meio de uma função objetivo 


$$
f(H, D)
$$

Outras possibilidades de estratégia de abordagem para a otimização dos sistemas de abastecimento é relacionada a redução dos diâmetros dos condutos e a redução das perdas (Equação 17), como exemplificado respectivamente por Carravetta et. al. (2013) e Nicola et.al. (2012).

$$
f(P, t)=\sum_{i=1}^{n} \gamma \cdot\left(P_{i, t}-P_{\min }\right)^{2}
$$

onde

- P - Pressão

- $\gamma$ - Peso específico da água

Podem ser utilizadas as tradicionais aproximações com o uso de programação não linear (PNL), descrita por Su et al. (1987), Lansey \& Mays (1989) e Xu and Goulter (1999). A PNL se utiliza de equações para delimitar uma área de interesse, onde poderão ser encontrados os valores ótimos esperados. Os valores máximos e mínimos estão localizados nas extremidades desta área de interesse, sempre ao longo de uma das curvas limites das equações não lineares.

Existem outros métodos de otimizar as características desejadas da rede, entre eles estão inclusos os algoritmos genéticos, que tem demonstrado algumas vantagens sobre os métodos tradicionais de otimização, como discorre Simpson et. a. (1994), sendo tema constante das mais recentes literaturas.

Os algoritmos genéticos são uma ferramenta robusta de busca iterativa baseada na evolução Darwiana e na sobrevivência dos mais fortes (Goldberg, 1989).

Com o intuito de exemplificar sobre os diversos tipos de otimização que podem ser utilizados para a mini e/ou micro geração, foram estudadas as seguintes programações de otimização encontradas na literatura. 
- Afshar, A, et al. (1990). "OPTIMIZATION OF HYDROPOWER PLANT INTEGRATION IN WATER-SUPPLY SYSTEM."

Discorre sobre a otimização dos custos decorrentes da instalação de pequenas hidrelétricas em sistemas de abastecimento de água.

Os autores determinam a otimização de uma rede de distribuição de água para integração com um sistema gerador utilizando o número, dimensão, localização e capacidades do sistema de geração na rede principal de distribuição.

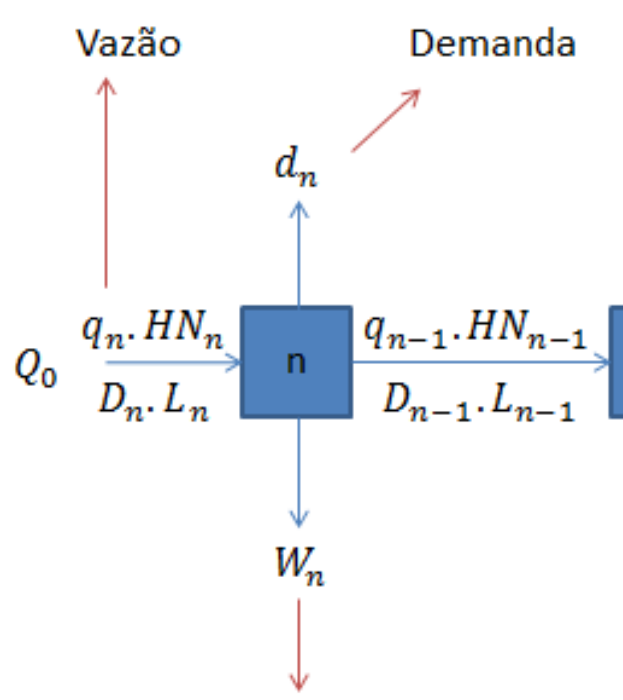

Energia Gerada
Demanda

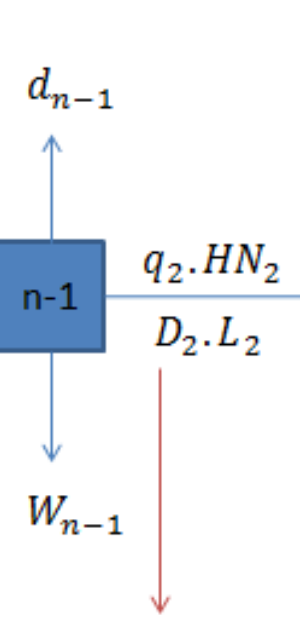

Diâmetro

\section{Desnível}

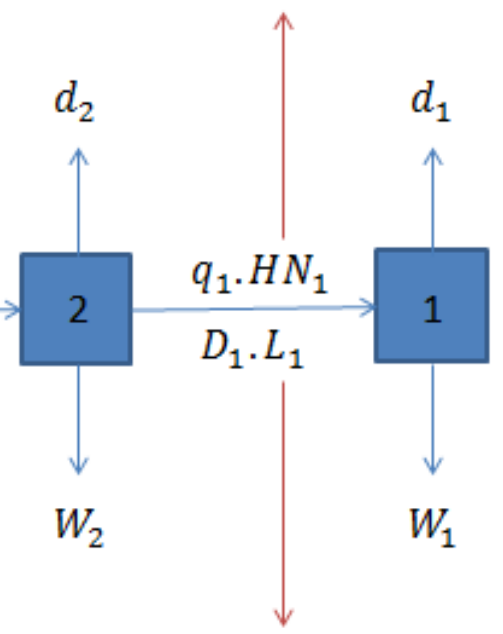

Comprimento

Figura 23 - Esquema de rede concebida por Afshar et al. (1990)

O objetivo da otimização é o de maximizar os ganhos associados à distribuição de água e à produção de energia, satisfazendo algumas condições, limites e restrições.

A função objetivo utilizada por Afshar et al. (1990) elenca os seguintes parâmetros:

- Retorno anual da hidrelétrica

- Preço da água ao consumidor

- Custo de tubulações

- Custo da hidrelétrica

- Fator de recuperação de investimento

- Custo de operação e manutenção 


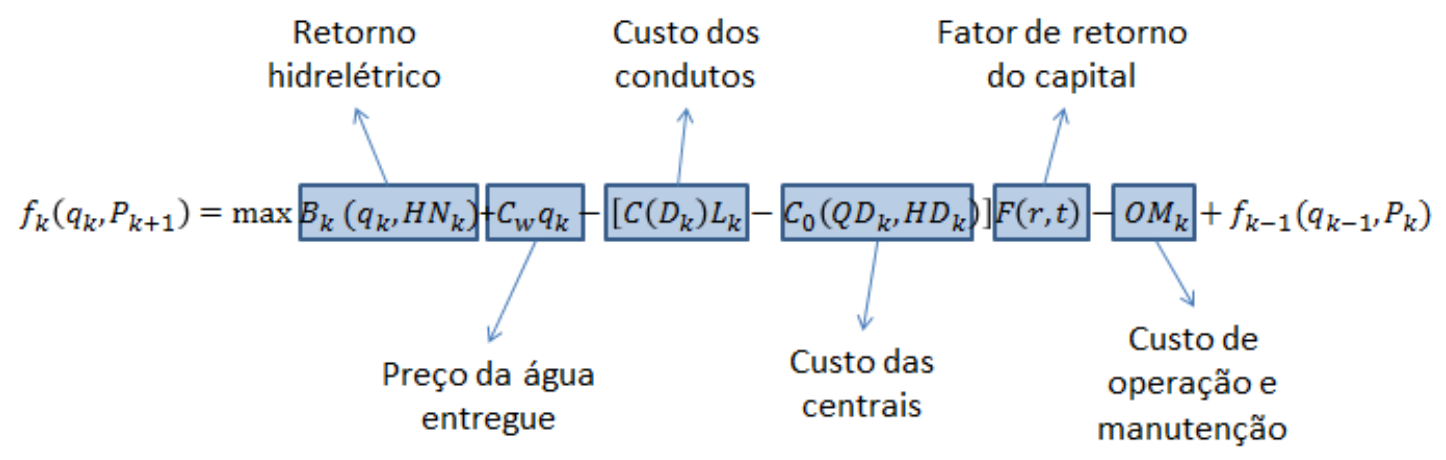

Figura 24 - Equação de otimização concebida por Afshar et al. (1990)

Sujeitos às seguintes restrições e limites:

Qk=d1+d2+...+dk, Vazão do conduíte k

Hmin $\leq$ HNk $\leq$ Hmax, Limites para o valor de quedas admissíveis;

$P \min \leq \mathrm{Pk} \leq \mathrm{Pmax}$, Potenciais limite instalados;

Dmin $\leq$ Dk $\leq$ Dmax , Diâmetros limite;

Existe ainda a ideia de utilizar programação não linear para a melhor gestão e operação de grandes sistemas produtores de água, como é descrito por Burgshweiger et al. (2005). Esses estudos se referem à otimização do uso energético em sistemas de abastecimento com o controle dos custos com bombeamento na produção de água.

\section{- Ramos, H., D. Covas, et al. (2005). Available energy assessment in water supply systems. XXXI IAHR Congress. Seoul, Korea.}

É demostrado experimentalmente que Válvulas Redutoras de Pressão (VRPs) e bombas como turbinas (BCTs) tem um comportamento similar em regime de escoamento estático e comportamentos diferentes sobre condições transientes.

Para tanto foi observado que mesmo que em alguns casos as bombas como turbinas tenham um desempenho melhor na regulação de pressões, em outros casos uma solução mais indicada é a que combina BTCs com VRPs.

Desta forma, propôs-se o método de otimização para definir qual seria o número de BCTs e VRPs necessárias para melhor desempenho em minimizar a pressão na rede. 


$$
\begin{aligned}
& \text { Pressão calculada no } \\
& \text { nó } \mathrm{i} \text { e no instante } \mathrm{t} \\
& \left.f\left(p_{i}, n v\right)\right|_{t=1} ^{T}=n v_{t} /\left.\left\{\sum_{i=1}^{N}\left[\frac{\left(P_{c a l, i, t}-P_{\min }\right)}{P \min }\right]^{2} * n v_{t}+n v_{t}\right\}\right|_{t=1} ^{2} \\
& \text { Número de válvulas } \\
& \text { no instante } t
\end{aligned}
$$

Figura 25 - Equação de otimização concebida por Ramos et al. (2005)

\section{- Liberatore, S. And G. M. Sechi (2009). "Location and Calibration of Valves} in Water Distribution Networks Using a Scatter Search Meta-heuristic Approach." Water Resourse Management 23(8): 1479-1495.

Usando uma aproximação meta-heurística, ou seja, uma aproximação onde não há conhecimento matemático suficiente para a descrição do comportamento do sistema, mas que contém uma estrutura genérica para a aplicação, Liberatore \& Sechi (2009) desenvolveram um método para determinar a localização e calibração de válvulas na rede de distribuição de água.

Foi utilizado o método de pressão de referência para que fossem identificados os pontos de instalação das válvulas redutoras de pressão, o que, com a ajuda de gráficos meta-heurísticos torna possível a melhor calibração das válvulas.

A função objetivo vem apresentada a seguir:

$$
\begin{aligned}
& \min O F=\gamma_{1} O F_{1}+\gamma_{2} O F_{2} \\
& O F_{1}=\sum_{d=1, K} \sum_{i=1, N}\left|c\left(H_{i, d}-H_{\max }\right)^{2}\right|_{H_{i} H_{\max }} \\
& O F_{2}=\sum_{i=1, N} f\left(H^{*}{ }_{i} D_{i}\right)
\end{aligned}
$$

\author{
Penalidade por \\ excesso de pressão \\ calculado com \\ padrões de demanda \\ d nos nós i \\ Função do custo das \\ VRPs com perda de \\ carga $H^{*}$ instalada \\ no conduto com \\ diâmetro D
}


Estes três tipos de otimização foram descritos por apresentarem as três principais características a serem estudadas no desenvolvimento de um procedimento de análise dos potenciais das redes de abastecimento, que são os custos e benefícios envolvidos na produção de energia, a localização dos aproveitamentos e as potências e perdas dos sistemas de abastecimento.

Tecnologias novas passam por períodos de adaptação e de aceitação no mercado, e o aproveitamento energético por mini e micro centrais hidrelétricas não se distancia desta afirmação. É necessário considerar que com a ampliação do uso de centrais de pequena capacidade de geração, existirá o efeito de economia de escala, barateando os equipamentos e custos de manutenção enquanto promove a melhoria do fator benefício $x$ custo.

Fazendo uso das características descritas e refinando o equacionamento das alternativas de otimização para 0 auxilio na aferição da viabilidade de aproveitamentos hidrelétricos na rede de distribuição, encontrou-se as seguintes citações.

Segundo Zyl et al. (2004), apesar da sensibilidade das perdas na rede de distribuição relacionadas às pressões ser bastante conhecida, os mecanismos responsáveis pelo comportamento do controle de pressões ainda não são bem explicados e entendidos. Com o intuito de compreender e rever o efeito da pressão nas redes, Zyl propõe o estudo da relação Pressão x Vazamentos.

A perda de carga considerada por Zyl é derivada da relação entre as perdas por furos na tubulação e pode ser calculada simplesmente pela equação do orifício.

$$
q=C H^{\propto}
$$

onde:

$q-A$ vazão pelo orifício

$\mathrm{C}$ - um coeficiente de vazamento constante

$\mathrm{H}$ - a pressão dentro da tubulação

$\propto$-- um expoente de vazamento contínuo

Utilizando-se de programação não linear, a equação pode ser minimizada, utilizando aproximações sucessivas variando as pressões e mantendo-as dentro das condições de contorno, pressões mínimas e máximas permitidas na rede de distribuição. 


$$
f(C, H, \alpha)=\min C H^{\alpha}
$$

$$
H \geq 10 \text { m.c.a }
$$

O coeficiente de vazamento não é relacionado com as vazões nos condutos e sim relacionado à pressão nos condutos e a suscetibilidade de ocorrer vazamentos.

Zyl et al. (2004) expõe em uma representação para demonstrar a influência da mudança que o coeficiente de perdas traz ao resultado da efetiva perda. Ele expos de forma gráfica os resultados da mudança do coeficiente, relacionando-o com as frações de redução da pressão (P1/ P0) no eixo X e a relação (q1/ q0).das perdas.

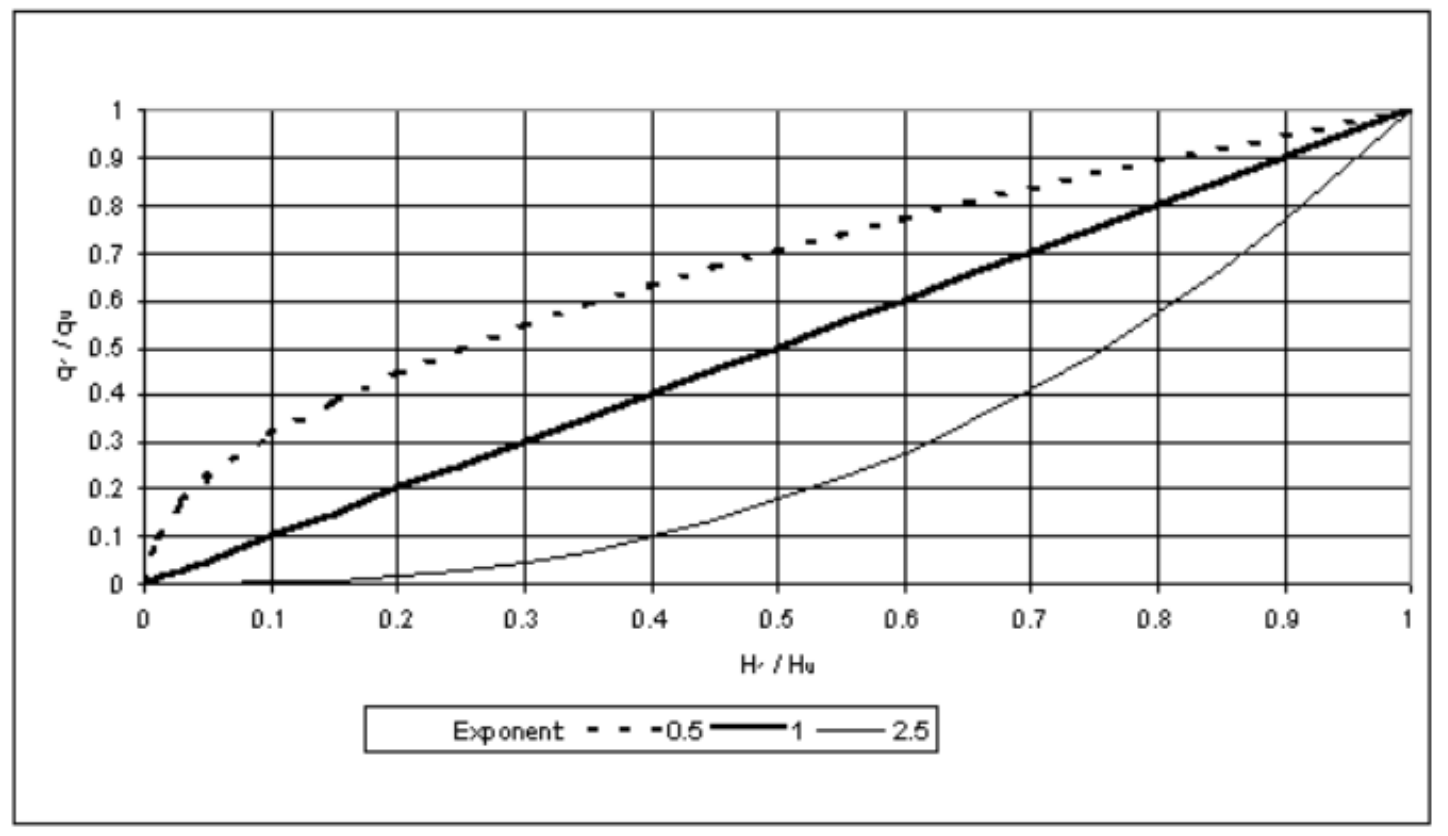

Figura 27 - Redução das perdas pela redução da pressão para diferentes coeficientes de perda

Ainda segundo os gráficos apresentados pela pesquisa de Zyl et al. (2004) pode ser notado que, com a redução em $50 \%$ na pressão, o resultado das perdas na rede serão reduzidas de 29 a 50 e $82 \%$, para os casos onde os expoentes de perdas são de $0.5,1$ e 2.5 respectivamente.

Portanto, o coeficiente de perdas causa em uma variação intensa nas porcentagens de perdas, devendo assim ser calibrado para obter valores 
mais próximos da realidade.

$\mathrm{Na}$ determinação do coeficiente é importante que estejam disponíveis dispositivos de medição e valores observados de perda para descrever onde e qual a quantidade aproximada da perda.

Existe a constatação de que a pressão realmente influencia nas perdas da rede, sendo assim fundamental a redução da pressão por meio de medidas de controle, como válvulas redutoras ou a proposta deste estudo que é a instalação de mini e micro turbinas para o aproveitamento energético. 


\section{MATERIAIS E MÉTODOS}

Neste módulo, serão descritos os materiais e métodos utilizados na descrição do procedimento para verificar a viabilidade e estabelecer quais as formas que mini e/ou micro abastecimento energéticos podem ser implantados nas redes de distribuição de água.

Para melhor compreensão dos materiais e métodos, o módulo foi dividido em três partes principais, sendo elas apresentadas a seguir:

\section{- Materiais e método de avaliação}

A etapa de levantamento bibliográfico foi realizada anteriormente promovendo o arcabouço técnico dos fundamentos necessário para embasar os procedimentos que serão utilizados no estudo de caso.

O levantamento também fará parte do conteúdo de materiais e métodos, fomentando equações e procedimentos adicionais mais específicos a cada um dos passos desejados de avaliação da viabilidade e posicionamento dos aproveitamentos na rede de distribuição de água.

Os levantamentos complementares foram propositadamente restritos ao módulo de materiais e métodos para facilitar a compreensão dos fundamentos básicos, sem carregá-los demasiadamente com uma série de equações, e fazendo com que na fase de desenvolvimento da técnica, o equacionamento não permanecesse sem fundamentação.

\section{- Estudo de Caso}

O estudo de caso é desenvolvido para avaliar de maneira mais direta e empírica o funcionamento dos equacionamentos e da efetiva viabilidade de aplicar a metodologia desenvolvida sobre uma rede real.

Neste módulo, a rede de distribuição de água do Município de Piquete será descrita, aplicando as ferramentas de avaliação e otimização dos aproveitamentos hidrelétricos de mini e micro dimensões, e instalando-os de modo fictício na rede.

A rede não sofreu qualquer intervenção física para estudo da metodologia. 


\section{- Rodada e Otimização de Modelos}

Para fundamentar e avaliar as questões e métodos propostos para este estudo, foram utilizados o modelo hidráulico de redes EPANET, e a otimização passo a passo dos cenários de instalação das turbinas propostas. Nesta última parte, de métodos e materiais, serão demonstrados os procedimentos utilizados para solucionar as questões relativas a viabilidade e dos benefícios esperados com a implantação dos mini e/ou micro aproveitamentos.

\subsection{Caracterização da área de estudo}

Ao iniciar os estudos de avaliação do potencial de aproveitamento mini e micro hidrelétrico em sistemas de abastecimento de água, devem ser levantadas as informações de terreno e localização da rede de distribuição. Neste procedimento ocorre uma pré-seleção das localidades com maior ou menor potencial, facilitando a escolha do local para aprimoramento dos estudos.

Caso o relevo da região onde o sistema está instalado seja menos acidentado e tendencialmente mais plana, o potencial aparentemente será mais baixo que aquele de uma rede localizada em terrenos mais acidentados e com grandes desníveis.

Como primeiro critério, o estudo preliminar da área deve ser abordado com visão crítica, não excluindo automaticamente as áreas de baixa variação de altitudes. Este cuidado deve ser tomado, pois elas serão estudadas nos demais passos da avaliação, e podem apresentar características que viabilizem o aproveitamento. 


\subsection{Caracterização da rede de distribuição}

A continuidade da avaliação de pontos de aproveitamento deve passar pela caracterização das curvas de demanda e verificação da configuração e singularidades hidráulicas das redes de distribuição.

A presença de sistemas de elevação e reservatórios distribuídos na malha da rede indica que existiu a necessidade de aumentar as pressões para suprir eventuais pontos que não atendam às normas brasileiras.

Sistemas que já tem instaladas válvulas redutoras de pressão são as redes que aparentemente tem o maior potencial de instalação, uma vez que as mesmas tem função compartilhada com a característica das turbinas na rede, que é a de redução das pressões.

Outros fatores a serem considerados são a disposição e configuração da rede instalada, sejam elas, ramificadas, malhadas ou mistas.

Oferecem maiores potenciais as redes de grandes dimensões e com vazões significativas e de grande solicitação. Redes ramificados tem maior facilidade de instalação frente as redes malhadas. As redes malhadas admitem que o fluxo mude de direção, prejudicando a instalação das turbinas, mas não excluindo a possibilidade de instalar equipamentos invertíveis.

Redes mistas englobam as duas possibilidades, sendo juntamente com as redes ramificadas as escolhas acertadas para o aprofundamento dos estudos. 


\subsection{Identificação dos pontos de maior pressão}

Para definir, com maior precisão, os aproveitamentos e sua viabilidade, identificar os pontos de maior pressão dá embasamento para definir 0 número de aproveitamentos, e consequentemente, o número de turbinas.

A localização dos pontos de maior pressão irá auxiliar também na definição de quais serão as configurações de instalação, obras civis e locação de espaço necessário para os aproveitamentos.

O cálculo das pressões utilizando modelagem matemática exige que a rede tenha detalhada ou que seja calculada a curva característica de demandas. Ela é obtida através da calibração e validação do modelo hidráulico da rede, utilizando informações de campo ou estimativas de consumo.

O modelo é então simulado para esta curva de consumo, obtendo os valores de pressão e vazão de projeto.

Após a construção do modelo e de rodadas de simulação, deve ser realizado o ordenamento das pressões encontradas de forma decrescente dos trechos e nós com maiores vazões e pressões.

Em seguida, deve ser realizado o cálculo do potencial de cada trecho, levando em conta as características do fluido em questão (água) para cálculo preliminar, que mais uma vez será ordenado de forma decrescente.

Com o potencial calculado, define-se um limite mínimo almejado para a potência de cada instalação. Este valor indica uma faixa de decisão, onde, trechos com potencial maior que o estipulado, serão considerados nos próximos passos do estudo, enquanto os demais serão descartados.

A escolha desta faixa leva em consideração o tamanho das centrais ou o número de turbinas que se deseja instalar.

Seguindo o ordenamento desta planilha, inicia-se o procedimento de definição e verificação das pressões em cada ponto da rede, modificados pela introdução das turbinas.

Desta forma, instalando um aproveitamento por vez, realiza-se a simulação passo a passo, permitindo que o tomador de decisão avalie os pontos mais adequados para a instalação e defina o número de turbinas a serem utilizadas de forma a não prejudicar as características de pressão e vazão de funcionamento da rede. 


\subsection{Identificação dos pontos de aproveitamento}

A definição dos pontos de aproveitamento depende de fatores relativamente simples, como vazão, pressão e tempo de funcionamento das turbinas. A vazão determina o volume de água que passará pelo sistema gerador e, portanto, é parte importante da curva de rendimento dos equipamentos geradores. Esta curva influencia diretamente a escolha não só dos equipamentos como da faixa ótima de funcionamento dos mesmos.

A pressão, por sua vez, compõe outro fator importantíssimo para a geração de energia, uma vez que determinará diretamente o potencial de geração das turbinas.

Outro fator que deve ser considerado na instalação de turbinas geradoras de pequeno porte na rede de distribuição de água é o tempo de funcionamento destes equipamentos.

A escolha do funcionamento se deve ao consumo de água ter um comportamento cíclico, com picos de consumo, portanto picos de vazão que coincidem com os menores valores de pressão em alguns pontos da rede.

A combinação destes três fatores não é uma tarefa simples. O funcionamento da rede de distribuição não proporciona a liberdade de apenas escolher os pontos de maiores pressões e vazões e instalar os equipamentos. Também devem ser analisados os valores combinados de todos os fatores, inclusive a perda de carga introduzida pelos equipamentos de geração.

Uma das alternativas mais utilizadas para reduzir os problemas de escolha dos locais de instalação é utilizar-se das posições das válvulas de redução de pressão para definir o ponto onde será instalada a turbina.

Isto ocorre porque a válvula redutora de pressão é um sistema protetor da rede, e alivia a pressão nos momentos mais críticos, ou seja, de maiores pressões e consequentemente maiores desníveis aproveitáveis.

Como o intuito deste trabalho é o de fornecer um procedimento que generalize a utilização das turbinas em qualquer tipo de rede de distribuição, decidiu-se apresentar algumas alternativas ao simples procedimento de tentativa e erro de modelagem empregado a seguir no estudo de caso.

As alternativas envolvem a apresentação de ferramentas de otimização do aproveitamento energético na rede, que possam ajudar na avaliação de redes mais complexas. 
Estas ferramentas tem a função de definir qual seria a configuração mais segura e com maior retorno de energia elétrica, sem prejudicar a o fornecimento de água para a população.

A otimização tem o objetivo de definir em quais pontos da rede, a perda de carga, pressão resultante, vazão e tempo de funcionamento dos equipamentos, melhor se adequa a rede estudada.

O procedimento que avalia as condições da rede, podem ser resolvidos por tentativa e erro. Caso a rede estudada tenha uma complexidade superior as demais, será necessária a ajuda das ferramentas de otimização mais complexas.

\subsection{Escolha dos equipamentos eletro mecânicos}

A escolha dos equipamentos eletromecânicos que constituem o aproveitamento hidrelétrico é fator vital para o bom funcionamento da rede de distribuição de água e para a geração de energia.

Segundo Ramos et al. (2010), para obter o melhor aproveitamento da geração em pequenas hidrelétricas, é possível obter bons resultados utilizando-se de Bombas como Turbinas (PATs) como solução para a instalação em rede.

Já Khosrowpanah et al. (1984), Fiuzat e Akerkar (1991), Desai e Aziz (1994), propõe a escolha de turbinas Crossflow, como sendo uma opção aos pequenos aproveitamentos, em substituição as válvulas redutoras de pressão (VRPs).

Estas duas propostas são bastante discutidas, já que o rendimento e aproveitamento hidrelétrico foram bastante estudados quando em substituição das VRPs.

Para o presente estudo, que generaliza a avaliação, não será adotado um tipo definido de turbina. A escolha da tipologia de turbina será parte atuante da tomada de decisão.

Assim, poderiam ser escolhidas conforme as pressões encontradas nos pontos da rede, da distribuição e atuação das turbinas na rede, definida pelo modelo de simulação utilizado.

O procedimento generalizado de escolha ajudará na determinação do tipo de equipamento eletromecânico, uma vez que as curvas de rendimento dos equipamentos serão consideradas como curvas limítrofes das zonas de melhor aproveitamento. A seleção será aprimorada a cada rodada de simulação do modelo 
hidráulico da rede por simples tentativa e erro, ou provenientes das ferramentas de otimização.

Desta forma, os resultados mais favoráveis demonstrarão quais turbinas devem ser utilizadas.

\subsection{Conexão dos elementos na rede de distribuição}

Seguindo as indicações da Resolução Normativa n482 de 2012 (ANEEL, 2012), existe a possibilidade de conexão direta do sistema gerador com a rede de distribuição de energia das concessionárias.

Deste modo, a conexão na rede de distribuição deve ser realizada apenas com 0 uso de um transformador, que fará a correção das tensões geradas para não haver oscilação na rede instalada.

Portanto, uma vez conectada na rede de distribuição, a contribuição do sistema gerador passa a fazer parte da energia distribuída pela empresa concessionária. Assim permite que o distribuidor de água tenha o abatimento nos seus custos de produção de água, mais uma vez dentro das determinações da Resolução Normativa 512 e 482.

Nesta etapa, a escolha dos locais de aproveitamento deve levar em conta a disponibilidade de espaço e a possibilidade de conectar, de modo eficaz e seguro, o sistema gerador à rede de distribuição mais próxima.

A disponibilidade de espaço se faz necessária para a instalação de inversor, transformador e alternadores, como demonstrado esquematicamente na Figura 29, a seguir. 


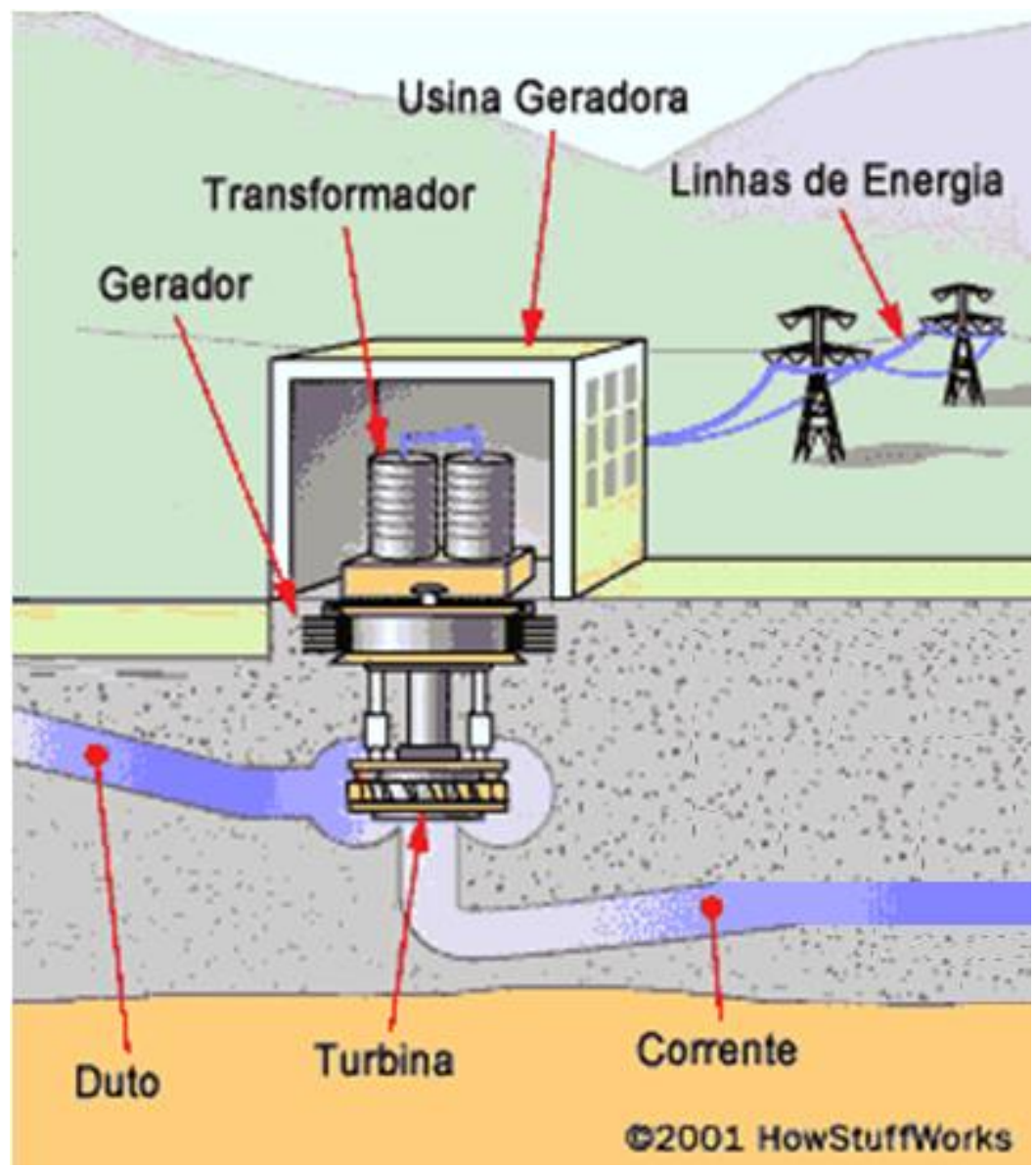

Figura 28 - Desenho esquemático da estrutura de conexão com a rede de energia. Fonte: Adaptada de HowStuffWorks 2001.

A conexão direta com a rede de distribuição deve ser o mais próximo possível da geração, uma vez que a transmissão de energia, além de gerar perdas, possui grande influência nos custos de implantação. 


\subsection{Comparação e correlação entre o consumo de água e a produção de energia}

Como já explicado anteriormente, a demanda de água varia com o tempo, tanto de forma sazonal quanto diária, e é regida pelas curvas características de demanda da rede.

Seguindo esta premissa, e analisando as pressões na rede ao longo do tempo, verifica-se que a relação entre pressão e vazão é inversamente proporcional. A pressão aumenta na medida em que a vazão se reduz, enquanto a redução da pressão representa um aumento na vazão.

A redução da pressão na rede em horários de alto consumo pode ser verificada a partir dos gráficos apresentados abaixo, gerado com uma simulação teste do modelo EPANET, e para a curva de demanda já previamente calibrada e validada para a rede utilizada.

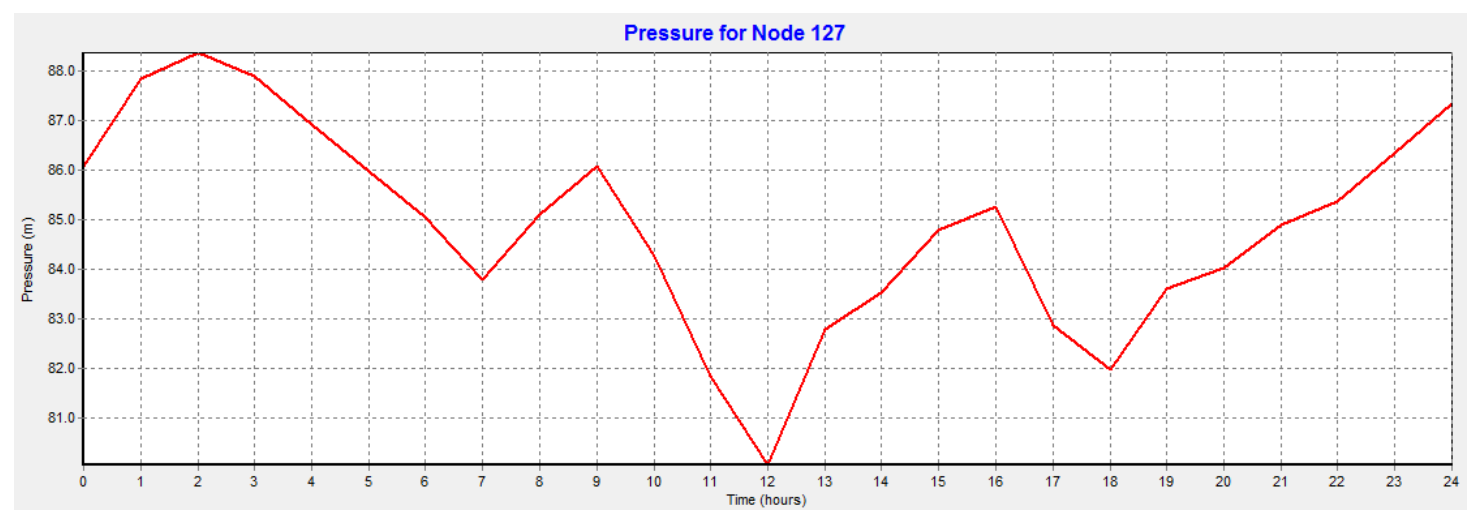

Figura 29 - Resultado das pressões ao longo de 24 horas.

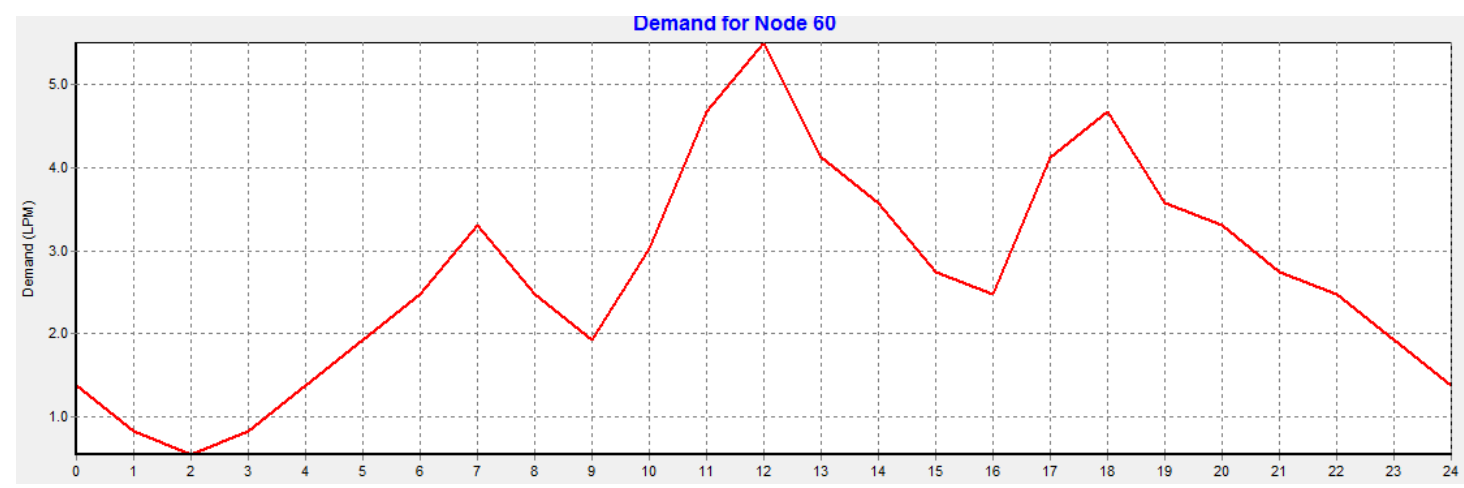

Figura 30 - Resultado da solicitação ao longo de 24 horas.

Com a flutuação das pressões segundo a vazão, é interessante avaliar os instantes em que é mais proveitoso acionar as turbinas e gerar energia. Com a ajuda de 
ferramentas de otimização é possível avaliar o tempo exato de acionamento conforme a demanda em cada ponto.

\subsection{Redução das pressões e perdas}

A redução das pressões é diretamente ligada à redução das perdas de água na rede de abastecimento. Ou seja, reduzindo a pressão serão reduzidas as perdas.

Como já explanado no módulo anterior no item 6 , o equacionamento proposto por Zyl et al. (2004), foca na verificação dos valores das perdas a partir de medições em campo para aferir os multiplicadores e expoentes da sua equação.

De forma simplificada, a equação proposta por Zyl et al. (2004), terá um papel essencial na análise de viabilidade dos aproveitamentos, pois introduz a participação das perdas de água no cálculo dos benefícios. Esse fato é proveniente da redução das pressões promovida pela introdução das perdas de carga promovidas pelas turbinas geradoras.

Esta parcela por si só pode garantir a instalação das mini e micro turbinas nas redes de distribuição, uma vez que o problema de perdas é um dos maiores enfrentados em qualquer sistema de abastecimento.

Os benefícios envolvidos em evitar as perdas transcende os ganhos financeiros e contribui com a manutenção das condições dos mananciais, evitando o desperdício do recurso hídrico e reduzindo o impacto da exploração de água.

Tais benefícios tem grande dificuldade de serem mensurados financeiramente, no entanto, o cálculo dos custos relacionados com a vazão perdida na rede podem ser realizados multiplicando o preço da água que seria cobrado pelas operadoras, com a vazão perdida.

A redução das perdas poderá então ser contabilizada como a diferença entre os gastos atuais com perdas com os futuros, com redução de perdas. Para a concessionária de águas isso representa a redução nos volumes transportados e tratados, reduzindo seu custo operacional.

Segundo dados da SNIS (2011), apresentados na Figura 31 a seguir, a relação das perdas é diretamente conectada ao faturamento das empresas de saneamento. 


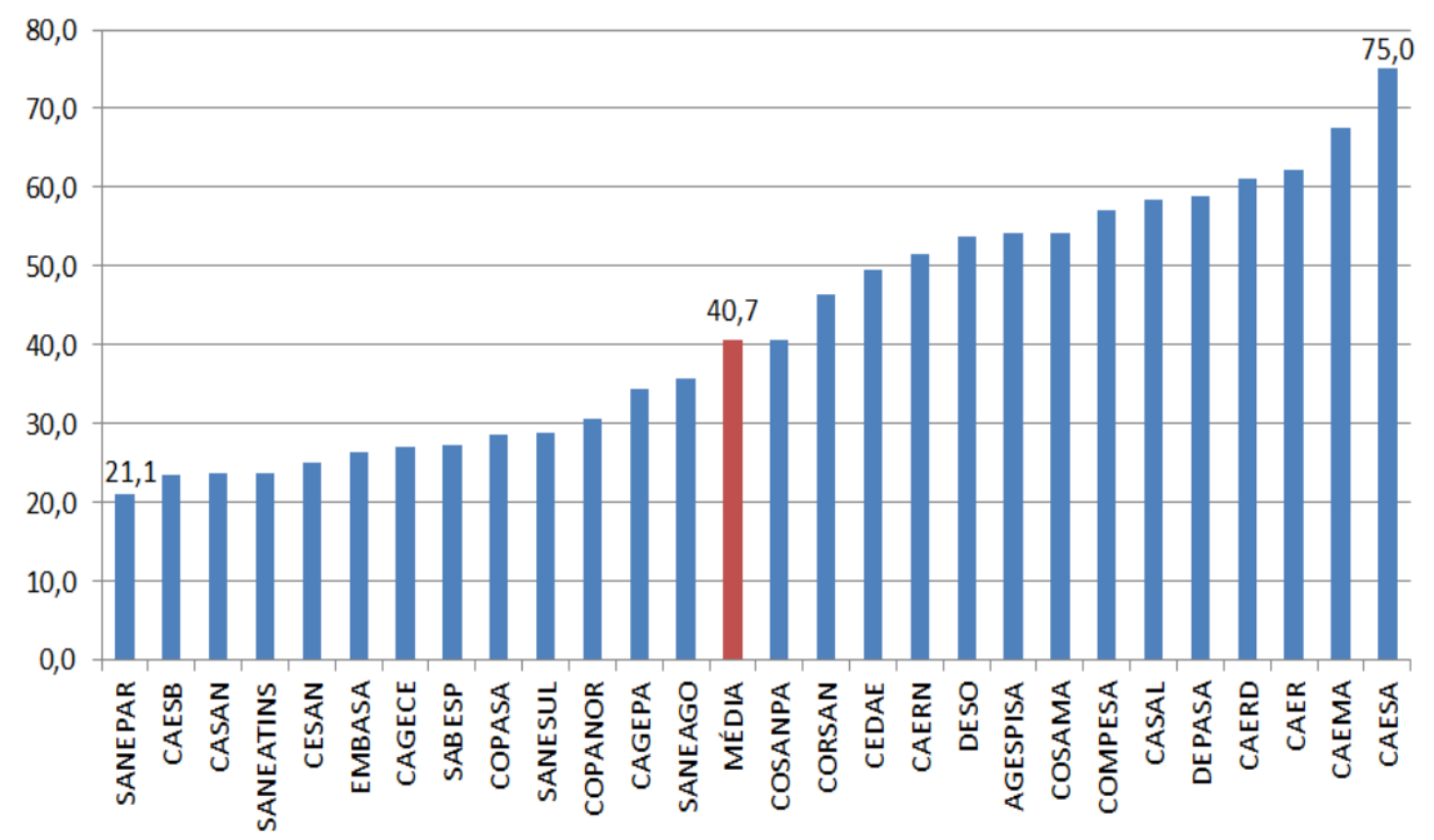

Figura 31 - Relação de perdas sobre o faturamento das principais empresas de saneamento.

Como se pode observar, as perdas podem chegar ao limite de representar $75,5 \%$ do faturamento, mas mantém-se em uma média de 40,7\% valor considerável se comparado a qualquer outro modelo de negócio que visa a lucratividade. 


\subsection{Desenvolvimento da metodologia de avaliação}

Mecanismos de otimização podem ser utilizados para viabilizar a avaliação do aproveitamento energético em redes complexas. A otimização facilita a escolha da configuração mais adequada em cada rede de distribuição, interpretando os resultados obtidos na modelagem hidráulica, e tomando decisões baseadas em funções objetivo e variáveis de decisão.

O principal resultado esperado é na maximização dos ganhos com a geração de energia, diretamente relacionado com 0 valor das pressões, compatibilizando a influência deste aproveitamento na rede de distribuição para que as necessidades de abastecimento sejam atendidas a qualquer instante.

Ao mesmo tempo, este procedimento eleva a capacidade de geração e escolhe a localização das turbinas para o melhor aproveitamento do potencial existente ao longo do tempo.

Como a geração de energia sofre flutuações diárias conforme as curvas de demanda no sistema de distribuição de água, os melhores momentos para o acionamento das turbinas também pode ser otimizado, garantindo 0 funcionamento na faixa de maior rendimento das turbinas.

Assim sendo, o funcionamento das turbinas deve ser compatibilizado com as condições de pressão e de consumo em que são utilizadas, fazendo com que elas sejam acionadas ou não, dependendo da necessidade e das condições ótimas de funcionamento do equipamento e da rede.

O acionamento ou não de cada uma das turbinas depende das condições de vazão em cada instante estudado e do funcionamento dos demais dispositivos na rede em conjunto.

Considerando a rede de distribuição de água como uma rede com diversos condutos e dispositivos hidráulicos controlados de modo independente, otimizar seu funcionamento privilegia a função de fornecimento de água, enquanto dimensiona a nova função de geração de energia proposta.

É possível imaginar a criação de uma metodologia capaz de unir todos os detalhes do seu funcionamento em um único modelo de otimização.

A atualização constante das redes, contemplando os novos desenvolvimentos e a possível introdução de novas estruturas de geração 
deve ser continua e compreende a fase de planejamento estratégico.

Desta forma, propõe-se formular uma metodologia, que engloba todas as etapas de otimização necessárias, e dimensiona a instalação de um sistema gerador disperso na rede de distribuição de água, que possa ser operado para as melhores condições possíveis.

A metodologia proposta resultou no seguinte fluxograma de atividades, apresentado na Figura 32.

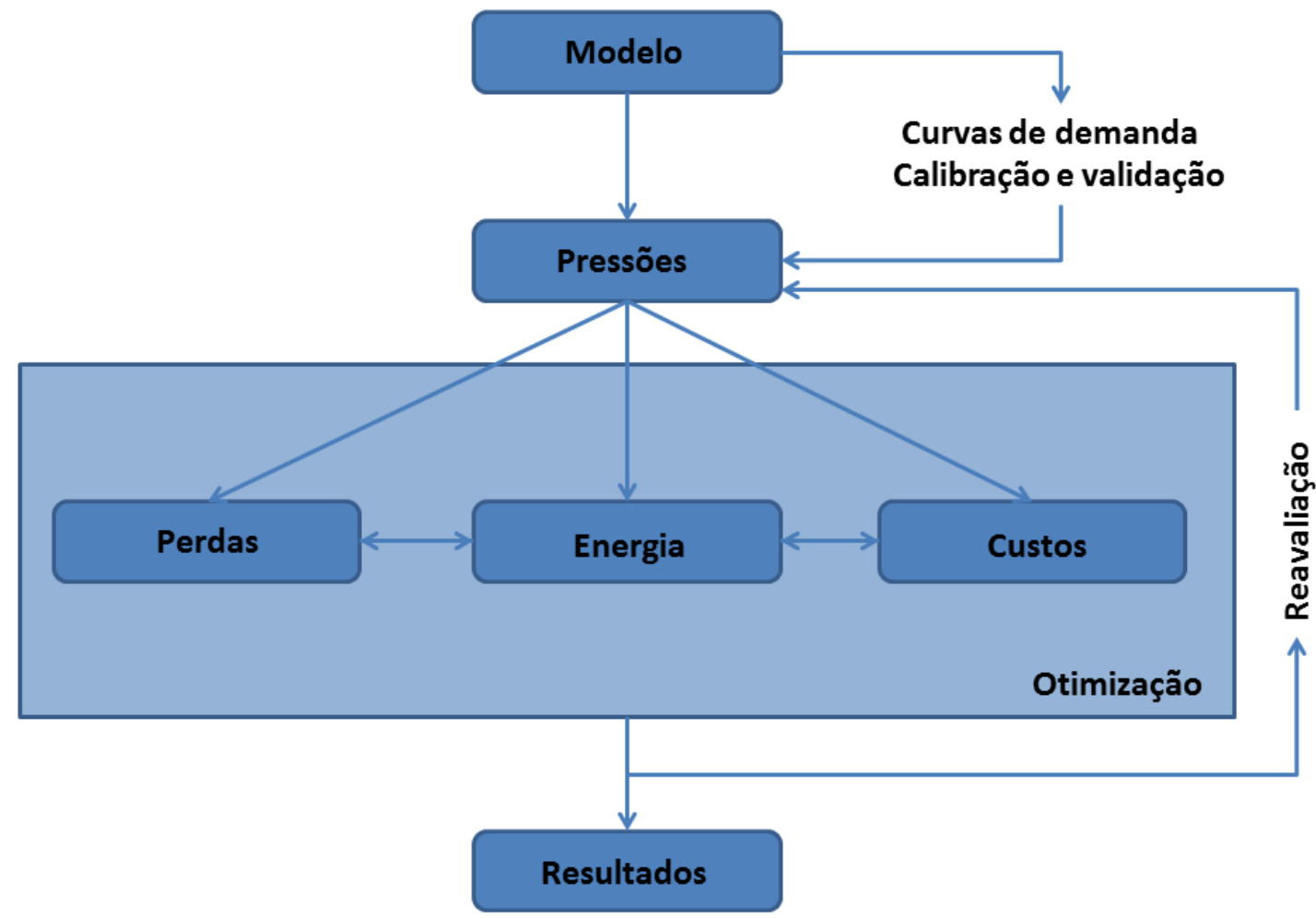

Figura 32 - Fluxograma de dados para otimização

O método engloba as ferramentas de otimização, e tem como função estabelecer as relações entre os mais diversos componentes da rede, e otimizar seu funcionamento, facilitando a tomada de decisões e o acionamento ou não dos equipamentos envolvidos.

As ferramentas de otimização incorporadas ao método serão próximas àqueles demonstradas anteriormente, fazendo frente aos diferentes objetivos desejados com a implantação dos sistemas de geração. No entanto, o procedimento apresentado a seguir no estudo de caso foi reduzido a ferramentas simplificadas, sendo desenvolvidas pela falta de acesso a uma ferramenta que conecte diretamente a otimização ao modelo EPANET. 
O processo, portanto será iterativo, otimizando e aplicando as modificações manualmente no modelo por tentativas, enquanto em redes mais complexas deve-se adotar a otimização com outras ferramentas igualmente complexas e modelos computacionais.

Na sequência será descrita cada etapa da metodologia.

Eles terão como principais características incorporar os seguintes objetivos:

- Definição do número de unidades geradoras a serem instaladas

- Localização das unidades geradoras

- Redução das perdas

- Maximização da geração de energia

- Redução dos custos de operação da rede de distribuição

Para tanto, utilizou-se da seguinte metodologia para caracterização das redes de distribuição descrita por Burgshweiger et al.(2005).

Primeiramente, consideram-se as pressões como sendo relação entre a diferença da elevação e pressão mínima, uma vez que considera-se a água incompressível.

As pressões são então calculadas a partir da simulação do modelo hidráulico utilizando a curva de demandas, definindo um limite máximo e mínimo para a verificação das condições de funcionamento da rede.

Como a pressão esta diretamente associada a curva de demanda, a escolha do instante onde os valores da pressão são mais baixos e mais altos, indica a faixa de pressões que a rede admite.

Desta forma, a otimização trabalhará sempre com valores razoáveis e dentro dos limites da NBR 12218 (1994).

Quando necessário, é interessante introduzir novas condições de contorno para restringir o conjunto de resultados possíveis e tornar o procedimento mais ágil.

Para definir o posicionamento das unidades geradoras, foi desenvolvida uma metodologia própria para facilitar a manipulação dos dados em cada ponto da rede de distribuição.

A metodologia simplificada agrupa os resultados de pressões e vazões em uma única tabela que foi trabalhada para que os dados fossem organizados por trechos de rede que ligam um ponto $A$ e um ponto $B$.

Desta forma, para cada trecho foram relacionados, seu ponto de entrada e 
saída, o comprimento, perda de carga $(\Delta \mathrm{H})$ e vazão $(\mathrm{Q})$.

Após realizada a organização, foi possível calcular a potência aproximada dos aproveitamentos, utilizando a equação simplificada:

$$
P=\Delta \mathrm{H} * \mathrm{Q} * \rho * \mathrm{~g}
$$

A lista de trechos é, então, classificada quanto ao potencial possível em ordem decrescente, determinando um limite do número de turbinas a ser utilizado ou quanto a potência mínima desejada para cada unidade.

As turbinas selecionadas são então instaladas manualmente no modelo de rede e simulada para verificar se as condições de contorno de pressão são satisfeitas.

Com esse procedimento, desloca-se a variável $\Delta H$ entre seus valores limites, modificando a diferença das pressões por meio da inclusão da perda de carga de cada turbina.

Inicialmente é possível que todos os trechos da rede estudada sejam admitidos como trechos com potencial de aproveitamento, no entanto devendo passar pela verificação descrita acima.

Em redes mais complexas, este procedimento se restringirá a estrutura de otimização por meio de ajustes realizados em um modelo de otimização adotado, não mais de forma manual.

O desenvolvimento em redes mais complexas modifica a quantidade de parâmetros a serem calculados, considerando redes ramificadas, malhadas ou mistas, deixando a avaliação mais complexa conforme aumenta o número de turbinas e aumenta o número de variáveis a serem consideradas.

Definido o número e posição das turbinas, inclui-se ao equacionamento a variável n, que representa o número de unidades desejadas.

Este número representa o índice de cada unidade, e identificara em uma representação gráfica a localização dos aproveitamentos, uma vez que o valor dos potenciais está conectado com cada trecho do modelo e, consequentemente, com a localização dos condutos onde serão implantadas as turbinas.

Com a definição de "n", serão satisfeitos dois dos cinco passos propostos para a otimização dos aproveitamentos, o número de unidades geradoras e 
localização das unidades.

Como o critério de escolha de "n" é diretamente relacionado com a redução das perdas em cada trecho da rede, é necessário ressaltar que ela será calculada através das equações de perda de carga do modelo EPANET.

As perdas de água na rede e pressões são diretamente conectadas. $A$ otimização da equação de perdas utilizada pelo modelo EPANET, é realizada variando a adição de uma perda de carga nos trechos indicados para o aproveitamento.

No estudo de caso a seguir foram usadas as equações de Chezy-Manning, para que fossem reduzidas as variáveis a serem inclusas. Utilizar as fórmulas de Hazen-Williams ou Darcy-Wiesbach também satisfaria as necessidades da otimização, mas optou-se em manter o equacionamento de ChezyManning por ser o método utilizado pela gestora da rede do estudo de caso para calcular as perdas com o EPANET.

$$
h_{l}=A \cdot q^{B}
$$

onde :

$\mathrm{hl}$ - Perda de carga

A - Coeficiente de resistência

$q$ - Vazão

B - Expoente de vazão

Sendo:

$$
A=4,66 . n^{2} d^{-5,33} L
$$

$\mathrm{n}, \mathrm{d}$ e L, respectivamente o coeficiente de rugosidade, diâmetro do conduto e comprimento do conduto.

Dando continuidade aos procedimentos iniciais para a análise da rede, após identificar os pontos possíveis de aproveitamento, é necessário identificar o caminho crítico do ponto mais a jusante com menor pressão (i, ponto de pressão crítica) até o ponto onde ocorre o aproveitamento.

Este caminho será identificado por quantos nós do modelo existirem entre estes dois pontos $(\mathrm{Nn})$ e pelo índice que identifica os aproveitamentos (n).

Para visualizar o procedimento será apresentada uma rede simplificada, sobre a qual serão exemplificados. 
Ela é uma rede ramificada, apenas para facilitar a descrição, enquanto é possível utilizar o caminho crítico para qualquer tipo de rede.

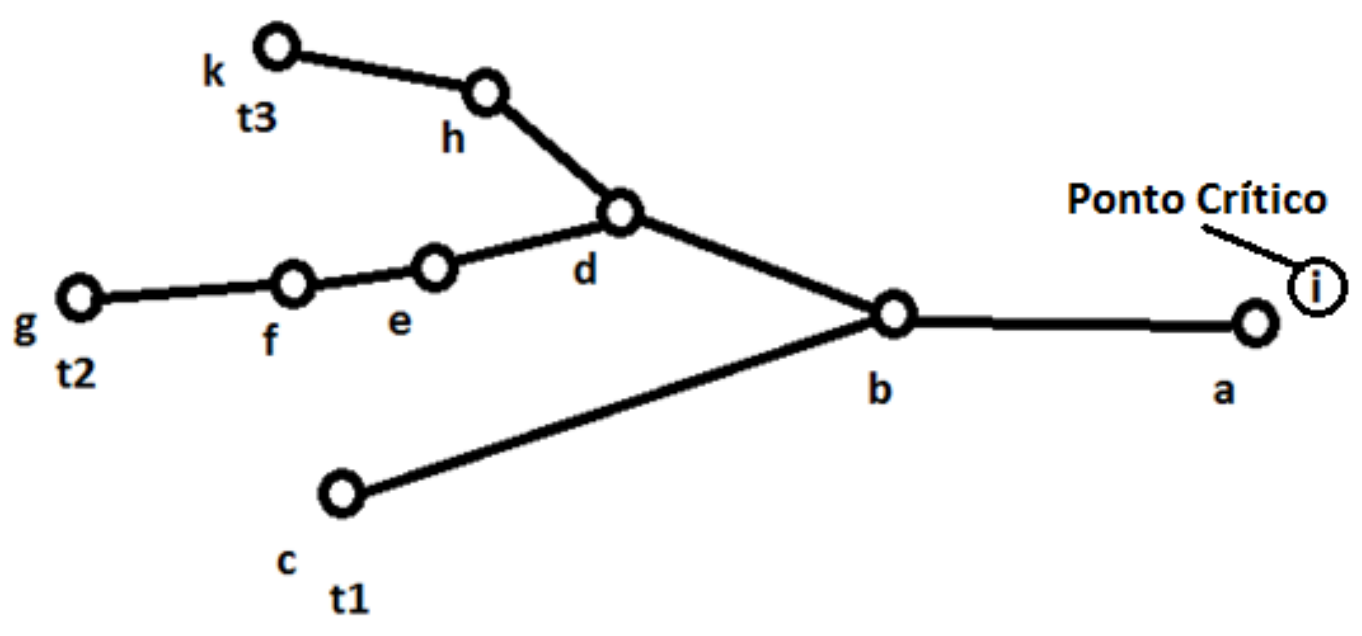

Figura 33 - Representação simplificada de uma rede para modelagem matemática

No exemplo fictício apresentado na Figura 33 os valores de $n$ e $\mathrm{N}$ seriam, $\mathrm{n}=1,2,3$ e $\mathrm{N} 1=2, \mathrm{~N} 2=5, \mathrm{~N} 3=4$, representando respectivamente os caminhos para os três aproveitamentos $\mathrm{t} 1$, t2 e t3.

O ponto i é aquele de menor pressão de toda a rede (ponto crítico). Ele será considerado como o limitante para a redução nas pressões ao longo da rede. Considera-se que a otimização das perdas se conecta diretamente com o cálculo do potencial de aproveitamento energético da rede. Ele pode ser simplificado com a introdução de uma perda de carga localizada com a introdução das turbinas (he).

Desta forma, o equacionamento será relativo à otimização da combinação de todos os caminhos possíveis atendendo às condições de contorno, hi $\geq 10$ m.c.a.

Maximiza-se, portanto, as perdas de carga introduzidas pelas mini e micro turbinas, obedecendo às condições de vazão e pressão.

Desta forma é calculado no caminho critico, percorrendo do aproveitamento até o ponto de menor pressão, a pressão resultante no próximo nó (a,b,c,d,e,f,g,h,k).

Caso o nó seja compartilhado entre caminhos críticos, será adotada a menor pressão obtida (como os nós d e b do exemplo).

Assim, utilizando a perda de carga gerada pela turbina (he), o modelo será 
ajustado para aproveitar plenamente as pressões disponíveis, e eliminará qualquer aproveitamento que seja prejudicial à máxima geração de energia.

Esta função de seleção e otimização foi realizada com a ajuda de planilha Excel, no qual introduziu-se o termo condicional "se", para variar entre os caminhos, aplicando o menor valor conferido pelas diferenças entre os " $n$ " aos cálculos de pressão.

Sendo os nós identificados a partir do IDs alfabéticos, teremos os caminhos críticos:

$\mathrm{N} 1-\mathrm{a}, \mathrm{b}, \mathrm{c}$

$\mathrm{N} 2-\mathrm{a}, \mathrm{b}, \mathrm{d}, \mathrm{e}, \mathrm{f}, \mathrm{g}$

N3 - a, b, d, h, k

Para Nn

$$
h_{n-1}=h_{n}-h l-h e
$$

Se d3<d2;d3;d2

Se $b 3<b 2<b 1 ; b 3 ; b 2 ; b 1$

$a=h i=h c t r i=10$ m.c.a.

Maximizando a equação que faz a diferença entre a situação das pressões antes e depois da instalação das turbinas, e tendo como variável he, obtémse o valor ótimo de he para todos os aproveitamentos da rede, evitando perdas e maximizando a produção de energia.

$$
\text { Máx } H=N n\left|\sum_{j-i}^{j}(h l+h e)_{n}-\sum_{j-i}^{j} h l_{n}\right|_{1}^{N}
$$

Onde:

H - Diferença de pressão na rede, com e sem turbinas

hl - Perda de carga no conduto

he - Perda de carga pelo aproveitamento

j- Nó de jusante

i - Nó de menor pressão

$\mathrm{n}$ - Caminho até a turbina " $\mathrm{n}$ "

Os trechos modelados onde não está presente nenhum tipo de turbina terá he $=0$, portanto encaminhando o cálculo para que he máximo esteja concentrado em apenas um ponto.

Seguindo a mesma linha, e aproveitando a otimização das perdas, é possível 
relacionar he ao equacionamento da otimização da geração de energia, que é otimizada variando também he e obedecendo à condição hi $\geq$ hcrit $=10$ m.c.a.

$$
\text { Máx } P=\rho \cdot g \cdot(\text { he }) \cdot Q_{\text {tur }} \cdot \eta_{\text {tur }} \cdot \eta_{\text {ger }}
$$

Com he $=h_{n}-h_{n-1}-h l$

A variação de he é considerada também no cálculo dos custo e benefícios envolvidos na instalação das turbinas. Conforme equacionamento de perdas e de potência, pode-se agregar ambas equações na equação de lucros totais. Ela será a função objetivo para maximizar os lucros obtidos e é apresentada a seguir.

$$
\text { Máx } D_{\text {lucro totais }}=D_{\text {lucro }}+C_{\text {água }} \cdot\left(Q_{\text {Perdas }}\right)-C_{\text {Equip }}(N)
$$

onde :

$$
\begin{gathered}
D_{\text {lucro }}=P_{\text {água }} \cdot\left(Q_{\text {Servida }}\right)-C_{\text {água }}\left(Q_{\text {Servida }}+Q_{\text {Perdas }}\right)-C_{\text {Energia }}(t) \cdot\left(Q_{\text {Bombeada }}(t)\right) \\
+C_{\text {Energia }}(t) \cdot\left(Q_{\text {Turbinada }}\right)
\end{gathered}
$$

e,

$$
\begin{gathered}
Q_{\text {perdas }}=7,5 \cdot\left(h e(t)^{\alpha}\right) \\
Q_{\text {tur }}=\frac{P}{\rho \cdot g \cdot(\text { he }) \cdot \eta_{\text {tur }} \cdot \eta_{\text {ger }}}
\end{gathered}
$$

$P_{\text {água }}$ - Tarifa da água para os consumidores em $\mathrm{R} \$ / \mathrm{m}^{3}$

$C_{\text {água }}$ - Custo da água para a distribuidora em $\mathrm{R} \$ / \mathrm{m}^{3}$

$C_{\text {Energia }}(t)$ - Custos de energia variável no tempo em $\mathrm{R} \$ / \mathrm{kW}$

$C_{\text {Equip }}(N)$ - Custo de implantação de cada unidade de aproveitamento em $\mathrm{R} \$$

$Q_{\text {Servida }}$ - Vazão entregue aos consumidores em $\mathrm{m}^{3}$

$Q_{\text {Perdas }}$ - Vazão de perdas na rede em $\mathrm{m}^{3}$

$Q_{\text {Bombeada }}(t)$ - Vazão bombeada para recarga dos reservatórios em $\mathrm{m}^{3}$

$Q_{\text {Turbinada }}$ - Vazão turbinada em $\mathrm{m}^{3}$

As vazões turbinada e de perdas dependem do acionamento das turbinas, e variam conforme a leitura de pressão na rede de distribuição. Desta forma, variando he, o 
valor dos lucros com a instalação são otimizados, dando como resultado as informações necessárias para o dimensionamento e avaliação dos benefícios e custos envolvidos.

\subsection{Viabilidade e restrições}

A viabilidade de um aproveitamento na rede de distribuição de água para recuperar energia elétrica é dependente de diversos fatores que devem ser considerados em um cenário atual e futuro. Assim será possível ter resultados conclusivos sobre a real possibilidade de aproveitar a energia.

São consideradas como condições de contorno para a otimização, as características necessárias para o bom funcionamento do sistema de distribuição de água, não privando-o de suas características de projeto e das necessidades existentes para manter as mínimas condições de qualidade e quantidade de água para o consumo.

Dentro destas características, são importantes, como citado, a manutenção das pressões e da qualidade da água transportada. A qualidade da água não deve ser afetada e portanto deve-se considerar estruturas de recuperação da energia que não a contaminem.

No entanto, para a simulação da viabilidade econômica e técnica da solução de instalação das turbinas, é interessante que este fator seja considerado como já obedecido, uma vez que não seria possível a implantação sem que este critério mínimo fosse atingido.

Considerando as pressões, os critérios técnicos estabelecem que seus valores mínimos e máximos desejados para a rede de distribuição e para os ramais de consumo não sejam inferiores a 10 metros de coluna d'água e não superiores a 50 metros de coluna d'água.

Existe a necessidade de verificar, segundo as demandas de água dos consumidores ao longo do dia, se o sistema gerador não afeta as condições básicas apresentadas. Além disso, verificar se o acionamento e configuração de instalação destes equipamentos pode ser implantada de forma a melhor aproveitar a variação de vazões e pressões, sem que sejam impostas reduções na eficiência da geração.

Como a consideração destes fatores impacta diretamente na produção de energia, foi possível desenvolver uma equação que relaciona as pressões e o retorno obtido com a produção de energia. 
Como levantado anteriormente, as condições legais no país determinam que a energia não poderá ser comercializada, e que deverá ser apenas compensada da energia consumida pelo mesmo detentor do CPF ou CNPJ que produziu a energia. Assim sendo, o retorno será decorrente do abatimento do consumo de energia, o que implica em utilizar os preços da energia comercializada diretamente ao consumidor final e não o preço da energia pago pelos geradores de energia. Este fato vem em beneficio dos ganhos, uma vez que o preço da energia que é vendida para o sistema de distribuição é menor do que aquele pago pelos consumidores finais.

Vilanova e Balestieri (2014) descrevem que a estimativa dos benefícios econômicos do aproveitamento de energia, deve ser realizada em uma primeira analise econômica que considera a média dos gastos com energia no sistema de abastecimento, uma vez que a normativa determina a compensação da energia gerada de forma distribuída.

Como descrito anteriormente, o sistema de compensação utilizado nas normativas, refere-se a troca de unidades de energia, ou seja, não permite a venda direta da energia gerada para que ela contribua para a sustentação da rede de energia. Ela contribui para o abatimento dos gastos com energia efetivos do consumidor produtor.

Esta compensação unitária, troca a necessidade de pagar por uma unidade de energia que o consumidor produziu, respeitando todas as flutuações tarifárias de forma horária, e sazonal.

Para exemplificar o procedimento de analise econômica Vilanova e Balestieri (2014), estudaram duas unidade do sistema de abastecimento de água de Itajubá, nas quais foram propostos sistemas de geração de energia. Foi verificada a possibilidade não só de compensar os gastos com energia do sistema, como também gerar energia para abater os custos decorrentes do consumo em outras atividades do mesmo proprietário da rede.

Deve-se também ser levado em conta, na otimização dos benefícios de um empreendimento que aproveita a energia das redes de distribuição de água, a possível e provável redução das perdas d'água na rede.

Isso porque o sistema de turbinas funcionará de modo semelhante às VRPs, o que reduziria as perdas levando em conta que a redução de pressões está diretamente ligada à redução das perdas. 
Desta forma, a viabilidade de implantação dos sistemas geradores passa pela soma de todos os benefícios acarretados tanto quanto a subtração das restrições sob as quais foram submetidos os aproveitamentos. 


\section{ESTUDO DE CASO}

\subsection{Caracterização da área de estudo do Município de Piquete}

O Município de Piquete está situado na porção central do vale médio do Rio Paraíba no Estado de São Paulo, entre o trajeto da Cidade de São Paulo ao Rio de Janeiro pela via Dutra. Ele (município) se encontra assentado nas encostas da Serra da Mantiqueira e com grande parte de seu território dentro de uma área de preservação ambiental de mata atlântica.

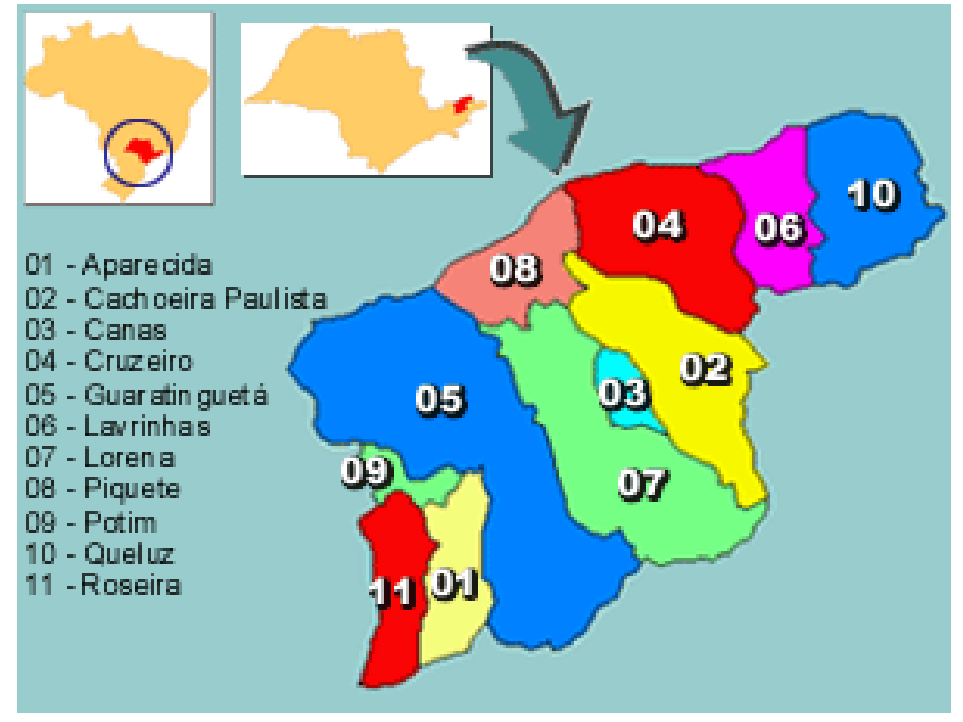

Figura 34 - Microrregião de Guaratinguetá e localização do Município de Piquete. Fonte: City Brazil

O Município faz limites com os municípios de Delfim Moreira ao norte, Lorena e Cachoeira Paulista ao sul, Guaratinguetá e Aparecida a oeste e Cruzeiro ao leste. Possui $176 \mathrm{~km}^{2}$ e 14.709 habitantes, resultando em uma densidade demográfica de $86,29 \mathrm{hab} / \mathrm{km}^{2}$ (IBGE, 2009).

Piquete tem sua economia estruturada na indústria e no setor de serviços, e em menor grau na agropecuária. $O$ setor de serviços responde por $74 \%$ do valor adicionado do município e ocupa $43 \%$ da mão de obra. A indústria responde por $20,7 \%$ e ocupa $45 \%$ da mão de obra, enquanto o agropecuário consiste de $5,3 \%$ do valor adicionado e ocupa $1,8 \%$ da mão de obra. Com esta configuração o PIB do Município é de $\mathrm{R} \$ 104$ milhões. 


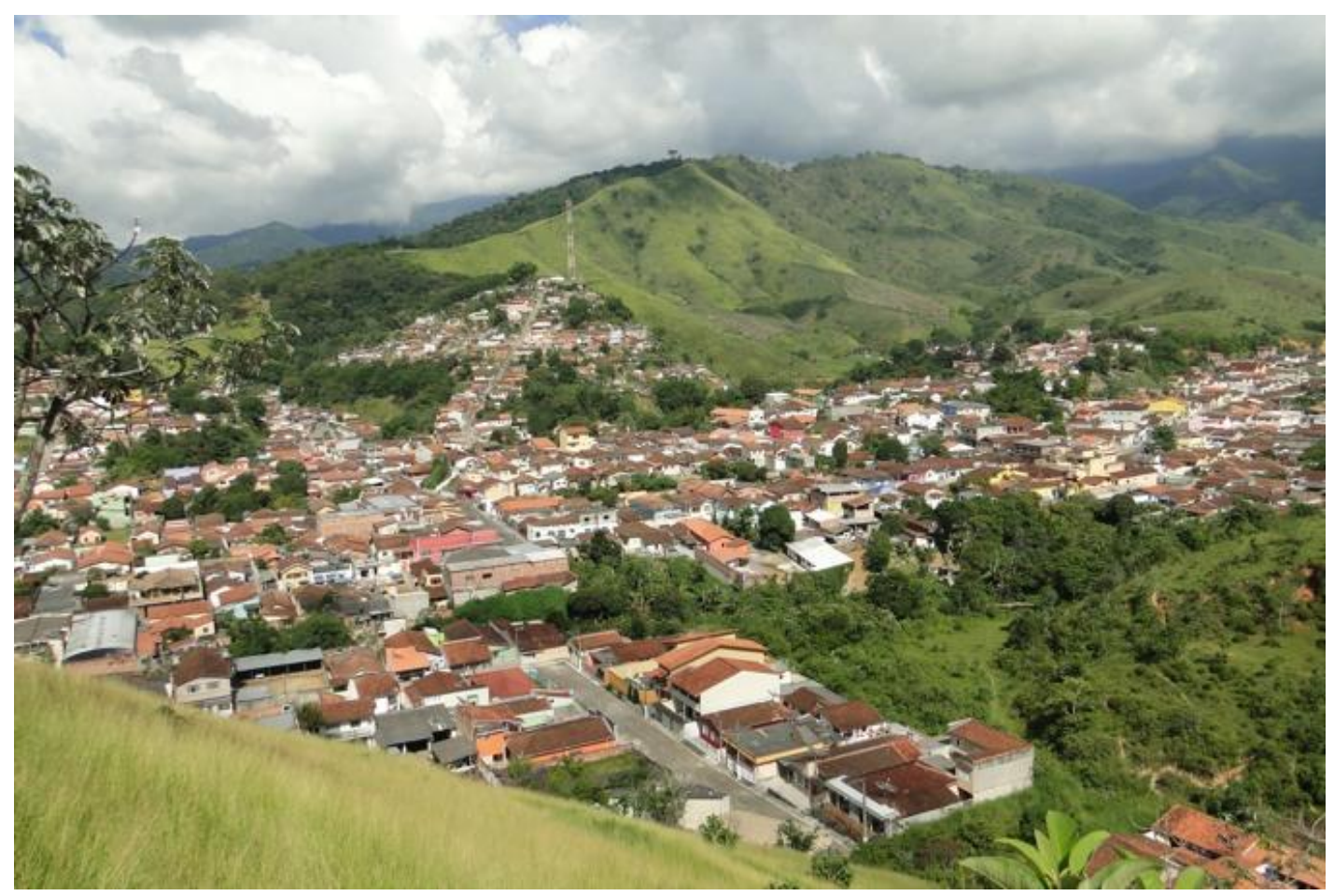

Figura 35 - Fotografia do relevo do Município de Piquete. Fonte: CAB Piquete

O relevo do Município é bastante acidentado, por estar localizado na serra da Mantiqueira, que possui elevadas escarpas e morros isolados (Prefeitura de Piquete, 2013), o que torna as condições favoráveis ao aproveitamento energético proposto neste trabalho. Na Figura 36, é possível notar a irregularidade do relevo do município.

É onde o planalto sul-mineiro termina diante do vale do Paraíba do Sul. Os desníveis compreendidos entre as cristas da serra e as planícies torna o relevo o mais abrupto do estado de São Paulo. Na área rural, localizam-se os picos, enquanto no perímetro urbano, os valores de cota são menos variáveis, mas permanecendo bastante acidentado, com cotas variando de 600 a 740 metros.

Em virtude deste relevo, as precipitações que atingem o Município, na ordem de $1720 \mathrm{~mm} / \mathrm{ano}$, causam frequentemente danos à cidade, uma vez que o escoamento tem tempo de concentração baixo, fazendo com que as vazões variem rapidamente e alcançando uma grande amplitude. 


\subsection{Caracterização rede de distribuição do Município de Piquete}

As características da rede de abastecimento do Município de Piquete foram fornecidas pela empresa gestora do sistema, CAB Piquete, disponibilizando os dados e as dimensões do seu sistema de abastecimento e distribuição.

Para tanto foram fornecidas as medidas de comprimentos, diâmetros, sistemas elevatórios, dimensão dos reservatórios, pontos de consumo e curva característica de demanda devidamente calibrada e validada.

O Município de Piquete é abastecido atualmente por três mananciais, sendo eles o Ribeirão Benfica, o Córrego da Tabuleta e o Ribeirão Piquete que estão situados na bacia hidrográfica Paraíba do Sul. Além dos mananciais, a cidade possui dois poços para abastecer alguns bairros descentralizados da cidade.
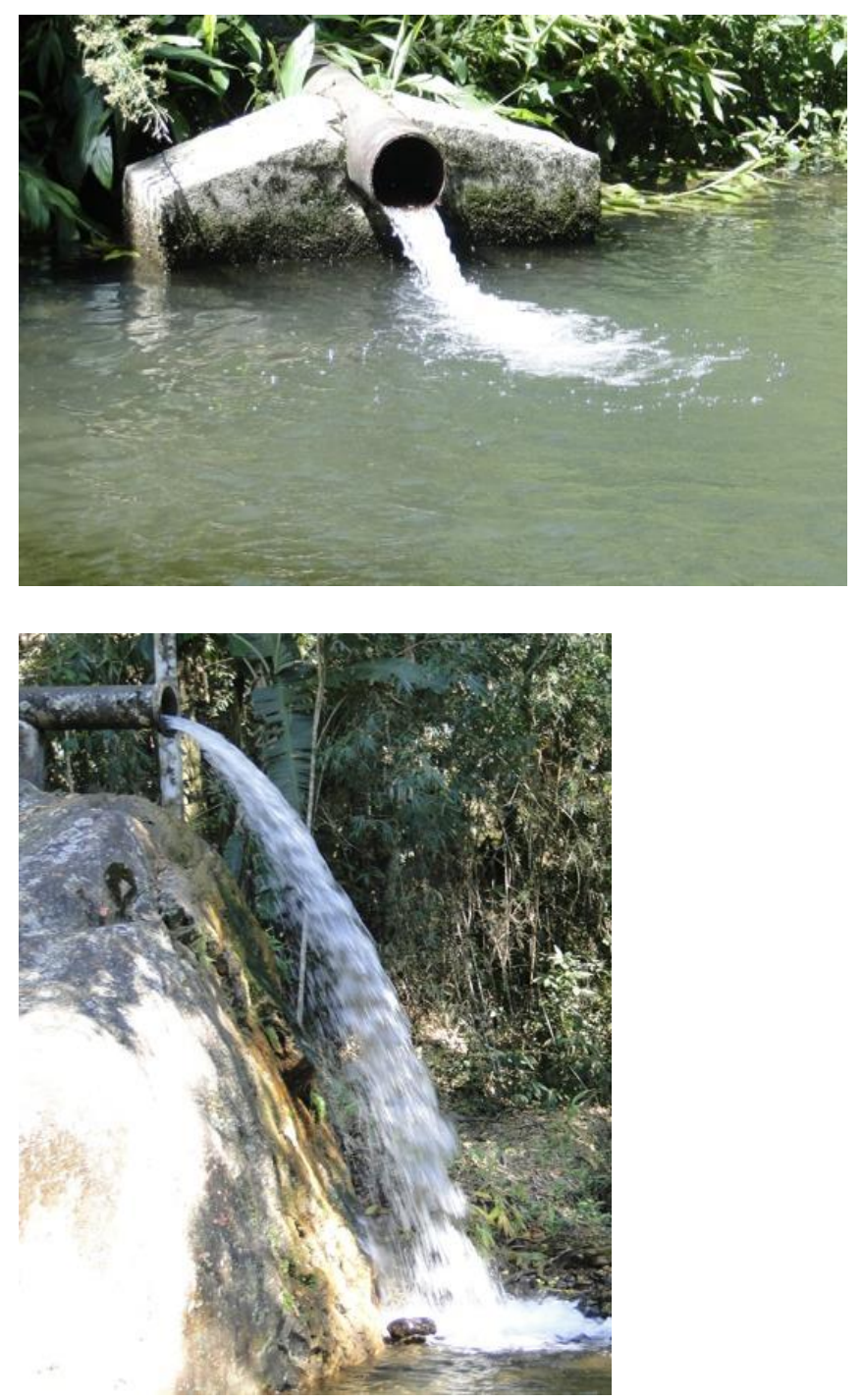

Figura 36- Mananciais do Município de Piquete Fonte: CAB Piquete 
Considerando que o consumo de água é equivalente ao de cidades com perfil predominantemente residencial, ele tende a aumentar no verão e reduzir no inverno. No entanto, a cidade tem uma flutuação populacional devido as suas características turísticas. Considerando este fator, a demanda será prioritariamente função da população nos períodos do ano, do que do perfil de consumo da população residencial fixa.

Portanto, segundo a SABESP/BBL (1999), na análise de dimensionamento do sistema de abastecimento, devem ser considerados os dados de macromedição dos últimos 12 meses.

Para os estudos, no entanto, foi possível utilizar as curvas de demanda fornecidas, uma vez que estas foram disponibilizadas pela gestora do sistema. Assim sendo, foram realizados os cálculos de demanda baseados no perfil de consumo de uma população com perfil residencial da cidade já calibrado. 


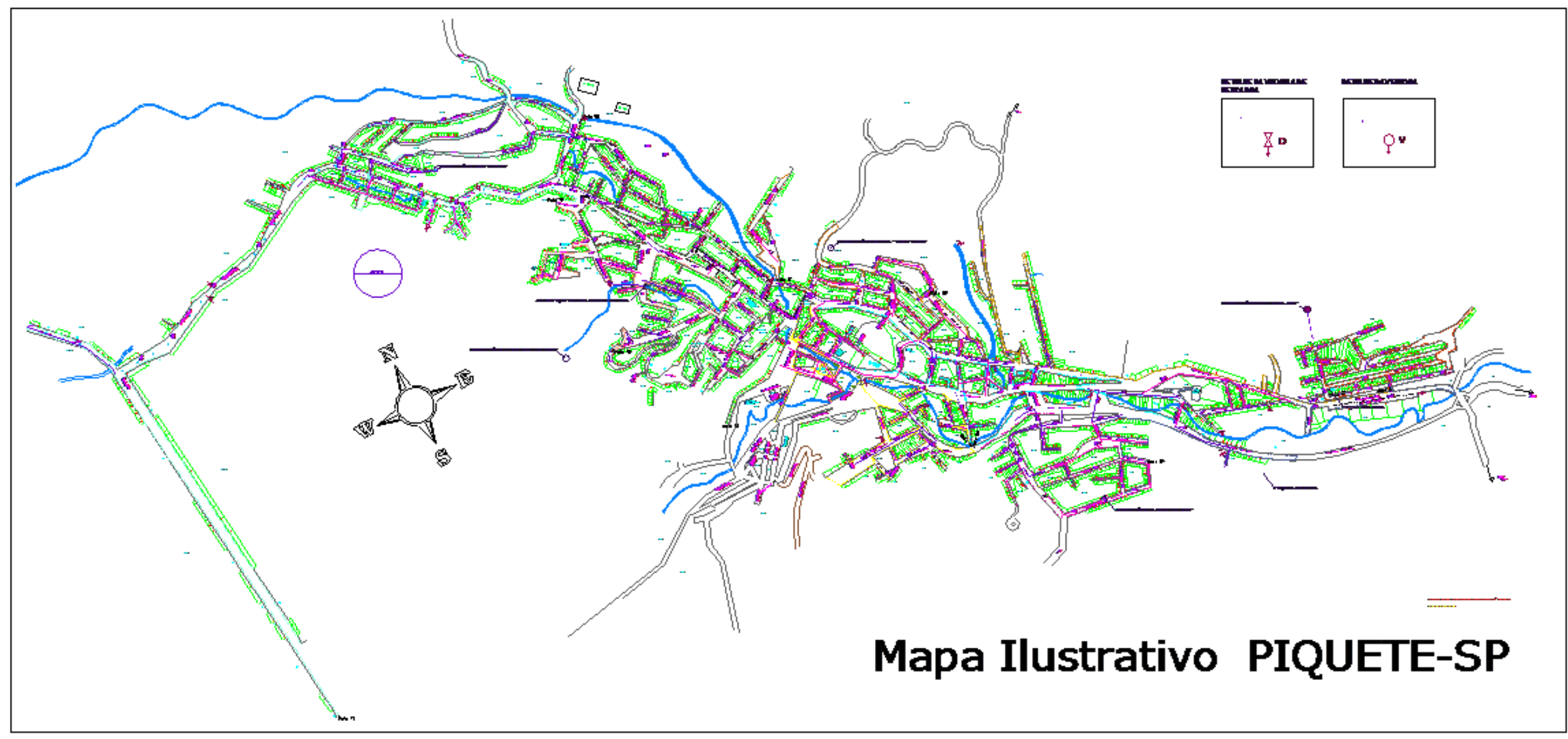

Figura 37- Esquema da rede de distribuição do Município de Piquete. Fonte: CAB Piquete 
Atualmente, o sistema de abastecimento de água de Piquete conta com uma estação de tratamento de água localizada no bairro da Tabuleta, com capacidade de tratamento de $67 \mathrm{l} / \mathrm{s}$, e dois poços que abastecem dois bairros da cidade, o Poço Vila Cristina e o Poço Santa Isabel. Existe também um poço que foi desativado, e se encontra mais próximo ao centro da cidade, o Poço EEAT Alto da Bela Vista.

Na rede estão presentes cinco reservatórios:

- Reservatório Santa Isabel $300 \mathrm{~m}^{3}$

- Reservatório Vila Cristina $250 \mathrm{~m}^{3}$

- Reservatório Central $1200+600 \mathrm{~m}^{3}$

- Reservatório Josefina $290 \mathrm{~m}^{3}$

- Reservatório Alto da Bela Vista $200 \mathrm{~m}^{3}$, único abastecido por meio de bomba Os reservatórios tem a função de regularizar o fluxo na rede, permitindo que o abastecimento seja constante, mesmo em picos de consumo.

\subsection{Identificação dos pontos de maior pressão}

Usando da ferramenta de modelagem matemática de redes EPANET com a curva característica de demanda fornecida, é possível determinar as condições de funcionamento do sistema atualmente instalado no Município.

Foram introduzidas as informações fornecidas pela gestora da rede no modelo EPANET 2.0, e consideradas as informações topográficas, identificando as cotas de cada nó de conexão do modelo, e as informações sobre o funcionamento do sistema de reservatórios e consumo da cidade. Foi possível então determinar experimentalmente quais seriam as pressões em cada ponto da rede.

O modelo EPANET utiliza as fórmulas de Hazen-Williams, Chezy-Manning ou a fórmula de Darcy-Weisbach, para calcular as perdas de carga contínuas na rede de distribuição, fazendo com que, juntamente às perdas de carga localizadas e às cargas introduzidas por sistemas elevatórios e reservatórios, seja possível o cálculo das pressões expressas em metros de coluna de água (MCA), para que seja mais facilmente avaliado o potencial de geração de cada trecho da rede de Piquete.

A fórmula de perda de carga utilizada pela gestora foi a de Chezy-Manning, portanto sendo mantida para os cálculos aqui descritos.

Nas Figura 38 e Figura 39 são apresentados o trecho da rede e o detalhe da escala de cores e a respectiva graduação nos nós do modelo. 


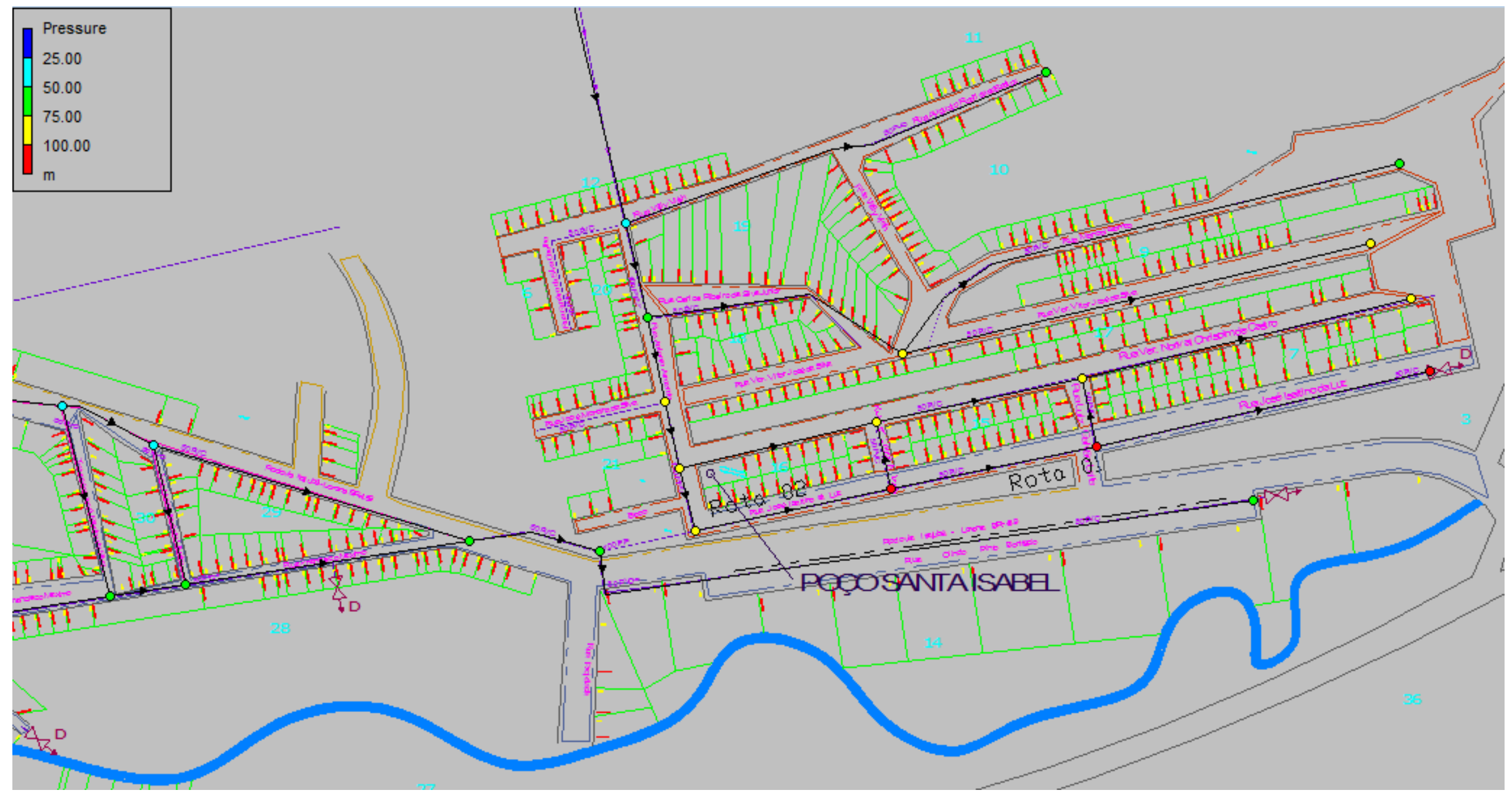

Figura 38- Representação das pressões em um dos trechos da rede 


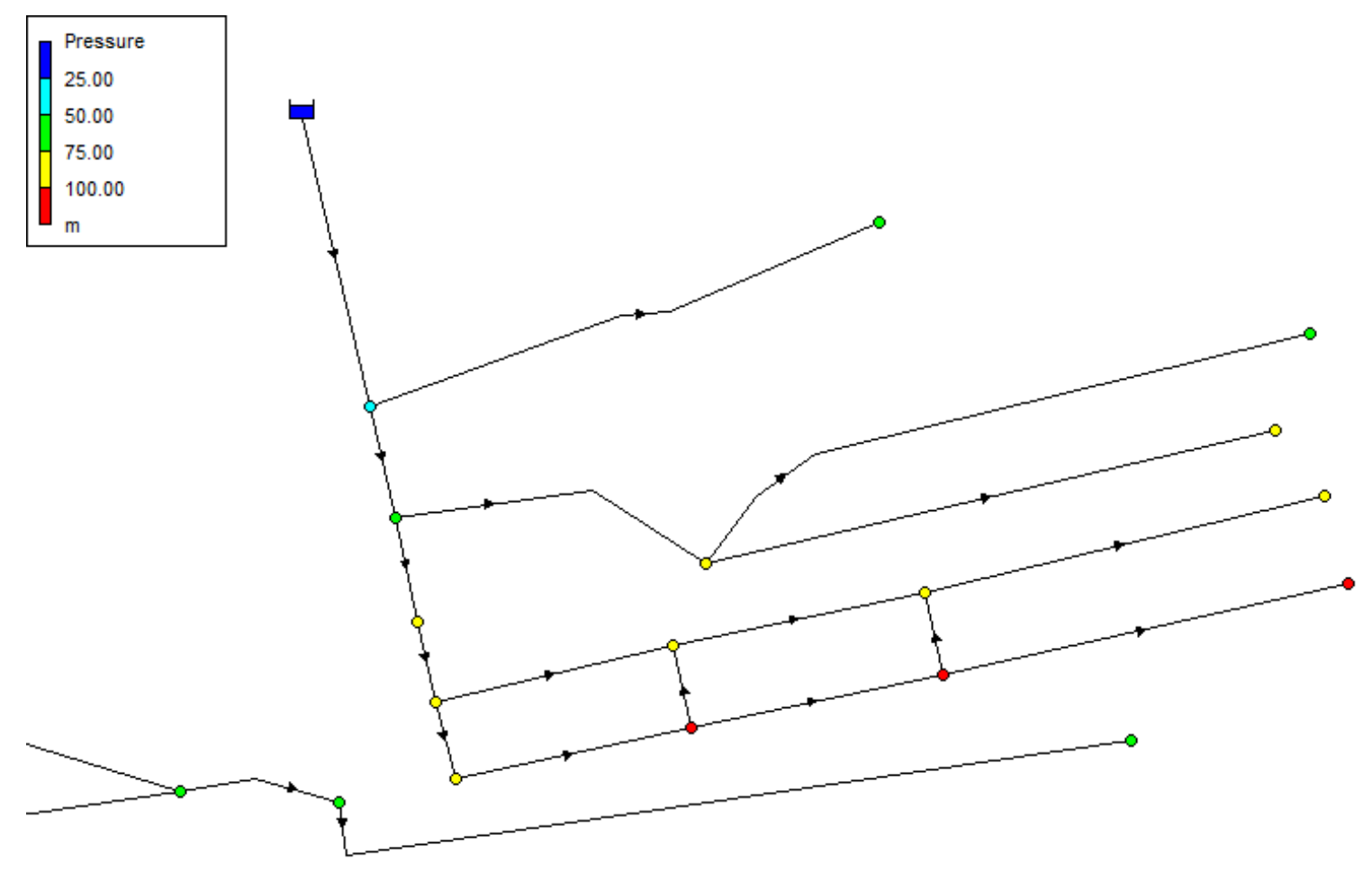

Figura 39- Representação do detalhe das pressões no trecho de rede destacado

\subsection{Modelagem da rede do Município de Piquete}

Utilizando-se da rede de distribuição do Município de Piquete, o sistema foi modelado pela ferramenta EPANET, sem que fossem instalados quaisquer equipamentos de controle de pressão. Desta forma, a rede apresentou valores de pressões bastante elevados, atingindo valores que por muitas vezes superou 50 m.c.a. Este valores são considerados interessantes para a geração de energia.

Os valores são indicativos da possibilidade de instalação de mini ou micro turbinas na rede de distribuição de água do município, e podem ser utilizados como base para os cálculos de potencial utilizável, localização e dimensionamento das centrais. Conforme explicado anteriormente, a curva de demanda fornecida evidencia oscilações de fluxo fazendo com que as pressões e vazões da rede flutuem ao longo do dia e das estações do ano.

A Figura 41 apresenta a rede modelada, que demonstra a partir de uma escala de cores a faixa de pressões atingida nos nós.

A rede possui um total de 196 nós, dentre os quais estão contidos 8 reservatórios. Dois destes, reservatórios fictícios que por manter o nível d'água constante, 
representam a afluência da captação de água dos mananciais. Os outros 6, funcionando como reservatórios de regularização das vazões. 


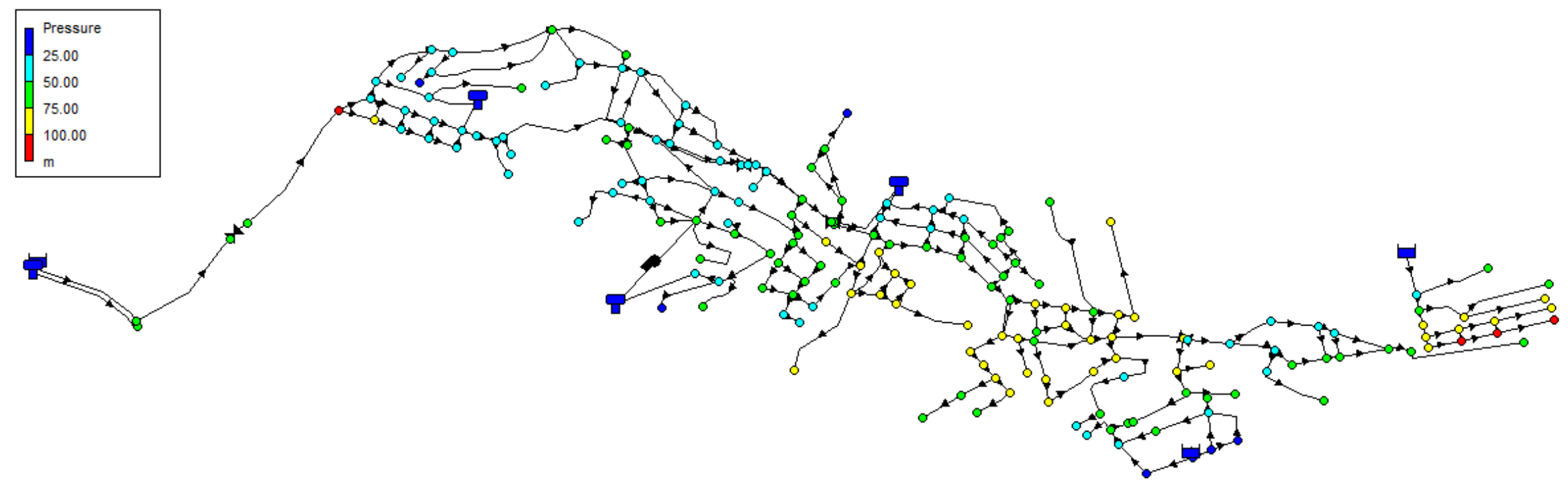

Figura 40 - Rede do Município de Piquete modelada segundo escala de pressão 
Como a NBR 12218 (1994), determina que as pressões não excedam 50 MCA e que não sejam interiores a $10 \mathrm{MCA}$, o modelo gerou resultados coerentes com a norma, relacionados às pressões mínimas, uma vez que o sistema instalado obedeceu a todos os critérios de projeto. No entanto a rede possui "nós" que atingiram pressões superiores a $100 \mathrm{MCA}$ quando solicitado em condições sem qualquer controle de pressões.

É interessante verificar que, dentro desta faixa de pressões é necessária a instalação de válvulas e dispositivos que controlem a pressão, o que torna viável a instalação de mini e/ou micro turbinas.

\subsection{Localização das turbinas}

As pressões atuam como um indicador do posicionamento das turbinas, no entanto, unicamente a pressão não representa inteiramente a posição ótima de uma instalação.

Recordando que a equação de cálculo do potencial de geração leva em consideração, entre outros fatores, principalmente as vazões e pressões, a seleção do posicionamento das centrais geradoras deverá levar em conta estes fatores principalmente para a definição do posicionamento das turbinas.

Neste estágio de desenvolvimento do projeto de aproveitamento também seria necessário analisar a disponibilidade de espaço existente adjacente à rede de distribuição, uma vez que a proposta é instalar os equipamentos paralelamente à rede, em configuração de "by-pass".

No entanto, para o estudo de caso da rede do Município de Piquete, o critério de espaço não será utilizado por falta de informações de cadastro.

A escolha dos pontos de instalação das turbinas foi determinada utilizando a malha total de nós introduzidos no modelo, que representam os pontos de interesse a serem modelados. Desta forma, criou-se uma planilha na qual foram introduzidos os identificadores de condutos e seus nós de entrada e saída. Este procedimento foi necessário, pois a identificação das diferenças de pressão na rede pode ser visualizada utilizando a diferença de pressão entre o final de um conduto e o início do trecho subsequente.

Com a diferença de pressões calculada, multiplicou-se este valor pela vazão que 
transita neste trecho da rede, possibilitando assim o calculo básico de um potencial de cada trecho que, na sequência, foi ordenado de forma decrescente.

Desta forma, foram escolhidos os pontos para os testes (Figura 42), identificados pelos círculos vermelhos, num total de cinco instalações, que são aquelas que obtiveram as cinco melhores colocações na tabela.

Os procedimentos de otimização existem e são grandes facilitadores da verificação dos melhores pontos de aproveitamento, como a ferramenta "deEPANET" desenvolvida e aplicada pela Universidade de Exeter por Morley et. Al (2006).

No entanto, são comercializados à parte ao modelo EPANET que é de livre acesso.

Desta forma, decidiu-se por utilizar as ferramentas já disponíveis para simular a rede, sem a necessidade de extensões. 


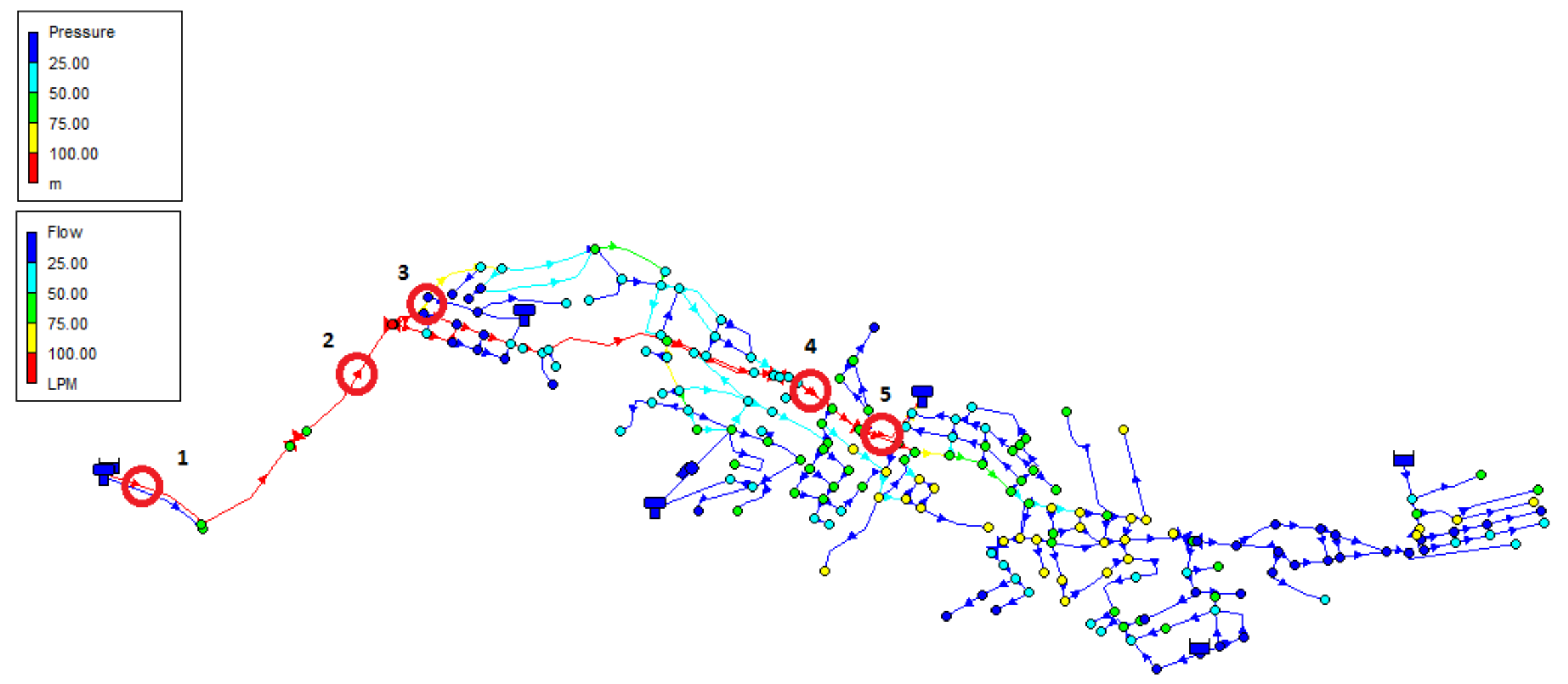

Figura 41 - Rede de Piquete modelada segundo escala de pressão identificados 5 prováveis pontos de aproveitamento 
O procedimento de instalar a turbina na rede teve como premissa introduzi-las em uma sequência que não prejudicasse as condições de pressão em qualquer outro ponto da rede. Fez-se necessária assim, a verificação da pressão em cada nó da rede após a instalação de apenas uma das turbinas escolhidas para só então proceder com a instalação da próxima.

Desta maneira, seguindo o procedimento descrito anteriormente, foi desenvolvida uma tabela em plataforma Excel, primeiramente calculando os potenciais possíveis para os trechos da rede de distribuição do município, apresentado na Tabela 4.

Tabela 4 - Procedimento de cálculo dos potenciais.

\begin{tabular}{|c|c|c|c|c|}
\hline Trechos & $\Delta \mathrm{H}(\mathrm{m})$ & $\begin{array}{c}\text { Vazão } \\
(\mathrm{LPM})\end{array}$ & $\begin{array}{c}\text { Vazão } \\
\left(\mathrm{m}^{3} / \mathrm{s}\right)\end{array}$ & $\begin{array}{c}\text { Potencial } \\
(\mathrm{W})\end{array}$ \\
\hline 8 & 12.51 & 243.36 & 0.00406 & 0.05074 \\
\hline 9 & 10.00 & -3.94 & -0.00007 & 0.00066 \\
\hline 10 & 10.00 & -1.71 & -0.00003 & 0.00029 \\
\hline 11 & 38.48 & -99.97 & -0.00167 & 0.06411 \\
\hline 12 & 2.39 & 236.85 & 0.00395 & 0.00943 \\
\hline 13 & 10.32 & 104.52 & 0.00174 & 0.01798 \\
\hline 14 & 28.16 & 132.33 & 0.00221 & 0.06211 \\
\hline 15 & 10.81 & 273.79 & 0.00456 & 0.04933 \\
\hline$\ldots$ & $\ldots$ & $\ldots$ & $\ldots$ & $\ldots$ \\
\hline
\end{tabular}

Os valores de potencial foram então ordenados de forma decrescente, definindo os pontos de maior potencial, como demonstrado na Tabela 5.

Tabela 5 - Ordenamento segundo os maiores potenciais.

\begin{tabular}{|c|c|}
\hline Trechos & $\begin{array}{c}\text { Potencial } \\
(\mathrm{kW})\end{array}$ \\
\hline 241 & 4.181 \\
\hline 1 & 3.850 \\
\hline 240 & 1.383 \\
\hline 244 & 0.858 \\
\hline 242 & 0.830 \\
\hline 243 & 0.809 \\
\hline 239 & 0.634 \\
\hline 254 & 0.464 \\
\hline$\ldots$ & $\ldots$ \\
\hline
\end{tabular}

Foram identificadas as tendências de que os trechos de maior potencial são aqueles 
que possuem maiores vazões ou maiores desníveis. No entanto, pelo fato da pressão ser mais sensível, escolheu-se trabalhar com os trechos com maiores vazões, selecionando assim os trechos centrais e não aqueles das extremidades secundárias da rede.

Assim, determinou-se a escolha do ponto mais próximo da captação para iniciar as rodadas de instalação (ponto 1).
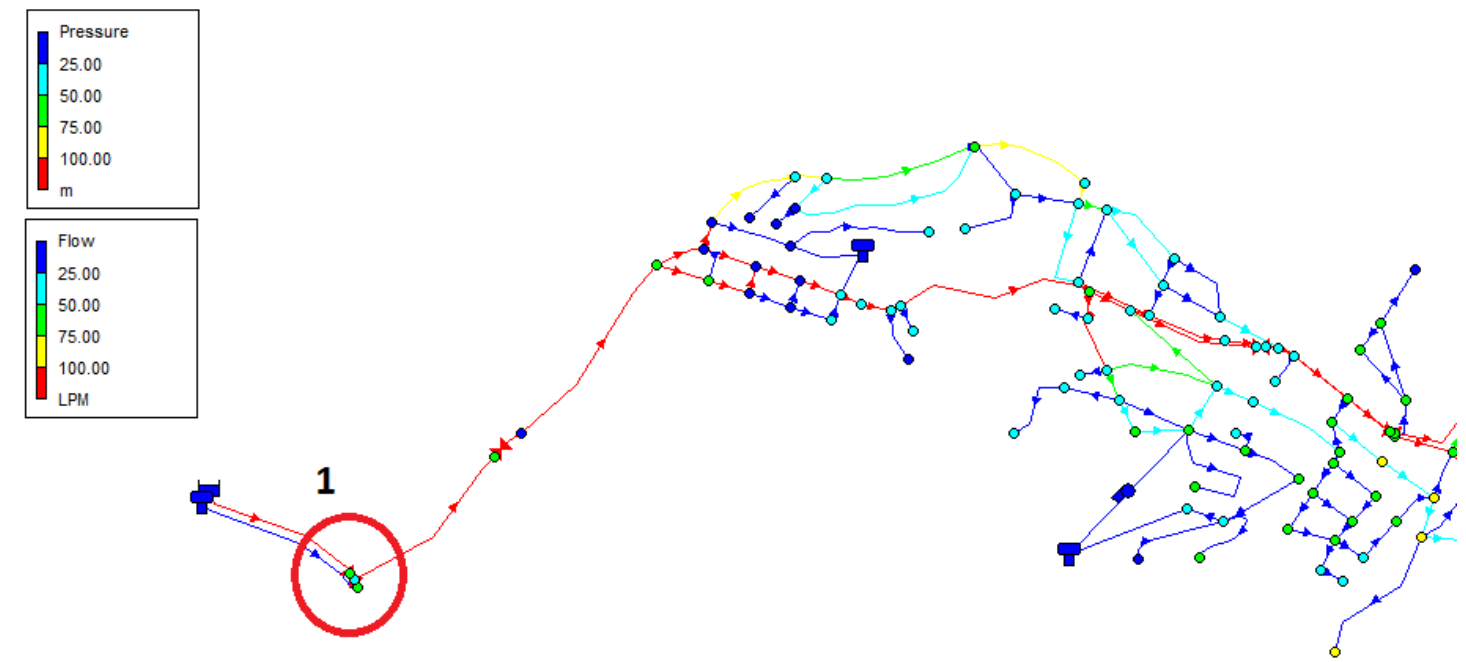

Figura 42 - Rede de Piquete modelada segundo escala de pressão com turbina no Ponto 1

Como o procedimento de escolha da localização não leva em conta ainda a otimização do abatimento das pressões pelas turbinas, para o aproveitamento do ponto 1 foi proposta inicialmente a redução de pressão em aproximadamente 10 MCA disponíveis para a geração de energia.

Este valor foi considerado para que as pressões ainda não sofressem uma grande queda, o que poderia acarretar em redução de pressão em algum ponto da rede com valores próximos ao limite inferior que é de 10 MCA impedindo a instalação de mais turbinas.

Fazendo a simulação, no trecho instalado, foram registradas vazões entre 1046 litros por minuto (LPM) a 1083 LPM.

Em seguida, foi verificada a ocorrência de pressões inferiores a 10 MCA nos demais pontos da rede, o que não ocorreu.

Como a intenção, nesta fase de verificação da viabilidade de instalação, é a de localizar os pontos de aproveitamento com melhores condições de geração de 
energia, não serão ainda verificadas as variações ao longo do dia das vazões para o calculo da potência instalada para otimizar a produção de energia.

Será somente considerada a condição mais critica para a rede, onde as vazões são altas e as pressões são as mais baixas. Neste caso, esta condição é atingida às 12 horas.

Portanto, na sequencia dos estudos foi introduzida a turbina no ponto 2 , selecionado por seu potencial aproximado, e vem indicado a seguir.

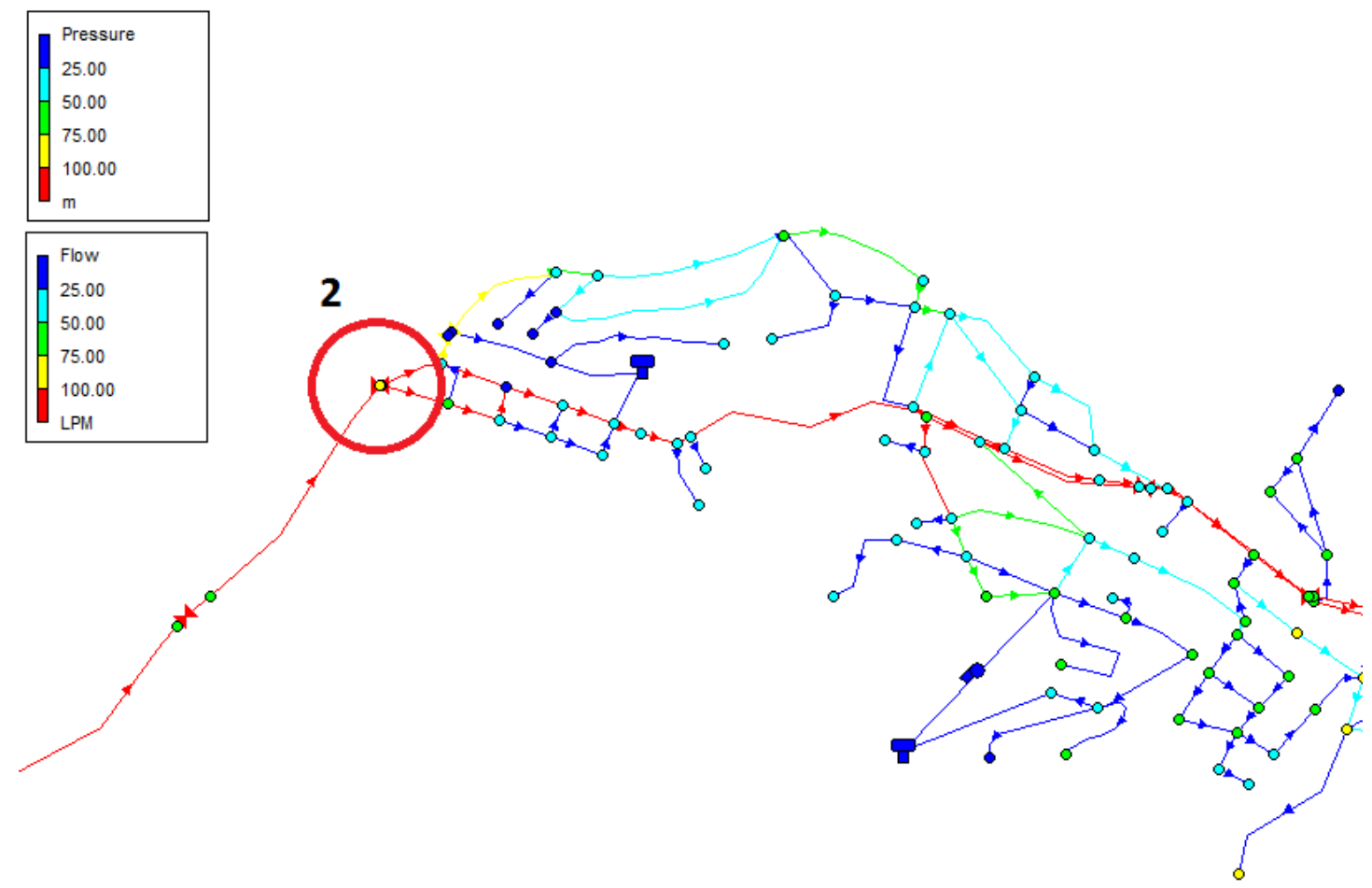

Figura 43 - Rede de Piquete modelada segundo escala de pressão com turbina no Ponto 2

Para o segundo ponto de aproveitamento, ponto 2, as vazões se reduzem para o patamar de 924 LPM a 967 LPM, o que é compensado por um aumento do abatimento de pressões em 15 MCA proposto.

O potencial de uso das pressões neste ponto também não foi utilizado em sua plenitude, uma vez que ainda devem ser instalados os demais pontos de aproveitamento. Da mesma forma, foram verificadas as pressões nos demais nós da rede e não foram encontrados pontos com pressões inferiores a 10 MCA. 


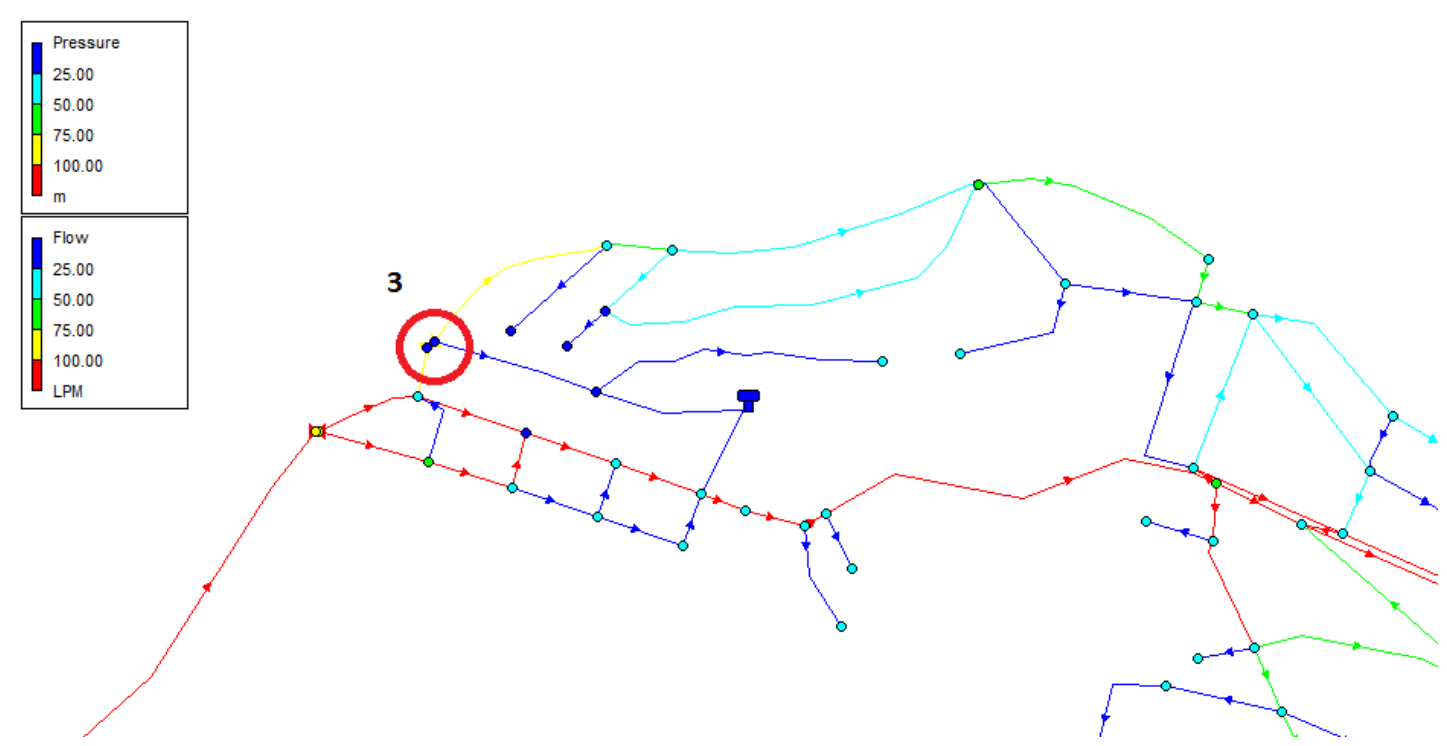

Figura 44 - Rede de Piquete modelada segundo escala de pressão com turbina no ponto 3

Inseriu-se no modelo uma terceira turbina, que proporciona uma perda de carga de aproximadamente $4 \mathrm{MCA}$, em um trecho com vazões de 78 LPM.

Neste terceiro ponto de aproveitamento passa a agir além do fator de controle das pressões nos outros pontos da rede, ainda atendida nesta configuração, o fator de variação horária de vazões e pressões.

Este critério passa a ser mais importante quanto menor for o desnível disponível para o aproveitamento hidrelétrico, uma vez que quanto menor o desnível, mais importantes são as variações ao longo do dia.

Considerando este fator, a escolha dos próximos pontos de aproveitamento, pontos 4 e 5, tiveram dificuldade em obedecer os critérios de pressão mínimos dentro da variação diária.

Desta forma, foi descartada a utilização destes dois pontos, priorizando a geração de forma concentrada nos três primeiros pontos selecionados que serão então otimizados, por tentativa e erro, para garantir o maior aproveitamento possível.

No entanto, com o futuro desenvolvimento de uma ferramenta de otimização conectada ao software EPANET, será possível realizar uma maior pulverização das turbinas pela rede. Isso porque será verificado o beneficio ou prejuízo que uma nova unidade traria ao sistema de abastecimento de forma mais rápida.

Foi então imaginado que o sistema de escolha do número e localização das unidades geradoras deve exibir um número inicial de pontos de aproveitamento, ou seja, inicia-se o procedimento de escolha sabendo que serão instaladas no máximo 
o número estabelecido pelo usuário ou decisor.

Sabendo o número máximo, o procedimento será de implementação das alternativas por testes sucessivos com o modelo EPANET, indicando a perda de carga máxima que cada um dos aproveitamentos pode introduzir na rede de abastecimento.

\subsection{Determinação da dimensão das turbinas}

A seleção das turbinas para o aproveitamento nas redes de distribuição é extremamente importante para viabilizar e estabelecer a geração em seu melhor desenvolvimento ao longo do tempo.

É exigido que sejam verificadas condições como, o rendimento, vazão e desnível/pressão sob as quais o equipamento será submetido.

Como a proposta deste estudo foi a de utilizar a instalação das turbinas de modo paralelo à rede, formando um "By Pass", é possível utilizar as turbinas otimizando os períodos de acionamento.

Este período foi considerado observando o encaminhamento das demandas ao longo do dia como demonstrado nas figuras do item 5.7 deste estudo, que representa a curva de demanda devidamente calibrada para a rede.

Comparando a curva de demanda com a curva de rendimento de um grupo de seis tipos de turbina, nas Figura 45 e Figura 46, é possível estabelecer qual a faixa de rendimento na qual as turbinas atuariam.

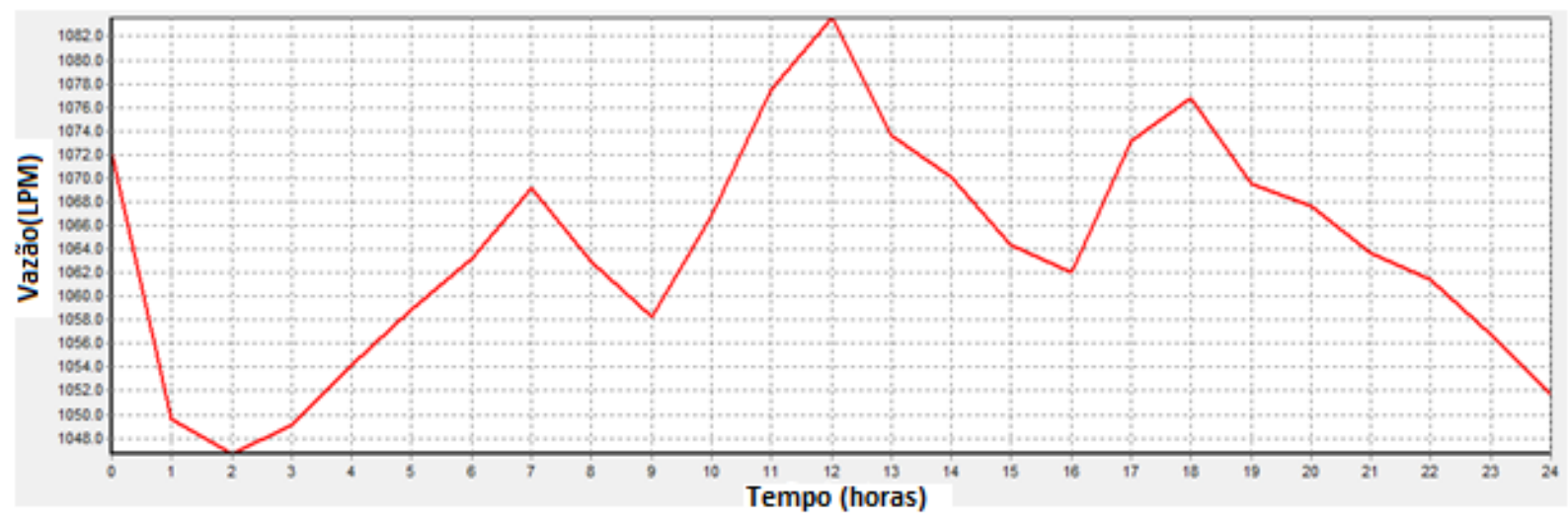

Figura 45 - Exemplo de resultado da curva de demanda ao longo de 24 horas 


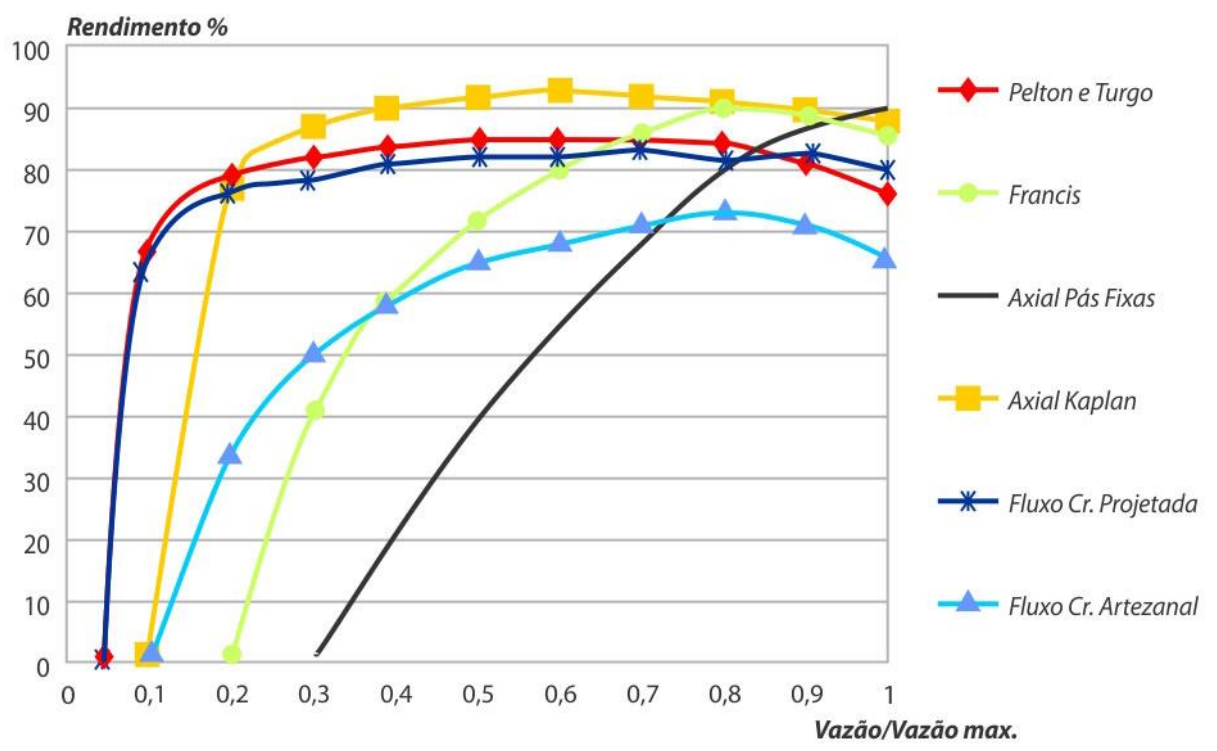

Figura 46 - Curvas de rendimento de seis turbinas mantida a pressão constante.

Fonte: Harvey

Observando a curva de demandas fornecidas pela gestora da rede (Figura 45), conclui-se que as vazões não se distanciam consideravelmente do valor médio, e tendo uma diferença entre os valores máximo e mínimos não inferiores a 0.96 (Qi/Qmáx).

Portanto, como o dimensionamento das turbinas vai depender do ponto ótimo de aproveitamento das vazões e pressões na rede, e estes numericamente demonstram que para quaisquer das curvas de rendimento, as turbinas podem ser utilizadas com rendimentos superiores a $70 \%$, a escolha se dará por critérios de mercado e preço.

Para isso, foi utilizado o catálogo de turbinas da empresa Micro-Hydro-Power, dedicada à construção de equipamentos para aproveitamentos de mini e micro dimensões.

No seu catálogo identificou-se que podem ser utilizadas as turbinas Turgo, que é uma adaptação de turbinas Pelton e axiais de diversas dimensões que melhor se adaptem às condições encontradas.

Posteriormente, o valor dos equipamentos selecionados será parâmetro na otimização de produção e acionamento na geração de energia. 


\subsection{Determinação dos horários de acionamento}

Uma das determinações interessantes ao aproveitamento das redes de distribuição para geração de energia é a variação temporal das pressões e vazões ao longo do dia.

Determinar o horário de atuação das mini ou micro turbinas influencia na eficiência das máquinas o que impacta diretamente na geração de energia.

No estudo de caso, não foi possível constatar para os pontos da seleção 1 e 2, a ocorrência de variações acentuadas das vazões e pressões, garantindo que a determinação de horários de acionamento não influencia no resultado final.

Apenas para 0 ponto de seleção 3 , houve influencia da variação da pressão, restringindo-se portanto somente a um dos pontos estudados.

No entanto, caso a escolha de pontos de aproveitamento pudesse ser mais apurada, com auxilio do modelo de otimização ligado ao EPANET, poderiam ser selecionados pontos mais próximos às extremidades da rede.

Eles poderiam ser selecionados mesmo sofrendo com a variação de forma mais pronunciada de vazão, pois são solicitadas por um menor número de conexões e consequentemente dependem diretamente das demandas intermitentes.

Para os pontos 1 e 2, escolhidos no estudo, essa influencia não existe, pois se encontram nos troncos de abastecimento, onde a influencia das demandas instantâneas é minimizada.

Nos exemplos da rede simulada nas, Figura 47 e Figura 48, é possível visualizar este comportamento.

Na Figura 48 está apresentada a curva de vazões para o trecho da seleção no ponto 3, na extremidade da rede de distribuição, onde as vazões variam de 0.1 a 2.2 LPM, o que representa uma variação de 21 vezes a vazão, enquanto na Figura 49, que apresenta um trecho no tronco de abastecimento da rede, onde a vazão varia de 925 a 968 LPM, representando uma variação 0.046 vezes da vazão. 


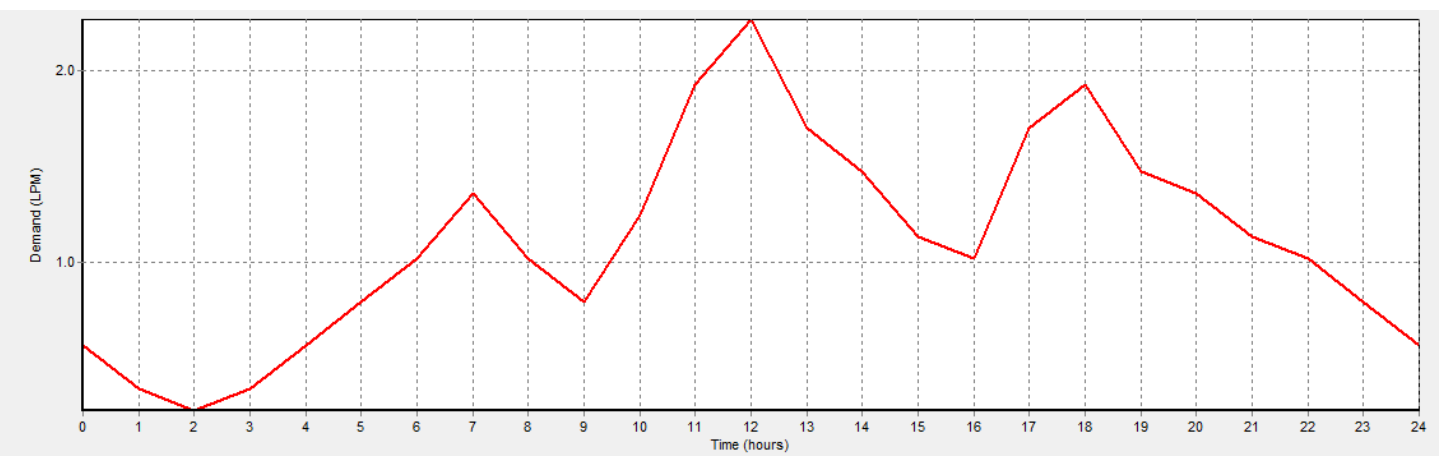

Figura 47 - Demanda nas extremidades da rede.

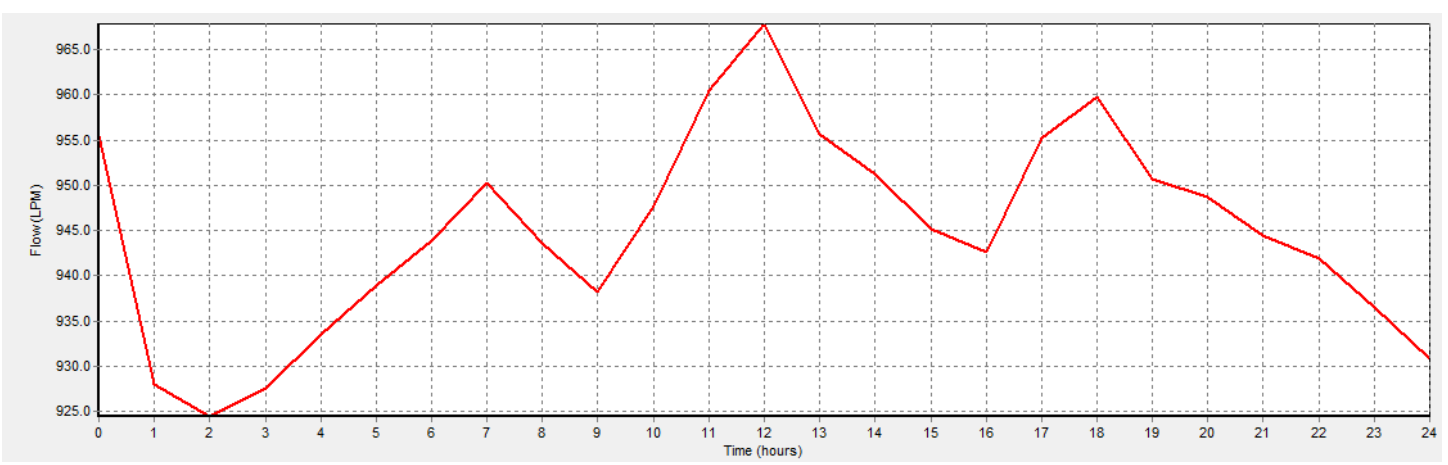

Figura 48 - Demanda nos troncos da rede.

\subsection{Redução das perdas}

Utilizando os estudos de Zyl et al. (2004), como base para o desenvolvimento dos trabalhos relacionados à redução das perdas, referenciando-as à redução das pressões, foi possível avaliar o impacto da redução das pressões pode auxiliar na redução das perdas.

Como foram instalados apenas três dispositivos que geram perda de carga, pode-se avaliar individualmente os impactos da instalação nas pressões dos demais pontos da rede, representados pelos nós da simulação.

Como exemplo, é utilizada a instalação no ponto 1 do primeiro aproveitamento.

Com a instalação, pode-se verificar a diferença entre as pressões nos demais pontos, antes e depois da intervenção, como pode ser visualizado na Tabela 1 do Anexo 1.

$\mathrm{Na}$ equação de perdas apresentada por Zyl et al. (2004), e utilizando as constantes, coeficiente de vazamento igual a 7,5 e expoente de vazamento variando de $0.5,1 \mathrm{e}$ 2, pode-se obter o valor das vazões de perda. Lembrando-se que é considerado um orifício de $1 \mathrm{~mm}$ como padrão para a saída de água do sistema.

Calculando os valores pela equação com as diferenças de pressão entre as 
situações com e sem instalação dos aproveitamentos, foram obtidos os seguintes resultados apresentados nos gráficos a seguir.

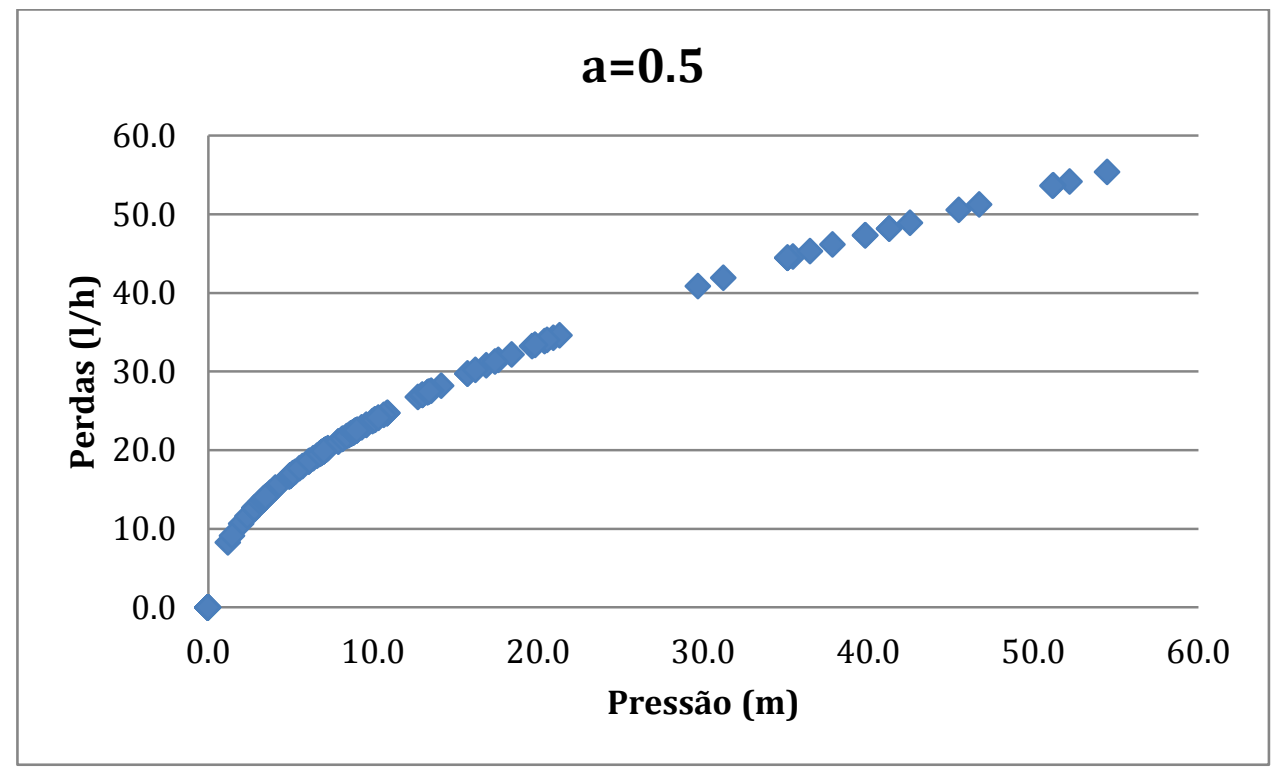

Figura 49 - Relação entre pressões nos nós da simulação x Perdas calculadas com expoente de perdas 0,5 .

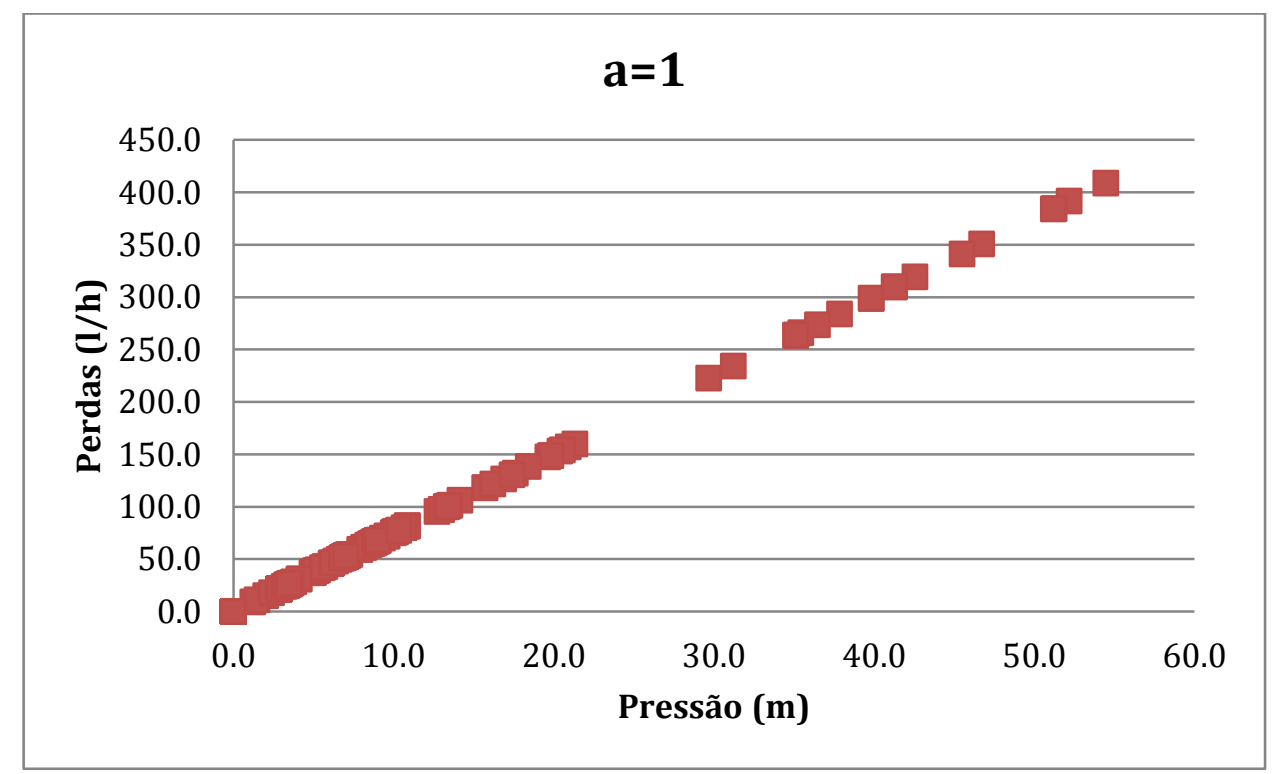

Figura 50 - Relação entre pressões nos nós da simulação x Perdas calculadas com expoente de perdas 1 


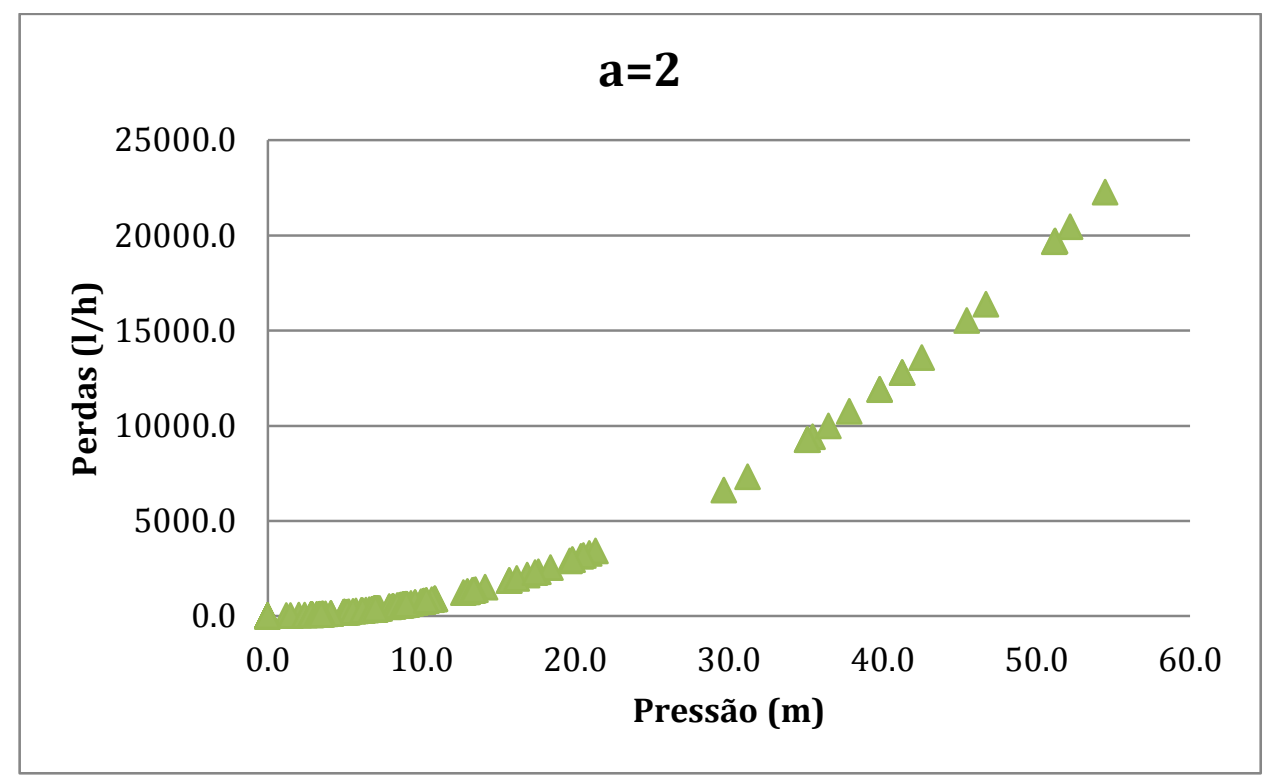

Figura 51 - Relação entre pressões nos nós da simulação x Perdas calculadas com expoente de perdas 2

Ainda segundo Zyl et al. (2004), a possibilidade de que a equação tenha como expoente 0.5 ou 2 é equivalente, variando conforme a instalação da rede e das tecnologias aplicadas.

Assim, pode-se fazer duas aproximações limitando inferior e superiormente as perdas na rede de distribuição de Piquete apenas incluindo os aproveitamentos na rede de distribuição.

\subsection{Maximização da geração de energia}

Vilanova e Balestieri (2014) calcularam uma equação de potência gerada em relação às vazões turbinadas de seus estudos para assim ser possível verificar a quantidade de energia que pode ser gerada (Equação (28)).

$$
P o t=-0.00015 . Q_{t u r}^{3}+0.00003 \cdot Q_{t u r}^{2}+1.45969 . Q_{t u r}+0.0366
$$

Foi possível desenvolver para cada um dos 3 aproveitamentos propostos uma equação da potência gerada ao longo do dia semelhante a apresentada na Equação (28).

Na Figura 52 é apresentada a curva de potência em relação à vazão turbinada e a curva que relaciona pressão com a vazão turbinada, representada por TURB 1. 
Com as curvas é possível verificar qual seria o ponto ótimo de acionamento da turbina. No caso estudado, a curva de potência se aproxima de uma reta ao invés de uma curva parabólica, fato decorrente da baixa variação das vazões no ponto de aproveitamento. Devido a esta característica, a escolha do ponto ótimo se resume a escolha do ponto de maior valor na curva de potência.

Esta característica é também verificada no ponto de aproveitamento 2, que tem suas curvas apresentadas na Figura 53, exatamente pela pequena variação das vazões no local.

Ressalta-se que o formato da curva se altera quando existe variação mais acentuada das vazões ao longo do tempo, como nas extremidades da rede. As maiores variações nas vazões ocorrem nas extremidades da rede, próximas às conexões com os usuários, situação observada no ponto de aproveitamento 3.

O resultado obtido para o terceiro aproveitamento é apresentado na Figura 54.

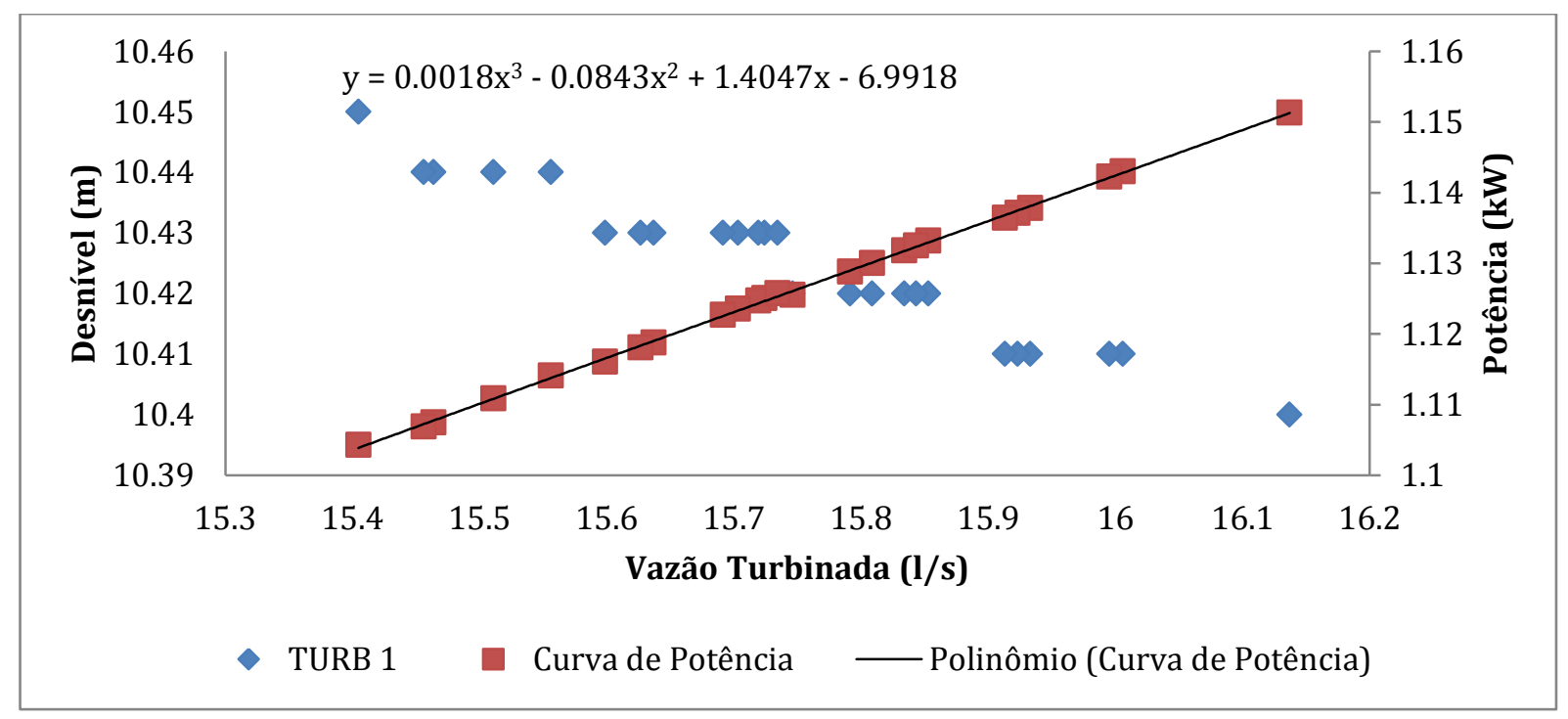

Figura 52 - Curva de Potência para a localização da turbina 1 


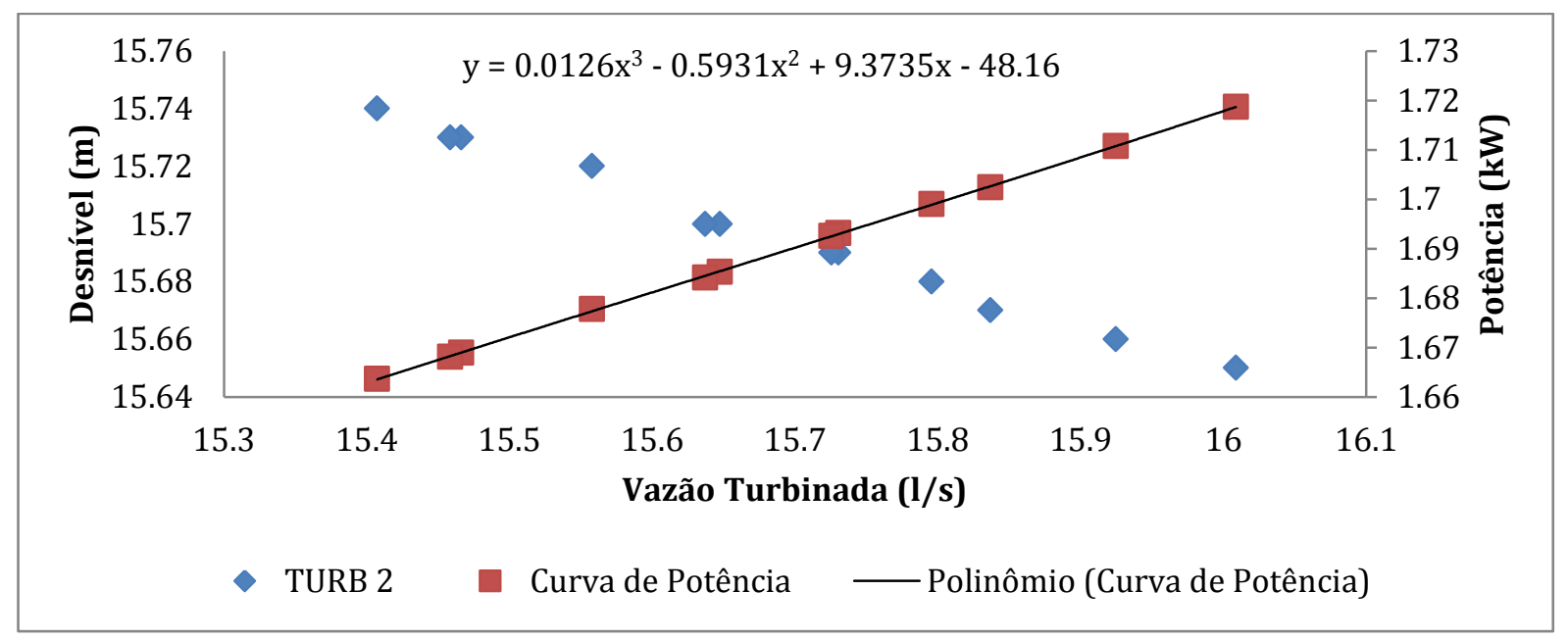

Figura 53 - Curva de Potência para a localização da turbina 2

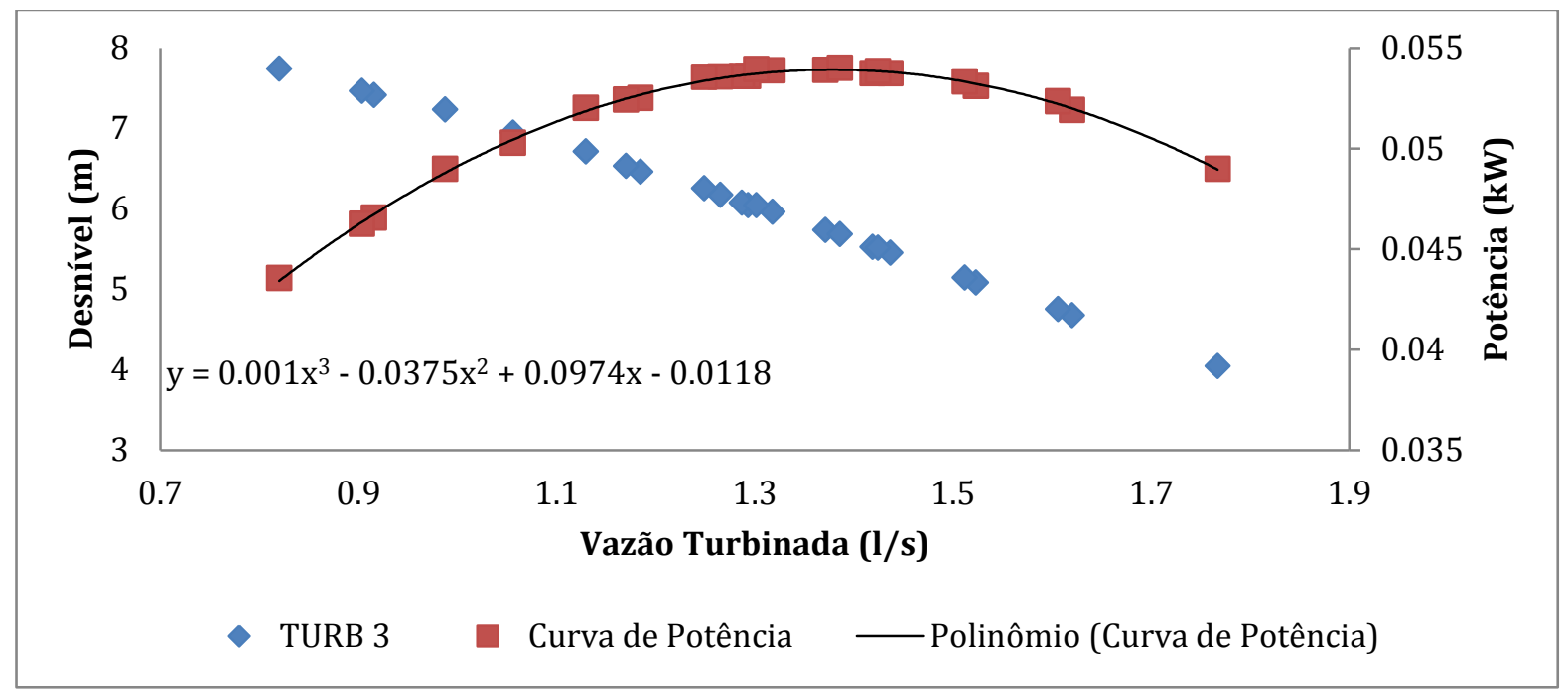

Figura 54 - Curva de Potência para a localização da turbina 3

Para identificar a potência ótima a ser utilizada em cada turbina, foi maximizada a equação resultante da aproximação, por polinômio de terceira ordem, da curva de potência, variando as vazões turbinadas.

A variação das vazões se deve a configuração de "by-pass" dos aproveitamentos, onde a vazão é controlada por válvulas que permitem a passagem das vazões sem interferência ou pela turbina.

Desta forma, maximizar a geração de energia significa instalar e atuar as turbinas o mais próximo possível do ponto ótimo de potência.

Utilizando as equações obtidas nos gráficos de potência e calculando o ponto ótimo define-se então a dimensão das turbinas a serem instaladas. 


\subsection{Redução dos custos de operação da rede de distribuição}

A redução dos custos de operação com a instalação das mini e micro turbinas se deve a melhor gestão dos gastos com energia, implementando a produção própria de energia e da redução das perdas com a regulação das pressões.

Levando em consideração estes fatores, é possível prever que com a introdução das turbinas, acrescenta-se uma variável às equações de operação das redes de distribuição, em especial neste caso a rede de Piquete.

Atualmente, a operação da rede do Município de Piquete é realizada apenas com a ajuda de 5 reservatórios que mantém o nível de norma das pressões em determinados trechos de rede. No entanto, a operação de enchimento destes reservatórios é realizada por demanda instantânea, ou seja, conforme a necessidade destas estruturas frente ao consumo demandado para o abastecimento.

A intenção de reduzir os custos com a operação segue o princípio básico de acionar os equipamentos eletro hidráulicos quando os custos de energia são mais baixos (períodos fora dos picos de consumo) e utilizar a água dos reservatórios até seu limite dentro dos períodos de pico de preços da energia, e implementar uma programação para o acionamento dos equipamentos é uma medida importante para a gestão da rede.

Implantar esta medida deve utilizar-se do seguinte equacionamento:

$$
\begin{array}{r}
D_{\text {lucro }}=P r_{\text {água }} \cdot\left(Q_{\text {Servida }}\right)-C_{\text {água }}\left(Q_{\text {Servida }}+Q_{\text {Perdas }}\right)-C_{\text {Energia }}(t) .\left(P_{\text {Bombeada }}(t)\right)+ \\
C_{\text {Energia }}(t) .\left(P_{\text {Turbinada }}\right)-C_{\text {Equip }}(N)
\end{array}
$$

onde:

$D_{\text {lucro }}$ - Lucro da distribuidora em $\mathrm{R} \$$

$P r_{\text {água }}$ - Preço da água para os consumidores em $\mathrm{R} \$ / \mathrm{m}^{3}$

$C_{\text {água }}$ - Custo da água para a distribuidora em $\mathrm{R} \$ / \mathrm{m}^{3}$

$Q_{\text {Servida }}$ - Vazão entregue aos consumidores em $\mathrm{m}^{3} / \mathrm{dia}$

$Q_{\text {Perdas }}$ - Vazão de perdas na rede em $\mathrm{m}^{3} / \mathrm{dia}$

$C_{\text {Energia }}(t)$ - Custos de energia variável no tempo em $\mathrm{R} \$ / \mathrm{kWh}$

$P_{\text {Bombeada }}(t)$ - Potencia bombeada para recarga dos reservatórios em $\mathrm{kWh} / \mathrm{dia}$

$P_{\text {Turbinada }}$ - Potencia turbinada em kWh/dia 
O equilíbrio entre custos e ganhos decorrentes da produção de água será realizado utilizando a variação temporal do custo de energia, desta forma, otimizando o consumo e produção de energia.

Abordando a questão das perdas discutida e formulada por Giustolisi et al.(2013), deve-se tratar das pressões, reduzindo-as nos momentos de baixo consumo de água, que coincidem exatamente com os picos de pressão na rede. Desta forma, o acionamento das turbinas neste período vem corroborar com o controle de perdas.

$O$ acionamento das turbinas influencia na pressão da rede e, portanto, 0 equacionamento de lucros totais envolvidos na distribuição ( $D_{\text {lucro totais }}$ ), será o seguinte:

$$
D_{\text {lucro totais }}=D_{\text {lucro }}+C_{\text {água }} \cdot\left(Q_{\text {Perdas }}\right)
$$

Com $Q_{\text {perdas }}=7$,5. $\left(\mathrm{He}(t)^{\alpha}\right)$ e $H e=$ variação das pressões com e sem aproveitamento.

Variando as atividades na rede ao longo de 24 horas, é possível atingir o valor ótimo de $C_{\text {totais }}$ a partir do cálculo de $Q_{\text {Perdida }}$ e $Q_{\text {Turbinada }}$ que melhor atendam às condições de contorno impostas.

As condições de contorno são a manutenção do abastecimento em $100 \%$ do período e trabalhar com pressões não inferiores a 10 MCA.

Para avaliar a viabilidade de instalação é necessário então realizar a comparação dos lucros totais com o custo de investimentos dos aproveitamentos. Como pode-se notar na equação de lucros totais, na parcela $D_{\text {lucro }}$ e nos ganhos com a redução das pressões/perdas, quando ocorre um aumento de $Q_{\text {Turbinada }}$ e $Q_{\text {Perdas }}$, ocorre um aumento no lucro, que no entanto deve abater 0 valor investido nos equipamentos e obras envolvidos.

Utilizando as tabelas de tarifas fornecidas pela SABESP (2014), e a partir de estudos realizados por Pasqualetto et.al.(2012), foram obtidos os valores dos custos envolvidos na produção e comercialização de água. Os valores de custo de produção de $1 \mathrm{~m}^{3}$ de água, já levam em conta os custos médios de bombeamento e tratamento. No entanto, para melhor descrever cada sistema estudado, seria necessário o detalhamento também destes sistemas de elevação, que variam significativamente entre redes.

No caso de Piquete, a rede possui apenas uma central de bombeamento com 13 a 
15 LPM ou $0.0002 \mathrm{~m}^{3} / \mathrm{s}$, o que simplificou a análise. Desta forma optou-se por utilizar o valor médio proposto por Pasqualetto et al. (2012), de 1,87 R $\$ / \mathrm{m}^{3}$.

As tarifas cobradas pela SABESP na região metropolitana, interior e litoral são divididas por faixas de tipo de uso e quantidades, no entanto foi selecionado o valor da tarifa Residencial / Normal, na faixa de 11 a $20 \mathrm{~m}^{3}$ para representar o valor médio cobrado. Assim sendo foi determinado que a tarifa seria de $2,63 \mathrm{R} \$ / \mathrm{m}^{3}$.

$\mathrm{O}$ custo de energia foi considerado igualmente tanto para a compra quanto para a venda, uma vez que o valor é compensado, como apresentado na resolução normativa $n^{\circ} 512$ (ANEEL,2012).

$O$ custo de energia foi referenciado no valor médio cobrado na região sudeste com fonte da ANEEL (2014), de $0.301 \mathrm{R} \$ / \mathrm{kWh}$. Existe variação por contratos, no entanto eles serão considerados em casos particulares em cada local quando necessário.

\subsection{Otimização}

Como o modelo EPANET não possui um módulo especifico para otimizar a produção de energia, o procedimento levou em conta que a cada rodada de simulação, os valores das pressões serão transferidos para uma plataforma externa (Excel) para que fossem consideradas as condições e características de escolha da melhor configuração dos equipamentos geradores.

Este procedimento leva em conta todas as condições de contorno levantadas anteriormente, de horários de consumo de água, relações de pressão e perdas, custo dos equipamentos, número de equipamentos e rendimento das turbinas.

A otimização dos aproveitamentos no sistema de abastecimento de Piquete usou da metodologia descrita anteriormente no item 7.9, estudando os três aproveitamentos propostos, portanto obtendo três caminhos críticos.

A escolha inicial de selecionar apenas três aproveitamentos para a rede de Piquete, elimina um dos primeiros passos para a otimização da instalação das mini e microturbinas na rede que é a escolha do número de pontos de aproveitamento. $\mathrm{O}$ passo de escolha do número de turbinas é um dos fatores que influencia decisivamente no resultado, na complexidade e no tempo de processamento da otimização.

Quanto maior o número de turbinas, maior o número de caminhos críticos e, consequentemente, iterações na verificação das pressões que deverão ser 
realizadas.

Foi imaginado que no procedimento de otimização do número de turbinas, deixe em aberto a seleção como critério de decisão dos planejadores. Em fase de planejamento será possível fazer diversos testes com o número de aproveitamentos, que, no entanto deve ser realizado com cautela uma vez que o aumento indiscriminado das instalações encarece a parcela de infraestrutura e equipamentos dos custos.

Ao eliminar este passo do estudo de caso aqui apresentado, agilizou-se o procedimento, passando diretamente ao dimensionamento das turbinas e a otimização do acionamento dos equipamentos.

Os caminhos críticos encontrados são apresentados nas Figura 56, Figura 57 e Figura 58.

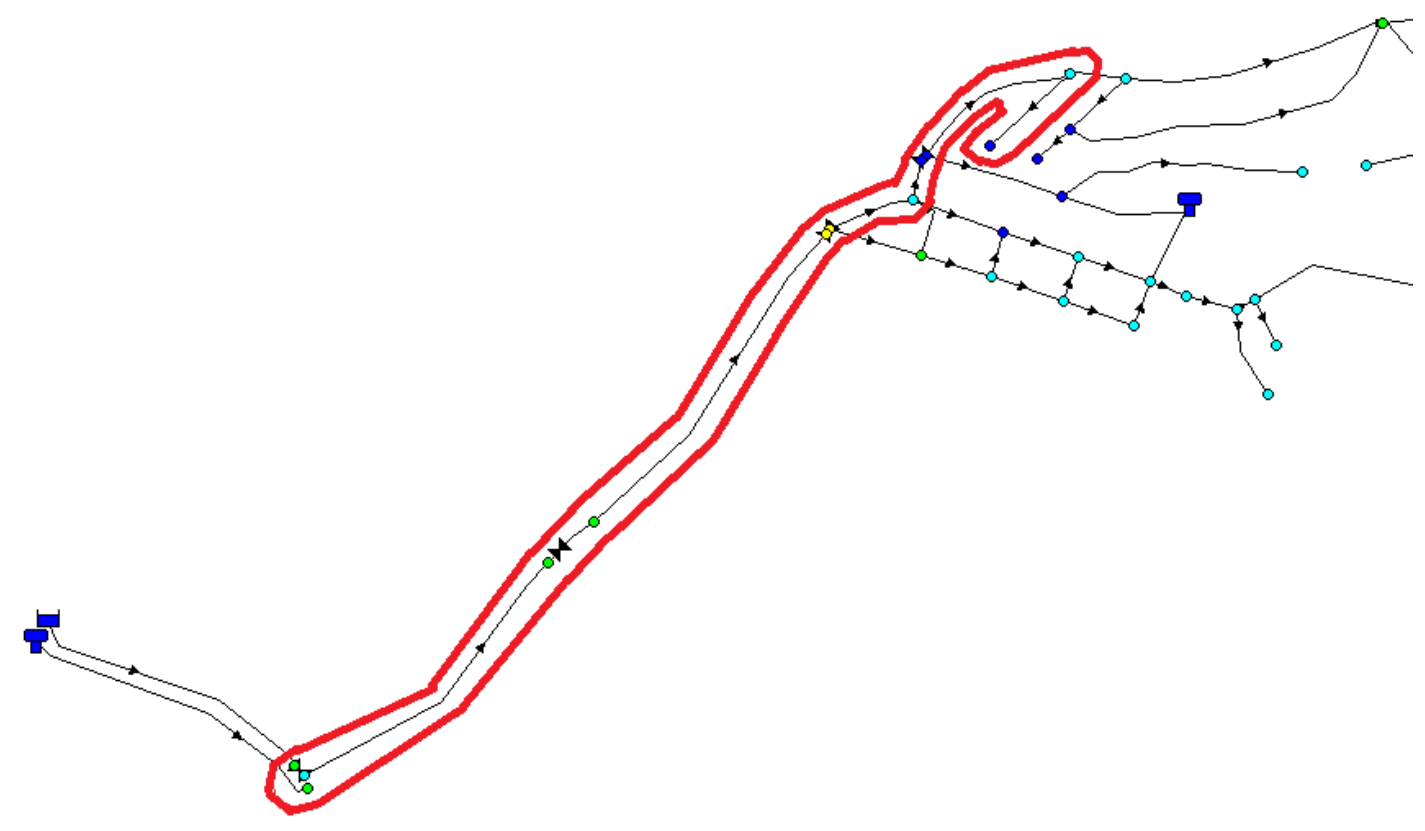

Figura 55- Caminho critico do aproveitamento no ponto 1 


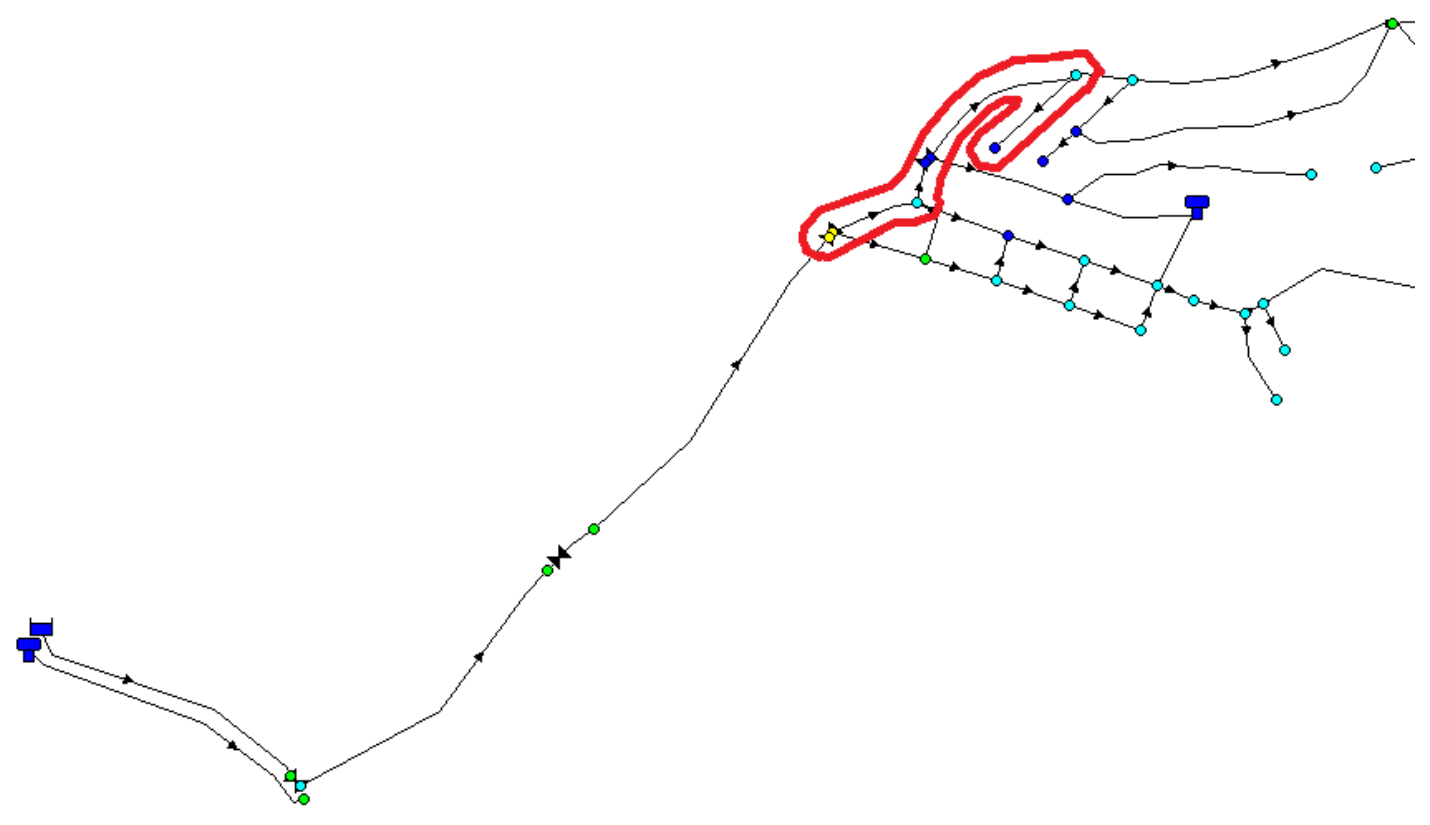

Figura 56- Caminho critico do aproveitamento no ponto 2

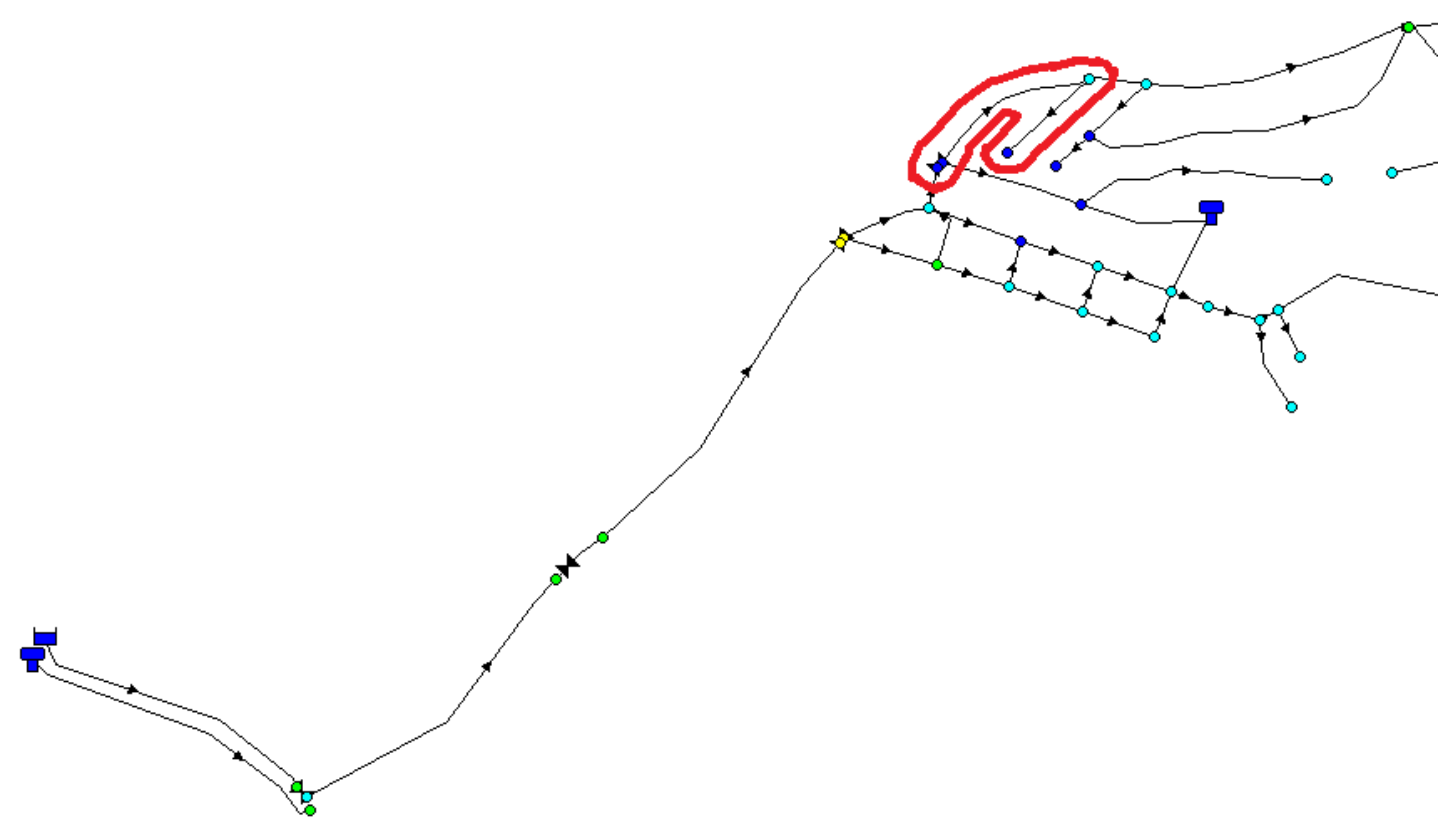

Figura 57- Caminho critico do aproveitamento no ponto 3

Com a análise dos caminhos críticos, foram otimizados os valores das perdas de carga em cada trecho do modelo onde seria instalada a turbina, desta maneira, foi maximizado o potencial de geração de energia.

O próximo passo, que é consequência da otimização do potencial a ser utilizado, é o dimensionamento das turbinas. Elas passam a utilizar dos dados de simulação da rede com os aproveitamentos instalados para calcular as curvas de potência hipotéticas utilizadas para encontrar o ponto ótimo de utilização das turbinas. Este 
procedimento foi descrito no item 8.9.

Desta forma, as três equações foram otimizadas, encontrando os pontos ótimos de aproveitamento.

Com estes resultados determinou-se que as turbinas deveriam ser do tipo Turgo que é uma adaptação das turbinas Pelton.

As turbinas foram selecionadas a partir do catálogo da empresa Micro-Hydro-Power, comparando as condições de vazão e pressão especificadas para cada modelo com os valores obtidos na simulação dos modelos da rede no ponto de interesse.

Com os equipamentos especificados, voltou-se ao acionamento das turbinas, determinando junto às curvas de vazão e pressão os melhores intervalos para ativar o sistema de "by pass", e gerar energia.

Utilizando as informação de vazões e pressões no aproveitamento 1 foi obtida uma divisão que privilegia a passagem o fluxo pela turbina, aproveitando $100 \%$ das vazões e privilegiando a geração de energia.

Como as informações gráficas apresentam limites mínimo e máximo dos picos de pressão às 2:00 e 12:00 respectivamente, a produção poderia ter a necessidade de permitir que as vazões passassem livremente pelo conduto principal para que fossem mantidas as características ótimas na turbina. No entanto, para a situação estudada, a vazões e pressões permitem que a qualquer hora do dia a turbina pode ser acionada.

O mesmo ocorre para o aproveitamento 2, permitindo o acionamento em $100 \%$ do tempo, determinando o desligamento das turbinas apenas para manutenção.

A variação de vazão demandada no ponto de aproveitamento 3 faz necessário um cuidado maior na politica de acionamento das turbinas. A escolha da turbina, levando em conta o ponto ótimo de aproveitamento, determinou que durante períodos de tempo determinados, o "by-pass" para as turbinas deve ser fechado.

Esta operação garante não só a operação da turbina em seu ponto ótimo como a preservação das pressões nos extremos da rede.

Na Figura 59, é demonstrado graficamente que existe a necessidade de restringir a passagem do fluxo pelo "by-pass" quando a carga supera o valor ótimo de 5,73 m, com a seta vermelha indicando quando o "by-pass" será fechado e a seta azul quando o "by-pass" será aberto para a geração. Assim, parte do fluxo passa livremente pelo conduto para não prejudicar as pressões a jusante deste ponto, além de permitir que a geração de energia seja utilizada nas melhores condições de 
vazão, que influenciam nos resultados.

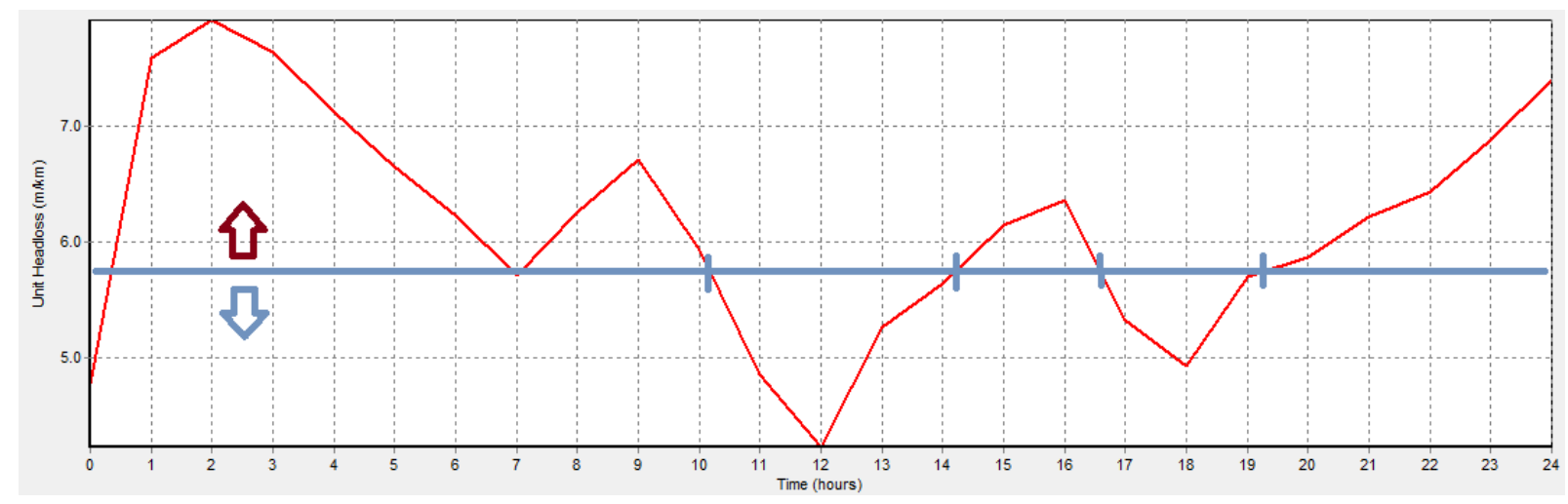

Figura 58- Limites para abertura ou não do "by-pass"

Para finalizar a metodologia proposta, resta a necessidade de avaliar e otimizar as perdas e benefícios/custos de perdas para o sistema de abastecimento.

A equação que determina as perdas é dependente da pressão que a rede é submetida, e a redução desta pressão é caracterizada pela subtração das perdas introduzidas pelas mini e micro turbinas. Como resultado, perda de carga introduzida será responsável pela redução das perdas na rede.

A variação da perda de carga (he) neste caso, apenas acompanha os valores estabelecidos pelos demais parâmetros aproximados nas otimizações anteriores. A redução da pressão em uma eventual otimização seria sempre a maior possível, seguindo os limites propostos como condições de contorno que a modelagem permite.

Portanto a otimização deste parâmetro não será necessária enquanto as demais otimizações já tenham sido realizadas.

Utilizando a formulação apresentada anteriormente no item 8.10, e aplicando os valores de "he" para determinar o potencial instalado no cálculo dos custos, ocorre o mesmo procedimento, uma vez que o aumento de "he" é diretamente proporcional com o aumento dos lucros.

Assim sendo, o procedimento de otimização não é necessário, permitindo o cálculo dos custos apenas com os procedimentos de otimização realizados anteriormente. Resulta desta conclusão apenas a necessidade de determinar, utilizando a equação proposta, os valores diários de retorno.

Como os valores utilizados nos calculados do item 8.10 foram os obtidos após as demais otimizações, considera-se os mesmo como saída final do procedimento. 
A partir desta ultima etapa, propõe-se que, por ser um processo iterativo, todos os procedimentos de otimização sejam realizados mais de uma vez em sequencia, considerando os resultados obtidos na primeira rodada para iniciar o procedimento subsequente. 


\section{RESULTADOS}

A seguir são descritos detalhadamente os resultados após a aplicação da metodologia.

\subsection{Configuração final da rede do Município de Piquete}

A configuração da instalação foi desenvolvida de modo que não houvesse interferência das turbinas quando não fosse desejada sua atuação. Desta forma, foi selecionada dentre as configurações possíveis, a integração entre turbinas e rede de abastecimento, indicada por Vilanove e Balestieri (2014).

A interface entre geração de energia e sistemas de abastecimento conecta as turbinas aos condutos, de forma que permaneçam em paralelo com a rede, formando um "by-pass" acionado nos momentos oportunos.

A configuração final da rede do Município de Piquete com a introdução das mini e micro turbinas resultou na instalação de três grupos geradores nos condutos principais.

A escolha dos pontos de instalação dos geradores levou em consideração as vazões e pressões, desconsiderando as necessidades de espaço e os custos de possíveis desapropriações na instalação das casas de força e na linha de transmissão.

Imaginou-se que com a evolução dos inversores e transformadores é possível a conexão direta destes geradores na rede de distribuição de energia usual, contabilizando e disponibilizando diretamente no ponto de geração.

É apresentada na Figura 60 a configuração final da rede com a instalação das três turbinas nos pontos indicados por círculos em vermelho. 


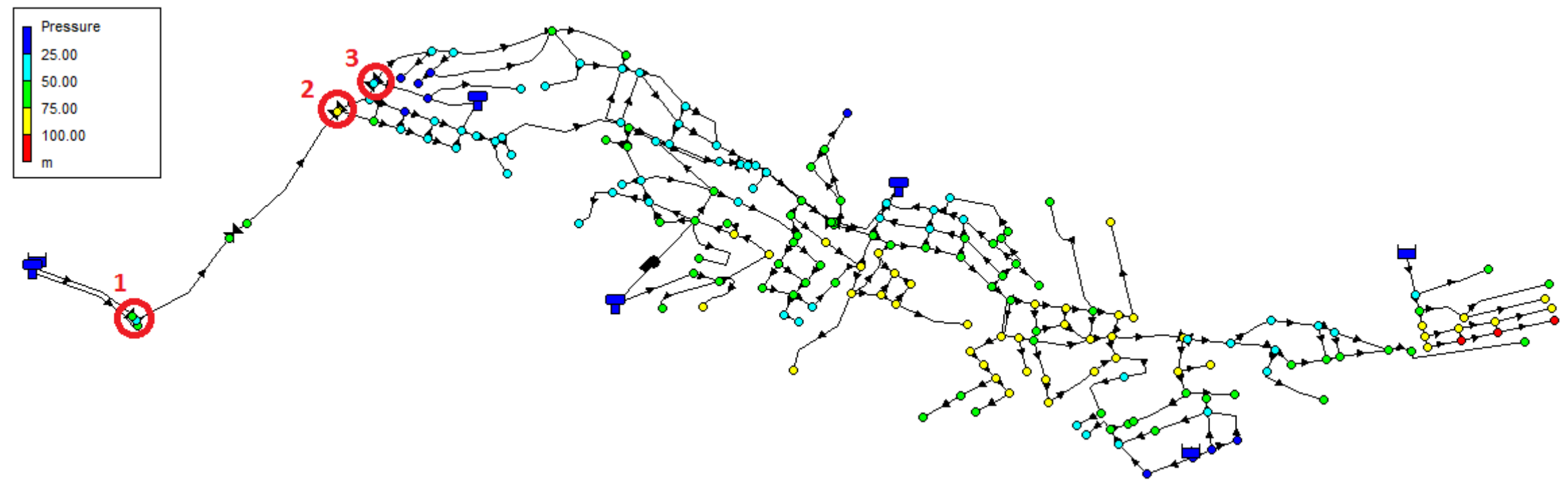

Figura 59- Configuração final dos três pontos de geração na rede do Município de Piquete 


\subsection{Otimização das pressões}

As turbinas foram então instaladas e modeladas, resultando em valores de vazão e pressão em cada trecho da rede simulada, permitindo a avaliação dos diversos pontos necessários para a otimização dos aproveitamentos.

Como resultados foram obtidos os mínimos valores de perda de carga adicionados pelos aproveitamentos para manutenção das pressões na extremidade da rede:

- Aproveitamento ponto 1: $11.42 \mathrm{~m}$

- Aproveitamento ponto 2: $16.67 \mathrm{~m}$

- Aproveitamento ponto 3: $4.99 \mathrm{~m}$

Anteriormente os valores haviam sido de 10, 15 e 4 metros respectivamente, o que indica que apesar de marginal, houve melhora no potencial proposto.

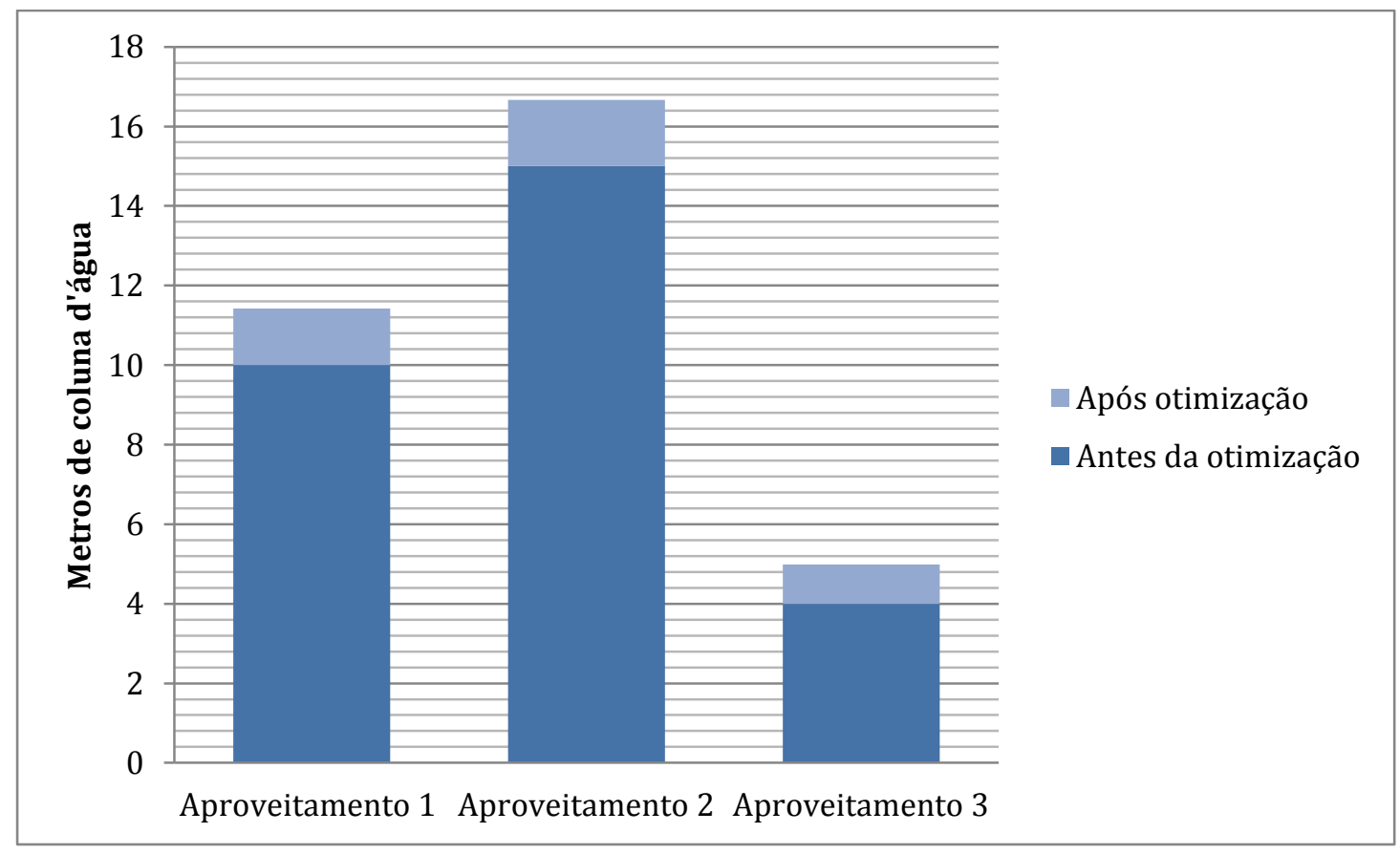

Figura 60 - Gráfico da evolução das pressões antes e depois da otimização

É necessário estabelecer um parâmetro que possa definir o termo marginal utilizado acima, definindo qual seria o impacto do aumento de 1 MCA para a geração de energia.

O acréscimo unitário resulta em um acréscimo de aproximadamente1 MW por ano na produção de energia. 


\subsection{Redução das perdas}

Foi realizada a partir destes valores de pressão otimizados com a ajuda do procedimento descrito por este estudo avaliando a redução das perdas como indicado no item 8 , e resultando em dois cenários, um anterior e outro posterior a instalação das turbinas.

O procedimento de cálculo das perdas foi realizado para os cenários, resultando nas respectivas vazões .

Anterior à instalação das turbinas:

- $A=0.5-3.932,4$ I/hora

- $A=1 \quad-15.371,0 \mathrm{l} / \mathrm{hora}$

- $A=2 \quad-372.133,8 \mathrm{l} / \mathrm{hora}$

Elas representam a soma das perdas em todos os trechos da rede.

Somando as vazões resultantes da instalação dos três aproveitamentos, no ponto 1 , 2 e 3, para cada um dos cenários foram obtidos os valores:

- $A=0.5-3776,8$ l/hora

- $A=1 \quad-14.359,1$ I/hora

- $A=2 \quad-339.382,3 \mathrm{l} / \mathrm{hora}$

Estes valores representam uma redução marginal das vazões de perda que, no entanto reduzem os custos e proporcionam benefícios para a manutenção dos mananciais.

A instalação de turbinas proporcionou a redução das pressões na rede, efeito semelhante ao resultante da instalação de válvulas redutoras de pressão na rede.

Sabendo que as perdas são diretamente proporcionais às pressões, e que esta relação varia consideravelmente conforme estudos relacionados, foram calculados três valores distintos de coeficientes para a equação de perdas por orifícios, 0,5, 1 e 2.

A diferença das perdas nos cenários com e sem aproveitamento resultaram portanto nas seguintes diferenças na vazão: 
- $A=0.5-3.932,4$ I/hora

- $A=1 \quad-15.371,0 \mathrm{l} / \mathrm{hora}$

- $A=2 \quad-372.133,8 \mathrm{l} / \mathrm{hora}$

A seguir é apresentado na Tabela 6 o resumo da redução das perdas na rede a partir da introdução das perdas de carga pelas turbinas.

Tabela 6 - Redução das perdas na rede

\begin{tabular}{|c|c|c|c|c|c|}
\hline $\begin{array}{c}\text { Ponto de } \\
\text { Aproveitamento }\end{array}$ & $\begin{array}{c}\text { Perda } \\
\text { de } \\
\text { Carga } \\
\text { (MCA) }\end{array}$ & $\begin{array}{c}\text { Coeficiente } \\
\text { A }\end{array}$ & $\begin{array}{c}\text { Situação atual } \\
\text { sem turbinas } \\
\text { (l/hora) }\end{array}$ & $\begin{array}{c}\text { Situação com } \\
\text { turbinas } \\
\text { (l/hora) }\end{array}$ & $\begin{array}{c}\text { Diferença } \\
\text { (l/hora) }\end{array}$ \\
\hline 1 & 11,42 & 0,5 & 3932,4 & 3776,8 & 153,6 \\
\hline 2 & 16,67 & 1 & 15371,0 & 14359,1 & 1011,9 \\
\hline 3 & 4,99 & 2 & 372133,8 & 339382,3 & 32751,5 \\
\hline
\end{tabular}

\subsection{Geração de energia}

$\mathrm{Na}$ sequencia foram obtidos os valores que maximizam a geração de energia na rede, resultando nos seguintes valores de potencia para cada um dos três aproveitamentos:

Tabela 7 - Resultados da geração otimização da geração de energia

\begin{tabular}{|c|c|}
\hline $\begin{array}{c}\text { Ponto de } \\
\text { Aproveitamento }\end{array}$ & Energia (kWh) \\
\hline 1 & 1,15 \\
\hline 2 & 1,71 \\
\hline 3 & 0,053 \\
\hline
\end{tabular}

\subsection{Máquinas hidráulicas utilizadas e configuração}

Levando em conta os valores da potencia em cada ponto, optou-se por verificar no mercado quais seriam as turbinas mais indicadas para o aproveitamento, e como resultado foram obtidas as seguintes maquinas hidráulicas:

- Aproveitamento ponto 1: Turbina Turgo modelo XJ22-1.1DCTH4-Z que tem como parâmetros desnível/carga de 15 m, vazão nominal de 10 a 15 l/s com diâmetro de 
125 a $150 \mathrm{~mm}$, trabalhando como uma eficiência de $70 \%$ e resultando em um máximo de $1100 \mathrm{~W}$ gerados.

- Aproveitamento ponto 2: Turbina Turgo modelo XJ25-1.5DCTH4-Z que tem como parâmetros desnível/carga de $15 \mathrm{~m}$, vazão nominal de 12 a $18 \mathrm{l} / \mathrm{s}$ com diâmetro de 125 a $150 \mathrm{~mm}$, trabalhando como uma eficiência de $70 \%$ e resultando em um máximo de $1500 \mathrm{~W}$ gerados.

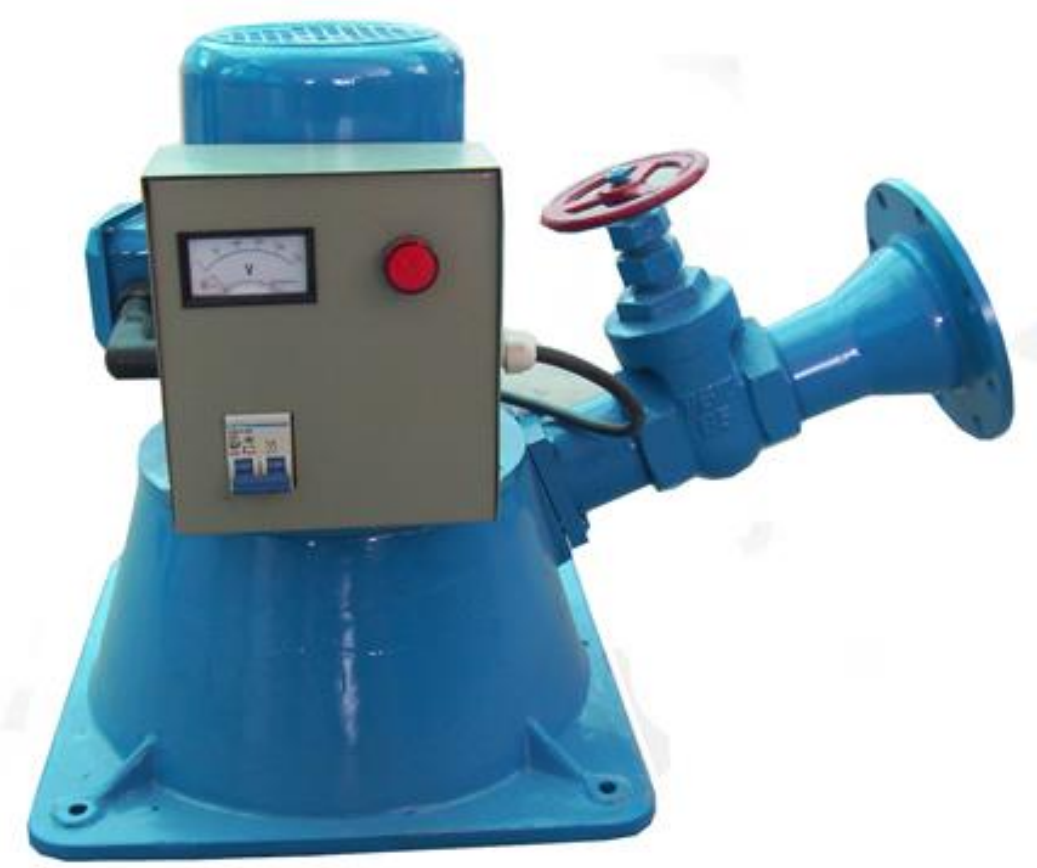

Figura 61-Turbinas XJ22-1.1DCTH4-Z e XJ25-1.5DCTH4-Z indicada para os pontos $1 \mathrm{e}$ 2 , respectivamente.

- Aproveitamento ponto 3: Turbina Turgo modelo XJ14-0.3DCT4-Z que tem como parâmetros desnível/carga de 12 a $14 \mathrm{~m}$, vazão nominal de 2 a $5 \mathrm{l} / \mathrm{s}$ com diâmetro de $50 \mathrm{~mm}$, trabalhando como uma eficiência de $70 \%$ e resultando em um máximo de $300 \mathrm{~W}$ gerados. 


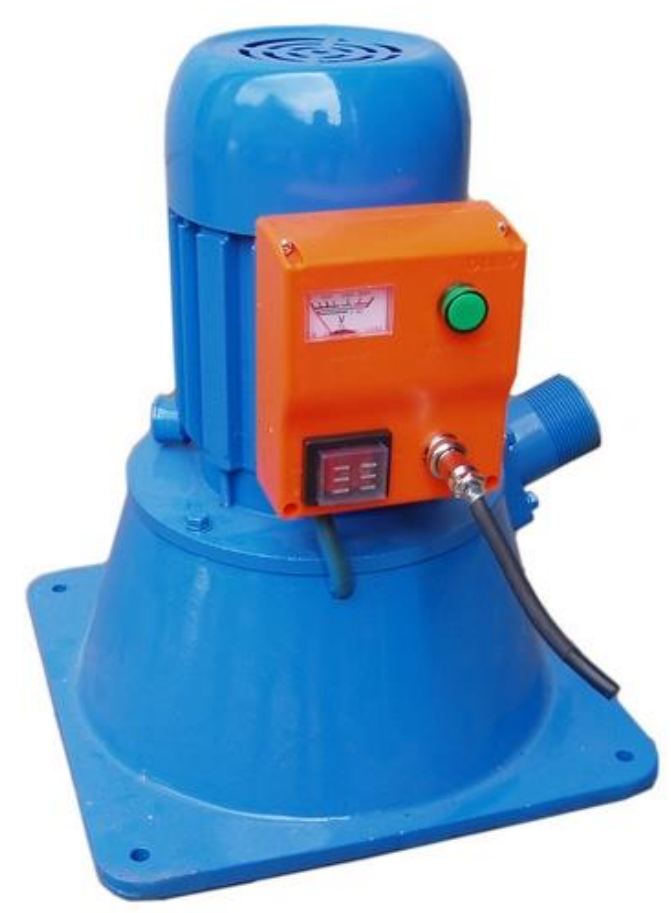

Figura 62-Turbina XJ14-0.3DCT4-Z indicada para o ponto 3.

\subsection{Energia gerada}

Considerando a potencia dos equipamentos instalados, e seu tempo de acionamento, foi calculada uma potencia gerada, resultando em um total de 68,96 $\mathrm{kW} /$ dia, que comparativamente com a energia consumida com o bombeamento na rede de 66,35 kW/dia, supera as necessidades da rede de Piquete em 2,61 kW/dia.

Tabela 8 - Relação de turbinas e energia gerada

\begin{tabular}{|c|c|c|c|}
\hline Identificação & Equipamento & Potência $(\mathrm{kW})$ & $\begin{array}{c}\text { Energia } \\
\text { gerada } \\
\text { (kW/dia) }\end{array}$ \\
\hline Aproveitamento 1 & XJ22-1.1DCTH4-Z & 1,15 & 27,6 \\
\hline Aproveitamento 2 & XJ25-1.5DCTH4-Z & 1,71 & 41,04 \\
\hline Aproveitamento 3 & XJ14-0.3DCT4-Z & 0,053 & 0.32 \\
\hline
\end{tabular}

A instalação de um número maior de turbinas na rede pode incrementar a geração de energia, no entanto, necessita de ferramentas que possam conectar a modelagem hidráulica com a otimização, facilitando 0 estudo de casos 
contemporaneamente aos ajustes necessários para o dimensionamento das turbinas.

O desenvolvimento apresentado nesta dissertação não inclui este tipo de ferramenta, sendo realizada a rodada do modelo hidráulico a cada rodada de otimização, atingindo através do caminho critico identificado os valores ótimos a cada iteração do processo. Este processo é trabalhoso e impeditivo para o caso do número de turbinas for elevado.

Como resultado destas iterações, foram obtidos os seguintes resultados:

Tabela 9 - Resumo dos aproveitamentos conforme parâmetros de dimensionamento

\begin{tabular}{|c|c|c|c|}
\hline Identificação & Vazão (l/s) & Potência $(\mathrm{kW})$ & Carga $(\mathrm{m})$ \\
\hline Aproveitamento 1 & 16.13 & 1,15 & 10.4 \\
\hline Aproveitamento 2 & 16 & 1,71 & 15.65 \\
\hline Aproveitamento 3 & 1,37 & 0,053 & 5.73 \\
\hline
\end{tabular}

Como a atuação do aproveitamento número 3 é influenciado pelo acionamento das turbinas, o horário de funcionamento baixa de 24 horas para 6 horas diárias.

\subsection{Benefícios financeiros}

Os benefícios financeiros da instalação das mini e micro turbinas na rede foram resultado da geração de energia e da redução das perdas.

Utilizando as equações destacadas anteriormente, foram obtidos os seguintes valores:

$$
\begin{aligned}
D_{\text {lucros totais }}= & 2,63 \cdot\left(Q_{\text {Servida }}\right)-1,87\left(Q_{\text {Servida }}+Q_{\text {Perdas }}\right)-0,301 \cdot 24 \cdot(17 \cdot 28 * 0.16) \\
& +0,301 \cdot 24 \cdot(2,913)+1,87\left(Q_{\text {Perdas }}\right)
\end{aligned}
$$

Com $Q_{\text {Servida }}=2206.35 \mathrm{~m}^{3} / \mathrm{dia} \quad$ e para $\mathrm{A}=1, \quad Q_{\text {Perdas }}=24,28 \mathrm{~m}^{3} / \mathrm{dia} \quad$ ou aproximadamente, redução de $6,6 \%$ de perdas que resulta em:

$$
\begin{aligned}
D_{\text {lucros totais }}= & 2,63 .(2206.35)-1,87(2206.35+24.28)-0,301 * 24 *(17.28 * 0.16) \\
& +0,301 * 24 *(2.913)+1,87(24.28) \\
& =5802,7-4171.28-19,97+21,04+45.41=1.677,95 R \$ / \text { dia }
\end{aligned}
$$


Estes lucros podem ser divididos em dois valores distintos, sendo eles os lucros usualmente obtidos com a venda de água e os valores obtidos com a produção de energia e pela redução das perdas promovida pelas turbinas.

Desta forma, foram obtidos $1.611,5 \mathrm{R} \$$ /dia de lucro que seria normalmente obtido e $66,45 \mathrm{R} \$$ /dia de lucro adicional com a produção de energia e redução das perdas.

Com $C_{\text {Equip }}$ sendo igual à multiplicação entre a potencia instalada e o valor médio das instalações de 13.500,00 R\$/kW:

$C_{\text {Equip }} 1=13.500 * 1,15=15.525$

$C_{\text {Equip }} 2=13.500 * 1,71=23.085$

$C_{\text {Equip }} 3=13.500 * 0.053=715,5$

A estes valores, deve-se somar o custo das obras civis, que podem dobrar o valor total da instalação, resultando em um valor aproximado de $R \$ 78.651,00$ em equipamentos e instalação.

Os valores dos equipamentos devem ser abatidos ao longo de um tempo de retorno do investimento que será calculado a partir da diferença entre os lucros normais e os com aproveitamento, resultando em $66,45 \mathrm{R} \$$ /dia calculado anteriormente que soma em um ano o valor de $\mathrm{R} \$ 24.254,25$.

A geração de energia, seguindo as indicações da Normativa 512 (ANEEL, 2012), gerou retorno abatendo integralmente os gastos de energia com o bombeamento existente, e adicionalmente podendo abater mais uma parcela da energia gasta com outras unidades da empresa de abastecimento.

Para o cálculo dos benefícios financeiros com a redução das perdas, considerou-se que o valor gasto com as perdas é representado pelo preço da água comercializada pela distribuidora.

Neste caso, com as perdas a distribuidora deixaria de faturar sobre estes volumes perdidos. Desta forma, os ganhos obtidos com a redução das perdas vêm da multiplicação dos volumes pelo valor cobrado.

O valor resultante representou benefício evidente para o retorno financeiro da implantação das mini e micro turbinas, que demandou $R \$ 78.651,00$, para a instalação. 
Este valor pode ser abatido em apenas 3,2 anos depois do inicio da operação, o que representa um tempo de "payback" muito baixo, frente aos tempos normalmente empregados na construção de redes de distribuição. 


\section{Discussão}

A metodologia formulada para a avaliação da produção de energia a partir de mini e/ou microgeração em redes de distribuição de água obteve resultados em acordo com o que é esperado de uma metodologia que simplifica os procedimentos de análise, proporcionando um caminho intuitivo e escalonado de atividades e pontos de apoio que resultam em uma avaliação compreensiva, tecnológica e numericamente de fácil compreensão.

$\mathrm{Na}$ área destinada ao estudo de caso, o andamento da metodologia mostrou que para redes de pequeno porte, como a do Município de Piquete, o procedimento pode muitas vezes ser realizado utilizando ferramentas menos complexas, e evitando procedimentos que tornam os estudos mais trabalhosos.

Intuitivamente, os passos apresentados encadeiam as atividades que devem ser realizadas impreterivelmente para avaliar a interferência em uma rede de distribuição de água já instalada, no entanto, utilizando redes hipotéticas e ainda em fase de projeto, os benefícios da metodologia podem ser mais disfrutados, lembrando que a escolha de diâmetros e encaminhamento podem mudar significativamente os resultados.

Para o cálculo de perdas de carga localizadas "hl", em fase de projeto é possível modificar o diâmetro das tubulações de forma que pressões e vazões sejam mais extremas em pontos específicos da rede onde podem ser mais bem aproveitados para a geração de energia, não deixando de garantir o abastecimento dentro das normas estabelecidas.

Esta discussão foi feita também por Carravetta (2013), que obteve em sua rede a conclusão de que seria possível reformar ou projetar diretamente as redes adaptadas ao aproveitamento hidrelétrico.

Em especial, o estudo de caso proporcionou um cenário crítico para a avaliação, pois é uma rede de pequenas dimensões, consequentemente com pequenas demandas e vazões baixas apesar de em primeira avaliação os desníveis de terreno aparentar condições favoráveis ao aproveitamento.

A partir deste fato, ao final do cálculo dos custos e do tempo de retorno de investimento, constatou-se que a produção de energia neste caso não foi decisiva para a implantação das turbinas, gerando energia suficiente para compensar os gastos com energia considerando uma única estação elevatória na rede. 
Foi possível notar que a maior parcela dos ganhos com a implantação das mini e micro turbinas foi obtida pela redução das perdas, e não pela produção de energia, onde foram obtidos $R \$ 21,04 /$ dia resultantes da produção de energia, enquanto foram obtidos $\mathrm{R} \$ 45,41 /$ dia por simplesmente reduzir a perda de água.

No Município de Piquete, a produção de energia compensaria integralmente a energia consumida com seu único bombeamento.

Imaginando que a mesma metodologia fosse aplicada em sistemas como o do Município de São Paulo, espera-se que os gastos com elevatórias sejam abatidos e/ou igualados, o que representaria um benefício de maior escala já que o número de elevatórias e os gastos com energia para distribuição são significativamente maiores, representando na escala do sistema de abastecimento de São Paulo, milhões de reais.

Comparativamente aos resultados obtidos nos estudos relacionados ao tema, ocorreram diversas compatibilidades. Como nos estudos de Lima (2013) e Silva (2012), onde foram obtidos benefícios suficientes para garantir que os custos envolvidos na instalação das turbinas fossem abatidos rapidamente com o retorno da produção de energia. Entretanto, na rede aqui estudada, utilizando a redução de perdas na rede como parâmetro de cálculo dos valores obtidos, constatou-se que seus benefícios são extremamente convidativos. Esta abordagem não havia sito levantada em nenhum dos outros estudos relacionados.

Lima (2013) cita que os aproveitamentos seriam mais indicados para pontos de grandes desníveis e de grandes vazões, o que acabou confirmado pelo estudo da rede do Município de Piquete.

No entanto, para o caso da escolha das turbinas, Ramos (2010) optou por utilizar turbinas reversíveis (bombas como turbinas), enquanto os resultados de Piquete demonstram que a melhor configuração seria a de instalar turbinas Turgo, que são uma categoria das turbinas Pelton. 


\section{Conclusões}

Para finalizar os estudos, é interessante gerar uma avaliação da viabilidade da instalação das centrais hidrelétricas na rede do Município de Piquete. Apesar de a análise prévia indicar que o aproveitamento energético é interessante para abater os custos da própria rede de abastecimento e demonstrar que com a redução das perdas os benefícios serão ainda maiores, a escolha dos pontos na rede é um fator que ainda necessita de maiores estudos.

Assim, a avaliação dos resultados será realizada, levando em conta o benefício que cada etapa de otimização e escolha na rede, trás ao Município.

Outro ponto a ser considerado nos resultados é a configuração das estruturas na rede, podendo ser elas em linha ou instaladas em paralelo com o conduto, tendo ou não a participação conjunta com válvulas ou outros dispositivos de controle. Neste caso foi adotada a configuração em paralelo, para que fosse possível o acionamento isolado das turbinas tornando melhores as condições de acionamento.

Além da instalação em paralelo, a possibilidade de instalação de válvulas em conjunto com as turbinas, cria um sistema com redundâncias capazes de proteger e desenvolver na rede a gestão dos recursos servidos.

A utilização das turbinas como dispositivos de controle das pressões e consequentemente de perdas para avaliar a viabilidade das instalações deve levar em conta que os benefícios resultantes desta aplicação também poderiam ser obtidos com a simples instalação de válvulas redutoras de pressão e controle.

Desta forma, a avaliação completa para determinar qual seria a medida mais vantajosa de instalação ou projeto das redes de distribuição, deve partir da comparação dos resultados de ambos cenários.

Neste caso, mesmo sem realizar qualquer tipo de simulação somente com a utilização de válvulas redutoras, é de se esperar que os benefícios trazidos pela instalação de mini e/ou micro turbinas na rede tenham um impacto mais benéfico por adicionar o beneficio da geração de energia aos demais compartilhados com as válvulas redutoras.

Portanto, como demonstrado na metodologia descrita pela dissertação, existe a possibilidade técnica de formular e posicionar sistemas de aproveitamento energético na rede de distribuição de água, sendo também considerada uma medida que trás benefícios que superam as medidas que são adotadas atualmente apenas 
para o controle de pressões.

Desta forma o agrupamento destas informações é suficiente avaliar que a viabilidade do procedimento proposto de estudo da viabilidade e metodologia de avaliação dos aproveitamentos por mini e/ou micro centrais hidrelétricas na rede, vêm incluir uma alternativa interessante para o aprimoramento dos sistemas de abastecimento já instalados e para fomentar as melhorias de projetos de redes futuras. 


\section{Referências Bibliográficas}

ABES - Perdas em Sistemas de Abastecimento de Água: Diagnóstico, potencial de ganhos com sua redução e propostas de medidas para o efetivo combate. Associação Brasileira de Engenharia Sanitária e Ambiental. Setembro de 2013.

Agência Nacional de Energia Elétrica - ANEEL, Resolução Normativa № 394, de 04 de Dezembro de 1998.

Agência Nacional de Energia Elétrica - ANEEL, Resolução Normativa № 482, de 17 de Abril de 2012.

Agência Nacional de Energia Elétrica - ANEEL, Resolução Normativa № 517, de 11 de Dezembro de 2012.

Afshar, A., F. Ben Jemaa, et al. (1990). "OPTIMIZATION OF HYDROPOWER PLANT INTEGRATION IN WATER-SUPPLY SYSTEM." Journal of Water Resources Planning and Management-Asce 116(5): 665-675.

Alperovits, E. and U. Shamir, Design of optimal water distribution systems, Water Resource. Res., 13 (6), 885-900, 1977.

Bertsekas D. P. (1991). Linear Network Optimization: Algotithms and Codes. ISBN 10,0262023344 .

BP - British Petroleum 2009. Statistical Review of World Energy 2009. 
http://www.bp.com/, 2014

CAB Piquete, http://www.cabpiquete.com.br, Prefeitura de Piquete, acessado em 2012.

Carravetta A., Fecarotta O., Sinagra M. e Tucciarelli T., Journal of Water Resources Planning and Management. June, 2013. doi:10.1061/(ASCE)WR.1943 452.0000384.

Cetesb, http://www.cetesb.sp.gov.br/userfiles/file/agua/aguas-superficiais/aguasinteriores/documentos/indices/03.pdf, Companhia de Tecnologia de Saneamento Ambiental, acessado em dezembro de 2014.

Charles E. Bayless, "Less is More: Why Gas Turbines Will Transform Electric Utilities." Public Utilities Fortnightly 12/1/94.

Decreto 5.163 de 30 de Julho de 2004, Presidência da República.

Eiger, G., U. Shamir, and A. Ben-Tal, Optimal design of water distribution networks, Water Resour. Res., 30 (9), 2637-2646, 1994.

European Small Hydropower Association - ESHA , 2010, www.esha.be/,2014a.

European Small Hydropower Association - ESHA , 2013, www.esha.be/,2014b. 
Gitman, L. J. Princípios de Administração Financeira. São Paulo, 10ª Ed. Pearson Addison Wesley, 2006

Giugni, M., N. Fontana, et al. (2009). Energy saving policy in water distribution networks. International Conference on Renewable Energies and Power Quality (ICREPQ'09). Valencia, Spain.

Giustolisi et. Al. (2013), Operacional Optimization: water losses versus Energy Costs, Journal of Hydraulic Engineering, ASCE, Abril 2013.

Goldberg, D. E. 1989. Genetic algorithms in search, optimization and machine learning , Addison-Wesley, Reading, Mass.

Gonçalves, F.V. (2012). Previsão e optimização de soluções hibridas sustentáveis de energia em SSA: concepção de RNA. Aplicação AG e análise experimental. Tese de doutorado. Lisboa, Portugal.

Hosseini S.M.H., Forouzbakhsh F., Rahimpoor M. (2005). Determination of the optimal installation capacity of small hydro-power plants through the use of technical, economic and reliability indices. Energy Policy, Vol. 33, pp. 1948-1956. doi: 10.1016/j.enpol.2004.03.007.

IEA, 2009. International Energy Agency. http://www.iea.org/, 2014.

INEE -Instituto Nacional de Eficiência Energética. O que é Geração Distribuída? Disponível em: http://www.inee.org.br/forum_ger_distrib.asp, 2012. 
IPCC - Intergovernmental Panel on Climate Change, 2009. Chapter 5, Hydropower, pp. 443-446.

IJHD (2010). World Atlas \& Industry Guide. International Journal of Hydropower and Dams, Wallington, Surrey, UK, 405 pp.

Karlis A.D., Papadopoulos D.P. (2000). A systematic assessment of the technical feasibility and economic viability of small hydroelectric system installations. Renewable Energy, Vol. 20, pp. 253-262.

Khosrowpanah, S., Albertson, M., and Fiuzat, A. (1984). "Historical overview of Cross-Flow turbine."Int Water Power Dam Construction, 38-4.

Labadie, G.M., Herzog, M.T. (1999). Optimal design of water distribution networks with GIS. ESRI User Conference, pp:756.

Lansey, K. E., and Mays, L. W. 1989. "Optimization model for water distribution system design."Journal of Hydraulic Engineering, 115-101 , 1401-1418.

Lei 10.848, de 15 de Março de 2004, Congresso nacional.

Liberatore, S. and G. M. Sechi (2009). "Location and Calibration of Valves in Water Distribution Networks Using a Scatter-Search Meta-heuristic Approach." Water Resources Management 23(8): 1479-1495. 
Lima, G.M., Microgeração em Sistemas de Abastecimento de Água, dissertação de mestrado, Universidade Federal de Itajubá, 2013.

Moreire, J.R. \& Poole, A.D. (1993) Hydropower and its constraints. In: Johansson T.B. et al, (1993) Renewable energy : sources for fuels and electricity (ISBN 185383-155-7).

Micro-Hydro-Power showroom, dezembro de 2014. http://www.micro-hydropower.com/index.htm.

Miotto F, Claps P., Revelli R, Poggi D. Produzione di energia idroelettrica ecocompatibile da acquedotti: analisi di fattibilita' economica. In: XXXI Convegno Nazionale di Idraulica e Costruzioni Idrauliche Perugia, 9-12 settembre 2008. 31i Convegno Nazionale di Idraulica e Costruzioni Idrauliche. Perugia. Settembre 2008. (pp. 1-8). Electronic Proceedings. [pdf]

Netto, A.J.M.; Fernandez Y Fernandez, M.; Araujo, R. de; Ito, A.E.- Manual de hidráulica. ed 8. São Paulo: Blücher, 1998.

Nicola Fontana; Maurizio Giugni; and Davide Portolano, Losses Reduction and Energy Production in Water-Distribution Networks, DOI: 10.1061/(ASCE)WR.19435452.0000179. American Society of Civil Engineers, 2012.

NBR 12218/94 - Projeto de rede de distribuição de água para abastecimento público. 
NBR 6445/88 - Turbinas hidráulicas, turbinas-bombas e bombas de acumulação.

Pasqualetto C. R. da C., A. $3^{\circ}$ Congresso Internacional de Tecnologia para o Meio Ambiente, Bento Gonçalves - RS, Abril 2012.

Plano Nacional de Eficiência Energética (2011), Ministério de Minas e Energia, 2013. http://www.mme.gov.br/mme/galerias/arquivos/PlanoNacEfiEnergetica.pdf.

Ramos, H.M., Mello, M., De, P.K. (2010). Clean power in water supply systems as a sustainable solution: from planning to practical implementation. IWA Publishing, Water Science \& Technology: Water Supply_WSTWS | 10.1 | 2010.

Ramos, H., D. Covas, et al. (2005). Available energy assessment in water supply systems. XXXI IAHR Congress. Seoul, Korea.

Relatório de Balanço Energético Nacional, 2013, http://www.epe.gov.br.

Rossman, L. (2000) EPA, EPANET 2 User Manual. Office of Water. United States Environmental Protection Agency. EPA/600/R-00/057, September 2000.

SABESP - Companhia de Saneamento Básico do Estado de São Paulo. www.sabesp.com.br, 2012.

SIPOT - Sistema de Informações do Potencial Hidrelétrico Brasileiro, dezembro de 2012, Eletrobras. www.eletrobras.com/elb/data/Pages/LUMIS21D128D3PTBRIE.htm. 
Schardong A., 2006. Aplicação de técnicas de programação linear e extensões para otimização da alocação de água em sistemas de recursos hídricos, utilizando métodos de pontos interiores. Biblioteca Digital de Teses e Dissertações da USP.

Silva B. L. A., 2012. Levantamento do Potencial Energético e Estudo da Viabilidade da Geração Hidrelétrica Utilizando a Rede Pública de Distribuição de Água - Estudo de Caso: Sistema de Abastecimento de Água de Pato Branco. Biblioteca de teses e dissertações, UTFPR, 2012.

Sindipeças - Combustíveis Veiculares: As Alternativas Viáveis, III Fórum do Meio Ambiente, Outubro 2005.

SOFFIA C., CLAPS P, POGGI D, Valutazione preliminare su grande scala del potenziale di produzione di energia idroelettrica eco-compatibile da sistemi acquedottistici, L'ACQUA, 2010, Vol. 2, ISSN: 1125-1255 [pdf].

Su, Y. C., May, L. W., Duan, N., and Lansey, K. E.,1987. "Reliability-based optimization model for water distribution systems.", Journal Hydraulic Engineering, 113-12, 1539-155.

SNIS, 2011. Sistema Nacional de Informações Sobre Saneamento. Diagnóstico dos Serviços de Água e Esgotos, Ministério das Cidades, Sistema Nacional de Informações Sobre Saneamento - SNIS, 2011. 
Tsutiya. M.T.,2004. Abastecimento de Água. 1aㅡ Edição. São Paulo - SP. Departamento de Engenharia Hidráulica e Sanitária da Escola Politécnica da Universidade de São Paulo. 2004. 643 p.

United Nations Educational, Scientific and Cultural Organization (UNESCO). The United Nations Word Water Development Report 3: Water in a Changing World. 2009.

Viegas J.V., Paz M.F., Gastaldini M.C.C., Danielle R.D., Barroso L.B. (2002). Simulação do comportamento hidráulico de redes de abastecimento de água utilizando o modelo EPANET. XXVIII Congreso Interamericano de Ingenieria Sanitaria y Ambiental, Cancùn, México.

Vilanova M. R. N. e Balstieri J. A. P. (2014). Hydropower recovery in water supply systems: Models and case study. Energy Conversion and Management. Volume 84, August 2014, Pages 414-426.

Voith (2014), (http://www.voith.com/br/gp2_vh_3_D_francis_x_000255.png

Voros N.G., Kiranoudis C.T., Maroulis Z.B. (2000). Short-cut design of small hydroelectric plants. Renewable Energy, Vol. 19, pp. 545- 563.

Xu, C., and Goulter, I. C.1999. "Reliability-based optimal design of water distribution networks.", Journal of Water Resource. Planning and. Management.,125-6, 352362. 
World Energy Council, 2002. http://www.worldenergy.org/publications/, 2012.

Zyl J.E. van (2004). The effect of pressure on leaks in water distribution systems.

Proceedings of the 2004 Water Institute of Southern Africa (WISA) Biennial conference, May 2004, Cape Town, South Africa. ISBN: 1-920-01728-3. 
Anexo 1

\begin{tabular}{|c|c|c|c|c|c|}
\hline \multicolumn{3}{|c|}{ Pressão (m) } & $a=0.5$ & $a=1$ & $a=2$ \\
\hline Sem Aproveitamento & Com Aproveitamento & Diferença & \multicolumn{3}{|c|}{ valores em L/Hora } \\
\hline 48.9 & 69.0 & 0.0 & 0.0 & 0.0 & 0.0 \\
\hline 46.4 & 48.0 & 0.0 & 0.0 & 0.0 & 0.0 \\
\hline 48.0 & 92.3 & 0.0 & 0.0 & 0.0 & 0.0 \\
\hline 42.9 & 23.2 & 19.6 & 33.2 & 147.3 & 2893.0 \\
\hline 47.1 & 33.0 & 14.2 & 28.2 & 106.1 & 1501.7 \\
\hline 69.0 & 48.1 & 20.9 & 34.3 & 156.9 & 3282.3 \\
\hline 36.7 & 19.1 & 17.6 & 31.5 & 132.1 & 2325.8 \\
\hline 52.9 & 42.7 & 10.2 & 23.9 & 76.1 & 772.7 \\
\hline 47.4 & 27.5 & 19.8 & 33.4 & 148.7 & 2949.2 \\
\hline 30.3 & 14.6 & 15.7 & 29.7 & 117.9 & 1853.4 \\
\hline 68.9 & 39.3 & 29.7 & 40.9 & 222.6 & 6606.8 \\
\hline 49.7 & 51.5 & 0.0 & 0.0 & 0.0 & 0.0 \\
\hline 39.0 & 40.0 & 0.0 & 0.0 & 0.0 & 0.0 \\
\hline 60.3 & 71.7 & 0.0 & 0.0 & 0.0 & 0.0 \\
\hline 45.6 & 32.9 & 12.7 & 26.7 & 95.4 & 1213.5 \\
\hline 53.7 & 42.8 & 10.9 & 24.7 & 81.4 & 882.9 \\
\hline 57.9 & 47.8 & 10.1 & 23.8 & 75.8 & 766.6 \\
\hline 44.4 & 23.1 & 21.3 & 34.6 & 159.9 & 3409.1 \\
\hline 48.7 & 28.3 & 20.4 & 33.9 & 152.9 & 3118.1 \\
\hline 76.4 & 63.1 & 13.3 & 27.4 & 100.0 & 1332.7 \\
\hline 54.5 & 46.4 & 8.1 & 21.4 & 61.0 & 495.7 \\
\hline 53.2 & 46.3 & 6.9 & 19.7 & 51.7 & 356.0 \\
\hline 49.9 & 44.2 & 5.7 & 18.0 & 43.0 & 246.2 \\
\hline 49.7 & 51.5 & 0.0 & 0.0 & 0.0 & 0.0 \\
\hline 43.4 & 36.6 & 6.8 & 19.6 & 51.3 & 350.9 \\
\hline 39.4 & 32.6 & 6.8 & 19.6 & 51.2 & 348.8 \\
\hline 44.2 & 37.3 & 6.9 & $\begin{array}{l}19.7 \\
\end{array}$ & 51.8 & 357.1 \\
\hline 67.3 & 60.3 & 7.0 & 19.8 & 52.4 & 366.5 \\
\hline 53.1 & 46.1 & 7.0 & 19.8 & 52.3 & 364.4 \\
\hline 48.6 & 46.5 & 2.0 & 10.7 & 15.2 & 30.6 \\
\hline 53.8 & 52.6 & 1.2 & 8.3 & 9.1 & 11.0 \\
\hline 33.9 & 35.1 & 0.0 & 0.0 & 0.0 & 0.0 \\
\hline 39.7 & 34.5 & 5.2 & 17.1 & 38.9 & 201.2 \\
\hline 55.4 & 49.3 & 6.1 & 18.5 & 45.8 & 279.1 \\
\hline 23.7 & 48.6 & 0.0 & 0.0 & 0.0 & 0.0 \\
\hline 33.7 & 62.0 & 0.0 & 0.0 & 0.0 & 0.0 \\
\hline 38.7 & 63.6 & 0.0 & 0.0 & 0.0 & 0.0 \\
\hline 68.7 & 79.9 & 0.0 & 0.0 & 0.0 & 0.0 \\
\hline 63.8 & 65.2 & 0.0 & 0.0 & 0.0 & 0.0 \\
\hline 63.7 & 73.6 & 0.0 & 0.0 & 0.0 & 0.0 \\
\hline 63.8 & 65.2 & 0.0 & 0.0 & 0.0 & 0.0 \\
\hline 33.9 & 35.1 & 0.0 & 0.0 & 0.0 & 0.0 \\
\hline 63.9 & 65.1 & 0.0 & 0.0 & 0.0 & 0.0 \\
\hline 45.0 & 28.1 & 16.9 & 30.8 & 126.5 & 2134.5 \\
\hline 55.1 & 57.2 & 0.0 & 0.0 & 0.0 & 0.0 \\
\hline
\end{tabular}




\begin{tabular}{|c|c|c|c|c|c|}
\hline \multicolumn{3}{|c|}{ Pressão (m) } & $a=0.5$ & $a=1$ & $a=2$ \\
\hline Sem Aproveitamento & Com Aproveitamento & Diferença & \multicolumn{3}{|c|}{ valores em L/Hora } \\
\hline 86.3 & 79.0 & 7.3 & 20.2 & 54.5 & 396.4 \\
\hline 61.3 & 54.3 & 7.0 & 19.9 & 52.6 & 368.6 \\
\hline 46.7 & 45.3 & 1.5 & 9.1 & 11.0 & 16.2 \\
\hline 72.3 & 65.3 & 7.0 & 19.8 & 52.4 & 365.4 \\
\hline 72.6 & 67.7 & 4.9 & 16.6 & 36.9 & 181.5 \\
\hline 72.6 & 67.7 & 4.9 & 16.7 & 37.1 & 183.0 \\
\hline 72.6 & 67.6 & 5.0 & 16.8 & 37.4 & 186.8 \\
\hline 62.6 & 57.6 & 5.0 & 16.8 & 37.4 & 186.8 \\
\hline 72.6 & 67.6 & 5.0 & 16.7 & 37.3 & 185.3 \\
\hline 62.6 & 57.6 & 5.0 & 16.7 & 37.4 & 186.0 \\
\hline 57.6 & 52.6 & 5.0 & 16.8 & 37.6 & 188.3 \\
\hline 42.6 & 37.6 & 5.0 & 16.8 & 37.6 & 188.3 \\
\hline 47.6 & 42.6 & 5.0 & 16.8 & 37.7 & 189.0 \\
\hline 51.4 & 44.2 & 7.2 & 20.1 & 53.6 & 383.4 \\
\hline 33.8 & 34.8 & 0.0 & 0.0 & 0.0 & 0.0 \\
\hline 45.7 & 25.1 & 20.6 & 34.0 & 154.1 & 3167.3 \\
\hline 57.4 & 37.6 & 19.8 & 33.4 & 148.7 & 2946.2 \\
\hline 40.3 & 24.6 & 15.7 & 29.7 & 117.9 & 1853.4 \\
\hline 51.2 & 35.0 & 16.2 & 30.2 & 121.5 & 1968.3 \\
\hline 58.9 & 50.2 & 8.7 & 22.1 & 65.0 & 562.5 \\
\hline 43.3 & 30.4 & 13.0 & 27.0 & 97.3 & 1261.7 \\
\hline 43.3 & 30.3 & 13.0 & 27.0 & 97.5 & 1267.5 \\
\hline 48.3 & 35.3 & 13.0 & 27.0 & 97.5 & 1267.5 \\
\hline 44.0 & 45.0 & 0.0 & 0.0 & 0.0 & 0.0 \\
\hline 49.6 & 40.9 & 8.6 & 22.0 & 64.7 & 557.3 \\
\hline 53.7 & 63.6 & 0.0 & 0.0 & 0.0 & 0.0 \\
\hline 42.7 & 35.8 & 6.9 & 19.7 & 51.9 & 359.1 \\
\hline 48.3 & 41.3 & 7.0 & 19.8 & 52.2 & 363.3 \\
\hline 39.4 & 32.6 & 6.8 & 19.6 & 51.2 & 348.8 \\
\hline 45.1 & 38.7 & 6.4 & 19.0 & 48.0 & 307.2 \\
\hline 63.7 & 88.6 & 0.0 & 0.0 & 0.0 & 0.0 \\
\hline 90.7 & 79.8 & 10.9 & 24.7 & 81.6 & 887.8 \\
\hline 71.4 & 64.2 & 7.2 & 20.1 & 53.7 & 384.5 \\
\hline 81.8 & 74.6 & 7.2 & 20.1 & 53.6 & 383.4 \\
\hline 66.8 & 59.8 & 7.0 & 19.9 & 52.7 & 369.6 \\
\hline 48.1 & 41.1 & 7.0 & 19.8 & 52.3 & 364.4 \\
\hline 66.8 & 59.7 & 7.0 & 19.9 & 52.8 & 371.7 \\
\hline 61.8 & 54.7 & 7.1 & 19.9 & 52.9 & 372.8 \\
\hline 66.8 & 59.7 & 7.1 & 19.9 & 52.9 & 372.8 \\
\hline 21.8 & 14.7 & 7.1 & 19.9 & 52.9 & 372.8 \\
\hline 56.3 & 49.3 & 7.0 & 19.9 & 52.7 & 369.6 \\
\hline 49.8 & 44.5 & 5.3 & 17.2 & 39.5 & 208.3 \\
\hline 39.7 & 34.5 & 5.2 & 17.0 & 38.7 & 199.7 \\
\hline 66.3 & 59.3 & 7.0 & 19.9 & 52.7 & 370.7 \\
\hline 55.4 & 49.3 & 6.1 & 18.6 & 45.9 & 280.9 \\
\hline 50.0 & 44.4 & 5.6 & 17.7 & 41.7 & 231.9 \\
\hline 71.3 & 64.2 & 7.2 & 20.1 & 53.8 & 385.6 \\
\hline 66.0 & 59.2 & 6.9 & 19.7 & 51.5 & 354.0 \\
\hline
\end{tabular}




\begin{tabular}{|c|c|c|c|c|c|}
\hline \multicolumn{3}{|c|}{ Pressão (m) } & $a=0.5$ & $a=1$ & $a=2$ \\
\hline Sem Aproveitamento & Com Aproveitamento & Diferença & \multicolumn{3}{|c|}{ valores em L/Hora } \\
\hline 60.8 & 54.2 & 6.6 & 19.3 & 49.6 & 327.7 \\
\hline 60.4 & 54.3 & 6.2 & 18.6 & 46.3 & 285.5 \\
\hline 32.4 & 30.1 & 2.4 & 11.6 & 17.9 & 42.8 \\
\hline 65.8 & 59.0 & 6.8 & 19.5 & 50.8 & 343.7 \\
\hline 86.9 & 78.1 & 8.8 & 22.3 & 66.1 & 583.4 \\
\hline 81.9 & 73.1 & 8.8 & 22.3 & 66.1 & 583.4 \\
\hline 76.9 & 68.2 & 8.8 & 22.2 & 65.9 & 579.5 \\
\hline 81.9 & 73.2 & 8.7 & 22.1 & 65.2 & 566.4 \\
\hline 81.9 & 73.2 & 8.7 & 22.1 & 65.2 & 566.4 \\
\hline 71.4 & 63.5 & 7.9 & 21.1 & 59.3 & 468.1 \\
\hline 91.4 & 83.5 & 7.9 & 21.1 & 59.3 & 469.3 \\
\hline 81.5 & 73.3 & 8.2 & 21.4 & 61.3 & 500.6 \\
\hline 86.5 & 73.2 & 13.3 & 27.4 & 99.8 & 1326.7 \\
\hline 91.7 & 78.2 & 13.5 & 27.6 & 101.4 & 1370.9 \\
\hline 91.6 & 73.2 & 18.4 & 32.2 & 138.1 & 2542.0 \\
\hline 66.7 & 58.1 & 8.5 & 21.9 & 64.0 & 545.7 \\
\hline 61.6 & 48.2 & 13.4 & 27.5 & 100.6 & 1348.7 \\
\hline 66.6 & 58.2 & 8.4 & 21.8 & 63.1 & 530.5 \\
\hline 91.3 & 44.6 & 46.7 & 51.3 & 350.5 & 16377.7 \\
\hline 87.3 & 44.7 & 42.6 & 48.9 & 319.1 & 13578.8 \\
\hline 87.3 & 49.5 & 37.9 & 46.1 & 283.9 & 10744.7 \\
\hline 77.2 & 25.0 & 52.2 & 54.2 & 391.5 & 20436.3 \\
\hline 76.0 & 21.5 & 54.5 & 55.4 & 408.7 & 22268.7 \\
\hline 79.1 & 61.7 & 17.4 & 31.3 & 130.5 & 2270.7 \\
\hline 90.7 & 79.9 & 10.9 & 24.7 & 81.5 & 884.5 \\
\hline 76.3 & 69.3 & 7.0 & 19.9 & 52.7 & 369.6 \\
\hline 82.1 & 73.1 & 9.0 & 22.5 & 67.3 & 603.5 \\
\hline 87.2 & 78.1 & 9.1 & 22.6 & 67.9 & 614.3 \\
\hline 87.2 & 78.1 & 9.1 & 22.6 & 68.0 & 615.6 \\
\hline 52.4 & 43.1 & 9.3 & 22.9 & 69.9 & 651.5 \\
\hline 76.8 & 41.7 & 35.1 & 44.4 & 263.3 & 9245.3 \\
\hline 76.8 & 41.7 & 35.1 & 44.4 & 263.3 & 9245.3 \\
\hline 98.6 & 87.9 & 10.7 & 24.5 & 80.0 & 852.3 \\
\hline 73.2 & 42.0 & 31.2 & 41.9 & 234.2 & 7310.2 \\
\hline 87.1 & 78.1 & 9.0 & 22.5 & 67.4 & 606.2 \\
\hline 82.0 & 73.2 & 8.8 & 22.3 & 66.4 & 587.4 \\
\hline 87.1 & 78.1 & 9.0 & 22.5 & 67.3 & 604.8 \\
\hline 82.1 & 73.1 & 9.0 & 22.5 & 67.3 & 604.8 \\
\hline 77.1 & 68.1 & 9.0 & 22.4 & 67.1 & 600.8 \\
\hline 83.2 & 72.9 & 10.3 & 24.1 & 77.4 & 798.8 \\
\hline 82.0 & 73.2 & 8.8 & 22.3 & 66.1 & 582.1 \\
\hline 77.0 & 68.2 & 8.8 & 22.3 & 66.1 & 583.4 \\
\hline 87.0 & 78.1 & 8.9 & 22.3 & 66.5 & 590.1 \\
\hline 27.8 & 25.0 & 2.9 & 12.7 & 21.5 & 61.8 \\
\hline 22.8 & 20.0 & 2.9 & 12.7 & 21.5 & 61.3 \\
\hline 17.8 & 15.0 & 2.8 & 12.6 & 21.2 & 60.1 \\
\hline 17.8 & 15.0 & 2.8 & 12.6 & 21.2 & 59.6 \\
\hline 47.8 & 45.0 & 2.9 & 12.7 & 21.6 & 62.2 \\
\hline
\end{tabular}




\begin{tabular}{|c|c|c|c|c|c|c|}
\hline \multicolumn{4}{|c|}{ Pressão $(\mathrm{m})$} & \multicolumn{2}{c|}{$\mathrm{a}=0.5$} & \multicolumn{2}{c|}{$\mathrm{a}=1$} & $\mathrm{a}=2$ \\
\hline Sem Aproveitamento & Com Aproveitamento & Diferença & \multicolumn{3}{|c|}{ valores em L/Hora } \\
52.8 & 50.0 & 2.8 & 12.6 & 21.2 & 60.1 \\
\hline 60.8 & 57.9 & 2.8 & 12.6 & 21.2 & 59.6 \\
\hline 62.8 & 60.0 & 2.8 & 12.7 & 21.4 & 60.9 \\
\hline 57.9 & 55.0 & 2.9 & 12.8 & 21.9 & 63.9 \\
\hline 62.9 & 52.8 & 10.1 & 23.8 & 75.8 & 765.1 \\
\hline 60.8 & 57.9 & 2.9 & 12.7 & 21.5 & 61.3 \\
\hline 60.8 & 50.8 & 10.0 & 23.7 & 74.9 & 747.0 \\
\hline 72.7 & 63.1 & 9.6 & 23.2 & 71.9 & 689.8 \\
\hline 52.7 & 43.1 & 9.6 & 23.2 & 71.9 & 689.8 \\
\hline 42.8 & 39.9 & 2.8 & 12.6 & 21.2 & 59.6 \\
\hline 62.9 & 52.8 & 10.1 & 23.8 & 75.8 & 765.1 \\
\hline 72.1 & 63.1 & 9.0 & 22.4 & 67.1 & 600.8 \\
\hline 82.1 & 73.1 & 9.0 & 22.5 & 67.6 & 608.9 \\
\hline 72.3 & 36.8 & 35.4 & 44.6 & 265.8 & 9420.0 \\
\hline 81.5 & 41.7 & 39.8 & 47.3 & 298.7 & 11892.2 \\
\hline 83.0 & 41.7 & 41.3 & 48.2 & 309.5 & 12774.1 \\
\hline 92.2 & 46.7 & 45.5 & 50.6 & 341.2 & 15520.1 \\
\hline 98.2 & 95.0 & 3.2 & 13.4 & 23.8 & 75.8 \\
\hline 93.3 & 90.0 & 3.3 & 13.7 & 25.1 & 84.2 \\
\hline 93.3 & 90.0 & 3.3 & 13.7 & 25.1 & 84.2 \\
\hline 93.3 & 90.0 & 3.4 & 13.8 & 25.4 & 85.7 \\
\hline
\end{tabular}

